\title{
Capturing the dynamics of commitment : temporal theory, methods, and an application to the organizational commitment attitude
}

Citation for published version (APA):

Solinger, O. N. (2010). Capturing the dynamics of commitment : temporal theory, methods, and an application to the organizational commitment attitude. [Doctoral Thesis, Maastricht University]. Universiteit Maastricht. https://doi.org/10.26481/dis.20100623os

Document status and date:

Published: 01/01/2010

DOI:

10.26481/dis.20100623os

Document Version:

Publisher's PDF, also known as Version of record

Please check the document version of this publication:

- A submitted manuscript is the version of the article upon submission and before peer-review. There can be important differences between the submitted version and the official published version of record.

People interested in the research are advised to contact the author for the final version of the publication, or visit the DOI to the publisher's website.

- The final author version and the galley proof are versions of the publication after peer review.

- The final published version features the final layout of the paper including the volume, issue and page numbers.

Link to publication

\footnotetext{
General rights rights.

- You may freely distribute the URL identifying the publication in the public portal. please follow below link for the End User Agreement:

www.umlib.nl/taverne-license

Take down policy

If you believe that this document breaches copyright please contact us at:

repository@maastrichtuniversity.nl

providing details and we will investigate your claim.
}

Copyright and moral rights for the publications made accessible in the public portal are retained by the authors and/or other copyright owners and it is a condition of accessing publications that users recognise and abide by the legal requirements associated with these

- Users may download and print one copy of any publication from the public portal for the purpose of private study or research.

- You may not further distribute the material or use it for any profit-making activity or commercial gain

If the publication is distributed under the terms of Article $25 \mathrm{fa}$ of the Dutch Copyright Act, indicated by the "Taverne" license above, 


\section{Capturing the dynamics of commitment}

Temporal theory, methods, and an application to the organizational commitment attitude

Omar N. Solinger 
ISBN:

(C) 2010 Omar N. Solinger

Cover Design \& Artwork by GrabaWeb.nl

Printed by Schrijen-Lippertz, Stein 


\title{
Capturing the dynamics of commitment
}

Temporal theory, methods, and an application to the organizational commitment attitude

\section{Proefschrift}

ter verkrijging van de graad van doctor

aan de Universiteit Maastricht,

op gezag van de Rector Magnificus,

Prof. Mr. G. P. M. F. Mols

volgens het besluit van het College van Decanen,

in het openbaar te verdedigen op woensdag 23 Juni 2010 om 12:00 uur

\author{
door \\ Omar Nathanaël Solinger \\ geboren te Paramaribo, Suriname
}




\section{Promotor:}

Prof. dr. Robert A. Roe

\section{Co-promotor:}

Dr. Woody van Olffen

\section{Beoordelingscommissie}

Prof. dr. Ko de Ruyter (voorzitter)

Prof. dr. Daan van Knippenberg

Prof. dr. Michiel Kompier

Prof. dr. Fred Zijlstra

Dit onderzoek werd gefinancierd door Maastricht Research School of Economics of Technology and Organizations (METEOR) 


\section{Voorwoord}
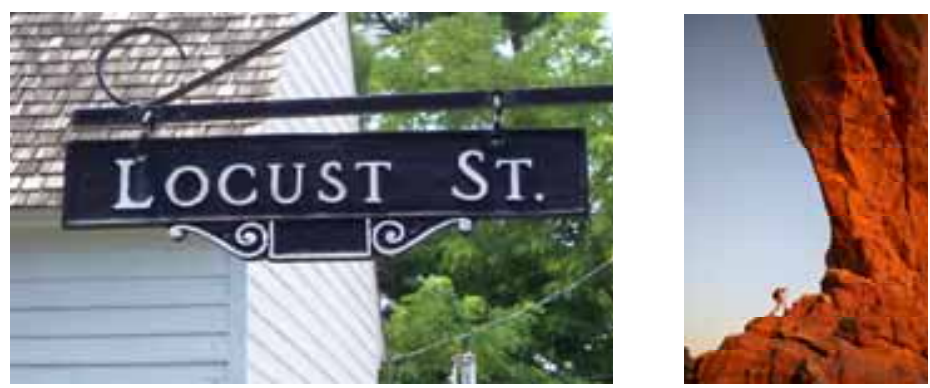

Het leven is als een weg die men inslaat, zonder exact te weten waar die uitkomt. En de mens, die het leven leeft, is als een reiziger die - met de nodige bagage - de beste bedoelingen heeft en graag de mooie plekken ziet. De reiziger kiest een pad, een globale route, een droom, een uitdaging. En dan, zodra men de aan de wandel gaat, komen de uitdagingen, omleidingen, teleurstellingen, euforische momenten en wat dies meer zij. De weg voert langs toppen en dalen, langs plekken die men het liefst gauw vergeet, maar ook langs mooie vergezichten waar men het liefst zo lang mogelijk was gebleven.

Wat fijn dat ik u op mijn reis tegenkom! U bevindt zich momenteel op de LOCUSTstraat, de weg die ik zo'n vijf jaar geleden ben ingeslagen. De weg dankt zijn naam aan een dynamisch meetinstrument dat ik, samen met Woody van Olffen (co-promotor) en Robert Roe (promotor) en twee IT-programmeurs (Arthur de Beaumont en Gildward Maduro) heb gebouwd ten tijde van mijn promotietraject. LOCUST staat voor Longitudinal Occupational $\underline{\text { State }}$ Tracker. LOCUST is een werkbelevingsmonitor, speciaal gebouwd voor volgtijdelijk onderzoek. Maar het staat ook voor de zes aspecten die mijn avontuurlijke reis van de afgelopen vijf jaar hebben gekenmerkt: Leven, Onderzoek, Charis, Uitdaging, Slijpen en de Top. In het onderstaande ga ik dieper op deze aspecten in. Al lezende, zult u de mensen tegenkomen aan wie ik mijn dank betuig. 
$L_{\text {even. }}$

Idealiter bestaat het leven uit drie aspecten die gelijk worden verdeeld over 24 uur: 8 uur werk, 8 uur spel en 8 uur rust. Hieronder beschrijf ik mijn werk uitgebreid, mijn dromen in tijden van rust zijn mij - helaas - onbekend gebleven, dus ik richt mij nu tot het spel. Afgelopen vijf jaar waren gekenmerkt door een boeiend spel, als wel een bloeiend samenspel van diverse passies, waaronder dansen, pianospelen, Spaans leren, reizen, lezen, filosoferen, enzofoorts. Mijn dank gaat uit naar alle personen met wie ik dansplezier heb beleefd (-)), aan alle leden van Grupo Seis Camimos, mijn ouders, al mijn dierbare vriendschappen (Daniel, Jose, Wubbo, Margarita, Pablo, Angelo, Ciro, Gideon, Jasper, Thomas, Serap, Silena, Rina, Bram, Nelly, Martie, Tijmen, Nicolien, en iedereen die ik ben vergeten) en natuurlijk Cilla, intieme reisgenoot en geweldige vrouw die mij blijft verbazen. Een betere bijstand na werk had ik niet kunnen bedenken. Dankzij al deze mensen ben ik gaandeweg uit de verf gekomen als persoon, een proces dat overigens nog steeds aan de gang is en (hopelijk) niet meer stopt. Immers, het leven bestaat mijns inziens - geheel in de temporele denktrant - uit het worden wie je bent ('tevoorschijn komen'), contact maken en in verbinding staan met anderen ('lateraal engagement'), en dan door het samenspel van je wat je doet en wie je ontmoet, worden tot....tja... wie zal het zeggen. Helaas bestaat het leven ook uit, om het muzikaal uit te drukken, het in harmonie komen met de eindigheid. Laat ik zeggen dat het momenteel mijn doel is van het leven een kunstwerk te maken, waarvan de kwaliteit, gelukkigerwijs, een kwestie is van smaak.

Qnderzoek

Onderzoek is het werk van een speurder die nieuwsgierig en gedreven op zoek gaat naar het hoe, wat en waarom van de dingen die hem/haar interesseren. In deze dissertatie put ik mijzelf uit om te benadrukken, dat we als onderzoekers bij deze speurtocht niet moeten vergeten wanneer de dingen gebeuren. Ik betoog dat een onderzoeker zou niet moeten denken in termen van 'dingen' of 'zaken', maar in termen van 'de loop der dingen' en van 'lopende zaken'. Ik heb aan den lijve ondervonden dat onderzoek een stuk leuker en uitdagender wordt als men deze 'knop' in het denken weet om te zetten. Het vergt wel wat, want we zijn erg gewend om dingen 'statisch' te bekijken. Het is net zoals onze Nederlandse voetbalheld - en 
onderhand onze huisfilosoof - Johan Cruijff het uitdrukte: "Je gaat het pas zien als je het doorhebt".

Onderzoek in de sociale wetenschap wordt gekenmerkt door de (soms heilloze) drang naar objectiviteit, de balans vinden tussen 'relevance' en 'rigor', problemen verhelderen (en jawel - die ook oplossen), kritisch analyseren, kwantificeren, categoriseren, generaliseren, de data laten spreken, statistisch toetsen, vragen blijven stellen, zaken van meerder kanten bekijken, zoeken van alternatieve verklaringen, stevig onderbouwen van wat je zegt en emotioneel afstand nemen van het beschrevene. Toch is het daarnaast ook - althans voor mij - voor een groot gedeelte een sociaal gebeuren, het volgen van intuïtie, serendipiteit, passie voor de zaak, een vleugje koppigheid en het slim gebruiken van retorica om je standpunt helder over het voetlicht te krijgen. Wat mij betreft makt deze combinatie sociaalwetenschappelijk onderzoek leuk, naast natuurlijk de leuke reisjes naar conferenties en cursussen, de internationale allure, de autonomie, vrijheid om datgene te onderzoeken wat je interessant vindt en de waarachtige waardering van creativiteit.

Ik voel uw aarzeling. Zijn er niet ook nadelen aan het promoveren? Jazeker, je verdient weinig, je werkt meestal alleen en daarnaast - zeker in het laatste half jaar - zie je weinig meer dan je eigen computerscherm. Maar hoezeer je onder de nadelen te lijden hebt, hangt voor een groot gedeelte van jezelf af. Ik heb gelukkig leuke collega-promovendi gehad die mij vaak tot professionele en persoonlijke steun zijn geweest: Sjir, Anneloes, Daniela, Andrea, Maarten, Li Jia, Gideon, Antonio, Ellena, Myrthe, Sebastian, Johannes, Thomas, Jasper en iedereen die ik ben vergeten. Daarnaast heb ik een hoop werk uitbesteed aan studenten en stagiaires die het werken zeer erg aangenaam hebben gemaakt en een grote bijdrage hebben geleverd aan de kwaliteit van het proefschrift. Hierbij dank ik Jose Rodriguez, Sanne Valk, Auke Berenbroek, Arthur "de colaman” de Beaumont (eerste programmeur), Gildward "kaboobie" Maduro (tweede programmeur), Carine van Ravestein, Stefan Selders en Jeroen Odink, zonder wie Excel spreadsheets en statistische analyses in SAS mij ongetwijfeld tot wanhoop gedreven hadden.

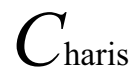

Charis komt uit het Grieks en staat voor 'gave'. Het is ook het nieuwtestamentisch Griekse woord voor "genade"; het is dat wat een mens gegeven wordt. Als je jong bent, besef je het niet gauw, maar het leven - ook het mijne - is een kwetsbaar evenwicht dat snel verstoord 
raakt. Tot twee keer toe ben in mijn promotieperiode geveld door zware RSI klachten. Dit drukt een mens met zijn neus op de feiten: de eindigheid, zwakheid, kwetsbaarheid van je gestel, maar ook de betrekkelijkheid van waar de mens zo in zijn dagelijks leven voor zwoegt. Immers, in een oogwenk kan de sneltrein van het leven je voorbijrijden en dan sta je aan de kant. Het kan een machteloos gevoel geven. Lichamelijke gezondheid blijkt een zeer kostbaar goed, en een 'genade Gods', een uiting van 'charis' optima forma. Maar ook het ervaren van heldere dagen, contacten, ontmoetingen, helden, inspiratie en talenten zijn alle vormen van 'begenadigd' zijn. Het feit dat ik dit woord zo tot u richt, stemt mij dankbaar. Immers, de mogelijkheid tot schrijven heb ik pas recent weer herwonnen. Mijn dank gaat hierbij uit naar het mijn familie (Gerard Solinger, Thea Santingh, Marjan van Houten en Gerard Rasingh, Fleur Solinger en Fabian Mol), naar Cilla, naar het Amsterdam Centre for Career Research (ACCR) en naar Sietske Trompert die mij hebben geholpen in de momenten dat de pijn zo hevig was dat beeldschermwerk onmogelijk was.

'Charis' is ook een temporeel begrip. In het heetst van de strijd is charis voor het oog of voor het verstand afwezig; men ziet het pas als men terugkijkt op een aantal voorbije jaren. Dan ontwaart zich een patroon, dat wellicht zin geeft aan wat indertijd 'onzin' leek en rust brengt in een hart dat indertijd onrustig was. Achteraf laat zich emotionele grilligheid makkelijker plaatsen, en (hier spreekt even de wetenschapper) bestuderen. Er zijn vertalingen die de naam van God in de Bijbel vertalen met "Ik ben" (heden), maar ook "Ik was er" (verleden) en "Ik zal er zijn" (toekomst). Al verhoud ik mij op dit moment tot God op een ongeduide manier, ik weet dat Hij "er was" op de momenten dat ik het nodig had. Nog vaker was het de "Ik ben" in de vorm van een medemens, een lied, een woord, een boek, een ingeving, een keertje dansen na een lange tijd, of een blik in de ogen van een mooi medemens. Al deze dingen zijn ontvangen door een dankbaar hart.

\section{Utdaging.}

Dit promotietraject is een groot experiment geweest dat met vurigheid is aangewakkerd. In de eerste plaats door mijn promotoren, maar daarna is diezelfde fakkel aan mij overgedragen. Volgtijdelijk onderzoek is een relatief onontgonnen wetenschappelijk gebied, waar een hoop te halen valt, maar waar je ook een vergrote kans loopt om vast te lopen. Het aangaan van deze weg is een sprong in het diepe, een avontuur, waarvoor het nodige lef noodzakelijk is, zoals bijvoorbeeld het onverschrokken opnemen tegen het establishment in de commitmentliteratuur (zie hoofdstuk 2). Het onderzoek dat ik heb gedaan laat zich kenmerken door wat 
Amerikaanse onderzoekers (Mark Peterson, 2009, persoonlijke communicatie) noemen: "high-risk-high-pay-off research". Als je experimenteert, zullen een hoop dingen mislukken. Je doet in ieder geval iets nieuws, wat de kans vergroot op het vinden van nieuwe dingen. Gelukkig ben ik hierin gesteund door mijn promotor Robert Roe, die zelf in zijn afscheidsrede het gezegde aanhaalde: "If you keep doing what you did, you keep getting what you got". Ik zou eigenlijk niet graag iets anders hebben gedaan. Grootste dank gaat hierbij uit naar Robert Roe, Woody van Olffen, Martin Carree, Mieke van Zutphen en de onderzoeksschool METEOR die me de mogelijkheid, sociale steun (onder het genot van vele Leffe's; thanks, Woody!) en de financiële ruimte hebben gegeven om te experimenteren.

\section{$S_{\text {lijpen. }}$}

Inspiratie is deels charis, maar deels ook intellectuele arbeid. Het is zoals men zegt: inspiratie is transpiratie. Opgroeien in de wetenschap impliceert het gewillig ondergaan van (soms pijnlijke) hersenslijpingen. Ik heb het hier over de arbeid van het onvermoeibaar slijpen van je eigen werk. Promovendus zijn betekent vooral het opnieuw bekijken van je stukken, en opnieuw, en opnieuw, en opnieuw...Een betere oefening in geduld is er waarschijnlijk niet. Hetzelfde fenomeen steeds op een andere manier bekijken en de narratieven erover steeds weer tegen het kritische licht houden. Het ambacht van onderzoeker zijn, vraagt om het aanleren van onbarmhartigheid ten opzichte van het eigen werk: willen zien en blijven vragen wat er nog aan s scheelt, schrappen, onbarmhartig (laten) slopen van je eigen ideeën die je stiekem bent gaan koesteren (om af en toe sip en suf van te worden!). De grootste uidaging hier is om er fris en vrolijk onder te blijven en creativiteit kunnen blijven aanspreken ondanks het feit dat het versie nummer 16 is van het bewuste artikel. Immers, uiteindelijk leidt slijpen tot slagen van het werk. In de wetenschap gaan rijpen en slijpen hand in hand. Ik heb het voorrecht gehad een artikel onder mijn handen te zien 'rijpen' tot een zeer goed artikel. Wetenschapper zijn is met recht de kunst van de onuitputtelijkheid. Belangrijke personen die me de kunst van het slijpen hebben aangeleerd, zijn - uiteraard - mijn promotoren, maar ook Hans Frankort (wat is hij inspirerend kritisch!), leden van het Ministry of Respectful Interaction (MRI), Boris Blumberg, Sjir Uitdewilligen, Anneloes Raes, Marc Peterson, Stewart Clegg, Mary Waller, Bart de Jong en alle collegae van het PhD seminar, en anonieme reviewers en toehoorders op conferenties. 


\section{$T_{\text {op. }}$}

De top is het streven. Je weet dat het in de zoektocht naar geluk niet gaat om de top, niet om het einddoel an sich, maar om de weg ernaartoe. Maar toch, het bereiken van de top is als het inademen van nieuwe lucht. Een vergezicht dat ik niet gauw vergeet. Wanneer bereikt men de top? Zodra men een doel bereikt dat aan het hart gaat - wat mij betreft. Het promoveren is dat zeker. Ik heb de piek behaald door mijn proefschrift af te ronden: de top is bereikt. Ik ben zo gelukkig geweest om te kunnen publiceren een toptijdschrift. Ik heb geweldige promotoren gehad die zowel genoeg ruimte boden als de juiste mate van 'tegengas' hebben weten te geven. Ik heb topcollega's gehad wat de typische Nederlandse kwalificatie "gezelligheid" meer dan verdient. Kortom: Top is behaald. Top tijdschrift. Top promotoren, top collega's; ik heb een top tijd gehad. 


\section{Table of Contents}

1 Introduction: Temporal thinking and organizational commitment

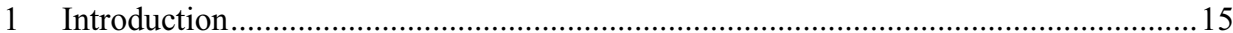

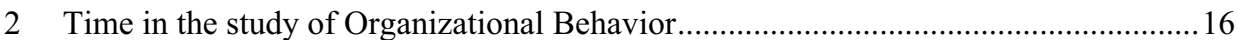

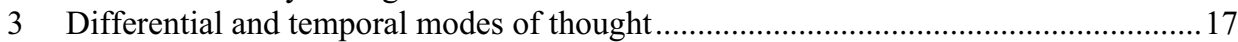

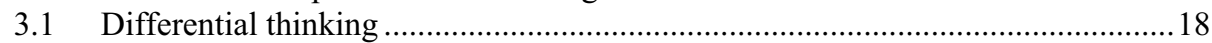

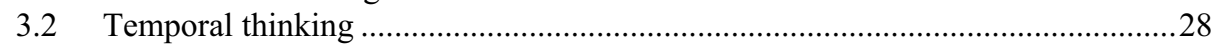

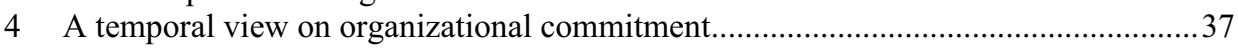

2 Beyond the three-component model of organizational commitment ....................45

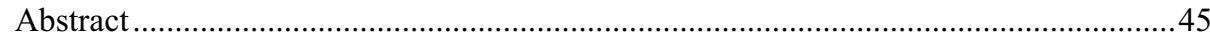

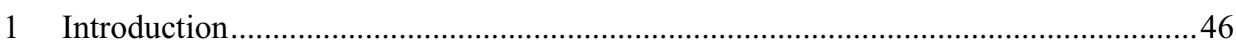

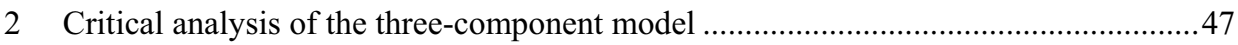

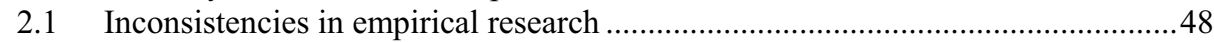

2.2 Organizational commitment as an attitudinal phenomenon .................................49

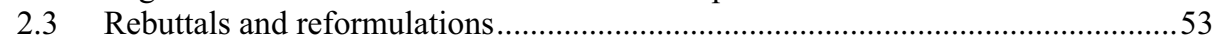

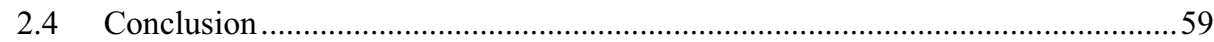

3 A road ahead for organizational commitment research .......................................5

3.1 Generating models of organizational commitment - organizational behaviors ....60

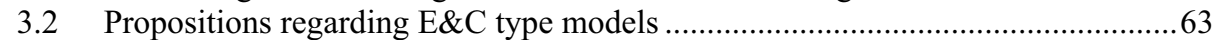

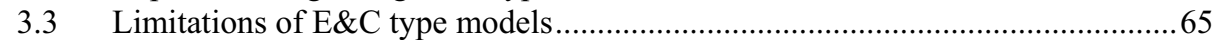

4 Toward a strictly attitudinal definition of organizational commitment .........................66

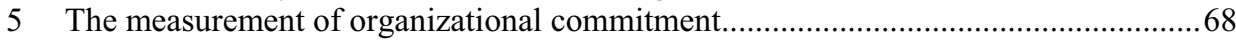

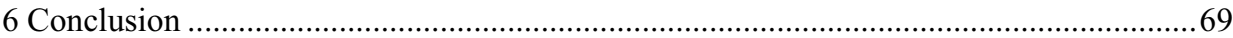

3 A life cycle perspective on commitment dynamics: A comparative review of trends

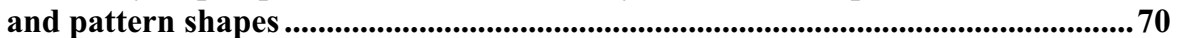

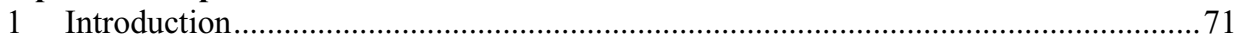

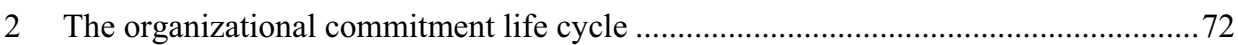

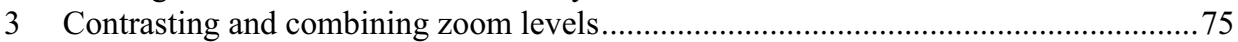

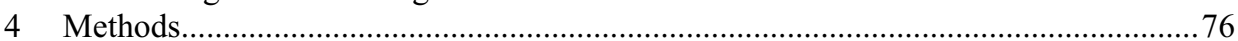

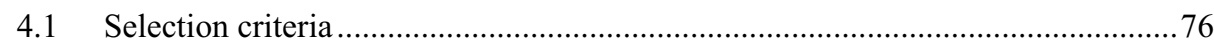

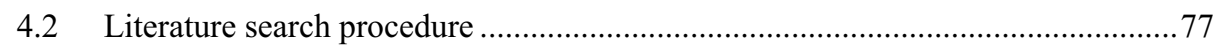

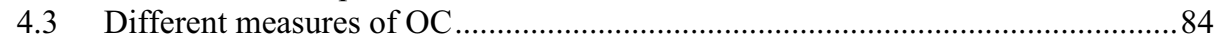

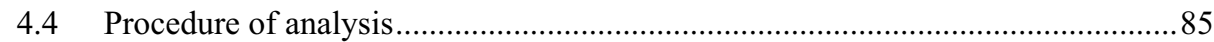

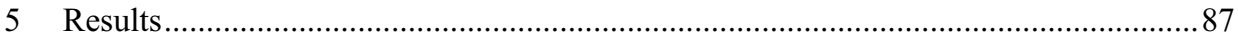

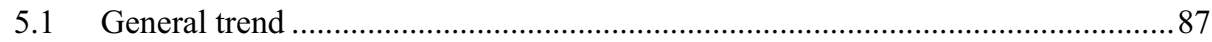

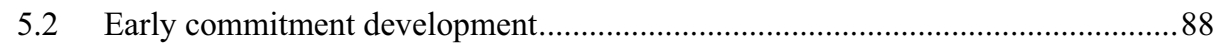

5.3 Commitment patterns after entering the organization ....................................... 89

5.4 Commitment patterns during the subsistence phase .......................................... 92

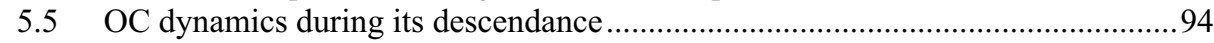

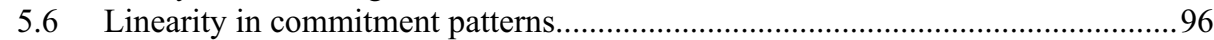

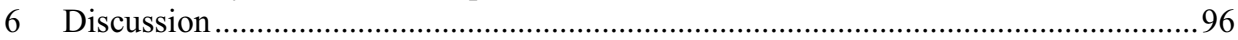

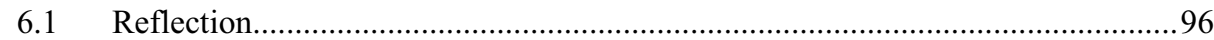

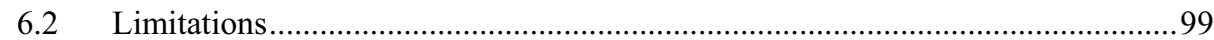

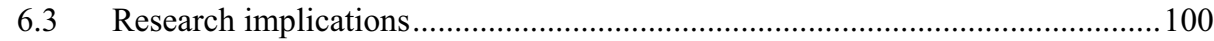

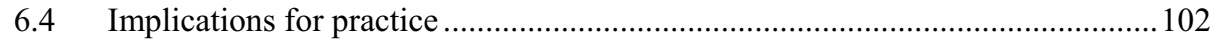

4 Real-time registering of history and attitude change in fine-grained and lengthy

longitudinal designs: The making of LOCUST ....................................................105

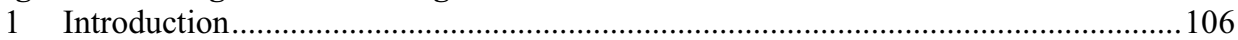

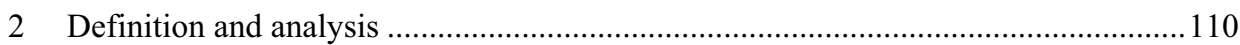




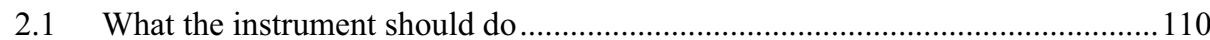

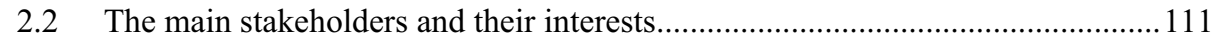

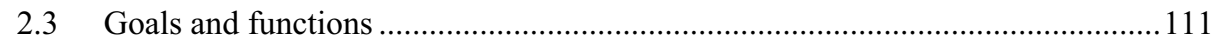

2.4 Common tools and practices in the field ...................................................... 112

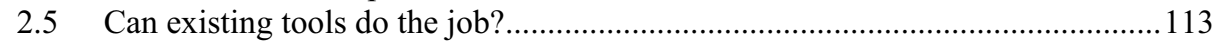

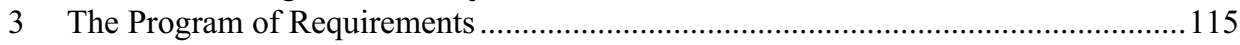

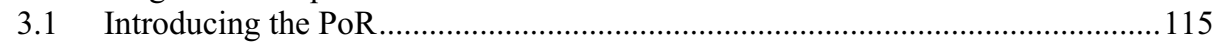

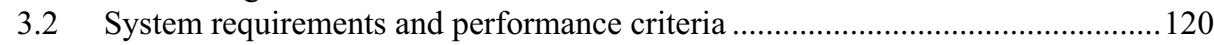

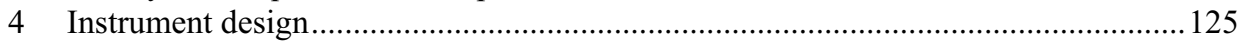

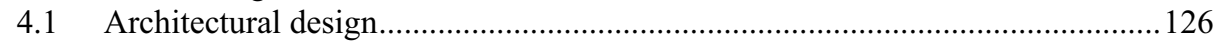

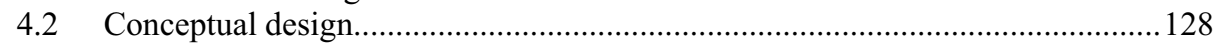

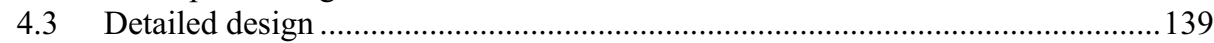

4.4. Alternative LOCUST variants.......................................... 146

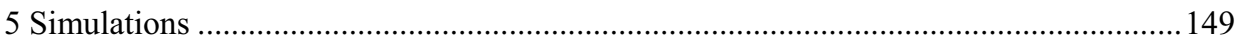

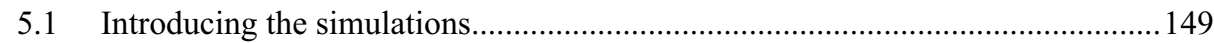

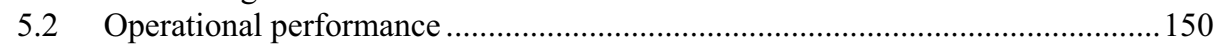

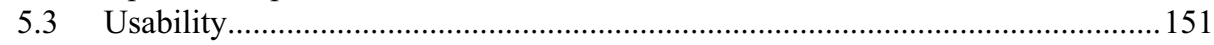

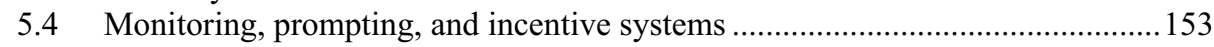

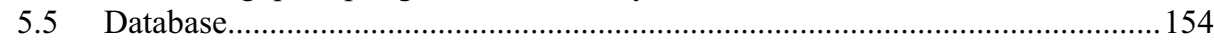

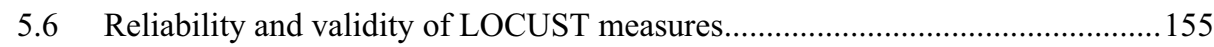

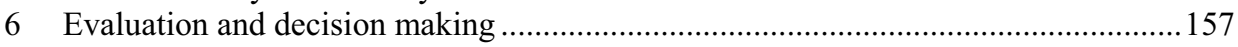

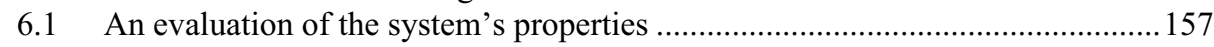

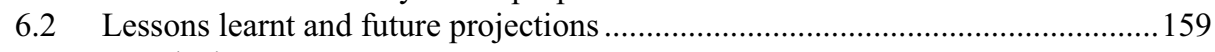

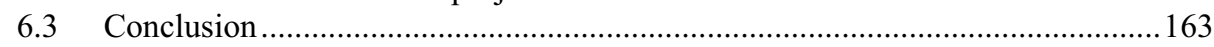

5 On the temporal form of newcomer commitment: A 25-week study ..........165

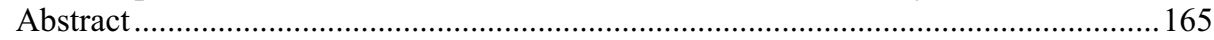

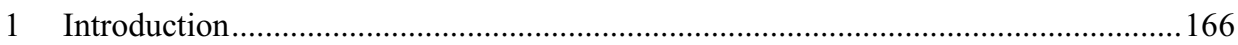

2 The development of commitment after entering the organization............................... 168

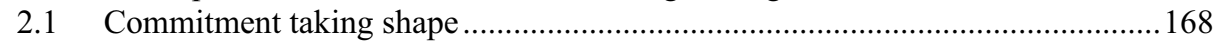

2.2 Literature on commitment change and newcomer adaptation.............................168

2.3 Limitations of the growth modeling methodology ......................................... 172

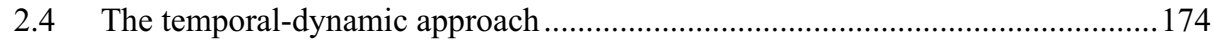

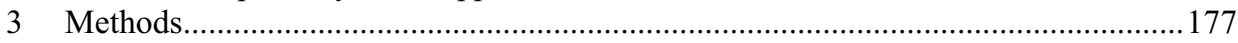

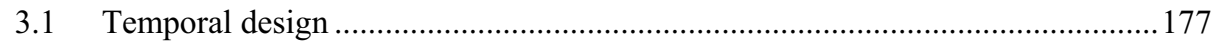

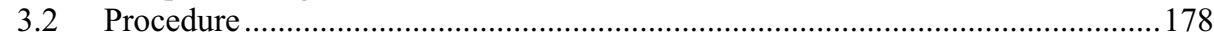

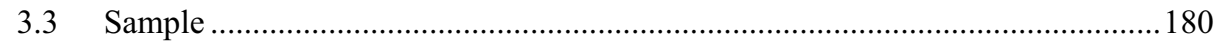

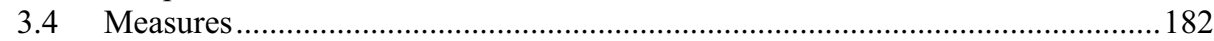

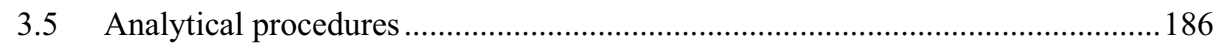

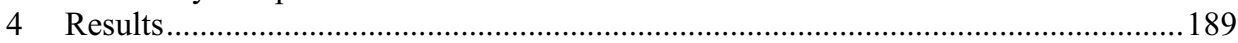

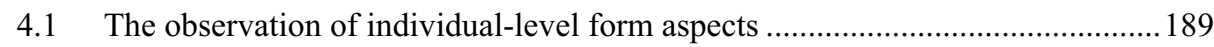

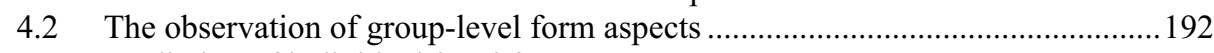

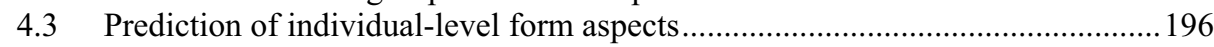

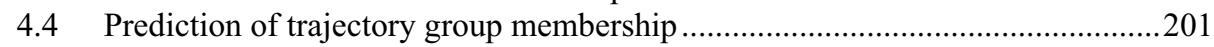

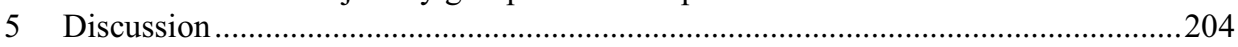

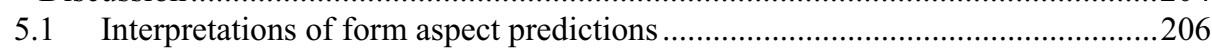

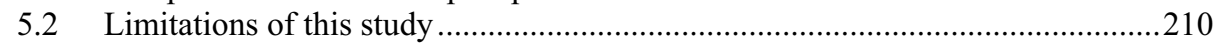

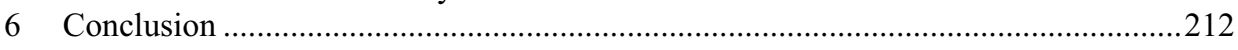

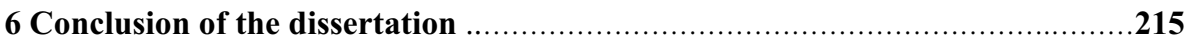

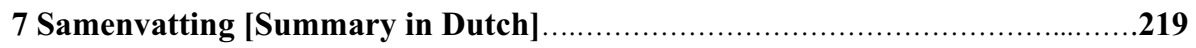


Bibliography of the dissertation .........................................................................223

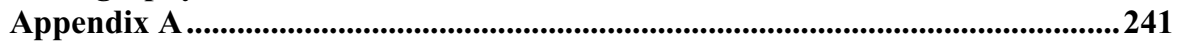

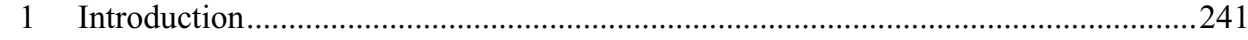

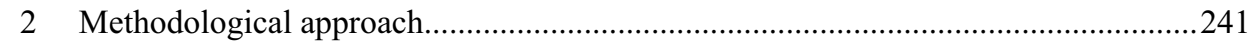

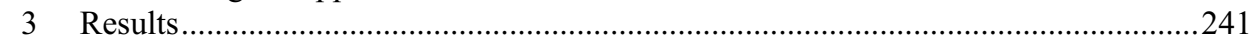

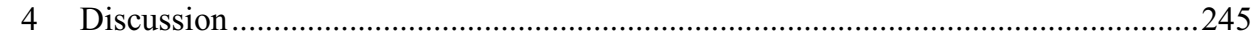

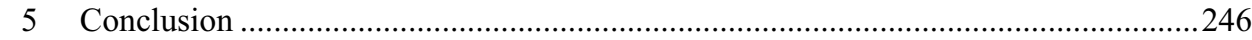

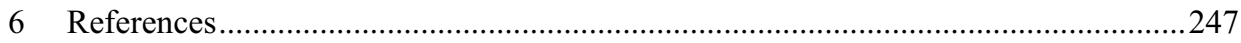

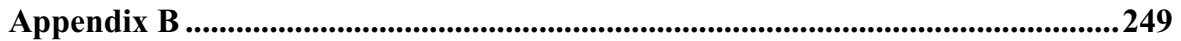

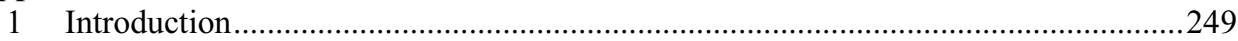

2 Criteria for reliability and validity in a temporal research context...........................250

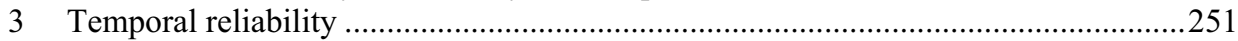

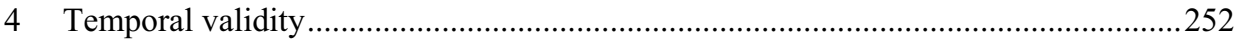

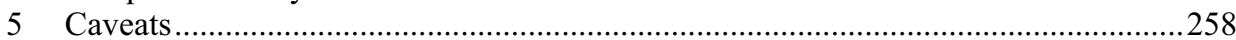

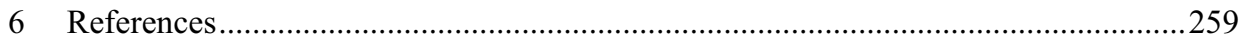

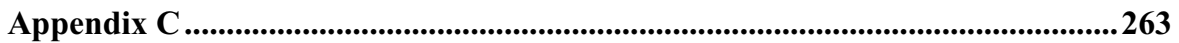

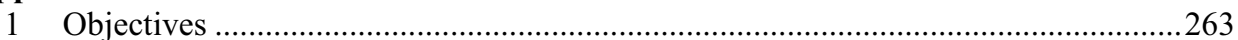

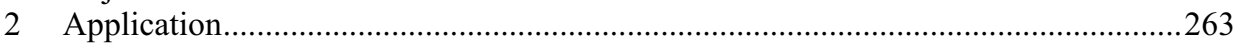

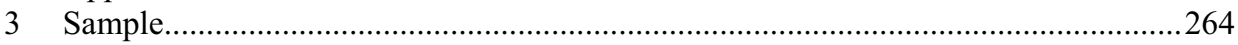

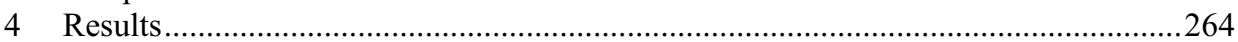

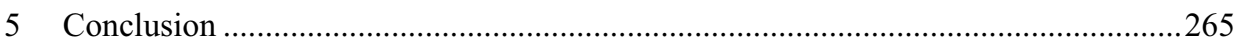

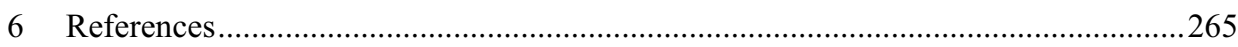

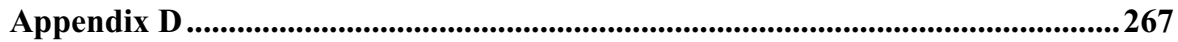

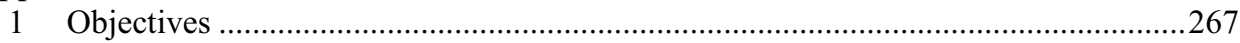

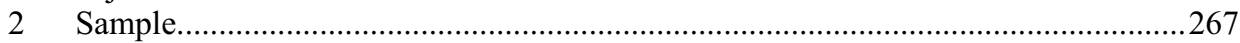

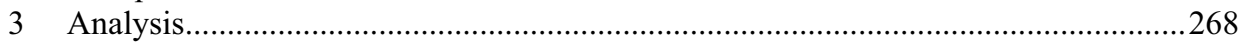

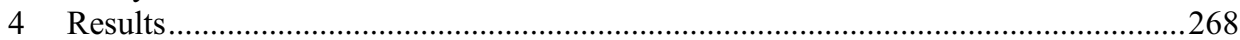

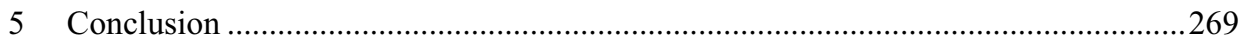

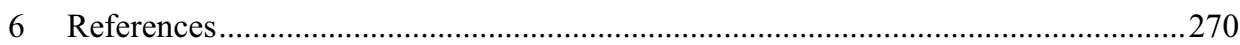

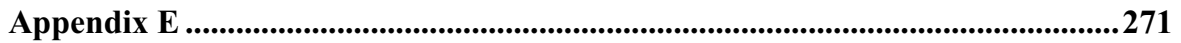

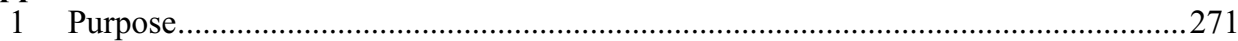

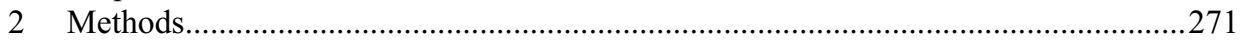

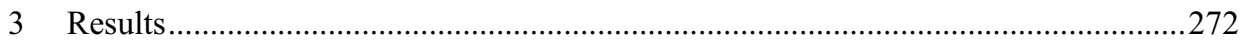

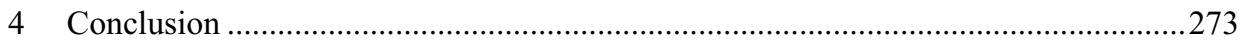

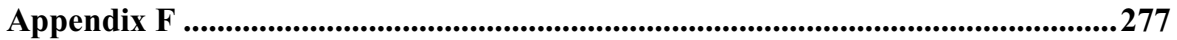

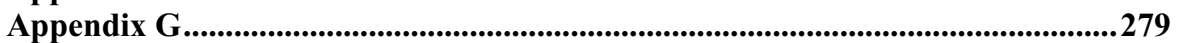

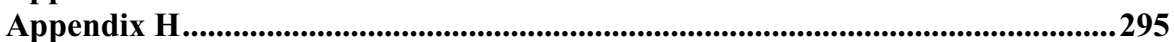

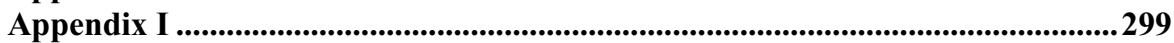

Omar N. Solinger: A brief curriculum vitae..............................................300 


\title{
1 Introduction: \\ Temporal thinking and organizational commitment
}

\begin{abstract}
Although many scholars acknowledge the fact that the inclusion of time in research efforts potentially improves theory, it is not yet systematically included in the study of Organizational Behavior. One of the potential explanations for the neglect of time is the dominance of a particular mode of thought - which we call 'differential thinking' - which biases research decisions. That is, we are used to think in terms of differences between individuals (differential thinking), and are less inclined think in terms of differences within individuals over time (temporal thinking). In this chapter we systematically juxtapose these two modes of thought, including their respective ontological and epistemological tenets. The potential use of temporal thinking to research on the organizational commitment attitude is discussed.
\end{abstract}




\section{Introduction}

In the field of Organizational Behavior (OB) calls for more longitudinal research are uttered regularly. And rightly so: Organizational Behavior is inherently temporal and coming to grips with it calls for the inclusion of time in theoretical models, designs and methodology. We like to study how organizations change, how employees react to these changes, what kind of work experiences create 'satisfied and committed employees', how we learn, and develop skills over time. These kinds of studies require a sort of 'temporal intuition', an eye for how things develop and change, and how the pattern of change can be explained. Scientific endeavors seem to become more and more 'longitudinal', not in the least because the editorial boards of leading journals are becoming more stringent in terms of methodological rigor (e.g., requiring longitudinal designs). Some authors even speak of a 'longitudinal zeitgeist' (Hunt \& Ropo, 2003).

Paradoxically, the growing popularity of longitudinal research and the awareness of the need for temporal research have not yet resulted in an increase in studies that incorporate elements of time. On average only $7.5 \%$ of recent research output in OB is of longitudinal nature (Avital, 2000; Roe, 2008a). It seems, however, that the absence of time in theory and research is not due to a lack of awareness of the importance of time. Nor is there a lack of analytical techniques that enable to study within-subject differences over time. In the last twenty years there has actually been a proliferation of sophisticated and accessible analytical techniques (Gottman, 1995; Poole, Van de Ven, Dooley, \& Holmes, 2000; Rabe-Hesketh \& Skrondal, 2008; Singer \& Willett, 2003).

Rather, the major obstacle, in our view, is a mental one. The problem is that we are used to think in terms of differences between people (differential thinking), while an intuition for the role of time (temporal thinking) requires to think in terms of differences within people over time (Chan, 1998; Collins, 2006; Poole, Van de Ven, Dooley, \& Holmes, 2000; Roe, 2008a). For example, if one studies how downsizing affects employee commitment, applying analytical techniques that assume stability in commitment over time is of limited use. Still, many papers on the effects downsizing investigate causal relationships between static variables. The aim of this dissertation is not primarily to make yet another call for more temporal research, but to explore how and where the adoption of a new epistemology - which we call 'temporal thinking' - is relevant and potentially adds value to the study of attitudes in the workplace. We demonstrate this by discussing a well- 
documented discourse in $\mathrm{OB}$ : the study of organizational commitment. We will encourage consistency of thought and research decisions in areas of conceptualization, research design, measurement, and analysis.

We start with a brief introduction as to why the incorporation of time adds value to research in Organizational Behavior, and then discuss the philosophical properties of temporal thinking as an alternative epistemology (this chapter). In the following chapters we re-ground organizational commitment in standard attitudinal theory (chapter 2), evaluate temporal trends in commitment found in previous research (chapter 3), explain the development of a new measurement system which is intended to measure the temporal development of attitudinal phenomena (chapter 4), and apply it in an exploratory empirical study on the dynamics of commitment during the first 25 weeks of work (chapter 5).

\section{Time in the study of Organizational Behavior}

Doing temporal research means acknowledging the element of 'time' in phenomena and their interrelationships. When studying a phenomenon with a temporal mindset it is conceptualized as an unfolding 'story' over a certain time span instead of a quasi-stationary 'given'. Useful concepts for such a narrative are change, stability, growth, decline, onset, offset, duration, variability, and so forth (Roe, 2008a). Likewise, thinking temporally about relationships between two or more phenomena means creating a prototypical story (cf. Weick, 1989) of what happens and when things happen between these phenomena over a certain time interval ${ }^{1}$. It is, thus, a form of reasoning which places high value on historical developments in phenomena of interest. Temporal research aims to build theory by finding regularities in temporal patterns in the observed phenomena and their relationships. For example, these temporal relationships can be studied by looking at temporal parameters of one phenomenon (e.g., decline in trust) and relate those to a temporal parameter in another phenomenon (e.g., onset of conflict). Further one could study dynamic effects like improvement, time lag, bifurcation, and relapse (Roe, 2008a). An example can be found in a study by Bentein et al. (2005) who show that decreases in organizational commitment at one moment in time are associated with increases in turnover intention at a later point in time.

\footnotetext{
${ }^{1}$ Time length is conceptualized in terms of clock time. We are aware that there is also a subjective experience of time, but we see clock time as basic background to which narratives of phenomena -even the subjective experience of time - can be portrayed (Roe, 2009).
} 
The common element in this type of research is that the role of time is taken seriously in the study of phenomena ${ }^{2}$.

There are a number of reasons why temporal research aids in building better theory. First of all, time is a desirable ingredient in perhaps any good theory as it increases a theory's sophistication. George and Jones (2000) have argued that time (the 'when') is not just a boundary condition but central to the what, how, and why in the theory. Temporal research leads to an account of 'what happens' over time when we study a phenomenon's temporal characteristics (e.g., duration, stability, incremental vs. discontinuous change, frequency, rhythms, cycles, spirals, and so forth). It leads to better understanding of the 'how' question by looking at interrelationships between temporal aspects of phenomena, and of the 'why' by looking at determinants of these temporal characteristics.

Second, there is an epistemological argument that causal (mostly linear) laws abstracted from time and space are, in fact, not applicable to organizational behavior which is inherently temporal (Abbott, 1988; Faulconer \& Williams, 1985; Slife, 1993). As all behavior occurs in time, temporal thinking improves theory because it gives a more realistic, plausible, and relevant representation of what actually happens. How hungry we feel depends on how long it has been since we ate. Likewise, uttering praise to a supervisor generally serves to make a good impression, but it may have a counterproductive effect if compliments were already given three times earlier that day. The list is endless.

Third, temporal thinking makes OB theories more interesting. Clearly, the element of time opens up insights and new questions on how, when and why phenomena are related: it creates richness. Interest is a prominent selection criterion to judge the plausibility of theoretical ideas (Davis, 1971; DiMaggio, 1995; Rynes, 2005; Weick, 1989).

\section{Differential and temporal modes of thought}

One of the largest obstacles to incorporating time in our theories is the mental bias of scholars to think in terms of timeless covariance relations between antecedents and

\footnotetext{
${ }^{2}$ Temporal research should not be confused with longitudinal research. There is a fine distinction between the two. It is possible to use a repeated measures design, while doing timeless research. For example, if the repeated measures design is only used to test for the direction of causality, the repeated measures design improves methodological rigor by excluding alternative explanations of reverse causality. However, the research is still 'timeless' since there is no reference to truly temporal patterns in the data, like growth, decline, or other forms of intra-individual variability over time. This is why we use the term serial cross-sectional to denote 'timeless' longitudinal studies.
} 
consequences ('what is') instead of how phenomena and their interrelationships manifest themselves over time ('what happens', Roe, 2008a). The distinction between these two doctrinal tendencies bears resemblance to already existing typologies. For example, developmental psychologists juxtaposed these modes of thought as between-subject heterogeneity versus within-subject variability (Collins, 2006; Salthouse et al., 2007); in personality psychology, and social psychology, one speaks of 'idiographic' versus 'nomothetic' kinds of research (Allport, 1960; Jaccard \& Dittus, 1990; Molenaar, 2004); sociologists speak of 'synchronic' versus 'diachronic' research (Bluedorn, 2002), or outcome-driven versus event-driven research (Abbott, 1990; Van de Ven, 2007); organizational theorists speak of 'variance' versus 'process' modeling (Van de Ven, 2007; Van de Ven \& Poole, 2005) and philosophers speak of substance versus process epistemologies (Rescher, 1996). All of these terms refer to more or less the same distinction, although there are differences in emphasis. For the purposes of this dissertation, we will henceforth use the term differential thinking to describe a mode of thought typically containing theoretical propositions based on between-subject differences. Temporal thinking will be used to indicate a mode of thought that draws on variability across time moments. We choose this terminology because it expresses more directly the underlying conceptual attributes. That is, differential thinking taps from differential attributes between subjects or cases, while temporal thinking taps from variations in temporal attributes within these respective individuals or cases.

In the following we will juxtapose differential and temporal thinking in terms of their respective ontological and epistemological tenets. Ontology deals with the way content is defined (the nature of things), while epistemology pertains to how knowledge about phenomena is obtained (learning about things). The two modes of thought differ in the description of phenomena and their interrelationships. More specifically, differential and temporal thinking differ with respect to ontology in the way they deal with time, in the approach to content, and in their views on cause-effect relationships. With respect to epistemology, the two modes of thought differ in the way they approach observation, in the inquiry of causation, in the level of analysis typically applied, and in the treatment of time.

\subsection{Differential thinking}

Differential thinking relates to the idea that differences in attributes between individuals or collections of individuals can help explaining phenomena and their interrelationships. In 
differential thinking, propositions and hypotheses are 'mininarratives' (Van de Ven, 2007, p. 154) that causally link dependent variables with independent variables. Individual differences with respect to scores on these variables are seen as 'variance'. The practical objective of researchers using differential thinking is to build or test hypotheses in order to explain maximum 'variance' in the dependent variable, based on one or more independent variables. In the differential mode of thought, simple statistics like standard deviations are taken to reflect between-subject differences. These differences in turn enable thought trials for explanatory mechanisms, propositions and hypotheses. For example, if a scholar thinking differentially - is asked about how many committed employees there are in a particular firm, the tendency will be to look for a percentage of highly committed employees or for the median score on the organizational commitment scale, classifying all employees exceeding it as being 'committed'. If asked for the effects of commitment on work performance, the researcher will hypothesize a causal relationship between 'organizational commitment' and 'performance'. After collecting data on organizational commitment as well as on work performance the researcher will investigate how much between-subject variance in work performance is 'explained' by between-subject variance on the organizational commitment variable. If such a relationship is found, the researcher will conclude that 'high commitment' is associated with 'high performance', inferring causality if a fitting theoretical narrative is available.

Differential thinking has such a long history that it permeates all research topics, from the way scholars observe the world to theory building, and from fundamental measurement theory to statistical methodology (Monge, 1990). Authors like Poole et al. (2000), Van de Ven (2007) and Rescher (1996) describe some ontological assumptions that underlie differential type models. These assumptions can be seen as the boundary conditions of the differential theory (Bacharach, 1989). We summarize them into three categories: view on the role of time, content, and causation. We will discuss them shortly.

Ontological tenets in differential thinking The first assumption deals with the role of time in understanding phenomena. In differential thinking one assumes that the world is made up of fixed entities with varying attributes (Van de Ven, 2007). In this respect, the differential mode of thought adopts an essentialist perspective, assuming that things consist of a basic eternal substance and maintain a unitary identity over time. Going back to our example of committed employees, it is (implicitly!) assumed that commitment level is invariant over time. The level of commitment is considered to be one of the many attributes on which individuals can differ. Between-subject heterogeneity in other individual attributes 
(e.g., age, gender, tenure, type of work, working conditions, etcetera) is subsequently used for explanation in causal analyses. Phenomena are assumed to exist for an indefinite period of time, which is the logical consequence of the assumption that things have a basic eternal substance. Thus, time does not play a significant role in the differential ontology.

The second ontological tenet pertains to the approach to content, which comprises the definition of what things consist of (the 'what' in theory) and the approach to agency and operations (the 'how' in theory). In the understanding of content it is assumed that entities are 'settings within which variables act' (Van de Ven, 2007, p. 151, emphasis added). In this mindset, any activity or event in the entities being studied (e.g., in managers or employees) is captured by 'variables'. For example, if a differential thinker studies the process of newcomer socialization, he/she will need to identify what causal antecedents of organizational socialization are 'variable' between subjects in a given population (e.g., proactivity in information-seeking, the number job alternatives, differences in newcomer orientation programs, and so forth). In this sense, content in the differential paradigm is defined in relation to other actors (supposedly) experiencing the same activity.

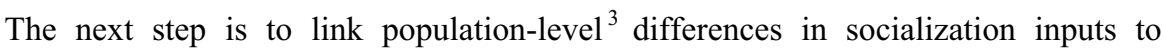
socialization outcomes, such as differences in organizational commitment. In the world of the differential thinker human agency exists only as a narrative explanation for a variance theory (Poole et al., 2000). Thus, 'activity' (e.g., a newcomer orienting herself in a new organizational environment) is analyzed as between-subject variation around the population mean, which labeled 'variance' in differential thinking. Van de Ven and colleagues (Van de Ven, 2007; Poole et al., 2000) argue that researchers reasoning from the differential mode ${ }^{4}$ of explanation 'variabilize' the world, that is, ...view the underlying observed phenomena as comprised of variables standing in relationship to each other' (Van de Ven, 2007, p. 151).

\footnotetext{
${ }^{3}$ With population-level we intend to convey aggregations to the level of the sample (e.g., the grand mean, covariance analyses, correlation, regressions between independent and dependent variables) which are claimed to be informative of and generalizable to a certain population.

${ }^{4}$ Philosophically speaking, differential thinking is strictly at odds with the idea of human agency. For the differential thinker, moving the locus of activity from the subjects to the variables is a matter of logical necessity, since this type of reasoning suffers from a tension between 'content' and 'human agency'. As human agents act and accumulate experiences, their activity will change them over time. For example, the act of starting a family generally leads to substantial re-prioritization of work-life arrangements. If there is a marked shift in attitudes from 'the highly committed worker' to being more balanced in terms of work-life arrangements, we can speak of a substantial change in commitment (a change in 'content') because of the act of starting a family ('human agency'). This idea is logically inconsistent with the essentialist idea of a unitary identity over time ('being' a highly committed worker). This incommensurability of the concepts of content and human agency is well known among philosophers in metaphysics. In fact, the 'substance-agency problem' - as they call it - has been the thorniest logical inconsistency in the differential epistemology (cf. Rescher, 1996).
} 
The third tenet deals with the ontology of cause-effect relationships, the 'why' of theory. The ontology of causation in differential thinking has two basic elements: uniformity (and consistency), and push-type causality. First, it is assumed that generality depends on uniformity across contexts. Differential thought trials are evaluated based on their potential generality. Thus, in the differential approach, one tries to find causal relationships that are recursive: the causal relationship is expected to apply uniformly and consistently across subjects and cases. The plausibility and validity of a conjecture of a causal mechanism in a differential mode of thought is dependent on its ability to apply to a large domain of subjects, contexts, and instances and to do so uniformly and consistently (Van de Ven, 2007). Moreover, causal mechanisms are never dormant; they are always 'on' at equal speed and in the same way. For example, the general effect of organizational commitment on work performance is expected to be operative anytime, anywhere. Inconsistent associations between organizational commitment and work performance have therefore troubled commitment researchers, using the differential paradigm, greatly.

The second element in the ontology of causation is that explanations are based on push-type causality. In theory, this means that a cause is seen as a force, acting on a unit of analysis (subject, group, or case) to make it what it is or change it from what it was (Mohr, 1982, p. 40). In practice, this means that explanations should emphasize immediate causation. In deterministic and stochastic differential models it is assumed that the immediate past is producing the future (Abbott, 1990). Particular twists and turns in the history of the subject are assumed to be cumulatively represented in the immediate past state of the entity (Abbott, 1990; Van de Ven, 2007). For example, all organizational events experienced by a subject in the past 5 years are assumed to be operative and balanced out by the subject who evaluates a particular general measure of 'perceived organizational support' or 'procedural justice'. This evaluation is believed to 'push' - or have pushed - one's organizational commitment and subsequent organizational behavior both in the immediate past and in an indefinite future. In Table 1.1 the ontological tenets are summarized.

(continued on next page) 
Table 1.1 Ontological tenets in differential and temporal thinking.

\begin{tabular}{|c|c|c|}
\hline Ontological assumptions & Differential thinking & Temporal thinking \\
\hline \multirow[t]{2}{*}{$\begin{array}{l}\text { 1. View on the role of time in } \\
\text { phenomena: how- } \\
\text { questions ('from whence' } \\
\text { and 'where to') }\end{array}$} & $\begin{array}{l}\text { Phenomena are time- } \\
\text { invariant and retain a } \\
\text { unitary identity over time. }\end{array}$ & $\begin{array}{l}\text { All phenomena imply change. } \\
\text { Stability is only a temporal } \\
\text { instantiation of an unfolding } \\
\text { process. In other words, } \\
\text { stability is only a special kind } \\
\text { of dynamic form observed over } \\
\text { a certain time interval. }\end{array}$ \\
\hline & $\begin{array}{l}\text { Phenomena have an } \\
\text { indefinite existence }\end{array}$ & $\begin{array}{l}\text { All phenomena have finite } \\
\text { existence. All phenomena } \\
\text { follow a life cycle of } \\
\text { ascendance, subsistence, and } \\
\text { eventual descendance. }\end{array}$ \\
\hline $\begin{array}{l}\text { 2. View on the content of } \\
\text { things: what, and how type } \\
\text { questions }\end{array}$ & $\begin{array}{l}\text { - Definition of content in } \\
\text { terms of 'What is'. } \\
\text { - Phenomena are fixed } \\
\text { settings within which } \\
\text { variables act. }\end{array}$ & $\begin{array}{l}\text { - Process is fundamental to the } \\
\text { understanding of content. } \\
\text { Human beings are agents and } \\
\text { their agency implies change } \\
\text { and transformation of entities } \\
\text { under study. } \\
\text { - Definition of content in terms } \\
\text { of 'What happens' } \\
\text { - Content is defined by its } \\
\text { activity: 'Things are what they } \\
\text { do'. }\end{array}$ \\
\hline $\begin{array}{l}\text { 3. Approach to causation: the } \\
\text { why-question }\end{array}$ & $\begin{array}{l}\text { - Causation is uniform (and } \\
\text { consistent) and is typically } \\
\text { push-type. Causation is } \\
\text { always (uniformly and } \\
\text { consistently) 'on'. }\end{array}$ & $\begin{array}{l}\text { - The form, intensity and the } \\
\text { kind of causation is time- } \\
\text { specific, path-dependent and } \\
\text { cannot be seen apart from the } \\
\text { context in which it operates } \\
\text { (i.e., causation is versatile). } \\
\text { Causation is contextual by } \\
\text { nature, and event-driven. }\end{array}$ \\
\hline
\end{tabular}

\section{Epistemological tenets in differential thinking}

Epistemology deals with the way knowledge about phenomena is obtained with regard to observation, causation, level of analysis, and the treatment of time. As for observation, in differential research phenomena are studied as fixed 'attributes', known as constructs, operationalized as 'variables', and related to other 'variables', as discussed before. These variables are always 'operational', and retain a unitary identity over time. Therefore, only a single snapshot observation will suffice. After all, why perform more observations if attributes do not change and retain a unitary identity over time? Thus, in the light of the ontological assumption that attributes are time-invariant, the widespread use of cross-sectional designs is defensible and logically consistent with the differential perspective. 
The epistemology of causation in differential thinking seems ambivalent at first glance as epistemology differs depending on which ontological assumption prevails. On the one hand, temporal antecedence of the causal variable $\mathrm{X}$ is a necessary requirement for causal inference, which follows from the ontology of a push-type causality, as discussed above. This means that, ideally, causation can only be 'proven' if $\mathrm{X}$ is measured before $\mathrm{Y}^{5}$. On the other hand, antecedence can be perceived as only a 'desirable' requirement for demonstrating causality, which allows the use of cross-sectional designs in differential studies where only a single measurement is considered (weak, though) sufficient. This practice - that temporal antecedence is only a 'desirable' requirement for causal inference is also defensible from the differential perspective as it is consistent with the ontological assumption that variables retain the same (uniform and consistent) causal meaning over time. This ambivalence potentially explains why some differential thinkers support the use of cross-sectional designs, while others oppose it.

There are four other epistemological consequences - typically prevalent in differential type of inquiry - that logically follow from the ontological assumption of uniform and consistent causation: (1) one must assume a minimal time unit of observation as uniformity implies that causal effects cannot be 'dormant' and 'active' in the same model, (2) causal effects are therefore only implied rather than observed, (3) temporal sequence of causal variables is immaterial to the outcome (4) mediation and moderation type of causal models are sought after with eagerness as only these kinds of models reconcile the assumption of uniformity in causality with observed order effects $(\mathrm{X}->\mathrm{M}->\mathrm{Y}$; which is solved by building 'mediation' models) or etiological inconsistencies (i.e., effect of $\mathrm{X}$ on $\mathrm{Y}$ differs, depending on the context in which it operates, which is solved by building 'moderation' models).

To start with the first consequence of the uniformity-of-causation assumption: the investigation of causal effects assumes a minimal time unit. Here lies a conceptual inconvenience in the differential doctrine (Van de Ven, 2007). The assumption of consistent operation over time of the causal variable requires that the variable be operative even if partitioned into equal temporal fractions. In each of these fractions the variables should be measurable and the causal effect should be identifiable. Otherwise, variables of different statuses would be incorporated in the same model, which leads to a logically erroneous

\footnotetext{
${ }^{5}$ More specifically, in the differential paradigm it is widely excepted that causation can be inferred if the following three elements are fulfilled: (1) causal variable $\mathrm{X}$ precedes dependent variable $\mathrm{Y}$, (2) variable $\mathrm{X}$ shows covariation with $\mathrm{Y}$, and (3) alternative explanations for this relationship can be excluded (i.e., no spuriousness).
} 
estimation (Poole et al., 2000). In other words, causal effects cannot be 'dormant' and 'active' in the same model, or as Van de Ven phrased it: 'If independent variables are assumed to be always in operation on a dependent variable, all variables - independent, dependent, categorical or continuous - must be susceptible to measurement at the same point in time...As temporal units grow finer and finer, the model breaks down because eventually the unit is so fine that at least one variable cannot be realized in the same time frame and measurement becomes impossible' (Van de Ven, 2007, p. 153). As a consequence, a differential researcher must assume a minimal time unit for the causal factor to take effect before measurement can take place. For example, if one investigates the causal relationship between the breach of a psychological contract and organizational commitment, a minimal time unit is assumed in which a breach can unfold. Differential thinking assumes that the effect of psychological contract breach is always operative (say, in all the 6 months of observation), while it may take a while (e.g., until the $8^{\text {th }}$ week of observation) before a significant event signaling a breach can take place. If the time frame of six months is then partitioned in 24 weeks, the psychological contract breach variable cannot be observed in all occasions $^{6}$, which would result in a variable with different statuses ('on' and 'off') in the same model $^{7}$.

The second epistemological consequence of the 'uniformity-of-causation' assumption is that causal effects are highly difficult to observe as they occur. Causal effects (e.g., being treated with procedural fairness 'pushes' levels of commitment) are assumed to have accumulated and translated into high levels in the particular attribute. How and when this 'pushing' came in effect remains unobserved. After all, if causal factors cannot be dormant and active in the same model, the activity of causation cannot be tested against a 'null' model (i.e. a baseline level, when causation is 'dormant'; Bordens \& Abbott, 2002). In differential analyses this null model is approached by comparing individuals, but not by comparing dormant versus active causal effects in the same individuals ${ }^{8}$. Thus, even if longitudinal designs are used, causation can only be implied by means of covariation (e.g., correlation, regression, time-lagged covariation, path-analysis), under the condition that a

\footnotetext{
${ }^{6}$ In differential research a continuous variable, typically measured in Likert-scale format (1-7), cannot be zero.

${ }^{7}$ This potentially explains why repeated measures in differential longitudinal research (e.g., applying serial cross-sectional research designs) are taken years (of half years) apart from each other and longitudinal designs shorter time intervals (e.g., weeks) are rarely seen. This was observed earlier by Roe (2008b) and Dormann (2006).

${ }^{8}$ A differential type of analysis, thus, assumes that subjects are interchangeable. This means that Tom's score

'2' and Sally's score ' 5 ' do not differ from Tom's score 2 at Time 1 and Tom's score 5 at time T2 (see Borsboom et al., 2003). This, in turn, implies a universalistic approach to the study of human beings (cf., Molenaar, 2004).
} 
fitting theoretical narrative is available. Thus, for a detailed account on how and when the causal effect took place the differential researcher must rely on the narrative rather than the observation. This may explain why the differential methodology is so seldom used only for exploratory, observational purposes.

A third epistemological consequence following from uniformity-of-causation assumption is that the temporal sequence of causal variables is immaterial to the outcome. That is, independent variables, $\mathrm{X} 1$ and $\mathrm{X} 2$, are typically combined in a particular formula (e.g., $\mathrm{Y}=\mathrm{a}+\mathrm{bX} 1+\mathrm{cX} 2+$ error) where temporal order is of no effect. The order has no effect on their causal meaning (Van de Ven, 2007; Abbott, 1990; Mohr, 1982).

A fourth consequence of the uniformity-of-causation assumption is that mediation and moderation models are indispensible analytical tools for differential inquiry. In the differential epistemology 'order effects' in causation are acknowledged to exist and are solved by incorporating 'mediators' in the model, where the effect of independent variable $\mathrm{X}$ on $\mathrm{Y}$ only works through mediator $\mathrm{M}$. For example, in $\mathrm{OB}$ the relation between procedural fairness (X) and work performance (Y) is believed to be mediated by the organizational commitment variable (M). Note that mediation effects in the differential epistemology are captured by creating 'statistical order', which does not necessarily translate to the idea of 'temporal sequence'. In differential inquiry, mediation (statistical order) can be statistically demonstrated with only a single measurement in time.

A popular analytical tool to reconcile the ontology of time-invariant operation of causal variables with observed etiological inconsistencies, is injecting a 'moderator variable' in the model. In moderation, $\mathrm{X}$ has a different effect on $\mathrm{Y}$ in different levels of $\mathrm{Z}$. For example, the impact of different degrees of psychological contract violation (X) on differences in commitment levels (Y) is moderated by individual differences in equity sensitivity (Z). If this model holds, the effect of psychological contract violation on organizational commitment is higher among individuals who score high on equity sensitivity in social exchange relationships than among individuals who score low. Moderators play an important role in the differential epistemology of causation. While the causal effects of both the causal variable $\mathrm{X}$ and mediator variable $\mathrm{Z}$ are fixed over time, their interaction changes their effect on Y. Thus, inconsistency in the causal operation of $\mathrm{X}$ (and Z) can be elegantly modeled and explained without violating the principle of uniformity. This very characteristic makes the moderator a prime candidate to increase the sophistication of differential type models and 'solve' empirical inconsistencies in cause-effect relationships. For example, contextual inconsistency in the effect of job satisfaction on task performance is solved by 
injecting a contextual variable, such as organizational climate, or differences in levels of trust in the organizational environment. In fact, even temporal inconsistency in the operation of causal variables is often solved by injecting 'time' as a moderator in the model ${ }^{9}$. Not surprisingly, moderation-effects (as well as mediation-effects) are the two most prevalent tools in the analytical repertoire of the differential researcher.

The epistemology of differential thinking with regard to the level of analysis is unequivocal as differential inquiry can only be performed at the group or population level of analysis. Unless multi-level type analyses ${ }^{10}$ are used, psychometric theory specifies that findings on covariation between independent and dependent variables apply to - and only to - the group- or population-level of analysis (Borsboom, Mellenbergh, \& van Heerden, 2003; Jaccard \& Dittus, 1990; Molenaar \& Campbell, 2009; Van de Ven, 2007). Differential analysis and the population level of analysis are closely tied, but should not be regarded as equals. Analyses at the population level are not necessarily differential (e.g., one can study the dynamics of an economy at the population level), but differential analyses are can only be performed at the level of the group or the population, as the analysis focuses on differences between cases. As such, operations, activity and causation at the individual level are of no concern in differential type analyses; individuals are exchangeable as knowledge is gained through the averaging process on group- or population-level.

Regarding the treatment of time, psychological processes and events are reduced to their separate parts as they are measured over time (e.g., commitment levels at Time 1 versus Time 2). This means that time is dealt with in a particularistic way. This is evident in the emphasis differential researchers place on the reliability and validity of 'scores', or a series of 'scores', as opposed to trajectories or 'patterns'. We will elaborate on this issue when we discuss the treatment of time in the epistemology of temporal thinking and its application to organizational commitment. In differential thinking time itself is not of substantial interest. Instead, temporal variation is treated as unintended disturbances of the normal state-ofaffairs. Time effects are typically treated as 'noise' or threats to the internal validity of the

\footnotetext{
${ }^{9}$ It is worth noting that incorporating time as a variable in a differential model implies that time is approached as an attribute on which subjects can vary. However, it also implies that 'time' is set 'still'; time is made into an invariant individual property (cf. Borsboom et al., 2003; Molenaar, 2004). Although this is computationally possible, it does not make logical sense: time - by definition - cannot be stationary (i.e., temporally invariant).

${ }^{10}$ Multi-level type analyses on attitudinal phenomena serve well to specify the level of analysis (individuals, groups, or populations) at which variables are defined. In Hierarchical Linear Modeling (HLM), a special type of multi-level analysis (Singer \&Willett, 2003), within-subject change over time (typically specified at the individual-level in a temporal analysis) is specified at Level 1 and differential attributes (e.g., personality) are specified at Level 2, explaining between-subject differences in within-subject change (e.g., differences in initial level and rate of change, which is a differential analysis). Only in this special case a differential analysis can apply to a phenomenon which is experienced by an individual over time.
} 
research (e.g., the infamous 'maturation-effect' in quasi-experimental research; see McGrath $\&$ Tschan, 2004). In Table 1.2 these epistemological tenets are summarized.

Table 1.2 Epistemological tenets in differential and temporal thinking

\begin{tabular}{|c|c|c|}
\hline $\begin{array}{l}\text { Epistemological } \\
\text { assumptions }\end{array}$ & Differential thinking & Temporal thinking \\
\hline \multirow[t]{3}{*}{$\begin{array}{l}\text { 1. Approach to } \\
\text { observation. }\end{array}$} & $\begin{array}{l}\text { - Phenomena are studied as fixed } \\
\text { 'attributes', known as constructs, } \\
\text { operationalized as 'variables', and } \\
\text { related to other 'variables'. }\end{array}$ & $\begin{array}{l}\text { - The historical unfolding is } \\
\text { studied; 'Letting things becor } \\
\text { manifest as they are' }\end{array}$ \\
\hline & $\begin{array}{l}\text { - Variables are always 'operational', } \\
\text { and retain a unitary identity over } \\
\text { time. Therefore, only a single } \\
\text { snapshot observation will suffice. } \\
\text { The use of time scale in repeated } \\
\text { observation is immaterial to the } \\
\text { outcome. }\end{array}$ & $\begin{array}{l}\text { - Phenomena can/should be } \\
\text { studies with 'a clock in the } \\
\text { hand'. Time scale is crucial to } \\
\text { the internal validity of the } \\
\text { research and it can have } \\
\text { conceptual meaning. }\end{array}$ \\
\hline & $\begin{array}{l}\text { - Only a small number }(\mathrm{e} . \mathrm{g} ., 2-4) \text { of } \\
\text { repeated observations will suffice. } \\
\text { Typically large time intervals } \\
\text { between measurements }\end{array}$ & $\begin{array}{l}\text { - High-density repeated } \\
\text { measurement (HDRM): fine- } \\
\text { grained (high-density) and } \\
\text { lengthy (high-frequency) } \\
\text { longitudinal designs. }\end{array}$ \\
\hline
\end{tabular}

2. Approach to causation - To some, temporal antecedence of the causal variable is required (i.e., when a push-type view of causality is dominant); to others simultaneity (in cross-sectional designs) is sufficient, depending on the quality of the theoretical narrative.

The (ontological) uniformity-ofcausation tenet dictates that: - One must assume a minimal time unit for a causal factor to take - or have taken - effect.

- Causation (by association) is inferred if a fitting theoretical narrative is available; causation is implied

- Temporal sequence of causal variables is immaterial to the outcome.

- Causal order is approached as 'statistical order' in mediation analyses.

- Inconsistencies in causation effects are solved by adding 'moderators' to the model.

In theory, findings apply to - and only to - the group or populationlevel of analysis. Individuals are exchangeable as knowledge is gained
- Beside antecedence, simultaneity and (anticipation of) future events are plausible accounts of causation, next to spiral effects. Hence, antecedence is not a necessary requirement for causation.

The (ontological) versatility-ofcausation tenet dictates that: - Causation can be 'dormant' at one time and 'active' at another time in the same model.

- Causation is observed as it unfolds and, thus, made explicit

- Time-ordering of causal phenomena is crucial to the outcome.

- Mediation in causation is approached as 'temporal sequence'.

- Etiological inconsistency is part of the 'versatile' nature of causation.

Applies to the population-, group, - and individual level of analysis, depending on the nature of the phenomenon. The most valid 
through the averaging process on group- or population-level.

4. The treatment of time

- Particularistic treatment of time:
psychological processes and events
are reduced to their separate parts as
they occur across time (e.g.,
commitment levels at Time 1 versus
Time 2).
- Temporal variation is treated as
unintended disturbances of the
normal state-of-affairs (i.e., time
effects are 'noise' or threats to the
internal validity of the research).

- Particularistic treatment of time: they occur across time (e.g., commitment levels at Time 1 versus Time 2) normal state-0 internal validity of the research). level of analysis is the one at which change in a particular phenomenon by definition takes place.

\author{
- Holistic treatment: time is in \\ events and processes which are \\ inextricably tied to each other in \\ a meaningful 'whole'. Focus on \\ patterns instead of 'points'. The \\ pattern cannot be reduced to its \\ constituent parts. \\ - Temporal variation is of \\ substantive interest.
}

Unmistakably, differential thinking has led to sophisticated ways of testing and to knowledge on (general) inputs and outputs in organizational processes. However, we can already conclude from the assumptions made in differential thinking that it has considerable trouble dealing with temporal concepts such as history, change, development, growth, and learning, to name a few. If one acknowledges the inherent temporal character of OB phenomena, such as affective and motivational states, many of the underlying assumptions do not hold because these phenomena can vary over time. It is for this reason, that the indiscriminate application of differential thinking and methodology to such phenomena, has prompted some authors to sarcastically speak of a 'general linear reality' (Abbott, 1988) and a resulting 'body of pseudo-knowledge' (Roe, 2005b). Instead, applying temporal thinking consistently in the study of OB phenomena could increase understanding of change, content and causation and expose unanticipated characteristics that are yet to be explored.

\subsection{Temporal thinking}

The temporal mode of thought dates back to the Greek philosopher Heraclitus $\left(6^{\text {th }}\right.$ century B. C.) who opposed his contemporaries' view that nature is composed of unchanging and inert atoms. Instead, he claimed, 'Process is fundamental: The river is not an object, but an everchanging flow; the sun is not a thing, but a flaming fire' (Rescher, 1996, p. 10). Later philosophers like Leibnitz, Hegel, Pierce, James, Bergson, Dewey and Whitehead further elaborated this epistemology.

In the study of organizations temporal thinking was re-introduced in the 1980 's as a reaction to the prevalent a-historic and deterministic way of doing research of that time. Since then, its application has been advocated by a number of organizational scholars 
(Ancona, Goodman, Lawrence, \& Tushman, 2001; Collins, 2006; George \& Jones, 2000; McGrath \& Kelly, 1986; McGrath \& Tschan, 2004; Monge, 1990; Roe, 2008a; Slife, 1993; Tsoukas \& Chia, 2002; Van de Ven, 2007). Temporal thinking is the capacity to represent and understand changes over time (Pons \& Montangero, 1999). To think temporally is also to be attentive to what happens in time, in relation to what happened before ('from whence') and what might happen in the future ('where to', Faulconer \& Williams, 1985). The definition of the 'present' in temporal thinking is therefore relatively unimportant as it studies phenomena over spans of time (Roe, 2008a; 2009).

Ontological tenets in temporal thinking The first assumption, which regards the role of time in the study of organizational behavior, is that concepts are systematically placed in time. A differential thinker therefore prefers to speak of 'phenomena' instead of 'attributes'. A phenomenon is defined as a (series of) related events taking place in a particular class of objects during a certain time interval (Roe, 2009). A phenomenon encompasses events ${ }^{11}$, i.e., items of experience such as activities, occurrences, and processes $^{12}$. Phenomena are described as 'items of experience' because they can be experienced and identified by the actor and - hopefully - picked up by the researcher. Systematically embedding phenomena in time also implies that they have finite existence, which means that phenomena do not exist for an indefinite period of time; they emerge during a process of ascendance, fluctuate in intensity during a period of subsistence, and inevitably decay during a period of descendance (Roe, 2008a; Rescher, 1996; chapter 3). This implies that temporal thinkers hold that all phenomena can be placed in the framework of the life cycle, the character of which (e.g., how fast they emerge and decay) fully depends on the unique temporal nature of the phenomenon (Roe, 2008a). Ontological assumptions in the temporal doctrine are summarized in Table 1.1, displayed earlier.

With regard to content, temporal thinkers hold that change has primacy over stability. Differential and temporal thinking represent opposing views in this respect. According to the temporalist view, change is inherent in activity and these activities can only be studied

\footnotetext{
${ }^{11}$ Note that - in this conception - 'events' are endogenous to and constituting the phenomenon (e.g., feeling proud of one's organization, as an item of experience, which is part of organizational commitment). There are also 'events' which need to be understood as incidents (or a meaningful colligations of incidents) that are exogenous to the phenomenon. For example, getting into a fight with a colleague (exogenous event) will result in a sudden drop in commitment (phenomenon).

12 Our conception of a developing phenomenon is closely related to the philosophical idea of 'process' which is defined as 'a sequence of activities and transactions that in each case constitutes an elaborate story of interconnected developments' (Rescher, 1996, p. 29). Processes are correlated with occurrences or events in the sense that processes always involve various events, but events exist only in and through processes (Rescher, 1996).
} 
dynamically. Stability is but a transient instantiation of an unfolding or emerging process (Rescher, 1996). It is assumed that the content of phenomena is endogenously constituted and exogenously determined by processes that unfold over time (Rescher, 1996). In contrast, differential thinking holds the assumption that social systems are harmonious, stable, and equilibrium-seeking, while temporal variation is treated as unintended disturbances of the normal state-of-affairs (Avital, 2000; McGrath \& Kelly, 1986; Orlikowski \& Baroudi, 1991). According to temporal thinkers, an organization is not a fixed entity with a unitary meaning over time, but an ongoing attempt to order and channel the intrinsic flux of human action; it is a pattern formed by and emerging from change (Tsoukas \& Chia, 2002). Note that a temporal perspective does not exclude stability, but regards it as just one among many temporal patterns possibly observed within a particular time frame.

As a second element in the temporal ontology of content, temporal thinking holds that things are what they 'do' (Rescher, 1996). Temporal thinkers are generally reluctant to define content in fixed, passive terms. Phenomena can be identified and experienced by means of their activity and the processes related to this activity. Therefore, phenomena are best described in terms of verbs ${ }^{13}$. For example, it is better to speak of 'leading' or 'following' than of 'leadership' (Rescher, 1996; Roe, 2008a). The distinction of 'leadership' in two verbs - leading and following - indicates that defining the content of phenomena in terms of their activities is helpful to discover the locus and kind of activity. To lead a group is different as an item of experience and is constituted by different sub-activities compared to following a leader (Roe, 2008a). Also, defining the word 'love' in terms verbs (as they say: 'love is verb') is easier than defining the true, invariant substance of it. For a temporal thinker, 'to love' should be understood as a meaningful mix of overt activities (e.g., embracing someone) and processes related to this activity (e.g., the addictive 'activity' in the hormonal constellation in the body) which are engaged in a process of continuous flux as one relates and reacts to another person over time.

The final tenet in temporal ontology pertains to the view of cause-effect relationships. Temporal causation is approached as a process unfolding over time where events are connected to each other. Causation is event-driven (Van de Ven, 2007), where particular exogenous incidents disturb, change, or transform a particular developmental

\footnotetext{
${ }^{13}$ Coming back to process metaphysics, if we equate what a phenomenon is, with what it does (the activities), it implies that a change in the activity is a change in the phenomenon and that a discontinuation of the activity (e.g., if one stops 'committing oneself') puts an end to the phenomenon itself. Therefore, the assumption of agency in temporal thinking does a better job reconciling content with agency, transformation, and finite existence than differential thinking.
} 
course of the dependent phenomenon. Causal events can be endogenous to a phenomenon (e.g., a sudden drop within the commitment trajectory causes increased job search behaviors) as well as exogenous (e.g., one's spouse decides to move to another part of the country, which causes increased job search behaviors). It should be noted the anticipation of a particular event (e.g., an impending downsizing) or an anticipated process (e.g., romantic activity) can be a strong causal factors as well. Simultaneity (e.g., getting a bad mood while decreasing in commitment) can also be a plausible scenario in temporal causation, as are spiral effects (e.g., trust and conflict in a team influence each other reciprocally).

Temporal thinking also holds the doctrine that theoretical generality in causation depends on its versatility. Both differential thinking and temporal thinking aim to find generality. However, the judgment of temporal generality depends on versatility, rather than uniformity and consistency (Van de Ven, 2007). Versatility is the degree to which the explanation 'can encompass a broad domain of developmental patterns without modifying its essential character' (Van de Ven, 2007, p. 156; Poole et al., 2000). That is to say, instead of causation being uniform with a singular outcome (i.e. the differential paradigm), temporal causation can come in various forms with various outcomes, depending on the time at which causation takes place and on the context in which it operates. For example, if commitment has a causal relationship with performance, causality can be demonstrated by a simultaneous decrease of commitment and performance patterns, or with a time lag in between the drop in commitment and a drop in performance (Monge, 1990; Roe, 2008a), depending on the unique conditions of the situation (e.g. a lag of effect of one week due to a holiday break). Temporal causation deals with the probability of A acting on $\mathrm{B}$, given a certain contextual opportunity. Thus, context can change the specific instantiation the cause-effect relationship without modifying the essential character of it. Causation is not uniform, implied, and outcome-driven - as in differential causation - but rather contextual, explicit, and eventdriven (Faulconer \& Williams, 1985; Kockelmans, 1984; Mohr, 1982; Slife, 1993; Van de Ven, 2007).

Epistemological tenets in temporal thinking The approach to observation in the temporal doctrine is characterized by 'letting things become manifest as they are' in time (Avital, 2000, p. 670). In this sense temporal researchers are not bound to a particular paradigm as they describe and explain 'what happens', rather than 'what is' (Roe, 2008a); the 'unfolding' is studied, not any particular 'state'; the process itself is of interest, not its inputs and outputs. Starting inquiry without theoretical paradigms - for example, when first 
observing the behavior of an attitudinal phenomenon in a different time grid - is recently encouraged (Hambrick, 2007; Miller, 2007).

According to the temporal mode of thought, all phenomena - as they stretch out in time - can (and should) be observed with a clock in the hand (i.e., chronometrically). Temporal researchers argue that time should be seen not as an ontological given, but rather as a construct invented with the aim to provide an external standard of reference that allows us to communicate and compare our experiences with others (McGrath \& Tschan, 2004; Roe, 2009). Time is a social construction to coordinate and synchronize human operations. Temporal researchers use time as universal 'currency' in an objective sense, even though it originates from a social construction ${ }^{14}$.

In the practice of inquiry into attitudinal phenomena, longitudinal studies must be designed such that one is able to 'capture' temporal movement as it unfolds (Collins, 2006; George \& Jones, 2000; Roe, 2008a). This places high demands on the use temporal design as observing unfolding change implies the use of fine-grained recordings for a sufficiently long period of time. For example, if one wishes to study how a tennis player strikes a forehand, high density recording (e.g., at least 20 snapshots per second, either by photo or video) is necessary to come to the right conclusions. Likewise, if one is interested in how employee commitment is affected by organizational upheaval, one must make sufficiently fine-grained recordings (like taking weekly measures) and choose the right time frime (e.g., one year). The currently dominant practice of using two or three waves of measurement - with arbitrary time intervals (see chapter 3, for a review) - is insufficient for making valid claims about temporal movement in phenomena. In this dissertation, the type of temporal design required to make inferences about temporal movement of phenomena and their interrelationships is called high-density repeated measurement (HDRM). HDRM is a combination of high-density and high-frequency measurement which allows for a fine-grained and lengthy look at temporal movement in phenomena. High-density attitude measurements are taken very rapidly one after another - say every hour, twice a day, daily, bi-daily, or once a week. High-frequency means that measures are taken in large quantities, say more than 20 , within a given time

\footnotetext{
${ }^{14}$ Straightforward as it may seem, this assumption is not trivial. For instance, chronological clock time (chronos) is usually different from experienced event-time or subjective time (kairos). And 'time-to-event' (for instance, the cyclical progressions of predictable events) is experienced differently from elapsed, clock time (Bluedorn, 2002; Jacques, 1982). However, to the temporal thinker these objections are not too problematic. Eating lunch can be described both as an activity measured on a clock and as the experience of an event, unrelated to clock time. The two views of time are compatible in practice (Bluedorn, 2002). Even subjective experiences of time can be studied with a clock in the hand if one makes the distinction in who is conceiving of time (the organizational actor or the researcher) and to what purpose (to define a time frame for the study or to conduct measurements, or to code event occurrences, Roe, 2009).
} 
frame. HDRM does not specify the exact time intervals used in the time frame of the design. The exact time interval can vary, depending on the temporal nature of phenomenon under study and the type of research question. In our studies we have chosen equal spacing between subsequent measurements.

Strong emphasis is placed on the choice of the time frame and time grid in the design as the temporal view holds that the choice of the time frame and the time intervals between observations directly affects the dynamic which is observed. In fact, the adoption of a different time frame can alter the conceptual meaning of a phenomenon (Zaheer, Albert, \& Zaheer, 1999). For instance, in the concept 'affect' the inclusion of time in construct definition serves to separate a singular concept into different phenomena (Watson, 2000). Time distinguishes the concept of 'affect' in trait affectivity (affective traits conceptualized as relatively stable over time), mood (transient affective states lasting up to a couple of hours) and emotions (affective states lasting only a couple of minutes or even seconds).

A second element in temporal epistemology is the approach to capturing causation. The ontological assumption of versatility of causation, as described before, implies that (1) causal factors can be 'dormant' and 'active' in the same model, (2) causation is therefore observed as it happens, thus, made explicit, (3) temporal sequence of causal events is crucial for explanation, (4) building moderation and mediation type models is not strictly required to account for etiological inconsistency or order effects in causation. Moderation and mediation may be replaced by more refined temporally-bound analyses that give more insight in 'what happens' when phenomena interrelate, and (5) it allows for a larger 'analytical repertoire' for studying cause-effect relationships. All of this is summarized in Table 1.2, displayed earlier.

To start with the first epistemological implication of the versatility-of-causation assumption, no minimal time unit is required for the causal effect to instantiate. As a causal factor does not have fixed meaning, and does not need to be invariantly operative, a temporal analysis can allow causation to be 'dormant' (that is, zero) up to the moment a particular event activates the causal influence. For example, temporal causation can be demonstrated when a base line commitment pattern across the first 6 weeks of work is abruptly disturbed in response to an event signaling the breach of the psychological contract in week 7 . The fact that causation is dormant during first 6 weeks and 'activated' in week 7 is not problematic in temporal inquiry. To the contrary, this type of observation is strongly indicative of a temporal causal relationship.

A second consequence of the versatility-of-causation assumption is that causation can be observed as it happens. For example, the effect of a team-building intervention day out in 
the forest may have an effect on the participants' sense of group commitment, which is measured three times a day for total period of 6 weeks ${ }^{15}$. To measure the effect of the company team building training day on group commitment, the temporal researcher starts to observe the initial baseline levels of group commitment for a week during 'business as usual'. Then he observes a drastic growth of experienced commitment in response to the team building day. However, in the following weeks many of the participants, back in their old environment, return to their old routines and behave as if no team building day ever took place. The researcher observed a convex decline in group commitment after the team building day.

What can be said about the causal effect of 'team building' on levels of group commitment? One can indeed speak of an immediate, context-specific effect (being out in the forest) of team building on group commitment, which lasts only for a number of days. After those days, participants 'relapse' into old habits as they return to familiar environments and to former attitude levels. Thus, the temporal thinker will observe that the effect of team building exercises on group commitment is immediate, context-specific, and prone to relapse if participants return to their old contexts. The temporal researcher learns that a change of environment facilitates an immediate causal effect of team building and that a return to the old environment serves to 'extinct' the causal effect very quickly.

Note the level of detail at which the alleged causal effect is described. The - however transient - effect of the team building day (i.e., the causal event) on group commitment is simply observed by inspecting its effect in the temporal pattern of group commitment (i.e., a disruption in the time-varying dependent variable). Causation is made explicit.

The third epistemological consequence, following from versatility-of-causation assumption is that events are only explanatory because of their particular position in a sequence of meaningful occurrences (time ordering), the position in the historical context and their embeddedness in the 'opportunity' of the external environment (i.e., the 'opportunity structure', our own words). Mohr (1982) came up with a classic example, 'If an anophyles mosquito bites a malaria victim and subsequently bites $A$, then A gets malaria' ( $\mathrm{p}$. 58). The temporal sequence of events (i.e., when first an anophyles mosquites bites a malaria victim) and the context (i.e., a tropical climate where the anophyles mosquito can thrive) is crucial to the explanation why A gets malaria. This kind of path-dependent causation can only be studied (and discovered!) with a temporal mindset. Other examples include the small

\footnotetext{
${ }^{15}$ Note that this is a single-case design (Bordens \& Abbott, 2002).
} 
accumulation of instances with dramatic effects ('the straw that broke the camel's back'), or typical colligations of incidents that make up meaningful events (Abbott, 2001).

A fourth epistemological consequence of the versatility-of-causation assumption is that there is no strict necessity to build mediation and moderation type models to increase a theory's sophistication - unlike epistemology in the differential doctrine. After all, inconsistency in cause-effect relationships (i.e., 'etiological inconsistency') is only natural as in versatile causality the causal effect can take a different form and intensity (depending on the time and context) without losing its causal character. Therefore, moderation models are useful to the temporal doctrine, but not strictly necessary in epistemological sense.

Moreover, moderation type models are already captured to a large extent by other types of analyses which are capable of giving a more refined description of 'what happens' when two factors interact with one another over time to influence Y. The temporal doctrine contains a large number of moderation-like analyses such as path-dependency in causation (i.e., when $\mathrm{X}$ interacts with 'history' to influence $\mathrm{Y}$ ), differential causal effects in distinct sub-patterns of interest on the cluster-level of analysis (e.g., if men and women display substantially different patterns over time, it has differential impacts on Y), accumulation or interaction of risk factors ('cocktail-effects') to the prediction of certain patterns of temporal development (cf. Nagin, 2005; Abbott, 2001; Poole et al., 2000), 'extinction' effects (when two opposing factors counteract each other, see our team building and group commitment example, discussed before), or amplification ${ }^{16}$ effects, to name a few.

The same holds for 'mediation' type models. Causal order is already captured by the concept of temporal sequence, which allows for a more refined picture of what happens when causal effects have a specific time ordering. For example, an event signaling a psychological contract breach in Week 5 results in a structural break (i.e., disruption) in the commitment pattern in Week 6 (i.e., time lag of effect is 1 week). This structural break, in turn, has an impact on decreases in levels of performance in Week 6-12. The question is whether this type of causal sequence always happens, or whether it happened accidentally in a particular historical context. In the temporal analysis of time-ordered causality one might make the distinction between causal chains and serial effects. While serial effects describe causal effects that occur incidentally after one another (i.e., there exists only $\mathrm{X}->\mathrm{M}$, and $\mathrm{M}$ $>Y$ ), causal chains constitute causal factors that are more tightly coupled in a temporal order

\footnotetext{
${ }^{16}$ Amplification and extinction are temporal analyses which are equal to the mathematical idea behind 'moderation'. In amplification, $\mathrm{X}$ and $\mathrm{Z}$ amplify each other to reach a greater effect on $\mathrm{Y}$. In extinction, $\mathrm{X}$ and $\mathrm{Z}$ work against each other, so that causal the effect of $\mathrm{X}$ (or $\mathrm{Z}$ ) on $\mathrm{Y}$ is reduced.
} 
$(\mathrm{X}->\mathrm{M}->\mathrm{Y})$ and are less dependent on the historical context. A mediation analysis calculating only 'statistical order' is not capable of distinguishing these two distinct sequence effects. Thus, a temporal perspective is perhaps better able to show 'what happens' in time-ordered causality by building more refined models of temporal sequence (e.g., causal chains versus serial effects), by emphasizing the role of generality and recursivity across historical contexts.

The fifth and final consequence of the versatility-of-causation assumption is that, as a general note, the 'analytical repertoire' in temporal epistemology is not restrained to moderation and mediation type models. The repertoire is larger, as it allows for studying not only causal chains, serial effects, path-dependency, amplification or 'extinction' effects, it also allows a detailed, explicit study of relapse, causal decay, lags of effect, spiral effects (Roe, 2008a; George \& Jones, 2000; Monge, 1990), as well as temporal convergence (e.g., isomorphism), temporal divergence (e.g., bifurcation effects), all of which can be studied with different time frames (e.g., varying 'zoom levels'; Zaheer et al., 1999; Roe, 2008b).

In temporal inquiry no specific level of analysis is specified, that is, inquiry can apply to the population-, group-, and the individual level of analysis (Borsboom, Mellenbergh, \& van Heerden, 2003; Molenaar, 2004; Molenaar \& Campbell, 2009), depending on the question at what level change in a particular phenomenon is defined. That is, temporal movement (change) in phenomena can have different analytical 'levels' at which they naturally occur. Change in the economy is a population-level phenomenon; change in group cohesion is a group-level phenomenon. Change in workplace attitudes is an individual level phenomenon. If the change in a phenomenon is studied at levels of analysis other than the level in which it is defined, observation of change will likely be distorted to some extent.

With regard to the treatment of time, temporal thinking holds that time is present in events and processes (Slife, 1993; McGrath \& Tschan, 2004; Roe, 2009); these elements are inextricably tied to each other in a meaningful 'unfolding'. Conform ideas put forward by Heidegger (Kockelmans, 1984; Slife, 1993), actor, object, context, and history are not independent from each other, but form a meaningful story of 'what happened'. In contrast to the differential approach - where time is reduced to its constituent moments (i.e., time points) - the temporal approach is holistic (cf. Slife, 1993) and deals with patterns, with developmental forms, with 'Gestalts', so to speak, where the 'whole' is more than the sum of its parts. That is, the reliability of a temporal pattern exceeds the analysis of the difference between two time moments. Although - yes - a pattern is a series of changes, it is a very distinct series of changes, which cannot randomly be reordered without destroying its 
meaning and informative message. An example from linguistics may serve to illustrate this argument. If - in contrast to how we normally build and present sentences - we present 25 words of a particular sentence in random order, its meaning is destroyed. Not only does this particularization of a sentence into random discrete words mystify the intended message, it also allows the reader to create a range of possible sentences of his own making that have a different meaning of arbitrary quality. Likewise, reducing a pattern of scores (a 'trajectory') to single, discrete scores mystifies its meaning (e.g., the temporal 'character' of a phenomenon). This practice also obscures potentially meaningful temporal prediction (e.g., how $\mathrm{Y}$ reacts dynamically if $\mathrm{X}$ happens) as the different waves of measurement are studied separately and only arbitrarily coupled. Thus, consistent temporal thinking dictates a holistic view of measurement - and analysis - where patterns are assessed, rather than points.

\section{A temporal view on organizational commitment}

The purpose of this dissertation is to show how the adoption of temporal thinking can alter the way we approach phenomena. For example, consistent adoption of temporal thinking could result in a different conceptualization and operationalization of phenomena, alter the way we theorize about phenomena, and lead to different approaches to methodology and measurement theory ${ }^{17}$. In fact, it may even lead to innovations in test development practices.

We have chosen an attitudinal phenomenon which is familiar and well-studied in the field of Organizational Behavior - partly with longitudinal designs - to demonstrate what a consistent temporal approach can add to existing knowledge. Organizational commitment (OC) is a particularly well-studied phenomenon in organizational settings (Harrison, Newman, \& Roth, 2006; Mitchell, Holtom, Lee, Sablynski, \& Erez, 2001). A simple entry in the Google Scholar search machine yields around 475,000 hits on organizational commitment (retrieved in June, 2009). By comparison, the organization-based self-esteem construct yields only 2.020 hits. OC has to date been studied with almost exclusively differential type studies; as such it is a prime candidate to research the scope of a temporal lens.

\footnotetext{
${ }^{17}$ A temporal measurement theory - including an understanding of the concepts of reliability and validity in a temporal context - is still to be developed. In Appendix B we shortly elaborate on this issue.
} 
OC fits in the Organizational Behavior discourse on work-related attitudes which is characterized by a large number of variables that seem all positively interrelated (Cohen, 2003; Dirks \& Ferrin, 2002; Mathieu \& Zajac, 1990; Zhao, Wayne, Glibkowski, \& Bravo, 2007). For example, meta-analyses consistently show that (affective) organizational commitment and job satisfaction are highly correlated. Correlations are consistently found to vary around .60 (Allen \& Meyer, 1996; Harrison, Newman, \& Roth, 2006; Harter \& Schmidt, 2008; Mathieu \& Zajac, 1990; Meyer, Stanley, Herscovitch, \& Topolnytsksy, 2002). Other work attitudes like trust, job involvement, occupational commitment, organization-based self-esteem, work ethic and even work motivation and work engagement are all positively interrelated (Harter \& Schmidt, 2008). That is, correlations roughly vary between .30 and .60 (Cooper-Hakim \& Viswesvaran, 2005; Dirks \& Ferrin, 2002; Mathieu \& Zajac, 1990; Pierce \& Gardner, 2004). Typical outcome 'variables' (note the differential language) used are turnover, intentions to quit, absenteeism, and work performance. Explaining differential work performance by job attitudes has been proven quite hard (Fishbein \& Ajzen, 1980; Harrison, Newman, \& Roth, 2006; Riketta, 2002), with correlation coefficients generally varying between .10 and .20 .

A clear example of the differential perspective typically adopted in the commitment literature is found in research on the effects of downsizing. In this particular research field, researchers look for the most essential elements in downsizing on which subjects might differ. The downsizing process is then 'variabilized' into e.g. psychological contract violation and feelings of insecurity. In the next step, these variables - measured once, or at two times during downsizing - are related to levels of organizational commitment after the downsizing. But what does this association at the level of the population tell us about the repercussions of downsizing at the individual level? Perhaps a temporal perspective can be helpful to answer such questions.

There is an increasing amount of studies that adopt a temporal design and have specifically dealt with the temporal development of job attitudes (Bentein, Vandenberg, Vandenberghe, \& Stinglhamber, 2005; Cohen \& Freund, 2005; Fuller et al., 2003). For example, Boswell and colleagues (Boswell, Tichy, \& Boudreau, 2005) did a study on honeymoon-hangover effects of job satisfaction among newcomers just after entering a new organization. Perhaps temporal thinking will cast new light on generative mechanisms on why commitment shows inclines or decreases, and how (and when) it impacts on performance. A leading research question to this dissertation will therefore be: How can temporal thinking add to our existing knowledge about organizational commitment? 
In the following we will separate out this question into sub-questions that relate to each of the (main) ontological and epistemological tenets described above. After all, if these tenets are applied consistently in research on organizational commitment new insight into temporal characteristics of the organizational commitment phenomenon can be expected in each of the respective domains.

In temporal ontology process and activity are viewed as fundamental to the understanding of content. Therefore, we will answer the question: What is the nature of organizational commitment and how should it be conceived of temporally? In chapter 2 we perform a conceptual analysis of the organizational commitment construct as it has been described in literature. We will demonstrate that the currently popular (though heavily debated) three-component model does not qualify as a general model of commitment, but should rather be seen as a specific model for predicting turnover. This recent turn in the conceptualization of commitment opens room for an attitudinal view. Commitment can be seen as an attitude where both affect, cognition, and action readiness (a classic triplet in attitudinal theory) should be conceived of as underlying processes. This is fully consistent with the temporal perspective which emphasizes processes as basic building blocks of phenomena. In chapter 4 we argue that these processes should be measured separately and in the purest form possible, using single-item measures. We also present some preliminary results on how the three components, measured separately, behave over time, how they interrelate dynamically, and how commitment relates to other time-variant phenomena. In chapter 5 we measure commitment as the net sum of the three attitudinal processes.

As we discussed before, temporal thinking holds that all phenomena imply change and stability is only a special kind of dynamic form observed over a certain time interval. In this dissertation we will therefore ask ourselves the question: What is the prevalence of change versus stability typically observed over time in longitudinal studies on the organizational commitment attitude? This question will be answered in chapter 3 where we assessed the relative prevalence of growth, decline, and stability as observed in 34 longitudinal studies.

As temporal ontology also holds that phenomena have finite existence and follow a life cycle pattern of ascendance, subsistence, and eventual descendance, another research question is: What dynamic patterns in organizational commitment are typically observed in the phases of ascendance, subsistence, and descendance? This question was also investigated in chapter 3, where we assessed what types of dynamic form (e.g. convex increase, straight decline, hill-shaped) are typically found in the three phases of the organizational commitment life cycle. 
The last element in temporal ontology is the approach to causation. According to the temporal doctrine it is claimed that causation is versatile, contextual, and event-driven. When applied to organizational commitment this leads up to the research question: How does the incidence of organizational events affect the observed dynamics in commitment? Unfortunately, the scope of this dissertation does not allow for fully answering this question. In our data collection efforts we did pay attention to measuring organizational events along with our observations of commitment, however space does not allow an extensive elaboration on this particular research question. Interested readers are requested to await (hopefully) forthcoming publications on this subject in the years to come.

The first element of temporal epistemology (see Table 1.2), which is the approach to observation, dictates that one should study phenomena as they unfold chronometrically. We argued that this translates into high-density repeated measurement (HDRM) designs in practical inquiry efforts. In the particular case of organizational commitment this leads to the research question: What (aspects of) dynamic form can be observed when high-density / high-frequency longitudinal designs are used? In chapter 4 we describe the making of a measurement instrument that allows for reliable and valid high-density (fine-grained) and high-frequency (lengthy) measurement of the commitment attitude in workplace settings. This could be compared to a biologist who created an improved microscope. In such a case, the first question is 'What did you observe?' We will do likewise in chapter 5 where we discuss what commitment dynamics we have observed using this instrument, and relate observed aspects of dynamic form to conventional predictors. We found that HDRM designs have allowed the discovery of a new dimension in time-based change ('variability'), in addition to 'level' and 'trend' conventionally captured in growth modeling approaches. Some variability could also be predicted from conventional predictors, which suggests that variability aspects ('aspects of form') bear substantive theoretical importance in the temporal study of organizational commitment.

In temporal epistemology no specific level of analysis is dictated. The choice of the level of analysis depends on the question at which level change in particular phenomena is defined. We define change in commitment as a continuous process of 'repositioning' happening in a particular individual. Thus, commitment change is a person-specific phenomenon and should be measured accordingly. The individual-level should be seen as the most basic (and valid) unit of analysis in the study of work attitudes. A focus on the individual level of analysis may add to the existing bodies of knowledge on behavioral phenomena. This choice is crucial for this dissertation. With respect to organizational 
commitment this leads up to the research question: How does the development of organizational commitment differ in the individual, group, and population level of analysis? In chapter 3 we demonstrate commitment dynamics only at the population (i.e., grand mean) level of analysis, and discuss some of the shortcomings of adopting only this level of analysis. In chapter 4 we discuss the making of a longitudinal measurement system where person-specific, historically tailored measurement of change is one of the characterizing features. In chapter 5 we demonstrate commitment dynamics observed at the individual, group and population level of analysis. The results clearly show that the adoption of different levels of analysis also leads to different conclusions on the temporal development of commitment.

Lastly, temporal epistemology is characterized by a holistic treatment of time where the pattern cannot be reduced to its constituent parts. If temporal thinking is applied this way, it has consequences for the way we approach longitudinal measurement. In this dissertation we ask ourselves the question: What are the consequences of a holistic treatment of time - a focus on patterns instead of single scores - to the longitudinal measurement of commitment? In chapter 4 we describe the creation of a measurement instrument which makes use of new features in longitudinal measurement, summarized under the name of graphic trajectory registering (GTR). GTR consists of three elements: (1) displaying person-specific, historically tailored graphs of development to respondents, (2) allowing real-time, incremental trajectory scoring, using these graphs, (3) allowing repeated corrective retrospective adjustment and subscription of the trajectory. This means that subjects are able to view their own response history depicted in a graph as they answer to the questions in the survey. In this way, the subject is actively involved in creating his/her own trajectory as newly added scores are evaluated relative to their previous patterns of scores. Additionally, subjects are asked to reflect on their trajectory and make changes if necessary. Thus, we have introduced a different form of self-inspection in longitudinal survey research, which could be described as 'real-time pattern scoring' and repeated confirmation of the pattern, as opposed the more conventional discrete score registering by respondents and post-hoc pattern reconstruction by researchers.

From the former can be concluded that including the time element could potentially lead to considerable improvement of theory. This dissertation is an attempt to show that the temporal study of phenomena and the temporal study of organizational commitment in particular, is an exciting and highly promising pathway to tread. Along the way, on the 
temporal road toward greater knowledge, we will come across many decision moments of a practical, conceptual or methodological nature.

In Table 1.3 we present an overview of the dissertation according to the research questions described above. In order to clarify once again how research questions (and answers) differ in differential versus temporal thinking, we have shown answers to these respective research questions according to each paradigm. 


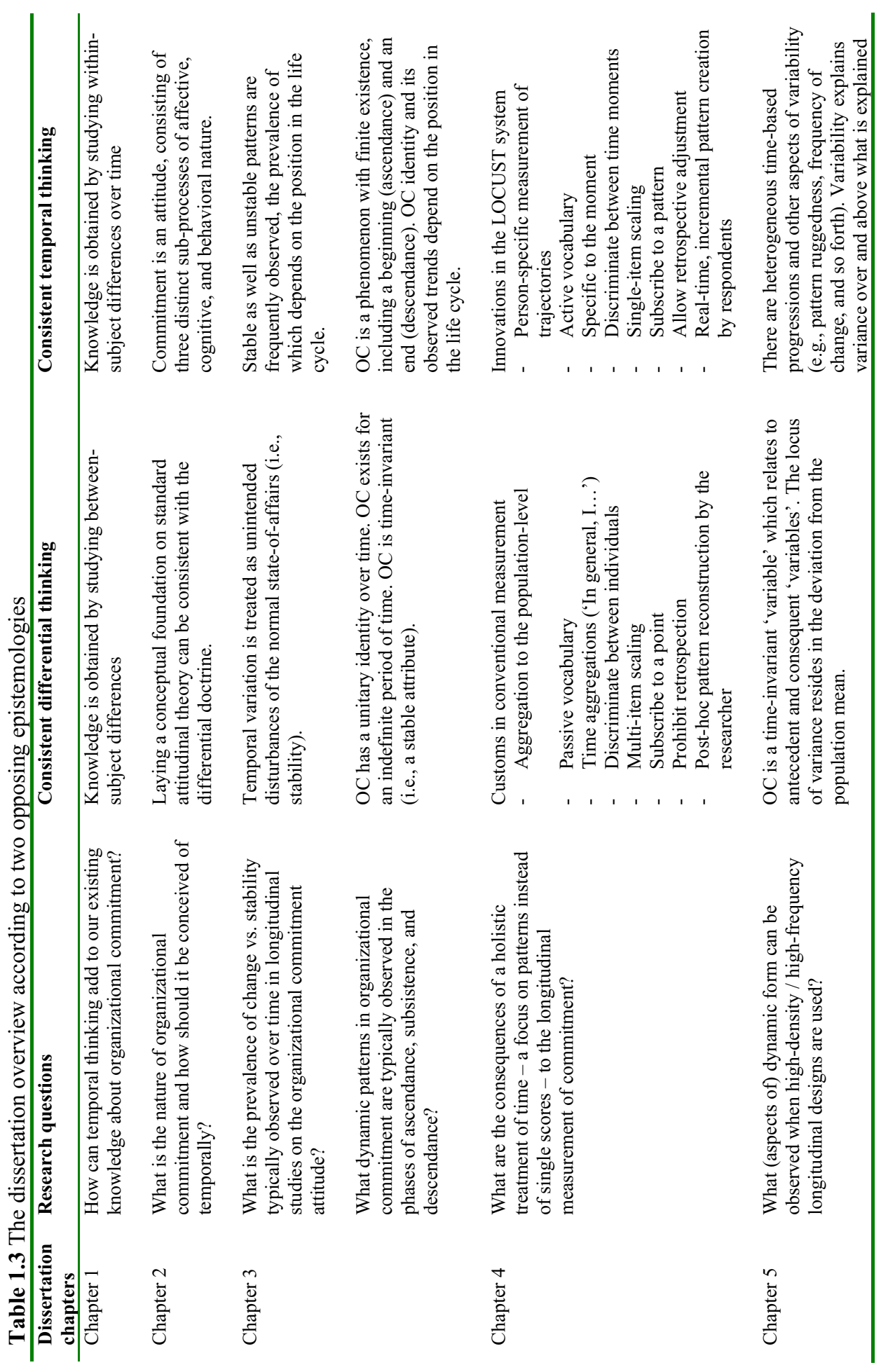




\title{
2 Beyond the three-component model of organizational commitment
}

\begin{abstract}
Adding to empirically based critique in the last 15 years, this paper offers a critical conceptual analysis of the three-component model of organizational commitment in order to arrive at an unequivocal grounding of the concept in standard attitudinal theory. Using the attitude-behavior model by Eagly \& Chaiken (1993), we demonstrate that the three-component model combines fundamentally different attitudinal phenomena. Instead, we argue that general organizational commitment can best be conceived of as affective commitment only, being a genuine attitude towards an object: the organization. Normative and continuance commitment, in contrast, appear to be attitudes regarding specific forms of behavior (i.e., staying or leaving) that may or may not follow from the affective bond with the organization. The conclusion of our analysis is that the three-component model fails to qualify as a general model of organizational commitment, but instead represents a specific model to predict turnover behavior. Therefore, we suggest limiting the use of the TCM to predicting turnover and to abandon it as a general model of employee commitment. We propose to return to the conceptualization of organizational commitment as an attitude towards the organization and to use Eagly \& Chaiken's model to generate specific models for predicting a broad range of organizational behaviors. Finally, we discuss the definition and measurement of organizational commitment, arguing that covering affective, cognitive and behavioral facets of this attitude helps to differentiate the construct from other constructs and to enhance the construct validity of measurement instruments.
\end{abstract}

This chapter is based on Solinger. O. N., van Olffen, W., \& Roe, R. A. (2008). Beyond the threecomponent model of organizational commitment. Journal of Applied Psychology, 91 (1), 70-83. 


\section{Introduction}

It has been over 15 years since Allen and Meyer (1990) proposed a three-component model of organizational commitment (henceforth called 'TCM'), based on the idea that organizational commitment comes in three distinct forms: affective attachment to the organization, perceived costs of leaving it, and a felt obligation to stay. These three forms, labeled affective, continuance, and normative commitment respectively, are referred to as 'components' of organizational commitment. The affective component is defined as employees' emotional attachment to, identification with, and involvement in the organization. The continuance component is defined as the perception of costs associated with leaving the organization. Finally, the normative component refers to employees' feelings of obligation to remain with the organization. As such, the TCM ties together three separate streams of earlier commitment research (Becker, 1960; Buchanan, 1974; Kanter, 1968; Mathieu \& Zajac, 1990; Mowday, Porter, \& Steers, 1982; Salancik, 1977; Wiener, 1982; Wiener \& Vardi, 1980). Common to these three streams was the notion of a 'psychological state that links an individual to an organization (i.e., makes turnover less likely)' (Allen \& Meyer, 1990, p. 14).

To date, the three-component conceptualization of organizational commitment can be regarded as the dominant model in organizational commitment research (e.g. Bentein, Vandenberg, Vandenberghe, \& Stinglhamber, 2005; e.g. Cohen, 2003; Greenberg \& Baron, 2003). Nevertheless, an accumulation of studies have shown that the model is not fully consistent with empirical findings (Allen \& Meyer, 1996; Ko, Price, \& Mueller, 1997; McGee \& Ford, 1987; Meyer, Stanley, Herscovitch, \& Topolnytsksy, 2002). To overcome these problems, a revision of scales has been proposed (Meyer, Allen, \& Smith, 1993; Powell $\&$ Meyer, 2004). However, some scholars have argued that the empirical inconsistencies do not derive from faulty operationalizations but rather from deeper rooted problems regarding the underlying concepts (e.g., Ko et al., 1997; Vandenberg \& Self, 1993). This paper identifies and discusses these problems through a systematic conceptual analysis of the TCM model.

We will start off with shortly reviewing the theoretical assumptions underlying the TCM and the main points of criticism that have emerged from empirical research over the last 15 years. Then we will use the attitude-behavior model by Eagly and Chaiken (1993) to offer a conceptual critique of the TCM, which leads to the conclusion that the model is inconsistent and that affective, normative and continuance commitment cannot be considered as components of the same attitudinal phenomenon. We extend our criticism to the rebuttals 
by Meyer \& Herscovitch (2001) and their proposal to interpret TCM in motivational rather than attitudinal terms and conclude that this reinterpretation fails to resolve the basic inconsistency. Our conclusion is that the TCM is, in fact, a model for predicting turnover. From this perspective we will reinterpret some typical findings from commitment studies. In the second part of the paper, we propose to return to the conceptualization of organizational commitment as a singular construct, i.e. an attitude to the organization, and to use the Eagly and Chaiken model as a basis for generating specific models that can predict various organizational behaviors beyond turnover. We conclude with discussing the merits of a purely attitudinal definition of organizational commitment - covering affective, cognitive and behavioral facets - in differentiating it from similar constructs and for enhancing the construct validity of measurement instruments.

\section{Critical analysis of the three-component model}

The TCM proposes that affective, continuance and normative commitment - although different in nature - describe a link between the employee and the organization that decreases the likelihood of turnover. In the words of Allen and Meyer (1990, p. 3):

'Employees with strong affective commitment remain because they want to, those with strong continuance commitment because they need to, and those with strong normative commitment because they feel they ought to do so'.

Three aspects are noteworthy when considering the presumed common conceptual ground of the three components. First, all three components are supposed to reflect a "psychological state' (i.e., want, need, ought) of an employee vis-à-vis the organization, which has made Allen and Meyer (1990) speak of attitudinal forms of commitment. Second, the three states are supposed to relate to the organization, reflecting the idea that organizational commitment is an attitude that has the organization as its object. Third, the three states can be present simultaneously. Hence the conceptualization in terms of 'components' (Allen \& Meyer, 1990) and the suggestion that the resulting 'total' organizational commitment should be seen as the 'net sum' of these three psychological states.

There is a more recent formulation of the TCM that retains the main ideas but proposes a motivational - rather than attitudinal - interpretation (Meyer \& Herscovitch, 2001). Since the dimensions and definitions of this 'revised model' are exactly the same, it is 
equally sensitive to our critique. Yet, we think it is useful to address the proposed reformulation as well. For the sake of clarity, we will first scrutinize the original TCM and then extend our analysis to the motivational version.

\subsection{Inconsistencies in empirical research}

Empirical criticism of the TCM has mainly revolved around two issues of construct validity topics, i.e., the position of continuance commitment as a dimension of the overall commitment construct and the relation between normative and affective commitment (e.g., Allen \& Meyer, 1996; Cohen, 2003; Meyer et al., 2002). First, continuance commitment generally correlates slightly negative or not at all with affective commitment and with important work-related outcome variables such as organizational citizenship behaviors, performance, turnover intention, and employee well-being (e.g., Cohen, 2003; Dunham, Grube, \& Castaneda, 1994; Hackett, Bycio, \& Hausdorf, 1994; Ko et al., 1997; Meyer et al., 2002). This casts doubt upon the convergent validity of continuance commitment. McGee and Ford (1987) have specifically addressed the lack of convergent validity of the continuance commitment scale and proposed two sub-dimensions, i.e., 'Lack of Alternatives' and 'High Sacrifices'. In response to this latter criticism, Meyer and colleagues (Meyer et al., 2002; Powell \& Meyer, 2004) have recently proposed to change the content of the continuance commitment scale by retaining only 'High sacrifices' items, which refer to unrecoverable investments in the organization by the individual.

Secondly, normative commitment has consistently been found to correlate very strongly with affective commitment (Allen \& Meyer, 1996; Hackett et al., 1994; Meyer et al., 2002; Somers, 1995). Different studies (Ko et al., 1997; Lee \& Chulguen, 2005) suggest that it is hard to separate normative commitment from affective commitment empirically. This apparent lack of discriminant validity led Ko et al. (1997) to regard the normative dimension as redundant, a statement which is supported by findings showing that some antecedents of normative commitment (e.g., self-presentation concerns and expectations of others) correlate similarly with affective commitment (Organ \& Ryan, 1995; Powell \& Meyer, 2004).

Empirical dimensionality problems of the TCM have prompted Meyer and colleagues to revise and improve the instruments used for measuring continuance and normative commitment (e.g., Lee, Allen, Meyer, \& Rhee, 2001; Meyer et al., 1993; e.g., Powell \& Meyer, 2004). However, it seems that the underlying problem with these components is conceptual rather than empirical in nature (cf., Bergman, 2006; cf., Ko et al., 1997; 
Vandenberg \& Self, 1993). Instable factor structures underlying the TCM over time have raised considerable concern about the ideas behind the model. Vandenberg and Self (1993), who detected these 'gamma changes', maintained that these were 'less of a case of true gamma change, and more a case of severe model misspecification' (p. 566).

Ko et al. (1997) have therefore proposed a return to the view that organizational commitment is only affective attachment as proposed by Mowday et al. (1982), as long as the ambiguity surrounding the TCM remains unresolved. Their preference for the affective component is not surprising since - in contrast with the other components - it represents the most reliable and strongly validated dimension of organizational commitment (Cohen, 2003; Meyer et al., 2002), and it has the greatest content and face validity (cf., Brown, 1996; Dunham et al., 1994). Moreover, of all three dimensions, affective commitment was found to correlate strongest and with the widest range of behavioral criterion variables (e.g., attendance, performance and organizational citizenship behaviors) (Meyer, Becker, \& Vandenberghe, 2004; Meyer et al., 2002). Given the finding that continuance and normative commitment have added little explained variance over affective commitment in explaining behavioral outcome variables, Somers (1995) questioned whether the three-dimensional view has contributed significantly to the concept of organizational commitment. For all these reasons, affective commitment is preferred as the core concept of organizational commitment by many authors (e.g., Brickman, 1987; e.g., Brown, 1996; Buchanan, 1974; Mowday et al., 1982) and it is used as the sole indicator of commitment to the organization in many recent studies (Armstrong-Stassen, 2006; Kuvaas, 2006; Payne \& Webber, 2006; Sturges, Conway, Guest, \& Liefooghe, 2005).

To date, most of the criticism on the TCM is empirical in nature. Although some authors have hinted at possible conceptual problems underlying these difficulties, these have not yet been systematically charted.

\subsection{Organizational commitment as an attitudinal phenomenon}

There is a widespread agreement in the literature that organizational commitment is an attitude (e.g. Allen \& Meyer, 1990; Angle \& Perry, 1981; Buchanan, 1974; Jaros, Jermier, Koehler, \& Singigh, 1993; Mowday et al., 1982; e.g. O'Reilly \& Chatman, 1986). Some scholars refer to commitment as a 'psychological state' (Allen \& Meyer, 1990), others simply to a 'bond' or 'linking' (Mowday et al., 1982; Mathieu \& Zajac, 1990) of the individual to the 
organization, a partisan, affective attachment to the goals and values of the organization (Buchanan, 1974), an 'orientation' (Sheldon, 1971), a 'readiness to act' (Leik, Owens, \& Tallman, 1999) or an 'unconflicted state of internal readiness' (Brickman, Janoff-Bullman, \& Rabinowitz, 1987). All these descriptions display a structural similarity to what is commonly understood as an attitude: a person's internal state preceding and guiding action, comprising feelings, beliefs and behavioral inclinations (Ajzen, 2001; Ajzen \& Fishbein, 1980; Eagly \& Chaiken, 1993).

Figure 2.1 Linking Eagly\&Chaiken's composite attitude-behavior model to the TCM

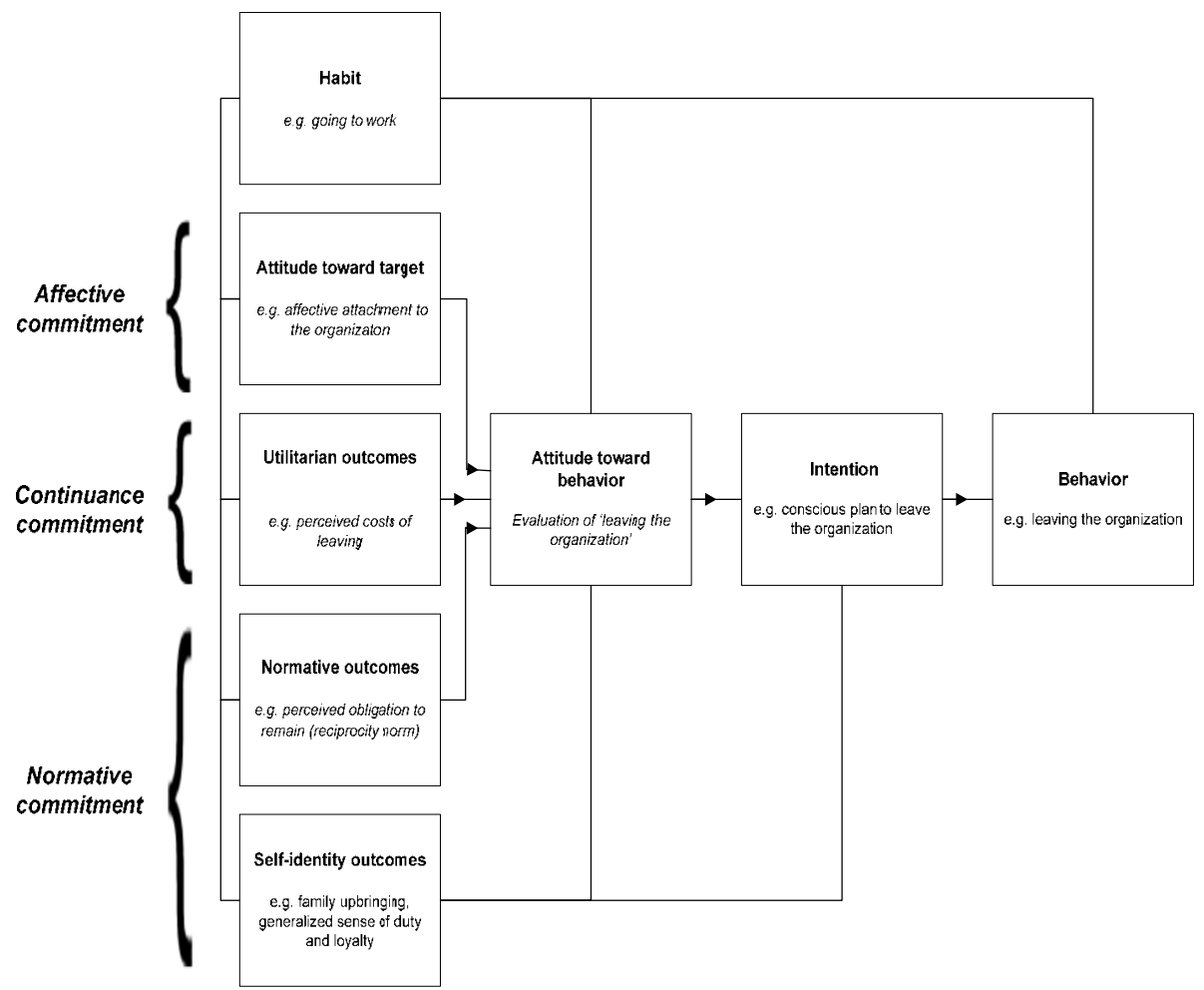

Since organizational commitment is so widely seen as an attitude, we consider it appropriate to scrutinize the TCM using a dominant and well-validated paradigm of attitudes: the theory of reasoned action (Ajzen \& Fishbein, 1980; 1975). More specifically, we will refer to Eagly and Chaiken (1993) who have elaborated this theory in a model that clarifies how attitudes toward targets relate to attitudes toward behaviors. The model is depicted in Figure 1. The examples are chosen to show how the model would apply to the TCM, i.e., they pertain to 
commitment towards the organization (target) and towards leaving the organization (behavior).

Central to the model is the attitude toward a specific behavior. This attitude directly leads to an intention (i.e., the conscious plan to carry out the behavior) and subsequently to the actual behavior. In the model, attitudes toward behaviors originate from the activation of habits, attitudes toward targets, and three classes of anticipated outcomes of behaviors: utilitarian, normative and self-identity. Habits need to be understood as sequences or repetitions of behaviors that have become relatively automatic (e.g., Triandis, 1977; Wood, Quinn, \& Kashy, 2002). Habits like 'going to work every day' are likely to lead to a positive evaluation of staying with the organization, since it is seen as a normal - hence positive thing to do (e.g., 'I am going to work every day, so I might as well continue doing that'). Attitudes toward targets consist of the evaluation of the persons or institutions, i.e., the targets toward which the behaviors are directed. Next are the evaluations of various outcomes of the behaviors. For example, the individual can perceive potential drawbacks associated with leaving the organization, such as losing pension plan guarantees (i.e., utilitarian outcomes), or feelings of guilt or shame toward colleagues or the institution itself (i.e., normative outcomes), or incongruence with the self-concept like that of being a 'good soldier' (i.e., self-identity outcomes).

The TCM fits very well within the Eagly \& Chaiken ('E\&C') model. First, because affective commitment in the TCM is defined as 'an employees' emotional attachment to, identification with, and involvement in the organization' (Allen \& Meyer, 1990, p. 14), it clearly represents an attitude toward a target in terms of the E\&C model. Note that affective commitment thus reflects an emotional attachment to the organization as a target and not to the behavioral act of leaving or remaining with the organization. Second, continuance commitment is defined as the perception of costs associated with leaving the organization. (Meyer \& Allen, 1991, p. 67). This corresponds to 'utilitarian outcomes', consisting of 'rewards and punishments that are perceived to follow from engaging in the behavior' (Eagly \& Chaiken, 1993, p. 209). Continuance commitment simply reflects the consideration of instrumental outcomes of a course of action: stay or go. It is - in other words - an attitude towards behavior, not towards the organization/target. Finally, normative commitment employees' feelings of obligation to remain with the organization (Meyer \& Allen, 1991, p. 67) - fits both the 'normative outcomes' and 'self-identity outcomes' in the E\&C model, depending on whether the felt obligations are derived from anticipated (dis)approval of significant others or from (in)consistency with conceptions of self. Normative outcomes 
pertain to 'approval or disapproval that significant others are expected to express after performing the behavior as well as the self-administered rewards (pride) and punishments (guilt) that follow from internalized moral rules' (Eagly \& Chaiken, 1993, p. 210). Selfidentity outcomes are 'affirmations or repudiations of the self-concept that are anticipated to follow from engaging in the behavior' (Ibid., p. 210). For example, a person that considers himself as a 'good soldier' (e.g. Organ, 1988) has a generalized sense of duty to serve the purposes of his organization. For this worker, leaving the organization will be associated with repudiating his self-concept. A generalized sense of duty (derived from self-identity) is an internalized moral obligation (Eagly \& Chaiken, 1993; Meyer \& Allen, 1997; Shamir, 1991; Wiener, 1982) and, hence, part of normative commitment. Taken together, it appears that normative commitment could be interpreted as the combination of considering 'normative outcomes' and 'self-identity outcomes' of behavior in terms of the Eagly \& Chaiken model. This distinction within normative organizational commitment between self and others is new and intriguing and warrants further investigation.

In sum, it appears that the three-component model of organizational commitment can be seen as a specific application of Eagly and Chaiken's model of the attitude-behavior relation in a workplace context. However, placed within this more general model, it also becomes clear that affective commitment equals an attitude toward a target, while continuance and normative commitment represent qualitatively different concepts: they refer to anticipated outcomes of a behavior, namely the act of leaving. From this we conclude that organizational commitment as conceived in the TCM is not a unitary concept and that grouping target- and behavior-attitudes under one general label is confusing and logically incorrect.

The attitude-behavior model by Eagly and Chaiken can give alternative explanations for something that is seen as contradictory in a 'multidimensional' conception of the TCM: i.e. the finding that affective commitment - when compared to normative and continuance commitment - shows stronger associations with relevant behaviors and is associated with a wider range of behaviors (Allen \& Meyer, 1990; Meyer \& Allen, 1997; Meyer \& Herscovitch, 2001; Meyer et al., 2002). These contradictions may be ascribed to the conceptual inconsistency in the TCM of conflating an attitude toward a target with an attitude toward a behavior. For instance, suppose - using the TCM - we explain individuals' concerns for quality in the organization by their normative commitment. We then actually explain concern for quality by a felt obligation to stay with the organization! That is: behavior A (i.e., maintaining concern for quality) is predicted by the normative pressure to perform behavior 
B (i.e., staying). Not surprisingly, low correlations are found (Randall, Fedor and Longenecker, 1990). Similarly, studies consistently have found insignificant relationships between continuance commitment and organizational citizenship behaviors (Meyer et al., 2002) because the former is defined and operationalized as a perceived cost to leave the organization. So again, behavior A (acting as a citizen) is explained by the disutility of behavior B (leaving). Much higher associations are to be expected when actual quality concerns are predicted by normative attitudes toward (related) quality-enhancing behavior, or when citizenship behavior is explained by the (related) utility of behaving as a citizen. Moreover, since an attitude toward a target (i.e., the organization) is obviously applicable to a wider range of behaviors than an attitude toward a specific behavior (i.e., staying), it does not come as a surprise that affective commitment is associated with a wider range of outcome variables as compared to normative and continuance commitment, as was noted above. We must conclude, therefore, that the TCM is inconsistent in focus. Affective organizational commitment is an attitude toward the organization, whereas continuance and normative organizational commitment are attitudes toward leaving the organization derived from imagined consequences.

\subsection{Rebuttals and reformulations}

The critique that the TCM is conceptually inconsistent has been raised before (e.g., Brown, 1996). Unfortunately, however, this has not discouraged the use of the model nor lead to a fundamental revision. Instead, over the years, proponents of the TCM have given a number of rebuttals and proposed some reformulations in defense of the model. Below we outline and discuss four major issues raised in this context.

\section{1. 'The commitment - behavior relationship is easy to infer.'}

Meyer and Herscovitch (2001) have defended the TCM by claiming that differences in focus within the model are merely a difference in emphasis and that the relevance of the different foci can be easily inferred.

'Careful consideration of existing uses of the term commitment suggests that differences in focus are largely a function of emphasis. When commitment is considered to be directed at an entity, the behavioral consequences are often implied, if not stated explicitly. Similarly, when commitment is considered to be to a course of action, the entity to which that behavior is relevant can often be inferred even when not stated explicitly' (p. 309). 
This argument is not totally convincing. Apart from the fact that the double use of the word 'often' poses a barrier to logical refutation, various objections can be raised. First, behaviors are not necessarily implied in commitments, nor do behaviors necessarily allow the inference of targets. Committed employees can leave for various reasons (such as better career opportunities elsewhere, or family circumstances), whereas non-committed employees can stay for reasons of being locked in financially or because of lack of opportunities on the labor market (Lee \& Mitchell, 1994). It is even possible that individuals are committed after they have left the organization, as seems to happen after retirement (Cude \& Jablin, 1992).

Second, it is questionable whether a consistent relationship between organizational commitment and commitment towards behaviors can exist at all. People who are highly committed towards their organizations are unlikely to show the same behaviors over time. Instead, the behavior to express commitment changes as careers unfold (e.g., Katz, 1997). For instance, Buchanan (1974) has argued that early in the career behaviors are important that 'secure one's position' (e.g., trying to please a supervisor). During the second through the fourth year the emphasis is rather on achievement, on 'making a mark' (Hall \& Nougaim, 1968). This wish to 'making a difference' may drive the committed employee to take a lot of responsibility and to work overtime for the benefit of the organization. At the final stage, that of consolidation, committed employees engage in behaviors such as introducing recruits in the organization or mentoring, and may even prepare for leaving the organization to enjoy a pension plan. Moreover, apart from the different expressions given to it, the level and meaning of organizational commitment itself is likely to change over time. It will vary in response to changes in the employment relationship through promotions, transfers and new career stages (Bentein et al., 2005; Cohen \& Freund, 2005; Fuller et al., 2003). Such changes in commitment may be accompanied by a wide range of behaviors and produce relationships between commitment and behaviors that are far more complex than the simple pattern suggested by Meyer \& Herscovitch (2001). To date there is not sufficient empirical evidence to draw firm conclusions about the consistency over time between commitment to the organization as a target and commitment to specific behaviors. But the available evidence seems to disconfirm the idea of a stable link. Several studies (e.g., Cohen, 1991; Mowday et al., 1982; Reichers, 1986) have shown that the relationship between commitment and specific behavioral outcomes depends on the career stage. This is congruent to findings on the links between job attitudes and work behaviors (Slocum \& Cron, 1985; Stumpf \& Rabinowitz, 1981; Super, 1957). 
A third and final objection is that commitment to a target and commitment to a behavior differ in nature. Commitment to a target, i.e., the organization, is an attitude that predisposes the individual to a variety of behaviors under a wide range of conditions. Commitment to behaviors is - by definition - a much more restricted concept that only makes sense in settings and in moments for which these behaviors are relevant. Thus, for instance, neither continuance commitment nor normative commitment makes sense immediately after entry into a new organization or just before retirement. When it comes to situations in which employees are expected to perform their work tasks, to adjust to organizational change, to help overcoming difficulties by means of citizenship behaviors, commitment to the organization is relevant while commitment towards the behavior of leaving is not.

To conclude, if we acknowledge that behaviors change over time in nature and in relevance to commitment, then inferring someone's commitment from specific behaviors inevitably leads to spurious results. In fact, this might very well explain why Vandenberg and Self (1993) encountered so-called gamma differences (i.e., changes in the underlying construct, see Terborg, Howard, \& Maxwell, 1980) when using the TCM in assessing newcomer's changing commitments to their organizations over time. In line with our arguments above, the use of behaviors as indicators of evaluations of targets (especially over larger time spans) may have led to the observed gamma differences. Knowing that the TCM incorporates evaluations of behaviors as well as targets, we can conclude that the model includes different concepts that cannot be represented by a single construct in a theoretically meaningful way. ${ }^{18}$ As the behavioral expression of attitudes toward targets changes over time, an attitude toward a target and an attitude toward specific behavior cannot meaningfully reflect a single underlying construct.

\footnotetext{
${ }^{18}$ It might be argued that organizational commitment in the TCM could be seen as a formative rather than a reflective construct (Bergman, 2006; Bollen \& Lennox, 1991; Edwards \& Bagozzi, 2000) if translated in terms of a structural equations measurement model. To our knowledge Meyer et al. have never proposed such a measurement model. While it might defend the TCM against criticism of low intercorrelations between the three components, a formative conceptualization would introduce more problems than it solves, such as the conceptual indeterminacy of the commitment construct, measurement inequivalence across studies (both due to dropping, altering or adding indicators used to measure it), questionable construct validity when using dependent variables other than turnover (cf., Bollen \& Lennox, 1991), and poor prediction of organizational behaviors other than turnover (which are not specified as indicators in the formative construct). But most importantly, specifying the TCM as 'formative' does not provide a solution to the conceptual inconsistency that underlies the TCM itself.
} 


\section{2. 'Attitudes and behaviors influence each other reciprocally over time.'}

Another justification that Meyer and Herscovitch (2001, p. 309) have provided for combining attitudes toward a target and attitudes toward a behavior in a single construct, is that 'the attitude versus behavior distinction relates more to the processes involved in the development of commitment than to the focus of commitment'. Attitudinal (affective) commitment and behavioral approaches to commitment might become integrated in an ongoing reciprocal influence process. To illustrate their point, Meyer and Allen (1991, p. 78) provide the following example:

'(...) employees who perform at a high level of proficiency may become (behaviorally) committed to that level of performance and, consequently, develop a more positive attitude (affective commitment) toward the organization. Such an attitude, once developed, may insure the continuation of a high level of performance in the future.' (Meyer and Allen, 1991, p. 78).

There are a number of problems with this statement. First, at a logical level it is not refutable, since it asserts that something that 'may' (or may not) happen can be associated with something else that 'may' (or many not) happen. Second, at a psychological level it hints at a type of reciprocal learning of which no empirical evidence exists. Whether future research will provide such evidence on the link between performance and organizational commitment remains to be seen. If the successful performance is attributed to unique conditions created by the organizations, this effect may indeed happen. But if it is attributed to conditions inherent in the job or to unique qualities of the person him/herself, it is not likely that greater organizational commitment will arise. One would rather expect greater job involvement or greater self-efficacy. Third, even if a link between performance and organizational commitment would exist, it would be of limited relevance to the TCM, since the behavior in this model is not performance but leaving. An important difference is that performance happens on a daily basis, while leaving happens relatively rarely in a person's career. It is highly questionable whether learning effects associated with daily performance would generalize to forming an attitude toward the (rarely occurring) act of discontinuing employment. Meyer and Allen (1991) use the above example to defend the presence of behavioral and attitudinal commitment in the TCM:

'This is recognized in the present model by including behavioral commitment as an antecedent of affective commitment and as part of a feedback chain in which positive 
work behaviors (for which the employee accepts responsibility) increase behavioral commitment and consequently, affective commitment' (p. 78).

We think that, apart from being based on a questionable premise, there is a major logical problem with this argument. If it is recognized that affective commitment and behavioral approaches to commitment are bound by an 'ongoing reciprocal influence process' or that one works as an 'antecedent' of the other, (Meyer \& Allen, 1991, p. 78), it is logically impossible to regard them as a single construct. Unless the components are conceptualized as separate constructs, causal modeling within a single (multidimensional) construct is impossible (cf., Edwards, 2001). If the TCM components indeed influence each other reciprocally over time, they cannot be components within a single construct.

\section{From 'binding to an object' to 'binding to a course of action'.}

In the same 2001 article, Meyer and Herscovitch have proposed to rephrase the general idea behind the TCM by characterizing overall commitment as a 'commitment profile', signifying the pattern of relations among three 'mind-sets' of commitment to the organization, designated as desire, cost, and obligation. They now refer to overall commitment as 'a force that binds an individual to a course of action, of relevance to one or more targets' (Meyer \& Herscovitch, 2001, p. 301). However, the three components are the same as before and no formal definitions are given to replace the older ones. Instead of considering the attitude towards the organization as the common ground for the three components, Meyer and Herscovitch now refer to 'a course of action' as their common ground, mentioning that the course of action (e.g., staying) is relevant to the organization. Furthermore, they describe these three forms as manifestations of a 'binding force' rather than as distinct attitudinal forms. This alludes to a motivational interpretation of the commitment phenomenon as elaborated by Meyer and colleagues in a more recent publication (2004). Whether the 'motivational' TCM must be seen as a revision of the older 'attitudinal' TCM is not fully clear. Since the attitudinal model has not been revoked, we are inclined to conclude that Meyer and colleagues (Meyer et al., 2004; Meyer \& Herscovitch, 2001) have merely offered an alternative interpretation of the same theoretical model, and therefore maintain our criticism. Thus, affective commitment is still defined as focused on an entity (or target) and continuance and normative commitment are explicitly tied to acts toward remaining employed (a behavior). 
Still, scrutiny of the 'motivational' TCM offers ground for additional criticism. First of all, it seems to us that the proposed definition of overall commitment as 'a force that binds an individual to a course of action of relevance to one or more targets' (Meyer \& Herscovitch, 2001, p. 301) suffers from severe underspecification, as it is in no way linked to the commitment phenomenon. The notion of 'force' might refer to almost any motivating factor (e.g., goals, values, interests, needs) known in the field of organizational behavior (Latham \& Pinder, 2005; Pinder, 1998) and a 'course of action' might refer to almost any behavior (e.g. selling products, presenteeism, creative action, sexual harassment, joking, verbal abuse, and so forth). As this reformulation is so broad as to lose any power of making specific predictions, it is unclear what theoretical or practical improvement it would bring.

The 'motivational' TCM also fails to resolve the fundamental inconsistency we have pointed out above. Within a motivational perspective, the emotional attachment to the organization (affective commitment) brings about a general readiness to act (cf., Brickman, 1987; Eagly \& Chaiken, 1993), that is, a general tendency to perform a range of behaviors in favor of the organization. It applies to virtually any category of behavior - whether broad or specific, immediate or long term, discrete or continuous (Shamir, 1991). Which behavior is viewed as appropriate to serve the organization depends on the specific situation and moment in the career (cf., Fazio \& Towles-Schwen, 1999). In contrast, the motivation to engage in a particular kind of behavior, i.e., to leave or stay, is of a different kind. Unlike the general 'readiness to act' (Brown, 1996) it has a narrow focus and arises out of a number of personal and situational factors that are specifically tied to the behavior. The motivation to remain employed by a given employer, whether arising from an affective attachment, a felt obligation, a perceived cost of leaving or any combination of them, does not generalize to the motivation toward other behaviors, while the motivational state described as a general 'readiness to act' in favor of the organization does. This difference is in agreement with the results of motivational research which have shown that the level of behavioral specificity leads to different motivational states (Gollwitzer \& Brandstätter, 1997; Gollwitzer, Heckhausen, \& Steller, 1990; Perugini \& Bagozzi, 2004). In addition, as we have elaborated on before, there is a difference with regard to the time variable. At different moments in time different behaviors may be most appropriate to express a commitment, while the more general action readiness remains relatively stable. This difference supports our earlier conclusion: if the motivation to perform a specific behavior changes over time in a way different from the action readiness inherent to an affective attachment, pulling these motivations together in a single construct is to obscure a relevant distinction. 


\subsection{Conclusion}

Although we are not the first to criticize the TCM, our conceptual analysis has demonstrated that the TCM suffers from a basic shortcoming that cannot be repaired by modifications of measurement or by reinterpreting the 'common ground' in motivational terms. We therefore propose to respectfully abandon the TCM and to return to the definition of organizational commitment as affective attachment to an organization (Brickman, 1987; Brown, 1996; Ko et al., 1997; Mowday, Steers, \& Porter, 1979). As the attitude-behavior model of Eagly \& Chaiken (1993) implies, continuance and normative commitment should not be seen as commitments but rather as antecedents of attitudes towards a specific behavior, more precisely as different classes of imagined consequences of (dis)continuing employment. This classification still acknowledges the apparent importance of normative and continuance considerations for staying on the job, which is paramount in a vast number of studies on the matter (e.g., Meyer et al., 2002). But when it comes to the prediction of other work-related outcomes, such as helping others or making overtime (Meyer et al., 2004; Meyer et al., 2002) it may be useful to include anticipations of the outcomes of those behaviors which would in turn help create a different set of behavior-specific attitudes. Unmistakably, the TCM has served to enrich our knowledge on different motivational grounds of staying with and leaving an organization. But for a better understanding of organizational commitment and its broader implications for organizations we now need to move towards an unambiguous and parsimonious conceptualization.

\section{A road ahead for organizational commitment research}

We see two steps to move ahead in organizational commitment research. First is the proper placement of the organizational commitment in a wider conceptual framework which will allow modeling the relationship between organizational commitment and various organizational behaviors. Here, we will propose to use the reasoned action model by Eagley \& Chaiken (1993). Second, is a re-grounding and measurement of organizational commitment itself as a truly attitudinal construct. Below we will develop and illustrate both steps. 


\subsection{Generating models of organizational commitment - organizational behaviors}

The value of the E\&C model is not limited to showing the shortcomings of the TCM. In our view it offers an alternative to the TCM that can explain the links between organizational commitment and several types of organizational behavior other than leaving and staying. While the E\&C model is a generic model that applies to any context in which it is appropriate to study the links between people's attitudes and behaviors, our proposal is apply it to organizational contexts and use it for explaining behaviors shown by employees. In this case the 'attitude to target' can be equated to organizational commitment and the 'behavior' can be any type of organizationally relevant activity. The habits and imagined outcomes of behavior from the $\mathrm{E} \& \mathrm{C}$ model are specific for the organizational behaviors to be explained. There is ample empirical evidence showing that organizational commitment is an antecedent to a wide range of organizational behaviors, most prominently organizational citizenship behaviors, work performance, and various types of withdrawal behaviors like absenteeism, tardiness, job search, intention to leave, and actual turnover (e.g., Meyer et al., 2002; Allen \& Meyer, 1996; Mathieu \& Zajac, 1990). This means that there is a rich empirical basis for developing commitment-behavior models.

Our expectation is that further research will considerably extend the range of behaviors to be explained from organizational commitment. Future research may profit from a typology of organizational behaviors that has emerged from research by Hirschman (1970), Farrell (1983), Rusbult \& Zembroth (1983) and Hagedoorn, Van Yperen, Van de Vliert \& Buunk (1999). This two-dimensional typology groups behaviors along a constructivedestructive and an active-passive axis. Although the original research focused on employees' responses to adverse organizational circumstances, the typology seems suitable for classifying any type of organizational behavior. Examples of constructive behaviors are championing (e.g., fund-raising, personal recruitment, enhancing sales, boasting), ambassadorship (e.g., mentoring, role modeling, figure heading), customer orientedness (Morgan \& Hunt, 1994), showing quality concern (Randall et al., 1990), personal deprivation (i.e., sacrificing private time, sleep or alternative employment opportunities), subservience (Adler \& Adler, 1988), organizational face-saving (i.e., protecting the organization's image, Dutton, Dukerich, \& Harquail, 1994), intrapreneurship, constructive voice (Mowday et al., 1982), prosocial behavior (O'Reilly \& Chatman, 1986) and proactivity during socialization (Wanberg \& Kammeyer-Mueller, 2000). While these behaviors all qualify as active, there are also behaviors of a passive nature, such as patience (Farrell, 1983; Hagedoorn et al., 1999), 
abiding with organizational norms (Kunda, 1992), engaging in praiseful gossip (Noon \& Delbridge, 1993; Gluckman, 1963), and so forth.

On the destructive side are withdrawal behaviors such as absenteeism and tardiness (Meyer et al., 2002), and a number of deviant behaviors, some of which can be quite harmful to the organization and to its employees (Robinson \& Bennett, 1995; Skarlicki \& Folger, 1997). Among these are corporate illegal behaviors (i.e., property or production deviance; e.g., theft), workplace aggression (e.g., bullying, verbal abuse, sexual harassment, violence), retaliatory behaviors (e.g., active resistance, sabotage), leaking to the press (e.g., whistle blowing), working to rule, withholding vital information (Randall et al., 1990), and political deviance (e.g., extreme interdepartmental antagonizing, blaming, favoritism; Robinson \& Bennett, 1995). While most of these behaviors can be considered as active, some of them e.g. working to rule and withholding vital information - can be seen as passive. Other examples of passive behavior would be neglect (Farrell, 1983; Hagedoorn et al., 1999), cynical talk (Ford, Ford \& McNamara, 2002) and shirking (Robinson \& Bennett, 1995).

Our position is that for each of these types of organizational behavior a specific commitment-behavior model can be developed on the basis of the E\&C model. To illustrate the approach we choose a behavior in the active-negative quadrant, namely employee theft. This particular behavior seems to be the fastest growing type of workplace deviance in the U.S. Depending on the definition of non-trivial employee theft, incidence rates among employees have been estimated to lie between $50 \%$ and $75 \%$; estimated financial losses range from of 40 to 120 billion dollars annually (Case, 2000; Coffin, 2003; Wimbush \& Dalton, 1997). In the organizational behavior literature, employee theft is predominantly seen as a retaliatory reaction to a perceived inequity or injustice (e.g., Greenberg, 1990; e.g., Skarlicki \& Folger, 1997). Figure 2 shows how the E\&C model could be used to generate a commitment-behavior model that predicts the occurrence of theft.

Employees who feel disappointed by their employers or experience inequity in their relationship are likely to lower their commitment to the organization (Brown, 1996). They psychologically 'distance' themselves from their employer to avoid harmful consequences to the self. As a consequence, they will feel less attached (affect), they will think less favorable about the organization (cognition) and they decrease the readiness to serve the organization's interests (action). This decline in organizational commitment may lift constraints on behaviors that might harm the organization and create room for retaliatory action, including stealing. 
Figure 2.2 Applying the E\&C model to corporate theft

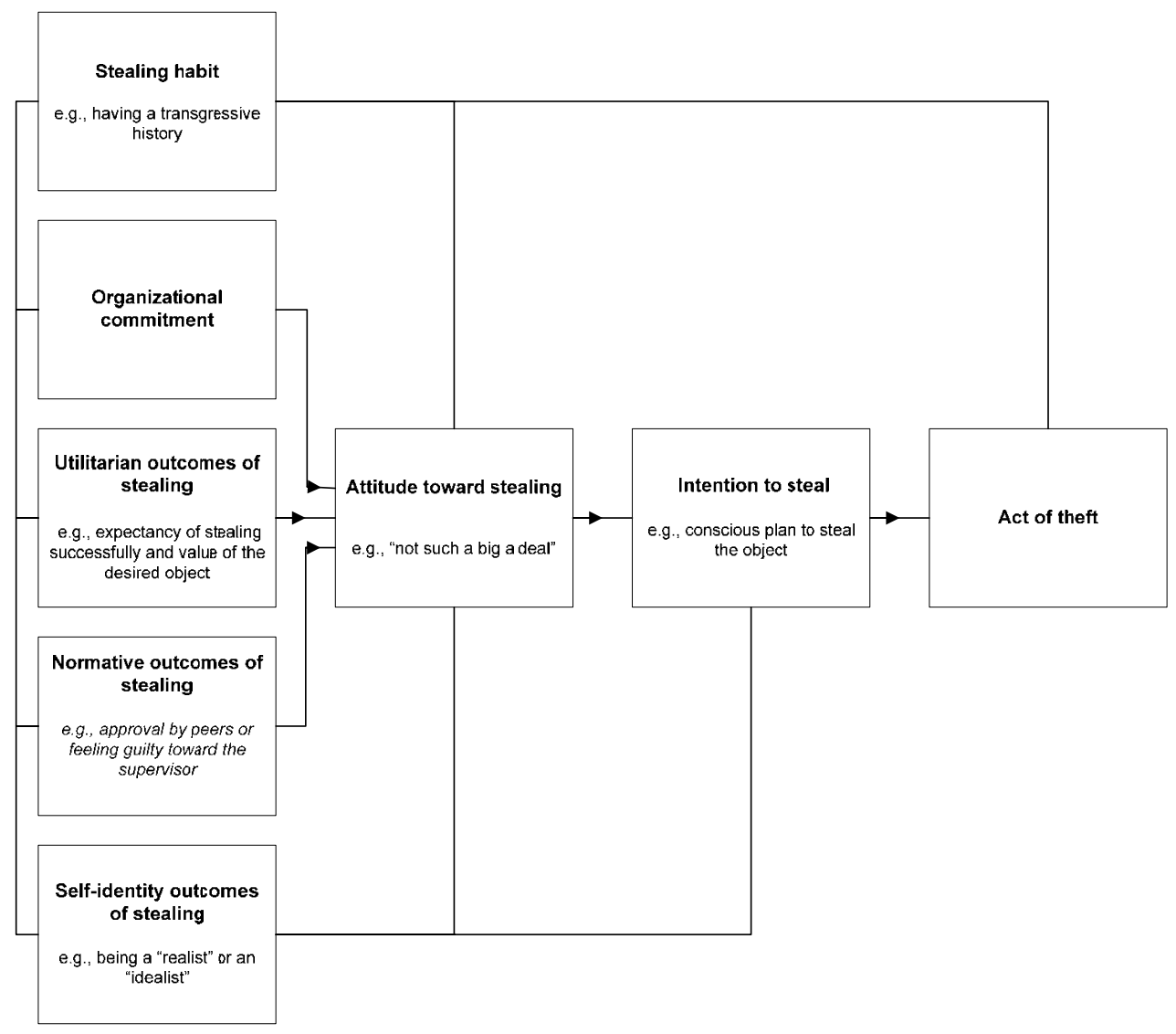

Whether employees actually engage in stealing will be affected by habit as well. Employees with a transgressive history (e.g., since childhood, or during their stay with the organization) are likely to evaluate stealing as 'not such a big a deal' and engage in stealing on a regular basis. Among habitual thieves one may find directly formed attitudes toward stealing that are consistent with their habit (Salancik, 1977; Wood et al., 2002). At the opposite end there will be employees who have never stolen anything from their employer and who have neither the habit nor the attitude of stealing.

Utilitarian outcomes (i.e., potential rewards and punishments associated with the behavior) are generally assessed using an expectancy-value paradigm (e.g., Eagly \& Chaiken, 1993; Scholl, 1981). In the case of stealing, individuals will weigh its potential benefits against its potential costs. More specifically, they will weigh the likelihood that the attempt to stealing will be successful and the value of owning the object without payment 
against the likelihood of getting caught and the value of its negative potential consequences. Normative outcomes of stealing can be experienced as a balance of the value of approval and the value of disapproval anticipated from significant others (Ajzen \& Fishbein, 1980). The employee might know many colleagues who consider stealing as 'normal' and anticipate their consent with the idea doing the appropriate thing to 'get even' with the employer. However, the employee might also anticipate feelings of guilt or shame toward the organization as a whole or toward significant others who clearly oppose the act of stealing. Again, the expectancy-value paradigm could be applied (Ajzen \& Fishbein, 1980; Eagly \& Chaiken, 1993; Fishbein \& Ajzen, 1975), since the (dis)approval of others may vary in likelihood and importance. Finally, self-identity outcomes enter into the equation. Individuals who have an 'idealist' self-concept will be more inclined to hold negative attitudes toward the act of stealing than people with a 'realist' self-concept (Henle, Giacalone, \& Jurkiewicz, 2005). All these influences might combine to form an attitude toward stealing. This attitude is expected to lead up to a conscious plan to steal something at a given time, i.e. the intention to steal, which is expected to result in the actual act of theft.

According to the resulting model organizational commitment would be a major factor explaining employee theft. A lack of commitment might favor the development of a prostealing attitude. A pro-stealing attitude and a habit of stealing, in combination with lacking commitment, will lead to a high probability of actual theft. High organizational commitment, on the other hand, will serve as a counterweight to bad habits and opportunism, and be associated with a low probability of theft.

\subsection{Propositions regarding E\&C type models}

Generating commitment-behavior models on the basis of the E\&C model has a number of specific implications. First, organizational commitment is invariably be part of any model. This means that commitment is given a central position in explanations of employee behaviors towards their organization, regardless whether the behavior is in the constructive or destructive, active or passive category. Even though other factors will affect the occurrence of particular behaviors, commitment is hypothesized to play a role in their ascendance. This in accordance with the outcomes of many research studies that were reviewed before (e.g., Meyer et al., 2002; Allen \& Meyer, 1996; Mathieu \& Zajac, 1990). Second, adding habits and anticipated outcomes of actions will improve the explanation of the behavior. Although the relative contribution of various factors may vary, depending on the type of behavior involved 
as well as the organizational context and/or employee population, together they will improve the explanation of the behavior over that given by organizational commitment alone. Third, the $\mathrm{E} \& \mathrm{C}$ model shows (see figure 1) that while the effect of organizational commitment on behavior is indirect (i.e. mediated) relevant behavioral routines (e.g., certain habits) may impact a particular behavior directly, without forming an attitude towards that behavior or forming an intention toward performing it (Eagly \& Chaiken, 1993; Wood et al., 2002). This means that, in the presence of strong habits, the explanatory value of organizational commitment for specific behaviors may be reduced. In general, habits will contribute to the explanation of particular behaviors both directly and indirectly, i.e. mediated by an attitude towards the behavior and a corresponding intention.

Fourth, the most important contribution of using E\&C type models is the distinction between attitudes toward targets and attitudes toward behaviors. Eagly and Chaiken (1993) argued that they are, in fact, separate constructs that are linked in a causal chain. This concurs with the assumption underlying the theory of reasoned action (Ajzen \& Fishbein, 1980; Fishbein \& Ajzen, 1975) that a thought of some sort must be formed to activate behavior: at a minimum an intention must be formed to direct behavior. Empirically, this means that the relationship between attitudes toward targets and actual behaviors should be fully mediated by the attitudes toward the behavior and intentions. From these considerations we derive the following propositions:

Proposition 1: Organizational commitment will significantly predict behavior in any category of the constructive-destructive and active-passive typology of organizational behaviors.

Proposition 2: If a particular behavior is predicted from organizational commitment, the degree of model fit will significantly improve when habits and anticipated outcomes of the behavior (i.e., utilitarian, normative, and self-identity) are taken into account.

Proposition 3: Habits will contribute to the prediction of a particular behavior both directly and indirectly, that is through an attitude and an intention towards the behavior; the habit-behavior relationship is therefore partially mediated. 
Proposition 4: After controlling for habits and anticipated outcomes of behaviors, the relationship between organizational commitment and specific behavior is fully mediated by the attitude toward the behavior and the intention to perform the behavior.

These propositions can best be tested by means of structural equations modeling. This type of analysis will allow to assess the strength of commitment-behavior links as mentioned in proposition 1, the improvement of model fit when adding variables as mentioned in proposition 2, and the presence of specific mediation effects as mentioned in propositions 3 and 4. In general, it is to be expected that a gradual build-up of phenomena (e.g., adding habits, and different classes anticipated outcomes of behavior, and mediators consecutively) will result in increasing fit of the model, while a gradual reduction will result in decreasing fit.

\section{Limitations of E\&C type models}

In spite of their advantages, commitment-attitude models based on the E\&C model also have their limitations. First of all, their applicability is restricted to behaviors that are performed consciously, that is, with a certain amount of cognitive deliberation (Eagly \& Chaiken, 1993; Fazio \& Towles-Schwen, 1999). For instance, it is not suitable to explain spontaneous, emotional and/or reflexive behavior. Second, some factors which may moderate or complement the role of organizational commitment may be added. For example, "perceived behavioral control' can be derived from the theory of planned behavior (Ajzen, 1991), and added if needed. Third, the E\&C model does not necessarily give the best prediction of specific behaviors. For instance, better predictions of turnover could be achieved with the job embeddedness model developed by Mitchell and colleagues (2001), which has been shown to produce high effect sizes. However, the major advantage of generating models in the way advocated here, in contrast to developing specific models for predicting each and every type of organizational behavior, is that it results in a structurally homologous and therefore parsimonious set of models that can account for diverse effects of organizational commitment on employee behaviors. An even greater advantage of using the $\mathrm{E} \& \mathrm{C}$ model is that it enhances the compatibility of organizational behavior research with more general theory on human behavior. 


\section{commitment}

Above we have concluded that organizational commitment should be conceived as an attitude toward a target (i.e., the organization) and we have argued that this attitude offers a fruitful basis for predicting a variety of organizational behaviors. Although organizational commitment conceived in this way bears resemblance to the 'affective' commitment construct from the TCM, we emphasize the importance of using a definition that does not restrict itself to the affective aspect, but includes cognitive and behavioral aspects as well. Below we will argue that this helps to differentiate the organizational commitment from other constructs in the organizational behavior domain, and will lead to greater construct validity of measurement instruments.

Standard attitudinal theory regards attitudes to be reflected in affect, cognition and an action tendency (e.g. Ajzen, 2001; Ajzen \& Fishbein, 1980; Eagly \& Chaiken, 1993; Hollander, 1971). Any definition of commitment honoring its attitudinal character should therefore reflect this classic triplet. However, if we look at current definitions and conceptualizations of organizational commitment in the literature, we find a range of definitions that capture the affective and cognitive aspects of attitudes but do not include the action tendency. Apart from a failure to really capture the concept in its entirety, this also leads to severe problems of discriminant validity with competing concepts. For example, Van Knippenberg \& Sleebos (2006) conceptualize commitment as an exchange-based attachment - which covers cognition and affect, not action - and is difficult to distinguish from the psychological contract (Rousseau, 1995). Likewise, when commitment is seen as predominantly value-based (e.g., Meyer, Becker, \& Van Dick, 2006) it comes very close to constructs like value congruence (O'Reilly, Chatman, \& Caldwell, 1991). These loose ways of defining commitment raise questions about the added value of the commitment construct and the need for using it at all. Our view is that a strictly attitudinal definition of organizational commitment does not only differentiate the construct from these alternatives but also produces an added value when it comes to predicting actual behaviors. Note that this view corresponds with the early idea expressed by Mowday et al. (1982) that organizational commitment goes beyond feelings and beliefs that could be experienced passively, and 
incorporates a willingness to give something of oneself to contribute to the organization's success ${ }^{19}$.

It is important to emphasize that the tendency to perform actions in the interest of the organization (Eagly \& Chaiken, 1993) should be interpreted as a general tendency (i.e., with no reference to a specific behavior), or a general readiness to act (Brickman, 1987; Leik et al., 1999). Many classic qualitative studies (e.g., Brickman, 1987: Brown, 1996; Adler \& Adler, 1988; Wyatt, 1999) on the nature of commitment display considerable consensus on what exactly constitutes this action readiness. They have argued that commitment is present when a person persists in a behavior even under circumstances that would otherwise have caused him or her to change that behavior. To put it even stronger, commitment implies an urge to perform behaviors that - by definition - exceed instrumental motivations of the individual (Buchanan, 1974; Scholl, 1981). Taken to the extreme, it can inspire individuals to go at great lengths and even sacrifice their own personal well-being for a 'greater good' that they identify with - like in combat units, religious communities, or athletic teams (Adler \& Adler, 1988; Salancik, 1977; Shamir, 1991). A commitment starts when some form of vow is made. More precisely, it is the state which one arrives at after having made a pledge (Salancik, 1977; Brickman 1987; Brown, 1996; Adler \& Adler, 1988). The stronger the pledge (i.e., the more public, irrevocable, volitional, and explicit) the stronger the commitment attitude (Salancik, 1977). Thus, commitment does not come cheap: it is a binding vow, a 'generalized behavioral pledge' to act in the interest of the organization. We therefore propose the following strictly attitudinal definition of organizational commitment.

Organizational commitment is an attitude of an employee vis-à-vis the organization reflected in a combination of affect (emotional attachment, identification), cognition (identification and internalization of its goals, norms and values), and action readiness (a generalized behavioral pledge to serve and enhance the organization's interests).

\footnotetext{
${ }^{19}$ The action component also distinguishes the commitment construct from job satisfaction which implies a more passive - or maybe even complacent - psychological state.
} 


\section{The measurement of organizational commitment}

Adopting a strictly attitudinal definition has implications for the measurement of organizational commitment. Allen \& Meyer's (1990) questionnaire focuses predominantly on emotional attachment (affect) to and identification with the organization (affect and cognition). Its items respectively tap into the notions of being happy to spend the rest of career with the organization, enjoyment of discussing the organization with people outside it, the degree to which organization's problems are perceived as one's own, the ease of becoming attached to another organization, feeling part of the family, emotional attachment, personal meaning, and belongingness (Meyer \& Allen, 1990). The notion of action is conspicuously absent. While this can be explained from the fact that they intended to measure 'affective' commitment, it is a limitation that should be overcome if one wants to measure organizational commitment as an attitude. Other instruments (e.g., the identification/internalization typology ${ }^{20}$ by O'Reilly \& Chatman, 1986) show similar limitations. The only exception is the Organizational Commitment Questionnaire by Mowday at al. (1982). However, this instrument explicitly contains a strong desire to remain employed (which is a specific behavior rather than a generalized behavioral pledge) and, thus, received the critique of producing inflated relationships with turnover (Reichers, 1985; O'Reilly \& Chatman, 1986; Bozeman \& Perrewe, 2001). In line with our attitudinal definition, we therefore suggest that existing instruments be expanded or refined so as to include all three attitude aspects. Such an expansion is necessary in order to improve the construct validity of these instruments in comparison to instruments measuring other constructs.

Proposition 5: The discriminant validity of organizational commitment vis-à-vis related constructs will improve when they are operationalized as a combination of affect (i.e., belongingness/identification), cognition (i.e., identification and internalization), and action readiness (i.e., a generalized behavioral pledge).

This proposition can be investigated empirically by means of standard methods for assessing construct validity, including factor-analysis, structural equations modeling, and multitrait-

\footnotetext{
${ }^{20}$ O'Reilly and Chatman's (1986) commitment typology consists of compliance, identification, and internalization. Following the definition (i.e., 'instrumental involvement for specific, external rewards', p. 493), the compliance component can be characterized as an evaluation of the utilitarian outcomes of behavior, and not as a component of an attitude toward a target.
} 
multimethod analysis (Netemeyer, Johnston \& Burton, 1990; Spreitzer, 1995; Netemeyer, Bearden \& Sharma, 2003; Nunnally \& Bernstein, 1994).

\section{Conclusion}

In this article we have shown that the TCM does not qualify as a general model of organizational commitment, as it suffers from a conceptual inconsistency and hence a lack of unequivocal empirical support. When looked upon from the attitude-behavior model of Eagly and Chaiken (1993) it appears to combine an attitude towards a target (the organization) with attitudes towards a behavior (leaving or staying). While the TCM might be retained to predict employee turnover, its use as a general model of organizational commitment should be discouraged. In line with the predominant practice in research on organizational behavior we propose to return to the original understanding of organizational commitment as an attitude towards the organization, and to measure it accordingly. Future research may improve discriminant validity of existing measures by giving due attention to the cognitive, emotional and behavioral components of the commitment attitude. We have proposed the Eagly \& Chaiken model as a viable alternative to the TCM and as a generic framework from which a variety of specific commitment-behavior models can be derived, all sharing organizational commitment as a common core. Unlike the TCM, the predicted behaviors are not limited to staying with the organization or leaving it, but represent a broad spectrum of organizational behaviors like corporate illegal behaviors, shirking, organizational championing, satisfying customers, unethical behaviors, and so forth. By studying the interplay between organizational commitment, behavioral routines, and imagined consequences of behaviors more insight into the real nature of the relationship between organizational commitment and its behavioral consequences may be obtained. 


\title{
3 A life cycle perspective on commitment dynamics: A comparative review of aggregate trends and pattern shapes
}

\begin{abstract}
We investigate dynamic trends in organizational commitment (OC) across three phases of the commitment life cycle: ascendance, subsistence, and descendance. We do so by extracting dynamic trends and pattern shapes from 34 longitudinal studies which contain three or more repeated measures, combining and contrasting shortterm and long-term longitudinal designs. From non-parametric comparative analyses one conclusion is paramount: stable OC patterns in mean OC levels exist, but unstable patterns are just as prevalent. Typically, at its ascendance OC rises, but after organizational entry OC probably declines in various forms. During subsistence $\mathrm{OC}$ can show quite some resilience in response to organizational upheaval as main trends are stable or tend to move back toward initial levels. Upward swings in OC are generally rare and short-lived. Full restoration after sharp decrease is possible, but it takes a long time (up to several years). Around descendance, OC naturally declines. We explore scholarly and managerial implications of the life cycle perspective and discuss the potential relevance of these findings for person-specific changes in OC.
\end{abstract}




\section{Introduction}

Since the nineteen eighties organizational commitment (OC) has enjoyed massive attention both in the academic and popular literature. A workforce of committed employees seems crucial for gaining competitive advantage and making successful transitions in times of change (Herscovitch \& Meyer, 2002; Hom, Griffeth, \& Gaertner, 2000; Mathieu \& Zajac, 1990; Schweiger \& Goulet, 2005; Thompson \& Van-de-Ven, 2002; Van Maanen, 1975). Commitment is therefore an important objective of socializing newcomers on the job. Committed employees are affectively attached to their organizations, generally loyal, and inclined to take that extra step to make their firms excel. It is now widely accepted that OC is related to a host of positive organizational behaviors, such as organizational citizenship behavior, punctuality, attendance, and task performance. Fostering commitment has become part of a normative rhetoric for managers seeking control of employee's work effort in times of economic downturn and prevention of unwanted employee behavior and turnover in times of economic upheaval (Roe, Solinger, \& Van Olffen, 2009). Interest in how OC can be enhanced and controlled has led many scholars to study 'antecedents' of commitment (Mathieu \& Zajac, 1990; Meyer, Stanley, Herscovitch, \& Topolnytsksy, 2002; Mowday, Porter, \& Steers, 1982).

There is, however, a hidden contradiction in the assumptions underlying managerial rhetoric on the one hand and the scientific study of OC antecedents on the other. The proposition (or wish!) that $\mathrm{OC}$ of employees can be enhanced or prevented from falling assumes that $\mathrm{OC}$ is dynamic and subject to influence. In contrast, scientific knowledge on antecedents and consequences is mainly based on associative evidence obtained by crosssectional research designs, which rest on the assumption that the phenomena (i.e., OC) under study are strictly stationary over time (Borsboom, Mellenbergh, \& van Heerden, 2003; Jaccard \& Dittus, 1990; Molenaar, 2004; Molenaar \& Campbell, 2009; Molenaar, Huizinga, $\&$ Nesselroade, 2003). The question is which of these contradicting assumptions on the temporal nature of OC hold.

We try to shed light on this matter in four ways: First, we investigate which of the assumptions fit best to empirical evidence on the longitudinal development of OC. Second, we explore to what degree researchers have overlooked dynamic information in their data. That is, we may already know more than we think we do. Third, we seek clues as to when and how changes occur. More specifically, we look for typical dynamic patterns from (1) the phase following entry into the organization (2) the phase of subsistence, where employees are 
tenured incumbents (3) the phase leading up to exit from the organization. Finally, we ask how managerial action can impact observed employee commitment dynamics.

In this study we will analyze data (i.e., a secondary analysis of aggregate means) reported in published longitudinal studies in order to find out how commitment typically changes over time. A systematic study of how OC behaves in different phases of the commitment life cycle is needed because it may pose a different view on the causal mechanisms underlying observed increases or decreases in employee's OC. For example, many 'effects' of interventions may be partly explainable by the 'natural' development of OC during organizational upheaval. Such spuriousness potentially obscures the true impact of interventions. Or some of the decreases observed around the moment of exiting the organization may be misinterpreted as a causal antecedent to turnover. Instead, it may occur in anticipation of the end of the employment contract. In short, we will try and answer the question: How does OC typically develop in the phases of ascendance, subsistence, and descendance?

To answer this question we will confine ourselves to dynamics at the level of the population (i.e., grand mean developments). We focus on the grand mean because (1) this is typically the only information available to us in existing studies (2) conventional regressions on cause-effect relationships with OC apply only to the population-level (Borsboom, Mellenbergh, \& van Heerden, 2003; Jaccard \& Dittus, 1990; Molenaar, 2004; Molenaar \& Campbell, 2009), and (3) managerial rhetoric has mainly focused on creating a 'committed workforce', which applies to the level of the population as well. It should be noted that analyses of aggregate mean developments possibly but not necessarily reflect individual change in commitment. Some of the observed dynamics could be due to changes in the sample (e.g. attrition).

\section{The organizational commitment life cycle}

The theoretical background for our study is provided by the life-cycle model of behavioral phenomena (Roe, 2008a). According to this model, a phenomenon is defined a series of related events happening to a particular object (e.g., individual, group, organization) during a certain time interval (Roe, 2009, p. 302). The life cycle model is a conceptual template that serves to generate research questions on the temporal dynamics of behavioral phenomena. It is meant to overcome limitations of conventional variance-based approaches many authors 
before us have pointed out (e.g., Abbott, 1988; Borsboom, Mellenbergh, \& van Heerden, 2003; Molenaar \& Campbell, 2009; Poole, Van de Ven, Dooley, \& Holmes, 2000; Van de Ven, 2007). The model can be used to specify temporal features (specifically, onset, offset, a duration, and dynamics) and how these features relate to antecedents and consequences. Figure 3.1 depicts a typical life cycle of a behavioral phenomenon applied to the organizational commitment attitude. This includes three phases of development (ascendance, subsistence, descendance), and specific moments that are unique to its development, such as engaging, entering the firm, disengaging, and exiting the firm.

Figure 3.1 The life cycle model as applied to organizational commitment

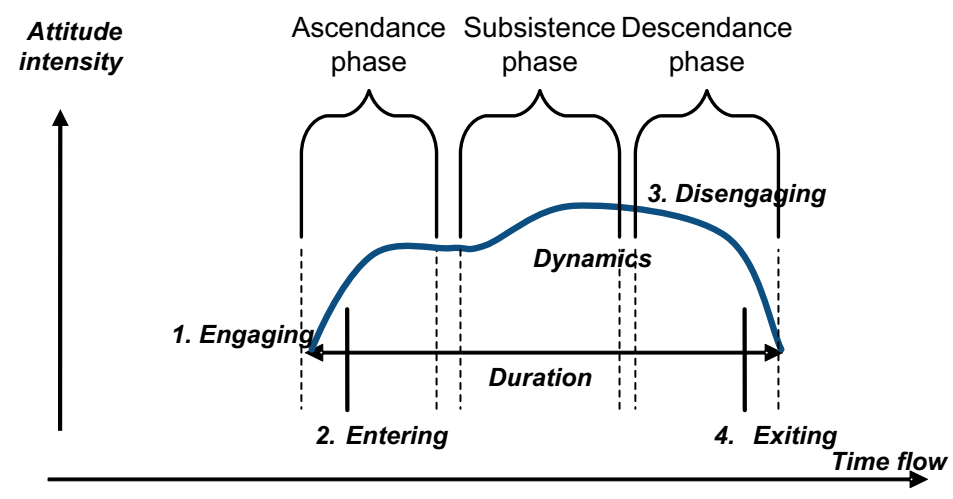

The life cycle model is based on the metaphor of human life. One of its major implications is that all behavioral phenomena have a limited existence (Roe, 2008a). If the proposition of finite existence is true in the context of behavioral phenomena, it has repercussions for the choice of time frame in temporal research. For instance, it does not make sense to measure constructs or extrapolate research findings beyond the finite existence of the phenomenon. Unlike variance-based approaches, the life cycle model takes the finite existence of phenomena into account by assuming a 'zero value', or non-existence of the phenomenon, before the moment of onset (the beginning) and after the moment of offset (the end).

In the case of $\mathrm{OC}$, the ascendance phase signifies the process of becoming a member of a new organization. After all, the attitude of organizational commitment has a specific organization as a target (Solinger, Van Olffen, \& Roe, 2008). Note that in the process of 
ascendance we distinguish two defining moments: (1) engaging ${ }^{21}$, which is the moment of making an implicit pledge or a promise to a specific organization, and (2) entering, which is the moment when the individual starts working for the firm. The phase of descendance in the commitment life cycle coincides with the process of leaving the firm. In the process of descendance we distinguish two defining moments: (1) disengaging, which is the initiation of decline, coinciding with the decision to leave the firm, and (2) the actual moment of exiting the firm ('exiting'). Note that the concepts of ascendance and descendance are not to be interpreted as 'switches', but rather as gradual trajectories (e.g., fading in, and fading out). We use the word 'ascendance' instead of the more common 'entry' to avoid confusion with the understanding of 'entry' in organizational socialization literature. In our case, 'entry' means the actual moment of entering a new organization, while ascendance means the process of developing commitment in anticipation to, during, and after entering. Duration can be interpreted in two ways depending on which life cycle is of interest. Thus, the duration of employment is the time in between the moment of entry and exit, while duration of the commitment phenomenon is the time between its onset and its offset. Dynamics reflects how the behavioral phenomenon fluctuates in intensity over time. More specifically, it describes a trajectory of a phenomenon across a certain time span.

The life cycle model of OC leads to interesting questions, like: How fast does OC grow; does it reach a plateau, and if so, when? How variable is it over time; what does this variability depend on; when does the moment of 'disengaging' take place; how fast is the decline; does it really level off to zero? In the present study we will explore whether the available literature on OC offers footholds to answer some of these questions.

We are aware of the fact that the life cycle model as used here is very generic and that specific antecedents have already explained increases or decreases in OC in particular studies. However, the model may do well in explaining OC dynamics over the entire duration of existence of the OC phenomenon. The purpose of this study is not to describe and explain specific increases or decreases in OC, but to take a more distant look at the OC phenomenon and to try and make general claims about typical OC trajectories in different phases of employment at the level of the population.

\footnotetext{
${ }^{21}$ When describing processes we are talking about activities and events 'happening' over time. We therefore use verbs instead of nouns (see Roe, 2008a)
} 


\section{Contrasting and combining zoom levels}

In order to arrive at valid conclusions and generalizations on typical temporal OC trajectories, specification of the time scale is crucial. The observed temporal form may depend on the time frame (the length of the study) and the time grid (measurement density) chosen by the researcher. Figure 3.2 shows how the timing of measurement can change results dramatically. The observation of gradual increase (circled), stability (squared), rapid decline (crossed), or dip-shaped variation (arrows) can all be observed from a single underlying 'true' function. We can also conclude from this graph that short term studies (crosses and arrows) can show seemingly opposing results compared to long-term studies (squares and circles). Combining and contrasting short-term and long-term time frames used in different studies may increase our understanding of underlying dynamics.

Figure 3.2 also shows that studies within short-term and long-term time frames do not necessarily agree. Simplistic accumulation of findings without knowledge about the unique properties of certain zoom levels is therefore dangerous (Zaheer, Albert, \& Zaheer, 1999). In our review we will therefore distinguish between short-term time frames (i.e., evolving over a week to six months) and long-term time frames (i.e., evolving over six months to several years).

Figure 3.2. The hypothetical impact of temporal designs on research findings

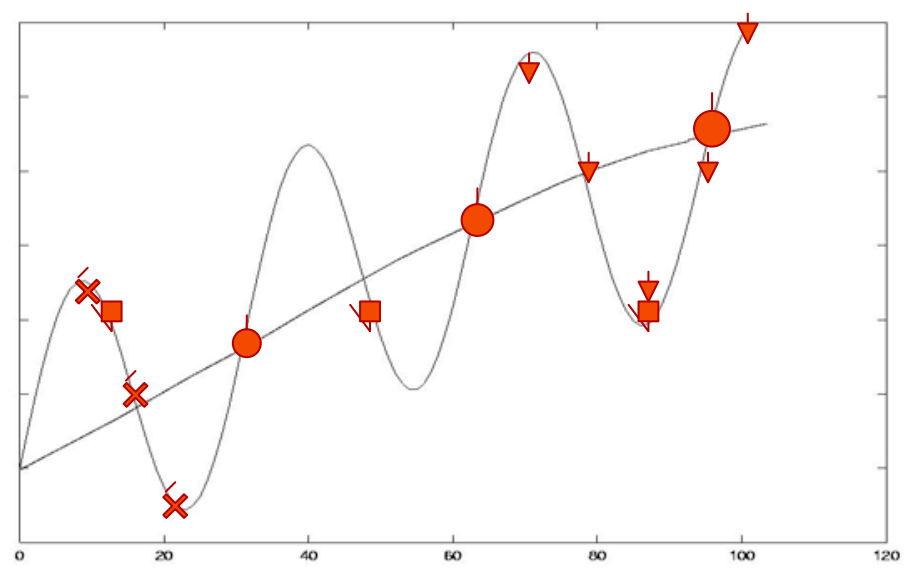




\section{$4 \quad$ Methods}

We are interested in typical developmental trajectories of OC in different phases of the employment life cycle. Crucial to this type of exploratory research is which studies to include and which to discard and how the 'sample' of studies we used can be characterized. Obviously, the criteria we set have impact on what generalizations we can make. We will now describe the criteria, the literature search process, the sample of studies used, and the kind of analysis procedure chosen.

\subsection{Selection criteria}

Note that we are talking about 'dynamics' and not about 'change'. Dynamics are distinct forms of change. We regard 'change' in OC as the difference between two scores measured at different time moments. In contrast, 'dynamics' of OC refers to developmental trajectories which cannot all be pinpointed by two time points only. For example, if two points in time have the same score, we cannot speak of 'stability' because the actual shape of the trajectory may be parabolic. We therefore include only longitudinal studies which contain a minimum of three repeated measurements ${ }^{22}$ (henceforth: the 'T-rule-of-three' for studying dynamics).

If means and standard deviations of OC levels at all time moments were not reported in the original article, we tried to obtain them from the authors. Studies which have used three or more waves, but took only two repeated OC measures were discarded from the sample. We only included studies on attitudinal commitment, which have the organization (as a whole) as a target ${ }^{23}$. Longitudinal studies on neighboring constructs, such as job satisfaction, work involvement, organizational identification, career/occupational commitment, work morale, or work motivation were also discarded. Studies on commitments to other objects than the organization as a whole (e.g., a goal, the supervisor, organizational change) were excluded as well.

\footnotetext{
${ }^{22}$ Naturally, any choice of the number of repeated measurements above 2 is arbitrary. We choose 3 in order to cast the widest possible net.

${ }^{23}$ Longitudinal studies on normative and continuance commitment were ignored because these dimensions of famous the three-component model (Meyer \& Allen, 1990) have recently been re-conceptualized as imagined consequences of leaving the organization and should therefore no longer be seen as commitment to the organization (Solinger, Van Olffen, \& Roe, 2008).
} 


\subsection{Literature search procedure}

Our literature search was based on three search engines, Google Scholar, Ebsco host (combining Business Source Premier and PsychARTICLES) and PsychINFO (last time checked: July 17, 2009). We used a wide array of search entries (i.e., longitudinal, Time, Time 3, wave, change, panel) in several combinations and in conjunction with various expressions of organizational commitment (i.e., organizational loyalty, commitment, attachment). Entering 'organizational commitment' in Google Scholar yielded 995000 hits (dd. July 17, 2009). When we added the word longitudinal to it, the number of hits reduced to 122.000 (which is about $8 \%$ ). It turns out that this is an overrepresentation of the actual number of studies that have used longitudinal designs, because Google Scholar also searches the text in the article where the word 'longitudinal' was only casually mentioned. Similar entries in Ebsco and PsychINFO show that out of the total amount of articles on OC respectively 4 and 5 percent have mentioned the word 'longitudinal'. These numbers match the analysis by Roe (2008b) on the state of affairs in Organizational Behavior literature in general.

Closer inspection of the studies that have used the word 'longitudinal' teaches us that only a few studies have actually done repeated measures on OC. Only around $4 \%$ of all research output on OC contains a longitudinal design (120 out of 2930). We found 34 studies which meet our minimum of three repeated measures criterion (i.e., T-rule-of-three). In total $1 \%$ (34 out of 2930) of all research output on OC contains a longitudinal design that allows for dynamic research. The bulk of studies we encountered had used three repeated measures (27 out of 34). Only five out of our pool of 34 studies has used more than three repeated measures of OC.

In Table 3.1 and 3.2 we have listed all 34 studies including research context, main constructs, main findings, number of repeated measures, the temporal design, and the characteristics of the sample. We think such an overview is useful since it specifically reveals what aspects authors have focused on and what proportion of them either did not focus on OC trends, mentioned them only casually, or took OC trends as main focus of the study.

According to Wright (2002) temporal designs with a duration shorter than 6 months can be labeled 'short-term'. We adopted this arbitrary but reasonable rule of thumb. A study was qualified as 'short-term' if at least three repeated measures were administered within this time frame. We made an exception if the third administration took place in the seventh month. Studies with a time frame longer than 7 months were designated as 'long-term'. Some 
studies qualified both as short-term and long-term because they had at least three measures within 6 months, and at least three measures spread out over years (i.e., Lee et al., 1992; Van Maanen, 1975). Out of 34 studies, 19 have dealt with the process of ascendance. The overwhelming majority (17 out of 19) started the research around the moment of entry (i.e., either 1 month prior to, on the first day of employment, or 1 month after entering). Two studies dealt with OC development prior to the moment of entering the organization when subjects were still aspiring organizational membership or just got hired (Meglino et al., 1998; Bauer et al., 1998).

Most studies on the subsistence phase dealt with the effects of managerial initiatives toward organizational change. We have categorized the types of interventions based on qualification 'hard' versus 'soft'. Hard interventions are incisive, typically externally induced, organizational reforms, like downsizing, mergers, acquisitions, drastic role transitions, whereas soft interventions are less incisive and generally intend to improve worker conditions, like the introduction of Total Quality Management, the launch of a new HRM program, promotion decisions, and work schedule changes.

Finally, we found 6 studies dealing with organizational exit (Cohen \& Freund, 2005; Kammeyer-Mueller, 2005; Porter, Crampon \& Smith, 1976; Farkas \& Tetrick, 1989; Bentein et al., 2005; Lee et al., 1992), see Table 3.1 and 3.2. Unfortunately, there was only one study from which we could derive the means and the standard deviations of employees exiting the organization (Porter, Crampon \& Smith, 1976). 


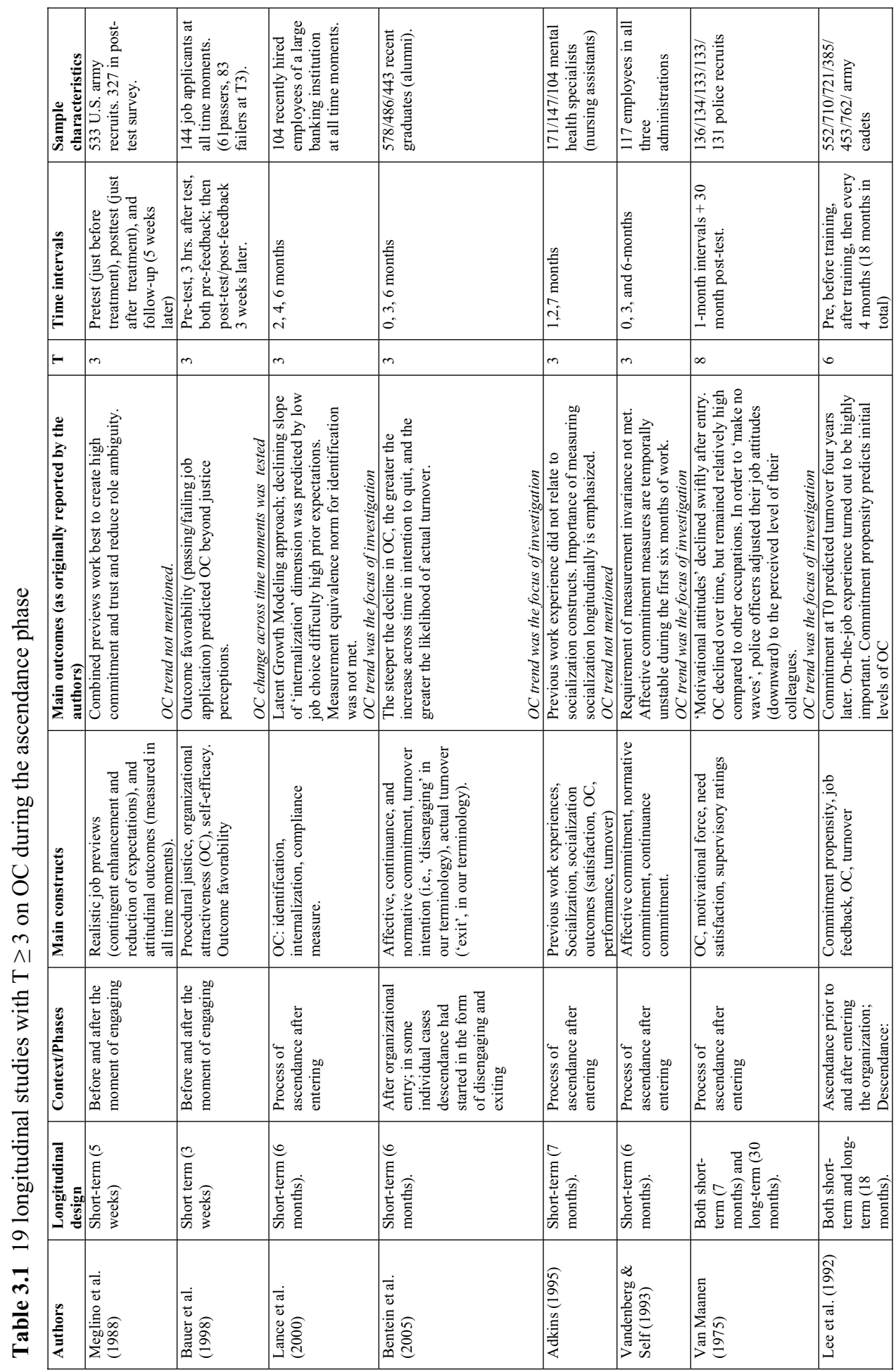




\begin{tabular}{|c|c|c|c|c|c|c|c|c|c|}
\hline & 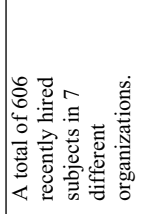 & 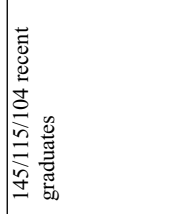 & 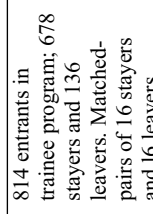 & 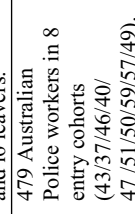 & 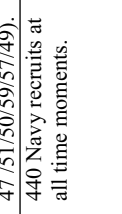 & 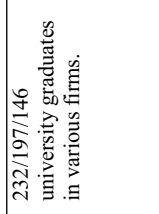 & 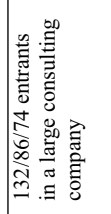 & 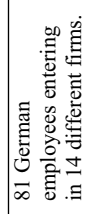 & 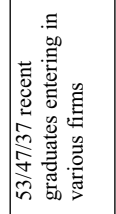 \\
\hline & 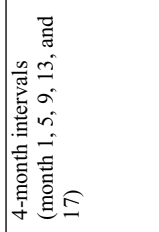 & 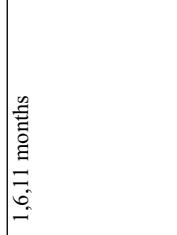 & 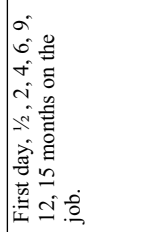 & 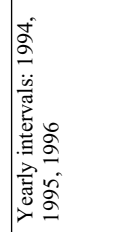 & 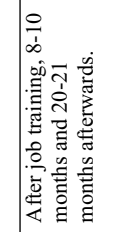 & 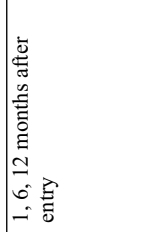 & 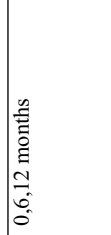 & 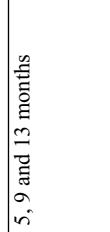 & 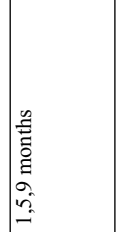 \\
\hline & in & $m$ & $\infty$ & $\lambda \mathrm{m}$ & m & $\mathrm{m}$ & $\mathrm{m}$ & $\mathrm{m}$ & $\mathrm{m}$ \\
\hline 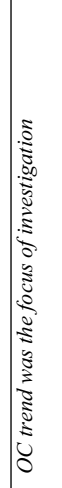 & 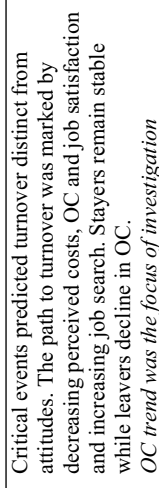 & 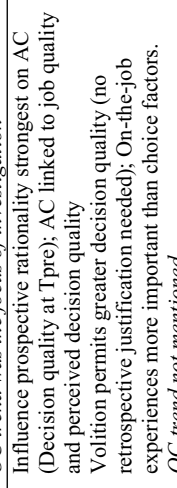 & 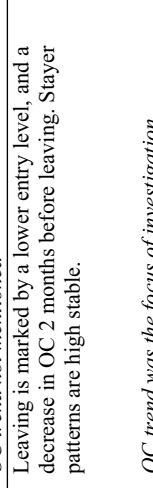 & 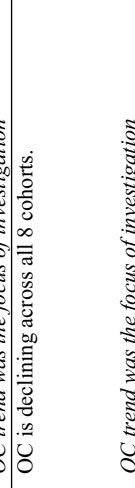 & 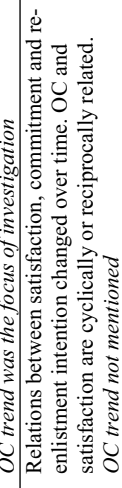 & 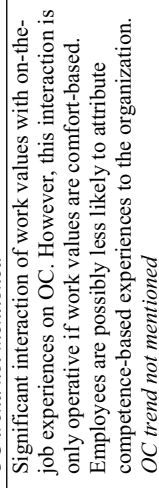 & 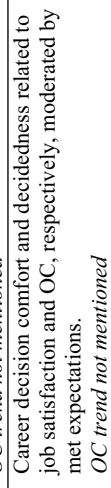 & 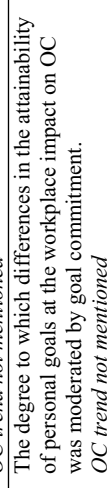 & 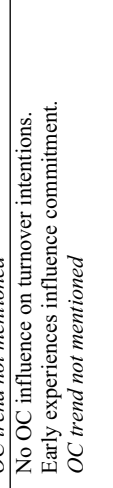 \\
\hline & 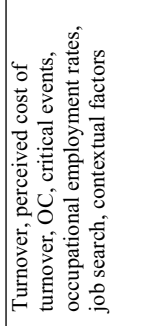 & 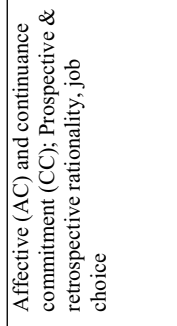 & 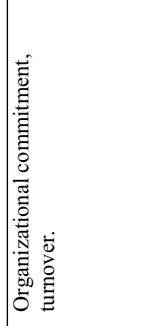 & 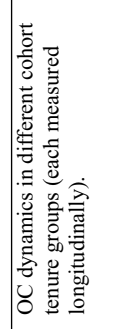 & 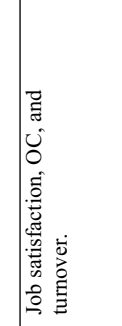 & 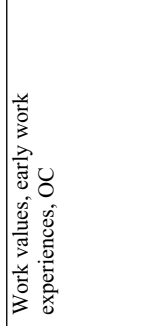 & 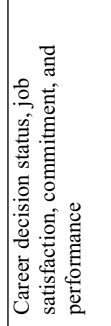 & 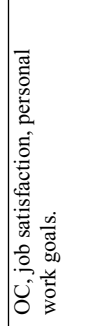 & 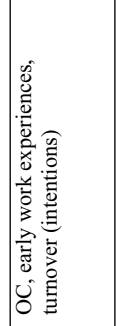 \\
\hline 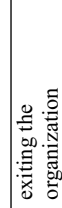 & 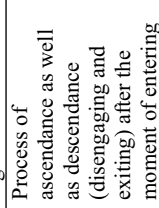 & 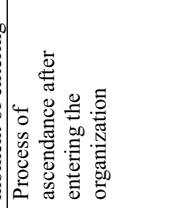 & 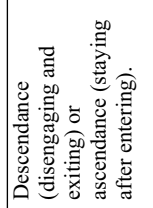 & 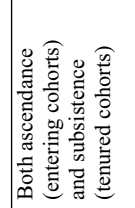 & 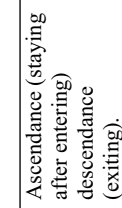 & 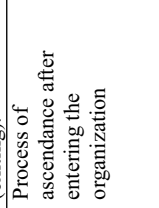 & 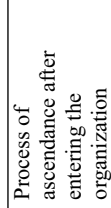 & 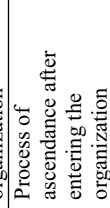 & 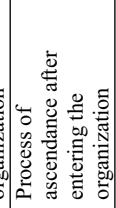 \\
\hline & 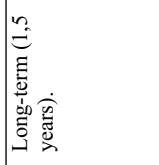 & 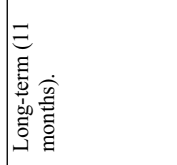 & 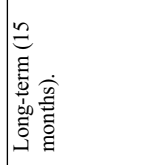 & 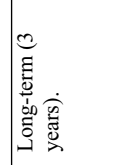 & 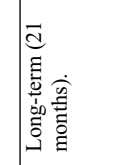 & 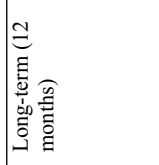 & 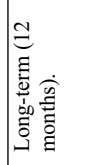 & 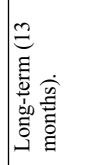 & 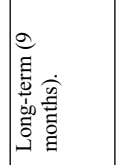 \\
\hline & 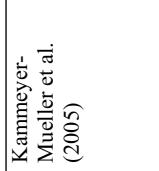 & 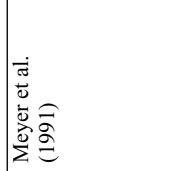 & 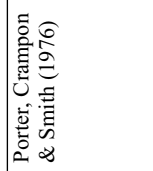 & 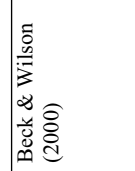 & 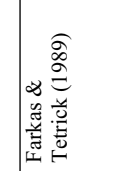 & 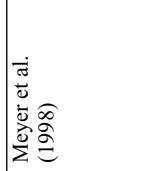 & 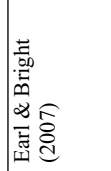 & 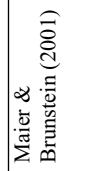 & 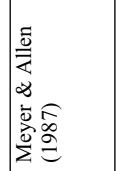 \\
\hline
\end{tabular}




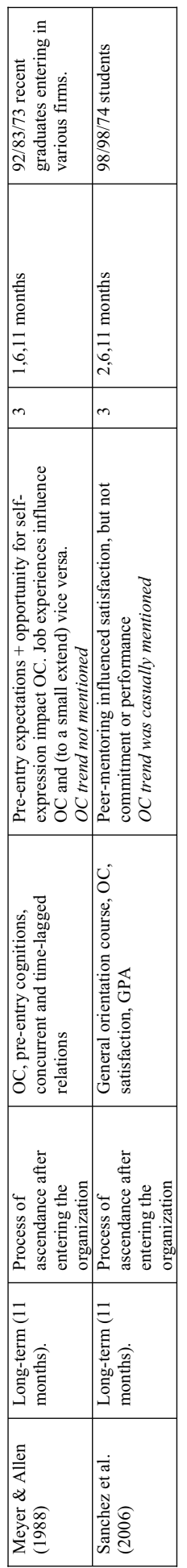

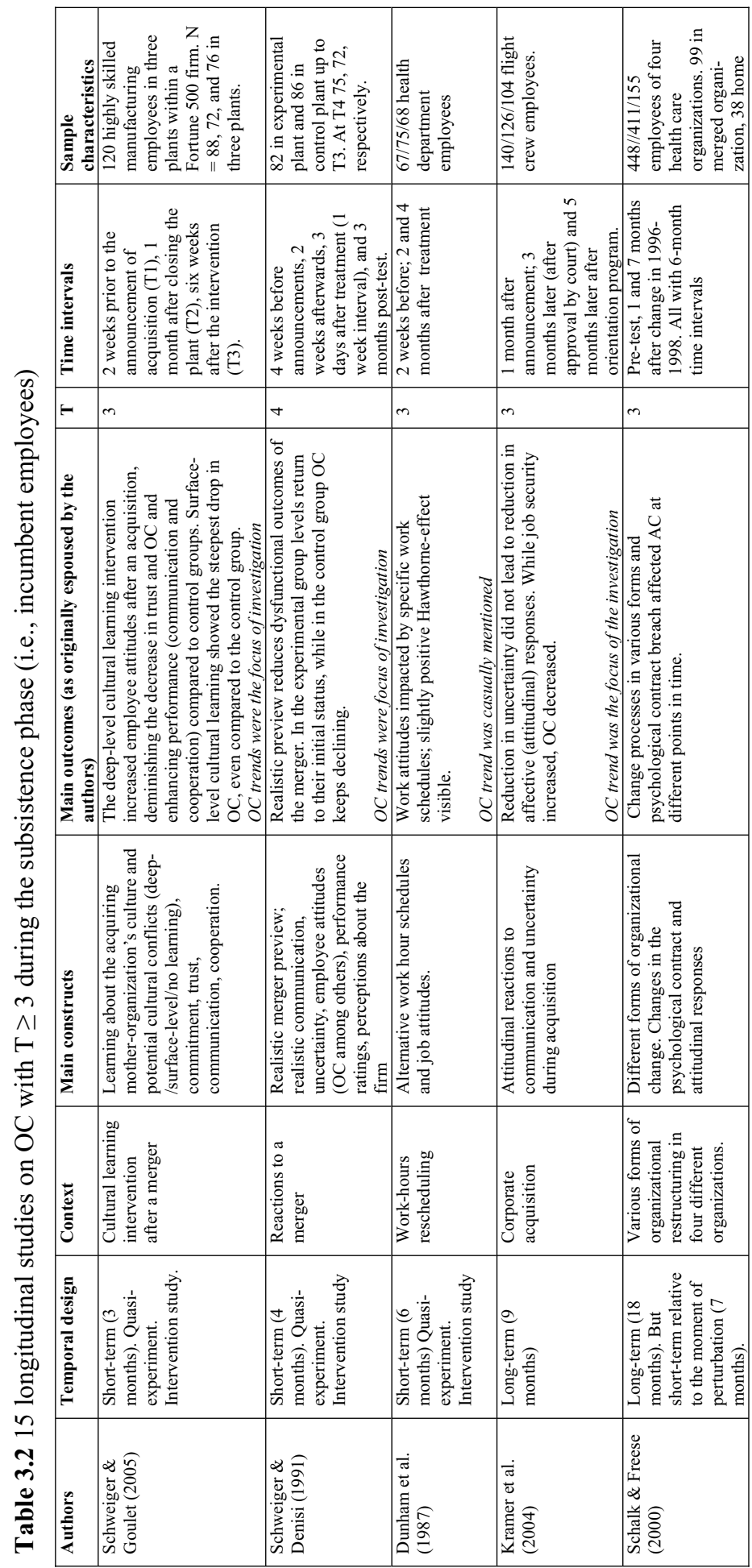




\begin{tabular}{|c|c|c|c|c|c|c|c|c|}
\hline 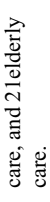 & 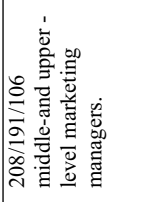 & 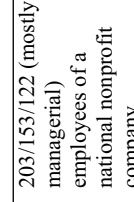 & 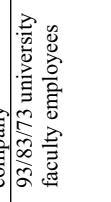 & 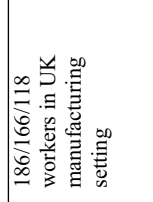 & 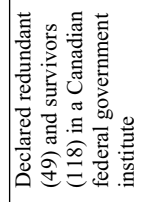 & 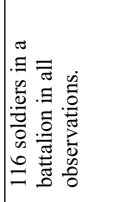 & 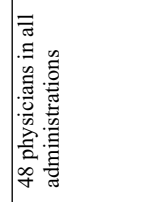 & 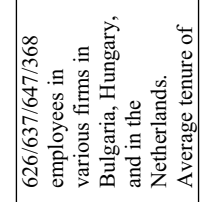 \\
\hline & 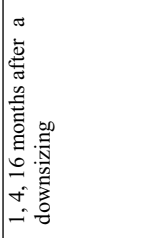 & 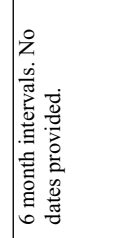 & 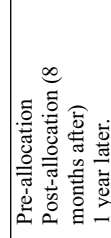 & 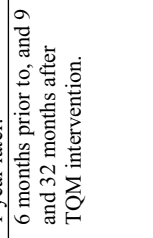 & 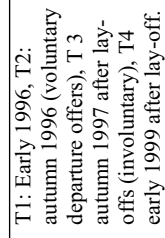 & 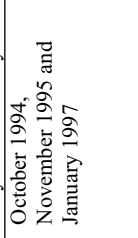 & 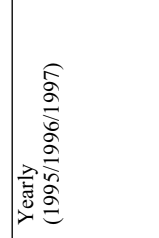 & 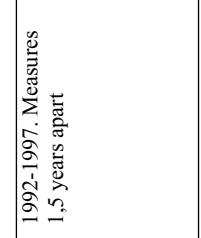 \\
\hline & $\mathrm{m}$ & $\mathrm{m}$ & m & $m$ & + & $m$ & $\mathrm{~m}$ & + \\
\hline & 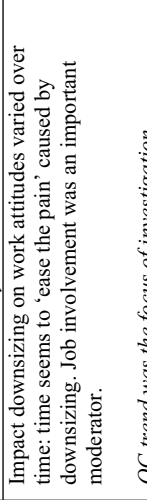 & 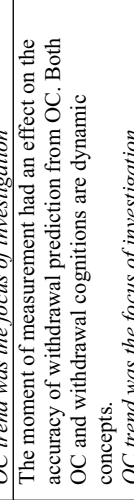 & 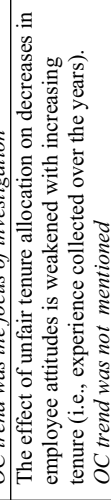 & 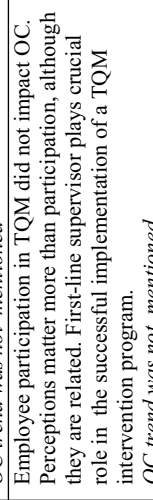 & 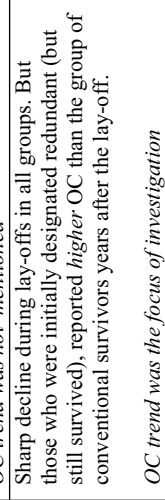 & 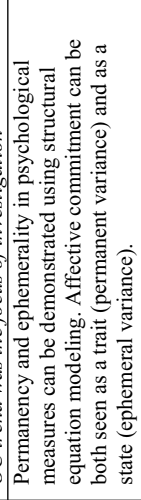 & 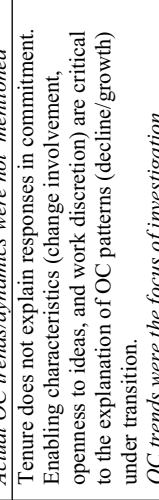 & 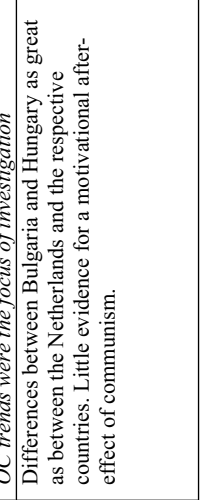 \\
\hline & 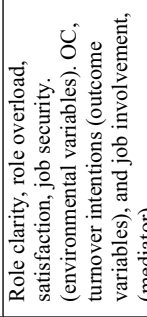 & 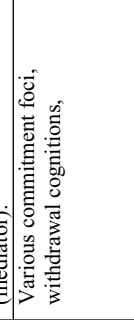 & 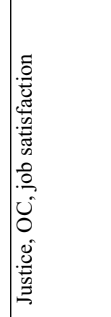 & 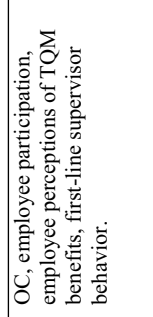 & 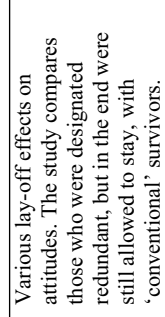 & 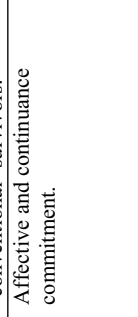 & 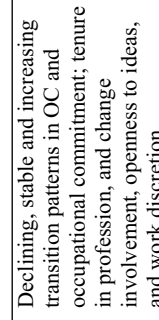 & 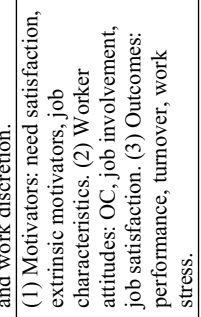 \\
\hline & 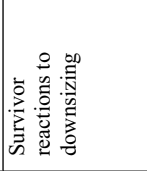 & 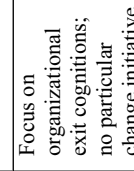 & 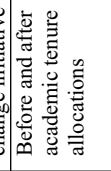 & 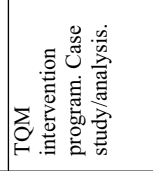 & 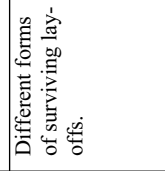 & 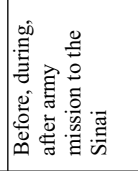 & 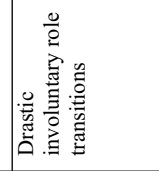 & 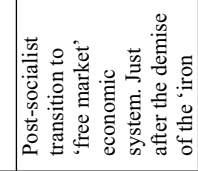 \\
\hline & 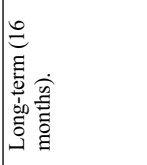 & 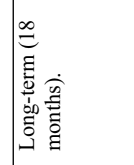 & 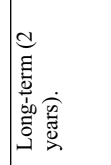 & 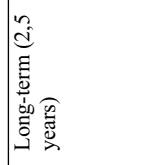 & 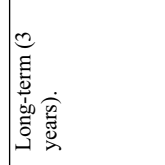 & 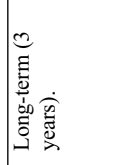 & 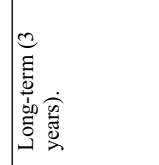 & 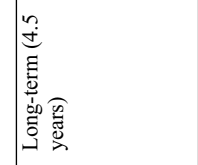 \\
\hline & 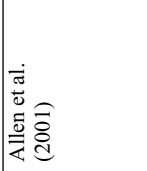 & 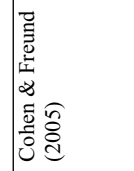 & 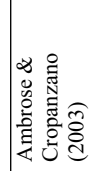 & 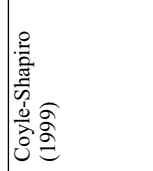 & 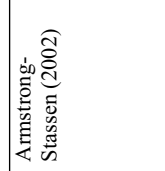 & 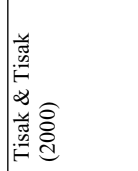 & 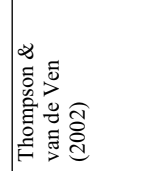 & 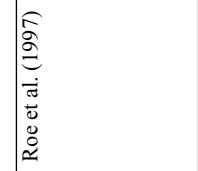 \\
\hline
\end{tabular}




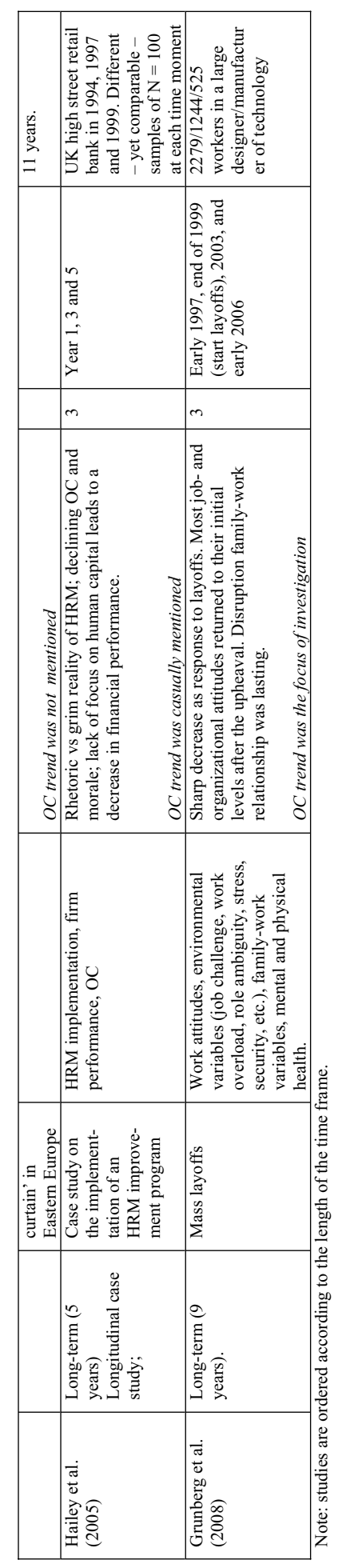




\subsection{Different measures of $\mathrm{OC}$}

We found many different ways in which organizational commitment was measured: the most widely used were the measure by Porter and Smith (P\&S; 1970), the Organizational Commitment Questionnaire (Mowday, Steers, \& Porter, 1979) and the Affective Commitment Scale (Allen \& Meyer, 1990)

Table 3.3 Frequency of the types of measures used

\begin{tabular}{ll}
\hline Organizational commitment measure & $\begin{array}{l}\text { Frequency of } \\
\text { use in our } \\
\text { sample }\end{array}$ \\
\hline Organizational Commitment Questionnaire & 1 \\
3-item & 1 \\
4-item & 1 \\
9-item & 6 \\
15-item & $\underline{6}$ \\
Porter \&Steers - 5 item & 1 \\
Porter et al., (1974) & \\
Affective Commitment Scale & 2 \\
3-item & 8 \\
full measure & 1 \\
Organizational attractiveness & 1 \\
Psychological attachment scale - internalization & 1 \\
Lincoln \& Kalleberg (1990) & 3 \\
Cook \& Wall (1980) & \\
\hline
\end{tabular}

Most of the questionnaire items in the P\&S scale are similar to the OCQ as both scales were constructed by the same author (Lyman W. Porter). Thus, we regard these measures as equal. The OCQ and P\&S has been used 15 times and the AC scale 10 times, which leaves only a very small proportion (6 studies) using other measures. Further, a meta-analysis (Meyer, Stanley, Herscovitch, \& Topolnytsksy, 2002) shows a corrected correlation coefficient of 88 in 8 studies between the AC and the OCQ measure. Other meta-analyses show that the prediction of work performance by OC does not even vary at least marginally with the type of commitment measure used (Wright \& Bonnet, 2002; Riketta, 2002). Moreover, in the study by Vandenberg \& Self (1993) the authors used both the AC and the OCQ and no differences in mean trajectories were found. We therefore conclude that - as long as applied to the population level of analysis - we can safely compare levels and dynamics of OC in different studies without having too many worries about how commitment was measured. 


\subsection{Procedure of analysis}

To make studies comparable, we transformed all reported means and standard deviations to a 5-point scale. Recalculations from seven-point (X) to five-point scales (Y) were based on the following formula: $\mathrm{Y}=.333+.667 * \mathrm{X}$. In two exceptional cases, studies reported only the means of quasi-experimental groups, and not the grand mean (Schweiger \& Denisi, 1991; Schweiger \& Goulet, 2005). In this case, we chose the control group showing the population level, leaving the other subsamples aside. If the grand mean was given (like in Thompson \& Van de Ven, 2002), we ignored the subgroups, to allow for comparison with other studies. If the grand mean was not given, and the subgroups had unequal distributions, we selected the control group.

In our analysis we followed a method developed by Li (2009a) who classified developmental trajectories defined by three measurement points in a number of discrete patterns. While she used a more refined classification with 17 patterns, we distinguished 9 basic patterns (see Figure 3.3). Note that this classification deals with the observation of pattern shapes, and not with commitment levels. In the first part of the trajectory - from the first to the second measurement moment - there are 3 possibilities: decline, stable, and growth. The same goes for the second part of the trajectory. What results is a 3-by-3 'nanogram'. Like Li, we used this diagram to perform non-parametric tests on the prevalence of pattern shapes. The logic of our test is as follows: if there is no 'typical' dynamic pattern across three time moments, one would expect that the patterns are randomly distributed across $\mathrm{k}$ number of studies. With an infinite number of trials we would end up with an average count of k/9 studies per cell which can be explained by 'pure chance'. These expected frequencies are then compared to actual frequencies in a chi-square test. If expected frequencies were less than one, we did not perform a non-parametric test.

Conventional rules of thumb in Chi-square tests do not allow expected frequencies to be less than five. However, there is statistical evidence that this rule of thumb is overly restrictive. Roscoe and Byars (1971), Camilli and Hopkins (1978), and Overall (1980) argue that uniformly distributed expected frequencies in chi-square tests (as in our case) with low sample sizes can be as low as 2 (or even 1) while still retaining adequate power and still remaining robust with respect to type-I-errors. We therefore only discard expected frequencies lower than 1 . This means that the minimum number of studies to perform a nonparametric test on the prevalence of pattern shapes is set to 9. Next to the Chi-square we also performed a permutation test (Exact-test), where the probability of finding the observed 
frequency distribution is calculated under the null-hypothesis that prescribes uniform cell frequencies (Mehta \& Patel, 1999).

Figure 3.3 A 'nanogram' typology of pattern shapes

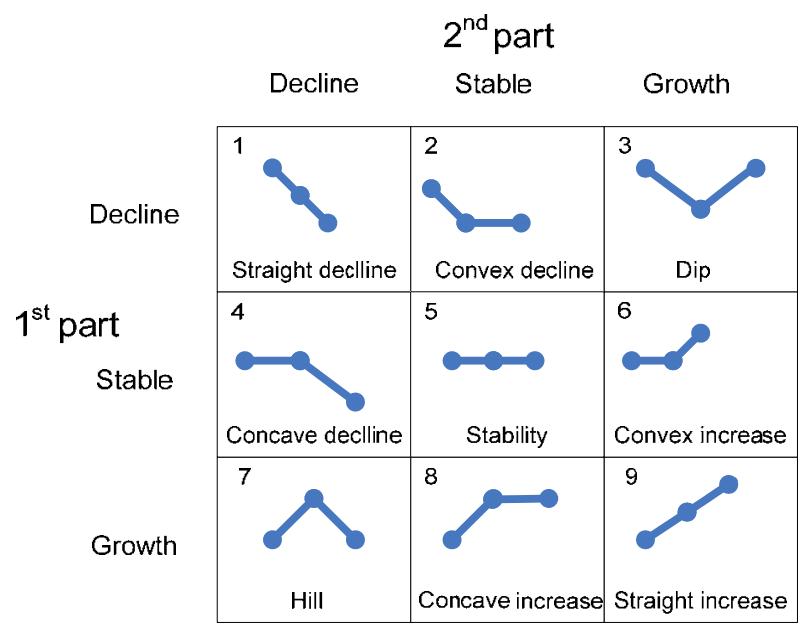

Most of the studies did not report significance tests to check whether changes from one time point to another were significant in the population. In the rare case that significance tests were conducted, we chose to ignore them and applied our own 'rules of thumb' in order to allow for cross-study comparison on pattern shapes. We have used the following rules of thumb: If the change between the first and the last measurement is less than $25 \%$ of the standard deviation ${ }^{24}$, we regarded the pattern as stable. If the pattern classification was ambiguous, we opted for the pattern shape that was the 'closest match'. We did not encounter truly arbitrary cases. Most of our cases could easily be classified. We then performed nonparametric tests (Chi-square and permutation tests) based on three trend categories (growth, stable, decline). Because the trend assessment was ambiguous for dip- and hill-shaped patterns (i.e. the absolute difference between Time 1 and Time $2>$ the absolute difference between Time 1 and Time 3), we discarded these particular shapes from the trend analysis.

\footnotetext{
${ }^{24} \mathrm{We}$ are aware that, conventionally, researchers opt for $1 \mathrm{SD}$ as critical value of deviation. However, 1 SD is only a viable heuristic for deviation of individual cases from the population mean. Adopting this rule would have led to the designation of 'stability' in studies where significant differences over time had been clearly demonstrated (e.g., Bauer et al., 1998; Allen et al., 2001; Van Maanen, 1975, to name a few). As it comes to temporal variation at the level of the population (which is naturally far more 'resistant' to change) a critical value of $1 / 4 \mathrm{SD}$ is reasonable.
} 
For non-parametric tests on the prevalence of declining, growing, and stable trends we set the minimum requirement to 6 studies per cell as there were only 3 cells.

The 'nanogram' was also used as input for an analysis on the prevalence of linearity in pattern shapes. Straight decline (nr. 1), stable (nr. 5), and straight increase (nr. 9) were considered linear, while the other patterns (nr. 2, 3, 4, 6, 7, and 8) were considered non-linear. Prevalence was analyzed using non-parametric tests, as described above. The minimum number of studies was set to 9, conform our argumentation described earlier.

\section{Results}

When describing observations in short-term and long-term time frames we will first discuss the most basic property of dynamic data, which is the pattern's trend (i.e. decline, stability, or growth). Then we will explore the prevalence of pattern shapes according to the nanogram, depicted in Figure 3.3. Both trend and pattern shapes are discussed based on frequency of their occurrence. In our tables we only mentioned those shapes that actually occurred. Finally, we will discuss the prevalence of linearity in pattern shapes.

\subsection{General trend}

Table 3.5 shows that - across all studies - there is no typical trend. The permutation probability of the grand total is only marginally significant $(p<.10)$. That is, declining or stable trends do not significantly occur more often than growing trends. However, if we determine observed trends for each of the phases in the commitment life cycle, trends differ substantially: there is no typical trend during ascendance, but stable trends are typical during subsistence and declining trends are typical during the descendance phase. An even more refined picture emerges when patterns are grouped by the length of the study's time frame. That is, long-term time frames are more likely to reveal 'typical' (prevalent) trends then short-term time frames. Long-term trends during ascendance are generally - although not significantly - declining, while long-term trends during subsistence are typically stable. 
Table 3.5 Prevalence of dynamic trends between life cycle phases

\begin{tabular}{|c|c|c|c|c|c|}
\hline Phase & Decline & Stability & Growth & $\chi^{2}(\mathrm{k}=3)$ & $\begin{array}{l}\text { Permutation } \\
\text { test } \\
\text { probability }\end{array}$ \\
\hline Ascendance total $^{1}$ & 9 & 5 & 2 & 4.63 & .07 \\
\hline - short-term & 3 & 2 & 1 & 1.00 & .49 \\
\hline - long-term ${ }^{1}$ & 6 & 3 & 1 & 3.80 & .09 \\
\hline Subsistence total & 3 & 10 & 1 & $9.57 * *$ & .01 \\
\hline - short-term & 2 & 3 & 0 & N too low & N too low \\
\hline - long-term & 1 & 7 & 1 & $8.00^{*}$ & .01 \\
\hline Descendance $^{2}$ & 6 & 0 & 0 & $12.00 * *$ & .00 \\
\hline Grand total & 12 & 14 & 4 & 5.6 & .02 \\
\hline \multicolumn{6}{|c|}{$\begin{array}{l}*=\text { significant at } p<.05 \text { level. } * *=\text { significant at } p<.01 \text { level } \\
1=\text { Two dip-shaped patterns were discarded from this analysis } \\
2=\text { We counted } 6 \text { studies indicating a decline in commitment around the moment of exit. We only had access to } \\
1 \text { study in which the data shows this decline in the 'leaver' group. In } 5 \text { studies, we only had access to the grand } \\
\text { mean development of OC which did not distinguish leaver patterns. However, in these studies declining 'leaver' } \\
\text { patterns could be inferred from the description of the analyses. For example, the study by Kammeyer-Mueller et } \\
\text { al. (2005) clearly depicts declining exit patterns as opposed to stable stayer patterns in a figure with } \\
\text { standardized scores. The fact that OC declines in the descendance phase can be inferred from these types of } \\
\text { descriptions. }\end{array}$} \\
\hline
\end{tabular}

\subsection{Early commitment development}

The life cycle model of time distinguishes two defining moments in the early commitment phase, namely: engaging and entering. Before the moment of engaging one aspires organizational membership and applies for the job, while after engaging one agrees to accept organizational membership. The question is how OC typically develops after the moment of engaging, but before the moment of entering the organization.

There are a couple of studies, like the one by Lee et al. (1992) who investigate commitment propensity prior to entering the firm, however these studies have not measured commitment propensity three times or more. The closest approximation is the study by Bauer et al. (1998), who used three repeated measurements, which reveals rising levels of 'organizational attractiveness' just after passing the employment test. This study shows that scores rise significantly between Time 2 and Time 3 among applicants who have passed the application test $(T=3,77 ; p<.01)$, while scores remain constant among those who failed the test. If - for the time being - we take organizational attractiveness as a crude proxy for commitment during this period, the study by Bauer et al. (1998) indicates that organizational attractiveness increases prior to entry. Figure 3.4 illustrates the impact of passing the application test on subsequent levels of organizational attractiveness (growth in anticipation of employment) compared to failing (disappointment and subsequent commitment decay). 
Figure 3.4 Organizational attractiveness after passing the employment test

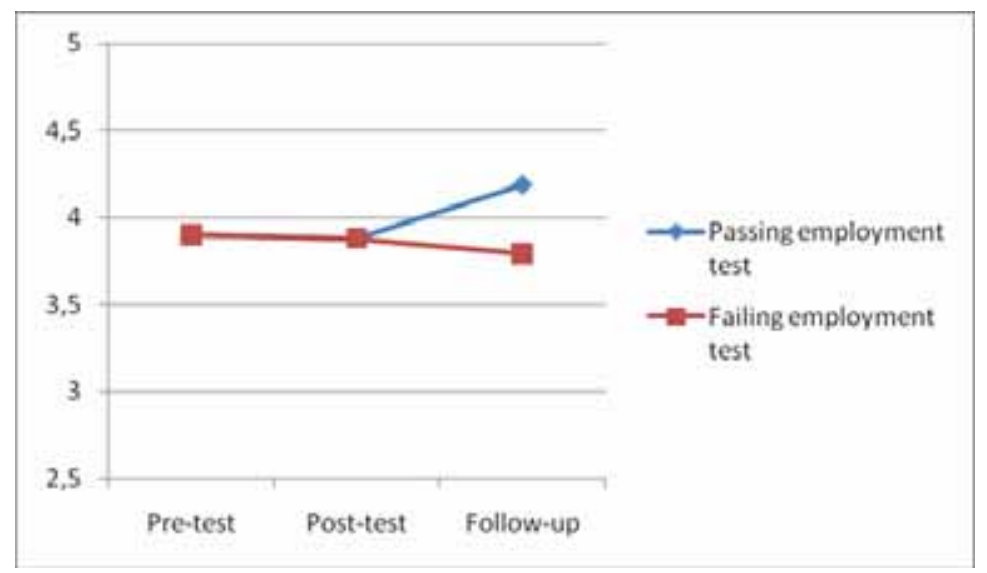

A study by Meglino et al. (1988) can be placed just after the moment of engaging, but before the moment of entering. After the moment of engaging, OC levels appear to be highly susceptible to external influence as dampening of expectations by organizational agents prior to entering has substantial impact on commitment dynamics. This is demonstrated by Meglino et al. (1988) who showed drastically declining levels of OC as a function of 'realistic job previews' prior to entering.

\subsection{Commitment patterns after entering the organization}

We have found 6 studies on the temporal development of OC over short-term and 12 studies with a long-term time span. Their OC levels and standard deviations can be found in Appendix I. The general picture is that initial levels are high, although there is quite some variation. After starting off high, entrants' OC remains stable or declines, but never rises. Figure 3.5 depicts all short-and long-term trajectories which displayed a decline. The proportion of declining patterns across many different professions, samples and nationalities is remarkable. However, Table 3.5 shows that declining trends are not significantly more prevalent in any time frame. This could be due to the low number of observations (i.e., $\mathrm{N}=6$ in short-term and $\mathrm{N}=12$ in long-term time frames).

In Table 3.6 we have counted dynamic OC shapes as observed in 6 short-term and 12 long-term studies. We numbered the shapes according to the nine-pattern typology (see Figure 3.3) and named them accordingly. The studies by Lee et al. (1992) and Van Maanen (1975) have been counted twice because they both qualified as short-term and long-term. 
Among the pattern shapes, the convex decline is most prevalent, given its score of 2 occurrences (see Table 3.6). Thus, if decreases were observed, they are especially steep at the beginning (i.e., the first part of the pattern). We cannot draw any conclusions on patterns shapes, given the insignificant chi-square value. Thus, if commitment declines on the long run, this decline comes in many forms.

If $\mathrm{OC}$ declines on the long-term, this puts the observation of stability in short-term time frames in a different perspective. For example, the observation of short-term stability (found in 2 studies) may end up in a 'convex decline' on the long-term term ( 2 observations as well). There are interesting exceptions. For example, convex decreases on the short-term and stable OC on the long-term were also observed in the study by Van Maanen (1975).

Figure 3.5 Declining mean trajectories after entering the organization

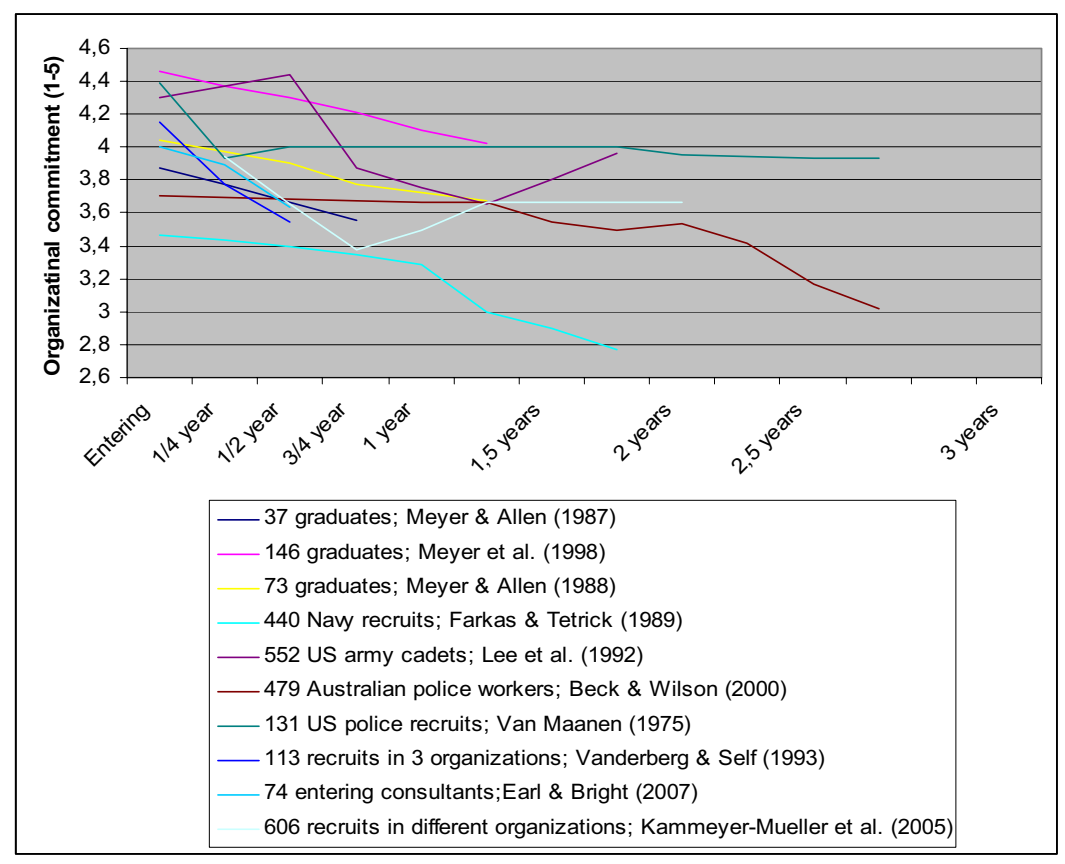




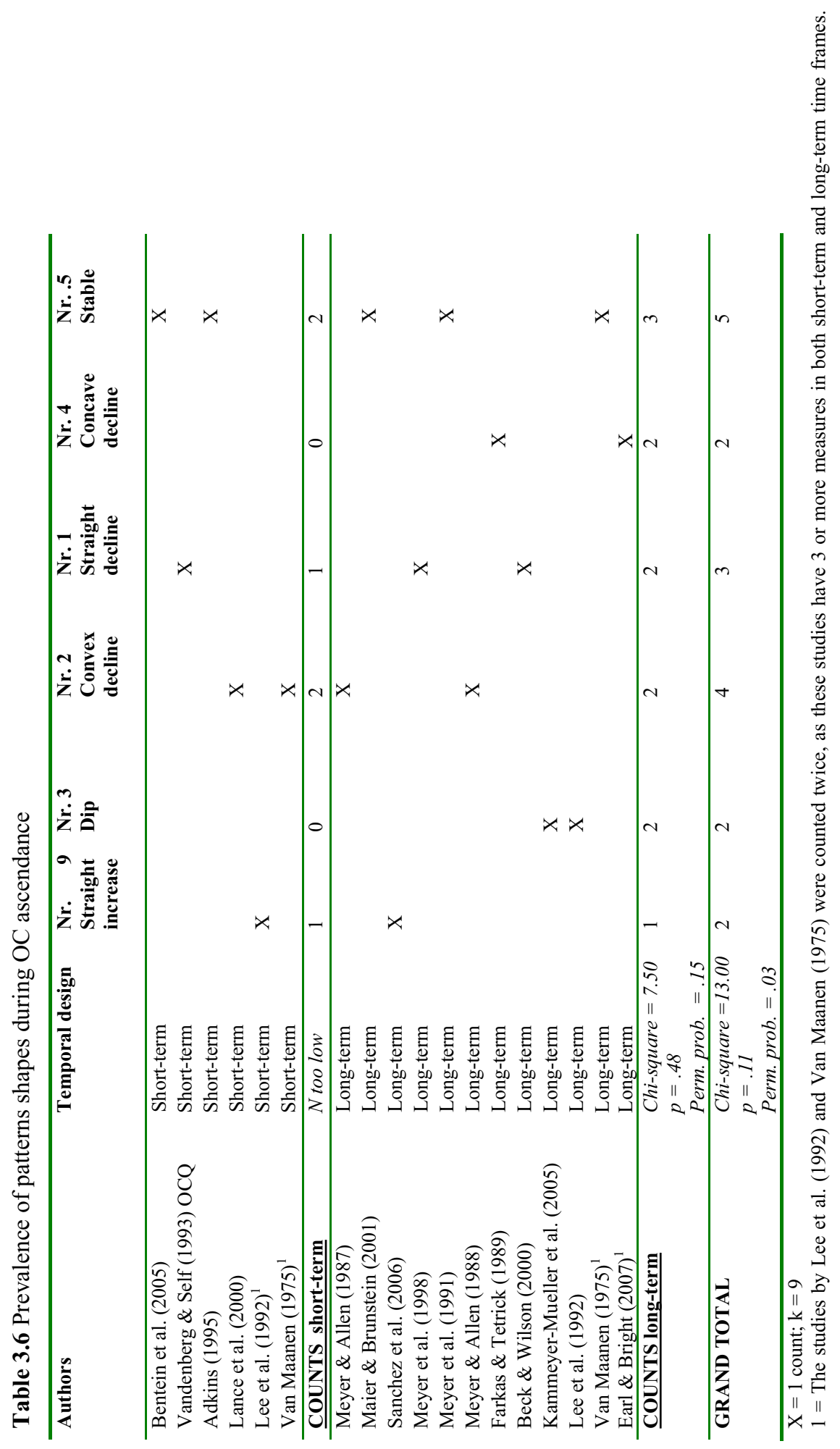




\subsection{Commitment patterns during the subsistence phase}

The general impression is that commitment during subsistence tends to remain stable over longer time spans (see Table 3.5), even under conditions of organizational upheaval. Values tend to decrease on the short-term in response to incisive corporate reforms, but tend to return to initial values on the long-term.

Not surprisingly, most of the studies on the subsistence phase dealt with employee reactions to various forms of organizational change interventions. We have distinguished the type of intervention by the labels 'soft' (benevolent) and 'hard' (incisive). Among the soft interventions are the following studies: Total Quality Management implementation (CoyleShapiro, 1999), the launch of a new HRM program (Hailey et al., 2005), work hour changes (Pierce \& Dunham, 1987), and promotion decisions (Ambrose \& Cropanzano, 2003). Among the 'hard' interventions are organizational downsizing (Allen, Freeman, Russell, Reizenstein, \& Rentz, 2001; Armstrong-Stassen, 2006), corporate acquisitions (Schweiger \& Denisi, 1991; Schweiger \& Goulet, 2005), drastic role transitions (Thompson \& Van-de-Ven, 2002), or various combinations of other organizational reforms (Schalk \& Freese, 2000).

Differences between reactions to soft interventions as opposed to hard interventions are pronounced. OC patterns in reaction to soft interventions (Table 3.7) are either stable (3 observations in total), or increasing (1 observation), but never declining. In contrast, the general direction during hard interventions was either declining ( 2 observations), stable (5 observations), or dip-shaped (2 observations, Table 3.8), but we never observe growth.

Table 3.7 Commitment dynamics in response to soft interventions

\begin{tabular}{|c|c|c|c|}
\hline Authors and type of inventions & Time frame & $\begin{array}{l}\text { Nr. } 6 \\
\text { Convex } \\
\text { Increase }\end{array}$ & $\begin{array}{l}\text { Nr. } 5 \\
\text { Stable }\end{array}$ \\
\hline Dunham et al. (1987) - Work hour changes & Short-term & & $\mathrm{X}$ \\
\hline Coyle-Shapiro (1999) - TQM implementation & Long-term & & $\mathrm{X}$ \\
\hline Hailey et al. (2005) - HRM program implementation & Long-term & $\mathrm{X}$ & \\
\hline $\begin{array}{l}\text { Ambrose \& Cropanzano (2003) - Academic tenure } \\
\text { allocations }\end{array}$ & Long-term & & $\mathrm{X}$ \\
\hline Total long-term & N too low & 1 & 3 \\
\hline
\end{tabular}


Table 3.8 Commitment dynamics in response to hard interventions during subsistence

\begin{tabular}{|c|c|c|c|c|}
\hline Authors and intervention type & & Nr. 2 & Nr. 5 & Nr. 3 \\
\hline $\begin{array}{l}\text { Schweiger \& Denisi (1991)- Corporate } \\
\text { acquisition }\end{array}$ & Short-term & $\mathrm{X}$ & & \\
\hline $\begin{array}{l}\text { Kramer et al. (2004) - Corporate } \\
\text { acquisition }\end{array}$ & Short-term & & $\mathrm{X}$ & \\
\hline $\begin{array}{l}\text { Schalk \& Freese (2000) }- \text { various } \\
\text { incisive reforms in } 3 \text { firms }\end{array}$ & Short-term & & $\mathrm{X}$ & \\
\hline $\begin{array}{l}\text { Schweiger \& Goulet (2005) - Corporate } \\
\text { acquisition }\end{array}$ & Short-term & $\mathrm{X}$ & & \\
\hline Total short-term & N too low & 2 & 2 & 0 \\
\hline $\begin{array}{l}\text { Tisak \& Tisak (2000) - army mission to } \\
\text { Sinai }\end{array}$ & Long-term & & $\mathrm{X}$ & \\
\hline Grunberg et al.(2008) - Downsizing & Long-term & & & $\mathrm{X}$ \\
\hline Allen et al. (2001) - Downsizing & Long-term & & & $\mathrm{X}$ \\
\hline Armstrong-Stassen (2002)- Downsizing & Long-term & & $\mathrm{X}$ & \\
\hline $\begin{array}{l}\text { Thompson \& Van de Ven (2002) - } \\
\text { Drastic involuntary role transitions }\end{array}$ & Long-term & & $\mathrm{X}$ & \\
\hline Total long-term & N too low & 0 & 3 & 2 \\
\hline GRAND TOTAL & $\begin{array}{l}\text { Chi-square }= \\
24.00 \\
p<.01 \\
\text { Perm. prob. }= \\
.001(p<.01) \\
k=9\end{array}$ & 2 & 5 & 2 \\
\hline
\end{tabular}

Commitment patterns during 'normal' times

Unfortunately, we only found three studies which did not explicitly focus on organizational upheaval. Nevertheless, we see that stable as well as straight declining patterns can occur in the absence of organizational interventions; see Table 3.9. Interestingly, tenured incumbents showed quite a steep straight decline in the study by Beck \& Wilson (2000). The other studies display a stable mean trend. Thus, we observe that declining trends are not necessarily signs of responses to extreme organizational restructuring. 'Business as usual' can be marked by stable as well as declining trends. What a 'natural' aggregate pattern is remains therefore as yet unkown.

Table 3.9 Commitment dynamics during 'normal times'.

\begin{tabular}{|c|c|c|c|}
\hline Authors & Time frame & $\begin{array}{l}\text { Nr. } 9 \\
\text { Straight } \\
\text { Decline }\end{array}$ & $\begin{array}{l}\text { Nr. } 5 \\
\text { Stable }\end{array}$ \\
\hline $\begin{array}{l}\text { Beck \& Wilson (2000) - } 479 \text { Australian police officer } \\
\text { incumbents in various tenure cohorts }\end{array}$ & Long-term & $\mathrm{X}$ & \\
\hline $\begin{array}{l}\text { Cohen \& Freund }(2005)-122 \text { Israeli managers in a } \\
\text { National not-for-profit organization. }\end{array}$ & Long-term & & $\mathrm{X}$ \\
\hline $\begin{array}{l}\text { Roe et al. (1997) - } 368 \text { Bulgarian, Hungarian, and Dutch } \\
\text { employees in various firms with varying tenure }\end{array}$ & Long-term & & $\mathrm{X}$ \\
\hline Total long-term & N too low & 1 & 2 \\
\hline
\end{tabular}




\subsection{OC dynamics during its descendance}

We have found 6 studies dealing with OC trends prior to exiting (Lee et al., 1992; Kammeyer-Mueller et al., 2005; Porter et al., 1976; Farkas \& Tetrick, 1989; Cohen \& Freund, 2005; Bentein et al., 2005). We only had access to 1 study in which the data shows this decline, which is the study by Porter et al. (1976). In 5 studies, we only have access to the grand mean development of OC which did not distinguish 'leaver' patterns. In these studies this decline could be inferred from the description of the analyses. For example, the study by Kammeyer-Mueller et al. (2005) clearly depicts declining exit patterns as opposed to stable 'stayer' patterns.

Common in the 6 studies is that leavers display a markedly different pattern, compared to stayers. That is, stayers tend to remain stable, while leavers decline before the moment of exit. How leaver patterns differ from stayer patterns could not be analyzed, as information on the shape lacked or patterns were specified as linear.

With only one observation we cannot draw any conclusions on the typical shape of the decline. In this particular case, the shape was a straight decline. Figure 3.6 depicts differences between stayer and leaver patterns. It shows that OC rapidly declines among leavers, even 6 months before exit.

Figure 3.6 Declining patterns of leavers compared to stayers

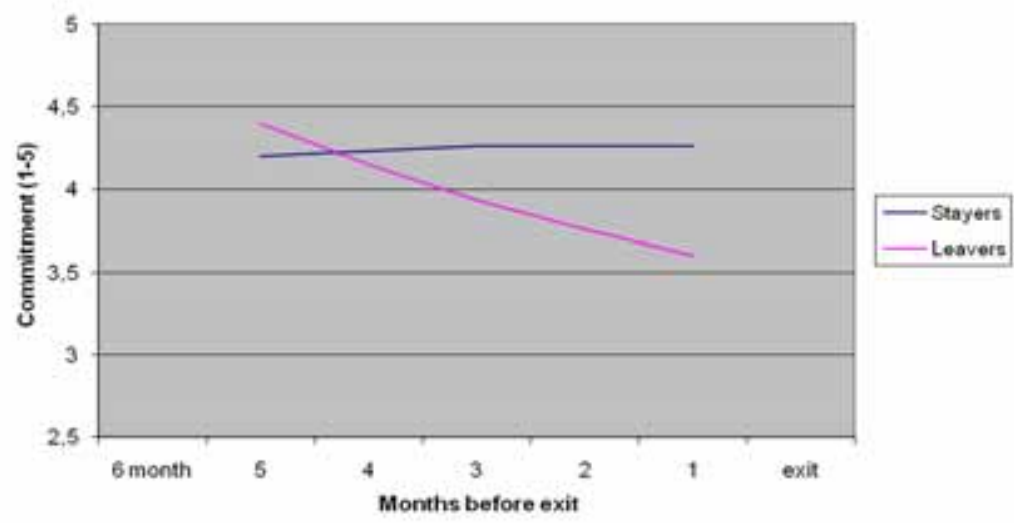

The moment of disengagement

According to the life cycle model of behavioral phenomena, every phenomenon has a finite existence and is therefore subject to eventual 
disappearance. In the case of organizational commitment this means that the process of OC descendance must start at some point in time, because all employment relationships must end at some point. When the moment of disengagement occurs - signaling the start of the descendance process - is difficult to pinpoint. For a start, one must make a clear distinction between OC decline and OC descendance. Decline can occur in any phase of the life cycle and can have any causal explanation. Descendance is a special form of decline as it is inextricably linked to the approaching end of the phenomenon's existence. Theoretically, one would expect that if individuals are free to stay or go, the moment of decline in OC starts when the incumbent has decided to leave the firm. At this particular point in time mere thoughts and 'day-dreams' have become concrete intentions (i.e., quit decisions). Once the choice to leave has been made, a process of de-identification starts, which paves the path for exit and decline (Ashforth, 2001; Brickman, 1987; Ebaugh, 1988).

There is quite some evidence that the pathway to leaving is marked by growing intentions to leave the organization (Cohen \& Freund, 2005; Kammeyer-Mueller, 2005; Bentein et al., 2005). This suggests that gradually growing dissatisfaction with the job, gradually declining OC, and growing intentions to quit lead to the decision to leave the firm and eventual departure ${ }^{25}$. But this is not the only thinkable pathway leading to departure. The 'unfolding model of turnover' (Lee \& Mitchell, 1994) specifies several scenarios that can lead up to it, like having attractive job alternatives (pull decisions), and critical events that function as 'shocks to the system' (push decisions). The model also specifies psychological mechanisms that explain how these factors lead to the decision to leave the firm among some people, but not among others. Another line of research is the literature on role exit (Ashforth, 2001; Ebaugh, 1988) where the decision to leave the role is typically preceded by a critical event.

Thus, there can be multiple pathways leading to turnover and not all of the pathways are directly related to OC. In fact, changes in job attitudes are able to explain only a small proportion of why people leave an organization. The largest proportion of reasons to leave come from off-the-job factors (Mitchell, Holtom, Lee, Sablynski, \& Erez, 2001). This line of research indicates that the perspective that commitment decline leads to turnover decisions is limited. The moment of disengagement can also be seen as the moment where the anticipation of exiting the firm starts to have an effect on commitment dynamics.

\footnotetext{
${ }^{25}$ Pinpointing the moment of disengagement from gradual attitudinal increases and decreases assumes a certain 'threshold value' which - once exceeded - marks a definite decision leaves the company.
} 


\subsection{Linearity in commitment patterns}

Next to studying shape (nine pattern shapes), the 'nanogram' allows another possibility for studying aspects of dynamic form, which is an analysis of linearity. Straight decline (nr. 1), stable (nr. 5), and straight increase (nr. 9) can be seen as linear, while the others (nr. 2, 3, 4, 6, 7, and 8) are non-linear. In Table 3.10 the results of this analysis are shown. Statistically, linearity was not found to be more prevalent than non-linearity in any of the phases. However, the grand total indicates that linear dynamic forms occurred more often than nonlinear forms. The fact that this did not translate into significant results may have to do with the small sample size. All in all, the results to do allow conclusions on the nature of commitment development with respect to linearity.

Table 3.10 Linearity in the three phases of the commitment life cycle

\begin{tabular}{|c|c|c|c|c|}
\hline Phase & Linearity & $\begin{array}{l}\text { Non- } \\
\text { Linearity }\end{array}$ & $\chi^{2}(\mathrm{k}=2)$ & $\begin{array}{l}\text { Permutation } \\
\text { probability }\end{array}$ \\
\hline Ascendance total & 10 & 8 & .22 & .33 \\
\hline - short-term & 4 & 2 & .67 & .47 \\
\hline - long-term & 6 & 6 & .00 & .23 \\
\hline Subsistence total & 11 & 5 & 2.25 & .13 \\
\hline - $\quad$ Hard interventions total & 5 & 4 & .11 & .49 \\
\hline Short-term & 2 & 2 & N too low & N too low \\
\hline Long-term & 3 & 2 & N too low & N too low \\
\hline - $\quad$ Soft interventions total & 3 & 1 & N too low & N too low \\
\hline Short-term & 1 & 0 & N too low & N too low \\
\hline Long-term & 2 & 1 & N too low & N too low \\
\hline - $\quad$ Normal times (long-term) & 2 & 1 & N too low & N too low \\
\hline Descendance total & 1 & 0 & N too low & N too low \\
\hline GRAND TOTAL & 21 & 13 & 1.89 & .11 \\
\hline
\end{tabular}

Note: The studies by Lee et al. (1992) and Van Maanen (1975) were counted twice in the analysis of ascendance as they qualified as both short-term and long-term. The research by Beck \& Wilson (2000) qualified as both an ascendance and subsistence study in our analysis.

Note: Findings are not significant

\section{Discussion}

\subsection{Reflection}

What do we learn from the literature on OC about the 'temporal nature' of OC? Starting with the most simple description of dynamics - stable or unstable - we soon realize that there is no simple 'either-or' answer. As a general note, stability as well as instability occur and general conclusions across all studies cannot be drawn. Whether we observe stability seems contingent upon the phase in the life cycle as instability prevails during ascendance and descendance, and stability during subsistence. We have also demonstrated that temporal 
instability can occasionally occur as a response to organizational events. Temporal invariance on the population level of analysis can, thus, only be assumed under very strict conditions, as it was only encountered in the subsistence phase at the population level of analysis (aggregate mean).

Although not 'proven' statistically, a counter-intuitive finding is that commitment during ascendance tends to decline over time. This is surprising because - reasoning from the life-cycle model - one would expect generally growing OC trends during the ascendance phase. The dominant explanation is that commitment starts off with inflated expectations (Griffeth \& Hom, 2001; Lance, Vandenberg, \& Self, 2000) and emotions of excitement which have led scholars to use the metaphor of a 'honeymoon' period (Boswell, Tichy, \& Boudreau, 2005; Chang \& Choi, 2007). Inflated expectations can only lead to disappointment and 'reality-shock' in the first year on the job, which the same scholars have more aptly called a 'hangover' period (Boswell, Tichy, \& Boudreau, 2005; Louis, 1980). The fact that we found (however mixed) evidence for the 'hangover-effect' across studies may indicate that declining OC could be a natural part of the ascendance phase in OC development. This was noted by Boswell and colleagues (Boswell, Tichy, \& Boudreau, 2005) who argued that hangover periods in fact 'sober' individuals and bring their OC levels back to the ones people had in the previous organization.

Another surprising finding is that even under drastic organizational upheaval mean levels of OC generally remain stable. In fact, stable patterns are - by far - most prevalent during times of organizational upheaval. We should, however, interpret observed stable patterns with caution as we have taken the grand mean as our unit of analysis. The grand mean may give the false impression that people were just 'passing through' the intervention, unaffected by it. But in reality there can be pronounced increasing, decreasing, and stable groups that are cancelled out against each other on the population level. This was found in two of the studies that we identified as 'stable' (Armstrong-Stassen, 2002; Thompson \& Van de Ven, 2002). Thus, although mean levels of a population under organizational upheaval suggest stability, the 'ordinal configuration' (i.e., the person who previously had the highest commitment may now have the lowest commitment, while the person with the lowest commitment now has the highest commitment) may have changed dramatically between measurement occasions. Population-level stability can mask a considerable amount of individual- or group-level instability over time (Li, 2009b).

Looking at pattern shapes, there were some that emerged as 'typical'. The best example is the convex decrease in short-term studies and the dip-shaped pattern in long-term 
studies in response to hard interventions. That is, during drastic organizational upheaval, OC typically declines rapidly on the short-term. On the long-term OC levels tend to return back toward initial levels, although this process this can take up to 7 years. On the one hand one could argue that time does seem to 'ease the pain' caused by hard interventions, but one needs to have quite a lot of patience for OC to return to initial levels. On the other hand one could say that OC increase at the level of the population is not necessarily a within-person increase. The increase could also be a result of selection and attrition effects (e.g., the organization started hiring new personnel with high levels of commitment, and low committed people left).

During ascendance the picture is more diversified. The typical decline during ascendance comes in many forms. The convex decline is most prevalent, but hard conclusions cannot be drawn. The studies by Lee et al., (1992) and Van Maanen (1975) are very instructive in understanding the 'art' of combining time frames and interpreting their meaning. For example, in the study by Lee et al., (1992) we observe a straight increase on the short-term, and dip-shaped on the long term. However, the initial growth of OC in the first six months is unlikely to be explained by the same phenomenon as the observed growth after 18 months. While the initial growth can be explained from the possible excitement of working for the US army and adopting a new social identity, long-term growth is more likely due to selective attrition (i.e., the ones with low commitment left the organization after 6 or 18 months). This explanation is consistent with the finding that the incidence of turnover was explained by low individual OC levels.

Alternative explanations of change discussed above provide interesting insights in the nature of OC change. This analysis shows that dynamics in the aggregate mean are not necessarily explained by the same mechanisms compared to dynamics at the individual level of analysis. Aggregate mean developments are likely to be explained by demographic sample effects, while individual-level effects are more likely to be explained by affective and motivational reactions to organizational events. The study of change in phenomena in levels of analysis other than the ones at which change 'naturally' occurs will always lead to some distortion in the validity of the findings. In chapter 1, we have argued that the most valid unit of analysis to study commitment change is the individual level. Perhaps an individual-level perspective on commitment change will result in substantially different - and more valid conclusions on the prevalence of pattern shapes.

It should be noted that we disregarded the methodological problem of scale recalibration (beta change) and concept redefinition (gamma change) over time 
(Golembiewski et al., 1976). The possibility of beta and gamma change is especially problematic in the phase of ascendance (Vandenberg \& Self, 1993; Lance, Vandenberg \& Self, 2000). Vandenberg \& Self (1993) argue that a commitment in the initial stages of ascendance may be of a qualitatively different nature than a commitment 6 months after entering the organization. At the start employees may have naïve expectations, which are corrected 6 months after entry. This correction has impact on how they fill out questionnaires - hence the problem of gamma change.

There were only two studies in our sample which contained an empirical analysis of beta and gamma change during the ascendance phase (Lance et al., 2000; Vandenberg \& Self, 1993). We chose not to include measures showing beta or gamma change because the chance of beta/gamma change is just as high in studies where these longitudinal contaminations were not analyzed. The only thing we can do in the context of this study is to acknowledge that the problem of beta and gamma change may have occurred. It could serve as an alternative explanation for the observed decreases during the ascendance phase. The generally observed decline is then a function of the transition from a 'naïve' commitment to a 'street-wise' type of commitment. The first form of commitment is mainly expectation-based, while the second form is mainly experience-based.

\subsection{Limitations}

A shortcoming of our analysis of OC development in the subsistence phase is that we only found three studies investigating 'typical' commitment patterns during the 'normal' state of affairs. In other words, we do not have studies investigating 'business as usual' during the subsistence phase. In addition, we only have 2 cases where the intervention initiative was implemented specifically to increase worker morale. Thus, it is possible that the general impression we get from the current set of studies is a distorted one. We hope future researchers will do more longitudinal research during the normal state of affairs as well as during change efforts intended to enhance appreciation, collaboration and meaningfulness of work. These kinds of change initiatives are more likely to lead to growing commitment trends.

Second, the combination of a low number of studies (34 in total), stratified in heterogeneous research settings (e.g., three life cycle phases, all divided in long-term versus short-term designs, plus three sub-divisions within the subsistence phase) with a high number of potential pattern shapes (i.e., 9 patterns in the "nanogram) did not allow for rigorous testing 
of the prevalence of pattern shapes. To circumvent this lack of power future studies could combine observed patterns of organizational commitment with patterns of other attitudinal phenomena, such as job satisfaction or work engagement. Regardless of the tentative nature of our findings, this study shows that it is possible to perform a non-parametric test in a comparative literature review setting.

A third limitation is that our rules of thumb for classifying patterns in categories of dynamic shape (trend, nanogram, and linearity vs. non-linearity) are arbitrary. For example, our choice for a critical value of $1 / 4 \mathrm{SD}$ could be replaced by a more stringent (e.g. $1 \mathrm{SD}$ ) or a more lenient rule of thumb (e.g. 1/6 SD). This would change our findings to some extent, but not dramatically. The prevalence of stable patterns would increase with the degree of 'rigor' applied in the rules of thumb. That is, with the rule of 1 SD stable patterns would have been regarded as more prevalent. However, $1 \mathrm{SD}$ is only a viable heuristic for deviation of individual cases from the population mean. Adopting this rule would have led to the designation of 'stability' in studies where significant differences over time had been clearly demonstrated (e.g., Bauer et al., 1998; Allen et al., 2001; Van Maanen, 1975, to name a few). As it comes to temporal variation at the level of the population (which is naturally far more 'resistant' to change) a critical value of $1 / 4 \mathrm{SD}$ is reasonable.

\subsection{Research implications}

In this study we have approached existing literature on $\mathrm{OC}$ from a temporal point of view. That is, we have approached $\mathrm{OC}$ as a phenomenon which unfolds over time, characterized by temporal properties, like finite existence, ascendance, subsistence, descendance, and dynamics. This sharply contrasts with the dominant perspective where OC is treated as a temporally invariant attribute (a cross-sectional 'variable') which is then causally related to other constructs (i.e., the 'variance' perspective; Van de Ven, 2007; Roe, 2008a). The number of studies on OC which have treated OC as a temporally invariant 'variable', related to antecedent and consequent variables in cross-sectional research designs is estimated around 96\% (Roe, 2008b). Such studies implicitly rely on the assumption of stationarity over time (Borsboom, Mellenbergh, \& van Heerden, 2003; Jaccard \& Dittus, 1990; Molenaar, 2004; Molenaar \& Campbell, 2009; Molenaar, Huizinga, \& Nesselroade, 2003).

Our findings show that the assumption of stationarity - at the population-level - is certainly not warranted during ascendance and descendance. Additionally, even though we have mainly encountered stable trajectories in the subsistence phase, the observed stability is 
based on mean trajectories, which leaves room for a considerable amount of individual-level and cluster-level temporal variability which is simply cancelled out against each other to form a 'stable' mean (Li, 2009b; Thompson \& Van-de-Ven, 2002).

Another contribution of the temporal perspective is that it opens a vast array of new research directions in all phases of the OC life cycle. For example, regarding the period of ascendance many questions have remained unanswered: when does 'engagement' happen? How fast does OC increase? When does the ascendance phase end? And so forth. Especially in the phase of descendance, the temporal perspective can be of great aid as turnover has been the major behavior of interest among scholars studying OC (Hom, Griffeth, \& Gaertner, 2000; Roe, Solinger, \& Van Olffen, 2009). The life cycle perspective sheds an additional light on extant literature on the relationship between OC and turnover. The dominant perspective is that low $\mathrm{OC}$ or decreases in $\mathrm{OC}$ lead to unwanted turnover. From this perspective one should prevent $\mathrm{OC}$ from falling to prevent unwanted turnover. However, this is quite a one-sided approach as the anticipation of leaving the firm may provide equally valid explanations for declining commitment. Thus, depending on what perspective we take, OC decline around the moment of exiting the firm can be seen as 'unwanted' or 'natural'. Whether we are talking about unwanted OC decrease or OC descendance depends on whether we are looking before or after the moment of disengaging. We think it is the moment of disengaging that should direct the greatest research attention in future turnover research. This approach connects to research lines already present, like the literature on role exit (Ebaugh, 1988; Ashforth, 2001) and the 'unfolding model of turnover' (Mitchell et al., 2001).

Reframing these findings in terms of the life cycle paradigm leads to a host of new questions which are still open for testing. For example, one could hypothesize that among employees with low initial commitment, decline will start sooner, the rate of decline will be faster and the moment of disappearance (zero level) will be reached earlier. Some studies on organizational exit report high levels of heterogeneity regarding the dynamics of commitment before exit (e.g., Porter, Crampon, \& Smith, 1976), which may indicate great differences in temporal dynamics prior to leaving. Identification of subgroups or clusters based on descendance trajectories may provide more insight. To our knowledge, there is no research on developmental OC patterns during the descendance process stretching out for a sufficient period of time to test these kinds of hypotheses. 


\subsection{Implications for practice}

A temporal perspective on OC has many practical implications as it deals with the question when managerial action is especially needed. Moreover, knowledge on OC dynamics leads to insight on how employees react to interventions, how long it takes them to recover, and how managerial action can make a difference. Useful research questions to practice are: What does the rate of change depend on? How can the drastic drop in OC after entry be prevented? Is prevention needed?

The finding that $\mathrm{OC}$ is generally a dynamic phenomenon and susceptible to influence is good news to practitioners as management rhetoric is often filled with calls for enhancing employee commitment. However, our pool of studies has indicated that raising employee commitment is hard, as increases are rare and short-lived. A more workable question is when OC can best be raised. Enhancing OC seems most easy at early ascendance, just before entry. However, we do not recommend this practice as it may lead to more severe disappointments later on. Whether the general decline in OC up to one year after organizational entry can be prevented is unsure. There is a large body of literature on the 'realistic job preview' which indeed suggests that realistic job previews prevent drastic declines in OC and seem to decrease the chance of turnover (Griffeth \& Hom, 2001; Meglino, Ravlin, \& DeNisi, 2000)

We have also observed that management efforts can make quite a difference in dynamic OC responses to events. Quasi-experimental studies by Schweiger and colleagues (Schweiger \& Denisi, 1991; Schweiger \& Goulet, 2005) have indeed confirmed that appropriate managerial action during corporate acquisition can make a difference - even on a short-term basis. They clearly demonstrated that periodically receiving information from the CEO reversed the sharp initial decrease to finally end up with a stable trajectory (Schweiger \& Denisi, 1991). This contrasted with the control condition, a plant which did not receive any communication from the CEO, and showed continuous decline over time. Similarly, receiving cultural-learning training during a corporate acquisition helped to bend a declining into a growing trend (Schweiger \& Goulet, 2005). This contrasted against two control plants: a plant receiving no cultural learning training (showing a modest 'maturation effect' in the form of an 'elbow' in the second part of the study), and a plant who only received 'surfacelevel cultural learning, which revealed a steep decline across the entire time frame of the study. The authors argue that it is not the content of the managerial action, but the symbolic value it entails which makes the difference. The symbolic value of receiving communication or training is that it makes employees feel heard, appreciated, and cared for. Despite the 
observation that it is indeed possible to enhance commitment, we should keep in mind that OC recovery after hard interventions also happens without managerial action (a 'maturation effect' see e.g., Allen et al., 2001; Schweiger \& Goulet, 2005). The expected effect of appropriate managerial action may be that it reverses the decline sooner. We should also keep in mind that $\mathrm{OC}$ recovery in the studies we observed can have a demographic explanation as well, as discussed before.

Considering the evidence from quasi-experiments, it does seem to be possible that observed rising average commitment levels are a result of managerial effort to raise commitment. But rising commitment trends are surprisingly rare. During ascendance and subsistence, growing OC occurs occasionally, but these increases are short-lived, usually following from initial decreases on the short-term. Is raising employee commitment really that hard? In the studies at hand, change efforts intended to enhance worker morale (e.g., TQM and HRM implementation programs) only resulted in marginal increases in OC. Growing OC is more likely encountered prior to the moment of entering the organization. The fact that is does grow was demonstrated by the rise in organizational attractiveness after the moment of engagement (Bauer et al., 1998).

On the other hand, the fact that we do not see many cases of growing trends in OC may reflect the types of research settings researchers typically opt for (e.g., the adverse impact of downsizing) rather than the difficulty of raising commitment (see Cameron, Dutton, \& Quinn, 2003, for an elaboration on Positive Organizational Scholarship). That is, had we observed a pool of studies where the dominant focus was on benevolent interventions aimed to improve worker conditions (i.e. 'soft' interventions) more increasing trends could have been observed.

Another possible explanation for the difficulty of raising commitment is that efforts to raise commitment are always path-dependent. If there are already many 'cracks' or 'faults' in employment relationship (e.g., low levels of trust due to repeated downsizing) there is no way an intervention could raise commitment (Roe, Solinger, \& Van Olffen, 2009). As a general note for practice, rather than trying to raise commitment we should find out how one can uphold high and stable patterns which could function as a basis for a healthy employment relationship. 'Decline prevention' may be a more realistic managerial rhetoric than 'enhancing commitment'. Considering the long period of time before restoration to initial levels naturally occurs (up to 7 years), preventing OC from falling seems more realistic than 'restoring' it or attempting to raise it. Making sure employees keep up the spirit is in itself quite an achievement. 


\section{LOCUST}

\section{A Longitudinal Occupational $\underline{\text { State }} \underline{\text { Tracker }}$}

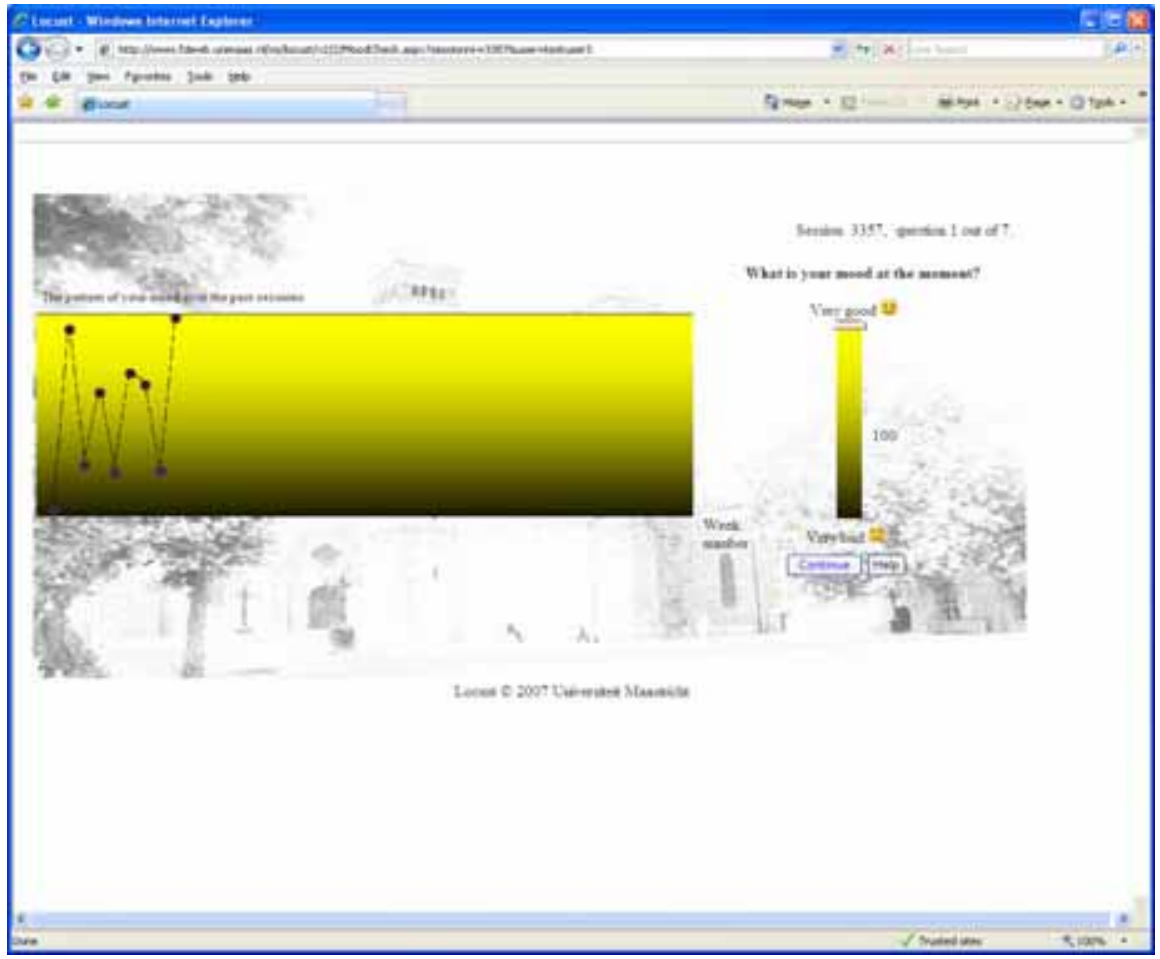




\title{
4 Real-time registering of history and attitude change in fine-grained and lengthy longitudinal designs:
}

\author{
The making of LOCUST
}

\begin{abstract}
Self-evaluation is inextricably tied to the study of human attitudes. Surprisingly, self-evaluation in the study attitude change over time is conspicuously absent. In this chapter we develop a measurement instrument which is designed to capture person-specific change in organizational commitment over time. To this end, fine-grained measurement and frequent re-use of the instrument with the same subjects is required. The instrument is called LOCUST - Longitudinal Occupational State Tracker. It reconciles conflicting interests of researchers and respondents and consistently focuses on creating reliable and valid temporal patterns of attitudes in work-place settings through repeated self-evaluation. Innovative features of the system are graphic trajectory registering (i.e., person-specific, historically tailored graphs of previous attitude measurements - the 'attitudogram' displayed to respondents to facilitate real-time, incremental trajectory scoring, and to allow for repeated trajectory confirmation or corrective retrospective adjustment), gamma change detection, a compact three-item operationalization of organizational commitment, non-intrusiveness, and an interactive user-interface. Using an internet-based and a paper-and-pencil format, the respective features were tested in 4 simulations with targetgroups in different temporal design contexts (i.e., 4, 12, 56, and 25 time moments, measured weekly or even twice a day). Results from these simulations are promising in terms of attrition rates, reliability and validity of measured patterns.
\end{abstract}




\section{Introduction}

A little less than 2000 years ago the apostle Paul asked the Corinthians the rhetorical question 'For what person perceives what passes through a man's thoughts except the man's own spirit within him?' (I Corinthians 2: 11, The Amplified Bible). This question has proven its value over the years as self-evaluation is one of the most widely adopted techniques in the study of human attitudes (Howard, 1994; Summers, 1969). The self-report survey is by far the most pervasive tool in the study of attitudinal phenomena in Organizational Behavior. We highly depend on self-evaluation because it is simply the best way to study operation of attitudes, motives, and dispositions and their relation to human behavior in organizations (Howard, 1994). Hence, we do not expect self-evaluation to disappear any time soon.

Nevertheless, self-evaluative surveys are also the most lamented and criticized tools known to applied psychological sciences. There is a long list of response tendencies and biases endangering the validity of self-evaluative surveys (Spector, 1994). Common response tendencies include yea-saying, central tendency, response leniency, and social desirability bias. The use of self-report surveys over time only exacerbates already existing response tendencies and adds several new problems: limited cooperation from the beginning, high and selective attrition, unreliable change, selective memory, recall bias, learning effects, and response-shift biases (Armenakis \& Bedeian, 1982; Howard \& Dailey, 1979; Lynn, Le Thi Cao, \& Horn, 1996; Menard, 2008; Sturgis, Allum, \& Brunton-Smith, 2009). Although there have been some attempts to avoid or compensate these weaknesses - like the use of diaries, pagers, reflective measures - longitudinal survey research of attitudes and attitude change is still underdeveloped (Bedeian \& Armenakis, 1989; Collins, 1991, 2006; Lynn, Le Thi Cao, \& Horn, 1996; Roe, 2008a; Van de Ven, 2007).

One of the problems researchers encounter in longitudinal attitude research settings is the lack of proper instruments to repeatedly measure attitudes at the individual level. Considering the fact that the experience of attitude change is defined at the level of the individual (see chapter 1,3, and 5), we propose a new approach to longitudinal measurement where self-evaluation is applied to change over time. In this chapter we describe the development of an instrument for person-specific measurement of organizational commitment. This instrument, called LOCUST, aims to track historical development in organizational commitment.

By person-specific measurement of change we mean real-time capturing of change as it unfolds over time. This implies a temporal-dynamic research focus, which entails a detailed 
study of 'what happens' to a phenomenon over a certain time span, as well as how temporal trajectories relate to predictors and outcomes (Collins, 2006; George \& Jones, 2000; Roe, 2008a). The type of temporal design required to make inferences about temporal movement of phenomena and their interrelationships is called high-density repeated measurement (HDRM). HDRM is a combination of high-density and high-frequency measurement which allows for a fine-grained and lengthy look at temporal movement in phenomena. Highdensity attitude measurements are taken very rapidly one after another - say every hour, twice a day, daily, bi-daily, or once a week. High-frequency means that measures are taken in large quantities, say more than 20, within a given time frame. HDRM does not specify the exact time intervals used in the time frame of the design. In our studies we have chosen equal spacing between subsequent measurements.

Using an HRDM design poses considerable challenges to researchers - and requires extra compliance efforts from respondents - which is one of the reasons that this type of longitudinal design is extremely rare. Existing tools (discussed hereafter) ignore a basic conflict of interest in the context of longitudinal research, namely between researchers and participants. The issue is that researchers highly depend on respondents for the quality of their data, while respondents generally participate on a voluntary basis and can quit whenever they want. If it is the case that respondents are generally doing researchers a 'favor', it goes without saying that a sufficiently appealing user-interface is necessary to get respondents to comply for the full time frame of the research. Such a user-interface has not yet been developed. With the development of LOCUST we aim to resolve this issue and create a tool for the reliable and valid measurement of intraindividual attitude change.

The design process In developing LOCUST we adopt a design methodology approach (Eekels, 2000; Roe, 2005a; Roozenburg \& Eekels, 1995), which comprises the following stages: definition (i.e., specifying goals and functions), analysis (specifying a Program of Requirements), synthesis (product design), simulation (try-outs), evaluation, and decision making. Crucial in the design methodology is the Program of Requirements against which test results are evaluated in an iterative process of improvement. It should be noted that these stages do not follow up on each other linearly (Roe, 2005a). Design should rather be seen as a cyclical process where feedback between different activities in the respective phases interact in a process of continuous adjustment; a classic example of learning-by-doing (Bunjens, 2009; Roe, 2005a). This is why the design methodology also goes by the name of the 'Design Cycle Methodology'. Product design is then a cyclical and iterative process. Another feature of the design methodology is that requirements set in the analysis stage may 
be conflicting due to diverging stakeholder interests. The methodology allows for a deliberate weighting and balancing of competing requirements. Below we describe the initial project plan and graphically display the process of product development up to this point.

Project plan The dynamic measurement system we intend to make should function as a work experience monitor, a tracking system to be used in organizational settings, following individuals over time and recording mood, critical events, and organizational commitment on a weekly basis for a total period of half a year (i.e., 25 weekly measures in total). The initial project description (Roe \& Van Olffen, 2004) mentions the fact that an IT programmer was one of the actors needed to complete the project. Thus, the main actors in the project are: a $\mathrm{PhD}$ candidate, the computer programmer, a supervisor (assistant professor), and a promotor (full professor). On the technical side, our product needs to be state-of-the-art. We hire an IT specialist to develop software that would exactly answer to our criteria. The product will go by the name of LOCUST, which is an acronym for Longitudinal Occupational State Tracker.

The amount of time available to craft and administer LOCUST is set to 4 years the normal time available to $\mathrm{PhD}$ candidates. Activities to be completed in this time frame include setting up the program of requirements, designing and crafting the instrument, testing it and finally using it to collect data in three large scale studies among people in three phases of their commitment life cycle: ascendance (organizational entrants), subsistence (organizational incumbents), and descendance (organizational exiters). The LOCUST development project is managed as several discrete sub-projects unfolding and ending over time, such as finding an attitudinal operationalization of commitment, the technical implementation, and the validity of the conceptual design. In Figure 4.1 the making of LOCUST is depicted, unfolding over an historical time line. It shows that the design process has been far from trivial as in total 10 people have been involved, including two ITprogrammers. 


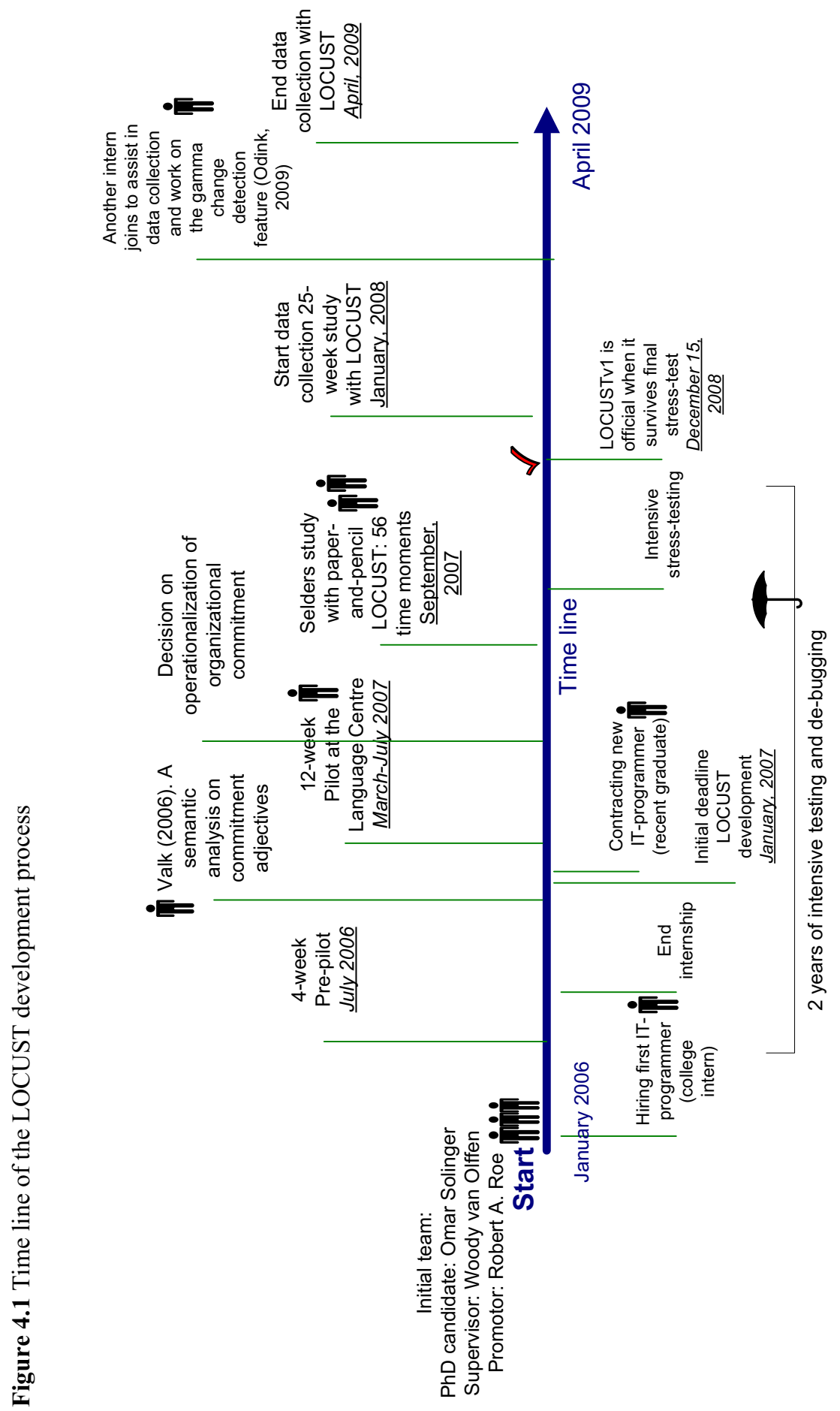


Although we have already done a reasonable amount of testing and validating, the process of design is still ongoing as the operation of some of our features still needs to be analyzed and the iterative process of continuous product improvement is still ongoing. LOCUST, as it is described now, should therefore be considered as a workable 'prototype'. Below we will describe the design of LOCUST, following the stages of the design cycle. We begin with the stage of definition and analysis, which includes generating the Program of Requirements (PoR). Next, we describe the stage of actual design, or synthesis, highlighting the major decisions we have taken. Next is a series of simulation studies testing the properties of LOCUST. We finish with an evaluation against the PoR.

\section{Definition and analysis}

\subsection{What the instrument should do}

We are interested in making detailed descriptions of individual developmental trajectories of workplace attitudes in general and of organizational commitment in particular. More specifically, we like to know how organizational commitment evolves from week to week among organizational newcomers over a time span of six months or more. We are also interested in how commitment develops over the days of a week, and even within a day. We need a measurement instrument which functions as an 'attitudinal microscope', so to speak, which is able to deliver temporal-dynamic descriptions across various 'zoom levels', say from week-to-week, day-to-day, or even hour-to-hour during a large span of time. We also need to know how changes in organizational commitment during a certain time span relates changes in other constructs, such as mood and the incidence of (organizational) events. The recordings should allow us to relate dynamic development in one construct to another. In other words, we aim to design an instrument which should deliver reliable and valid recordings of change under the conditions of high-density/high-frequency repeated measurement in workplace settings (i.e., HDRM). Crucial to the design of such an instrument is that there is an optimal translation (i.e., as little distortion as possible) from the real-time experience of organizational commitment in employees to numerical data in a spreadsheet. 


\subsection{The main stakeholders and their interests}

In our case we consider 'clients' using our measurement system to be researchers doing longitudinal research. 'Users' are respondents who participate in a particular longitudinal study and interact with our product. To avoid confusion we will henceforth stick with the more specific terms 'researchers' and 'participants/respondents'. As said, what is typically of interest for the researcher is not necessarily of interest to the participant. In fact, their interests are conflicting. Researcher interests are in the ability to carry out longitudinal research. Therefore, their needs relate to reliable and valid measurement of change. For example, a researcher is looking for an instrument with high predictive power, minimized systematic and non-systematic measurement error that can be repeatedly used over long time periods. Additionally, a researcher is interested in research consisting of many respondents, and low attrition rates. On the other hand, respondents (employees) see themselves confronted with growing demands on their personal time, and an increasing intrusion of the 'organization' in their lives and minds. As cooperation in research is still predominantly voluntary, a typical condition for respondents' willingness to cooperate in research is low intrusiveness of participation. Other conditions are ease of use, meaningfulness to themselves, and opportunities to learn.

The critical issue in these conflicting demands is that the researcher highly depends on respondent compliance, while the latter prefers to decide freely to quit participation. Strangely enough, existing instruments tend to focus mainly on researcher interest, while ignoring respondent interests. Considering the high dependence of researchers on respondent compliance, this lack of balance is risky. Therefore, striking a balance between researcher and respondent interests is crucial to a repeated measurement system's success.

The lack of balance between researcher and respondent interests is understandable from the perspective of the (differential) researcher using conventional cross-sectional designs, where administering one measurement is sufficient. In such research, neglecting the interest of the respondent is of little consequence because respondents are interchangeable. In contrast, in temporal research one has to secure an ongoing relationship by taking respondent interests seriously.

\subsection{Goals and functions}

We aim to create a measurement instrument that maximizes initial compliance and minimizes attrition, which allows for a temporal-dynamic (i.e., using HDRM type designs) investigation 
of attitudinal phenomena in workplace settings, which is capable of registering reliable change, even if changes are small, and adopts a valid measure of organizational commitment. We aim to reach our goals by a consistent, holistic, and temporal-dynamic focus applied to all aspects of longitudinal testing and valid measurement of organizational commitment. On the respondent side, we try to reach our goal by setting serious constraints to compliance load and creating a positive 'feel' with our measurement system.

\subsection{Common tools and practices in the field}

As said, the most prevalent and pervasive empirical data gathering methodology used in the field of Organizational Behavior is the self-report survey, which - in longitudinal settings - is simply administrated repeatedly. Innovations in the practice of longitudinal data gathering, are basically variants of the same method. They are known as (1) diary methods (Bolger, Davis, \& Rafaeli, 2003; Conway \& Briner, 2002), (2) experience sampling (Alliger \& Williams, 1993; Csikszentmihalyi \& Reed, 1987), and (3) ecological momentary assessment (Beal \& Weiss, 2003). The techniques go by different names, but they share the basic goal of capturing constructs of interest as they manifest themselves over time. Typical tools used by these approaches are prompting devices (e.g., pagers, beepers, palm tops, cell phones), sometimes used in combination with paper and pencil event-recordings (e.g., pocket-books, scrap books and diaries) and questionnaires (either planted on the palm tops or added in a booklet subjects carry around with them). The use of prompting devices and event-recordings - in various combinations - is relatively new to the field. Paper-and-pencil surveys continue to prevail. The improvement of digital infrastructure in corporate environments, which already allows digitalization of surveys and the use of the internet, provides an opportunity to increase the ease of communication between researcher and respondent. We expect internetbased survey administration to become a pervasive tool in the near future.

We are aware of a host of techniques for qualitative data gathering, like repeated interviews, film recordings, participatory observation, and passive behavioral recording and coding. However, alternatives to the self-evaluative surveys are not necessarily better as they come with other problems (Howard, 1994). For example, taking only behavioral measures as proxies for commitment has the advantage of being more 'objective', but has the downside of alternative explanations of certain focal behaviors. 


\subsection{Can existing tools do the job?}

Existing tools and practices have all offered their unique improvements with respect to longitudinal measurements. The question is, however, whether the existing tools qualify for our purposes, which is reliable and valid high-density repeated measurement (HDRM). Below we argue that existing instruments fall short on practical, conceptual, and methodological grounds.

As for the practical grounds, the intrusiveness of repeated measurement of the same employees is often a reason for practitioners not to cooperate and grant access. Apart from initial non-compliance, attrition is problematic as well. It is not uncommon that only $20 \%$ of the subjects out of the initial pool of participants keep participating until the last administration - even though the measures are administered months (or even years) apart. Additionally, the problem of response leniency (e.g., non careful responding due to fatigue, boredom) is common in repeated administrations. Problems are exacerbated by a dominant belief with many in the field of OB that only multi-item measures can lead to reliable measurement (Bergkvist \& Rossiter, 2007; Wanous, Poland, Premack, \& Davis, 1992). Unfortunately, this belief supports the use of long questionnaires which are highly tedious to fill out. Consequently, this practice limits cooperation compliance and enhances the problem of attrition. It also shows that researcher and respondent interests have not been systematically charted, balanced, and reconciled.

Apart from practical inconveniences in the administration, longitudinal measurement is plagued by methodological problems of different kinds, namely unreliable and invalid recordings of change because of systematic response shifts over time, temporally insensitive item phrasing, ill-suited temporal designs, and temporally insensitive scaling methods. For a start, longitudinal self-report surveys are vulnerable to systematic response-shift over time (Howard \& Dailey, 1979; Howard et al., 1979). These kinds of shifts pertain to scale recalibration (i.e., responses are differently calibrated across different time moments, which goes by the name of 'beta change') and concept redefinition (i.e., the meaning of the concept changes across measurement occasions; known as gamma change). The occurrence of scale recalibration and construct redefinition can seriously threaten the validity of the observed changes over time because they obscure the change researchers typically try to measure using conventional questionnaire scaling techniques (Golembiewski, Billingsley, \& Yeager, 1976; Horn \& McArdle, 1992; Terborg, Howard, \& Maxwell, 1980; Vandenberg \& Self, 1993). Various methodologies have been proposed to distinguish the types of change through the use 
of factor analytic techniques (Chan, 1998; Golembiewski, Billingsley, \& Yeager, 1976; Schmitt, 1982), ideal scores (Bedeian, Armenakis, \& Gibson, 1980), criterion variables (Van de Vliert, Huismans, \& Stok, 1985), or the so called 'retrospective-then' measure (Terborg, Howard, \& Maxwell, 1980). However, none of these methodologies have been able to provide lasting answers (Armenakis \& Bedeian, 1982). Moreover, the methodologies mentioned above are predominantly based on a differential paradigm, which means that the techniques as such are ill-suited to the analyses of longitudinal distortions at the individual level over time (Li, 2009b; Terborg, Howard, \& Maxwell, 1980). To date, the potential of scale recalibration and/or concept redefinition remains a serious threat to any inference of time-based change in the differential paradigm.

Additionally, crude, insensitive measurement devices hamper reliable observation of change. Current instruments are ill-suited in the context of HDRM. An example is the lack of congruence between the choice of time frame (the 'zoom level') and the content of the questions posed in the survey. The following examples are general statements frequently observed in construct measurement: 'In general, I am willing to work overtime', 'On the whole, I like my manager', I am generally satisfied with my colleagues'. These kinds of items are ill-suited to the inference of time-based change.

Another methodological problem is the lack of congruence between the research question and the temporal design (Collins, 2006; Dormann, 2007). In the previous chapter we have shown that organizational commitment researchers have used zoom levels of years, half years, quarters, and months, applying conventional measures of organizational commitment ${ }^{26}$. It can be seriously doubted whether these types of longitudinal designs are able to pick up on real-time change in the commitment attitude.

Lastly, existing measures are not sensitive enough to record micro-change across administrations in a dense longitudinal design. The amount of scoring alternatives in 1-5 or 17 scaled Likert-formats is simply too low to indicate nuances of change from day to day, or week to week.

The final reason why existing instruments fall short is a conceptual one. Measurement systems have not yet incorporated a user-interface which is congruent with temporal thinking. As we have argued earlier, all tools and devices so far have focused on optimizing the validity and reliability of a single score, but we have not seen a measurement where the realtime development of patterns of responses was incorporated in the respondent-interface. In

\footnotetext{
${ }^{26}$ One might suspect that the typical 3 or 4 year cycle of $\mathrm{PhD}$ research projects poses a practical/institutional barrier to collecting HDRM data as well.
} 
addition, current measures of organizational commitment do not qualify as conceptually complete measures of organizational commitment, as none of them are defined as an attitudinal construct, containing both affective, cognitive, and a behavioral component (Solinger, Van Olffen, \& Roe, 2008).

\section{The Program of Requirements}

\subsection{Introducing the PoR}

We previously mentioned the critical functions which the temporal measurement system should possess: a consistent, holistic focus on temporal dynamics which translates into a methodological instrument which can thrive in high-density repeated measurement (HDRM) longitudinal designs. Measurement in such designs should meet a couple of criteria (e.g., reliable measurement), constraints (e.g., survey length), and specifications (e.g., type of measurement). Requirements are desired and generally formulated properties of the system. Requirements are generally formulated to allow for flexible adaptation in the iterative process of continuous improvement in the design cycle. Constraints are elements which limit design choices and their implementation. Specifications are pre-set system properties which the designer must incorporate in the design and in construction of the system. In Table 4.1 we have displayed requirements, constraints, and specifications which the measurement system should meet. They are all weighted differently, and apply to different stakeholders.

As for stakeholders, we assume that requirements that are directly research-output related (such as reliability and validity of temporal patterns, temporal sensitivity of the instrument, and a usable database) are primarily relevant to researchers, while requirements related to the use of the instrument are primarily relevant to respondents (e.g., usability). On the respondent side, we reach our goal by drastically minimizing compliance load and creating a positive 'feel' with our measurement system. The distinction is not fully black-orwhite as the high usability is likely to increase response rates and reduce attrition, which, in turn, is highly relevant to the researcher. Likewise, monitoring of responses and operational reliability of the system are relevant both to researchers and respondents.

We have weighted the requirements, constraints, and specifications in order of their relative importance to longitudinal measurement in a HDRM environment, where 1 stands for 'essential', 2 is 'desirable', and 3 is 'not really needed'. The weighting has been informally discussed when we first set up the project. Because we initially aimed to make a conceptual 
contribution, all requirements, constraints and specifications that bear conceptual innovations are set to 'essential'. That is, requirements 'reliable and valid person-specific measurement' (R1), temporal sensitivity (R2), robustness against re-use (R3), and usability (R4) were set to 'essential'. Note that this weighting differs from conventional weighting, where the usability of an instrument is of much less importance. As said before, in conventional (cross-sectional) research, neglecting the interest of the respondent is of little consequence because respondents are interchangeable. In contrast, in temporal research one has to secure an ongoing relationship by taking respondent interests seriously. Our deliberate focus on securing respondent interests is also reflected in the weighting of the response time constraint (C1), and the single-item measurement specification (S1), which should drastically diminish the system's intrusiveness. If weights of competing requirements were of equal importance (e.g., reliability and usability) we tried to balance it in the design choice.

Requirements of practical nature (e.g., usable database, response monitoring) were considered later in the process when the technical implementation of the system was at hand. These requirements did not have conceptual value, thus, weighted 'desirable'. Administrative constraints (time and money) were considered least important and were weighted as 'not really needed'.

Performance criteria When can we say the dynamic measurement system is a success? The design methodology advises to translate the Program of Requirements (PoR) into objective criteria, that is, 'measurables'. As is conventional in the design methodology, one can revert back to (preferably objective) evaluation criteria in the evaluation stage and decide to engage in another iteration of design and implementation. We have inserted performance criteria in Table 4.1 because the criteria for evaluation make an integral part of the PoR. Some of our criteria in Table 4.1 are objective (e.g. dynamic correlations, attrition rates), while others are subjective (e.g., researcher satisfaction with the system).

If objective criteria are set before design choices are made, one can still incorporate instruments that directly measure the system's performance on those criteria in the design of the system. However, we did not incorporate measurement instruments that assess performance criteria in our design choices, because we did not have standard metrics or criteria to choose from. The largest problem with finding objective measures for judging LOCUST is the fact that criteria, metrics and guidelines for the assessment of reliability and validity of temporal patterns - in our case, from HDRM designs - are yet to be developed. That is, up to this moment psychometric criteria for reliability and validity have generally focused single, discrete scores. How the concepts of reliability and validity should be 
evaluated in a temporal context - where the reliability and validity of temporal patterns is the object of investigation - has remained unexplored (see Appendix B, for an elaboration).

Given this lack of guidelines and criteria, we have used a couple of tentative, intuitive proxies. First, the reliability of a temporal pattern (R1.1 in the PoR) is defined as the precision by which an individual trajectory is (re)produced (see Appendix B), thus emphasizing the pattern, not the discrete scores. As an approximation of this reliability concept, we looked at the degree to which a particular subset of an individual's trajectory could be predicted from another subset (e.g., the first half predicts the second half of the pattern). We approached this idea by looking at the predictability of the trajectory, using the proportion of explained variance $\left(\mathrm{R}^{2}\right)$ obtained from curve fitting analyses (PC-R1.1 in the PoR). Second, construct validity was assessed by relating OC dynamics to time-variant criteria by means of dynamic correlations. The dynamic correlation is a very basic proxy for the degree of relatedness of two trajectories. This is the main proxy we used to evaluate construct validity (R1.2-R1.5). A subjective proxy is to assess to what extend disruptions in individual OC patterns can be meaningfully related to the event occurrences. If this is demonstrated, a sufficient construct validity of the measure is plausible.

In the following (after Table 4.1) we will discuss the elements in the PoR one by one, including their performance criteria.

Table 4.1 Program of Requirements to a dynamic measurement system

\begin{tabular}{|c|c|c|c|}
\hline Requirements & $\begin{array}{l}\text { Weights } \\
1=\text { Essential } \\
2=\text { Desirable } \\
3=\text { Not really } \\
\text { needed }\end{array}$ & $\begin{array}{l}\text { Stakeholder } \\
\text { Resp.= } \\
\text { Respondent } \\
\text { Res. = Researcher }\end{array}$ & $\begin{array}{l}\text { Performance } \\
\text { Criteria (PC) }\end{array}$ \\
\hline $\begin{array}{l}\text { R1 Reliable and valid person- } \\
\text { specific measurement of change }\end{array}$ & 1 & Res. & Objective evaluation \\
\hline $\begin{array}{l}\text { R1.1 The measure should have } \\
\text { adequate temporal reliability. }\end{array}$ & 1 & Res. & $\begin{array}{l}\text { PC-R } 1.1 \text { The } \mathrm{R}^{2} \text { of } \\
\text { individual trajectories } \\
\text { (in curve fitting } \\
\text { analyses) must exceed } \\
.30\end{array}$ \\
\hline $\begin{array}{l}\text { R1.2 The measurement system } \\
\text { should measure organizational } \\
\text { commitment according to the } \\
\text { classic attitudinal triplet: affect, } \\
\text { cognition, and action readiness. }\end{array}$ & 1 & Res. & $\begin{array}{l}\text { PC-R1.2 Dynamic } \\
\text { correlation between } \\
\text { OC facets must not be } \\
\text { too low }(>.20) \text { and } \\
\text { not too high }(<.90)\end{array}$ \\
\hline $\begin{array}{l}\text { R1.3 The measure should have } \\
\text { adequate construct validity in } \\
\text { relation to event occurrences. }\end{array}$ & 1 & Res. & $\begin{array}{l}\text { PC-R } 1.3 \text { Temporal } \\
\text { variation in OC must } \\
\text { be significantly }\end{array}$ \\
\hline
\end{tabular}


R1.4 The measure should demonstrate sufficient temporal discriminant validity with mood trajectories.

R1.5 The measure should demonstrate concurrent validity with job satisfaction trajectories. associated with event occurrences

PC-R1.4 The dynamic correlation between $\mathrm{OC}$ and mood must not exceed .90

PC-R1.5 The dynamic correlation between $\mathrm{OC}$ and job satisfaction should be significant.

\section{R2 Temporal sensitivity}

1

Res. Subjective evaluation

The dynamic measurement system 1 must be able to pick up on longitudinal change and fluctuation, even if 'real change' is very small.

\section{R3 Robustness against re-use}

R3.1 The measurement system should allow for rapid and frequent re-use.
R3.2 The measurement should be able to auto-correct non-systematic biases due to re-use (e.g., erroneous recall of previous responses).

R3.3 The measurement system should allow correction of systematic re-use biases due to scale recalibration.

R3.4 The measurement system should be able to detect the content of systematic re-use biases in the form of construct change.

\begin{tabular}{|c|c|c|c|}
\hline R4 Usability & 1 & Resp. & Objective evaluation \\
\hline $\begin{array}{l}\text { R4.1 The measurement system } \\
\text { should be non-intrusive. }\end{array}$ & 1 & Resp. & $\begin{array}{l}\text { PC-R4.1 Low attrition } \\
(<50 \%) ; \text { high }\end{array}$ \\
\hline $\begin{array}{l}\text { R4.2 The measurement system } \\
\text { should have sufficient appeal to } \\
\text { start participating in the study and }\end{array}$ & 1 & Resp. & $\begin{array}{l}\text { compliance rate } \\
\text { PC-R4.2 Low } \\
\text { attrition; few }\end{array}$ \\
\hline
\end{tabular}




\begin{tabular}{|c|c|c|c|}
\hline $\begin{array}{l}\text { keep participating during the entire } \\
\text { time of the study. }\end{array}$ & & & $\begin{array}{l}\text { complaints; many } \\
\text { positive reactions }\end{array}$ \\
\hline R5 Monitoring of responses & 2 & Res./Resp. & Subjective evaluation \\
\hline $\begin{array}{l}\text { The measurement system must } \\
\text { allow for real-time monitoring of } \\
\text { response compliance. }\end{array}$ & 2 & Res./Resp. & $\begin{array}{l}\text { Researcher } \\
\text { satisfaction with the } \\
\text { system }\end{array}$ \\
\hline R6 $A$ usable database & 2 & Res. & $\begin{array}{l}\text { Objective and } \\
\text { subjective evaluation }\end{array}$ \\
\hline $\begin{array}{l}\text { R6.1 The values in the database } \\
\text { should be ordered in a time series } \\
\text { format, easily accessible, and } \\
\text { ready-to-use for subsequent } \\
\text { analysis by the researcher. }\end{array}$ & 2 & Res. & $\begin{array}{l}\text { PC-R6.1 Researcher } \\
\text { satisfaction with the } \\
\text { current system }\end{array}$ \\
\hline $\begin{array}{l}\text { R6.2 There should be a reliable } \\
\text { translation from the input values to } \\
\text { the values retrieved in the database. }\end{array}$ & 1 & Res. & $\begin{array}{l}\text { PC-R6.2 If reliability } \\
\text { and criterion-related } \\
\text { validity of OC is } \\
\text { demonstrated (PC-R1- } \\
\text { R4) the translation is } \\
\text { sufficient }\end{array}$ \\
\hline Constraints & Weights & Stakeholder & \\
\hline $\begin{array}{l}\text { C1 Total completion time for a } \\
\text { single response session should not } \\
\text { exceed } 4 \text { minutes in total. }\end{array}$ & 1 & Resp. & \\
\hline $\begin{array}{l}\text { C2 The operational reliability of } \\
\text { the measurement system should be } \\
\text { minimally vulnerable to } \\
\text { malfunction. }\end{array}$ & 1 & Res./Resp. & \\
\hline $\begin{array}{l}\text { C3 The system development } \\
\text { (including try-outs and } \\
\text { evaluation) should not exceed the } \\
\text { time period set by the promotion } \\
\text { project (4 years). }\end{array}$ & 3 & Resp. & \\
\hline $\begin{array}{l}\text { C4 The development of this } \\
\text { product may not exceed an } \\
\text { operational cost of more than } \\
2000 \text { Euro's. }\end{array}$ & 3 & Res. & \\
\hline Specifications & Weights & Stakeholder & \\
\hline $\begin{array}{l}\text { S1 All measures in the system } \\
\text { should be single-item }\end{array}$ & 1 & Res/Resp. & \\
\hline $\begin{array}{l}\text { S2 The attitudinal dimensions in } \\
\text { OC (affect, cognition, action } \\
\text { readiness) should be measured } \\
\text { separately and contain as little } \\
\text { overlap as possible }\end{array}$ & 1 & Res. & \\
\hline $\begin{array}{l}\text { S3 Effective and efficient } \\
\text { prompting }\end{array}$ & 2 & Res. & \\
\hline
\end{tabular}




\begin{tabular}{|lll|}
\hline $\begin{array}{l}\text { S2.2 The prompting procedure } \\
\text { must procure optimal response } \\
\text { compliance }\end{array}$ & 1 & Res. \\
$\begin{array}{l}\text { S2.2 The prompting procedure } \\
\text { must be time-efficient to the } \\
\text { researcher }\end{array}$ & Res. \\
\hline S3 Back-up systems & 2 & Res. \\
$\begin{array}{l}\text { S3.1 The system should have a } \\
\text { ready-to-use internet-based back- } \\
\text { up option, which can function as a } \\
\text { reasonable alternative in case of } \\
\text { operational malfunctions } \\
\text { (LOCUST-alt). }\end{array}$ & Res. \\
$\begin{array}{l}\text { S3.2 The system should have a } \\
\text { paper-and-pencil alternative in } \\
\text { cases where the use of internet is } \\
\text { not an option (LOCUST-PP). }\end{array}$ & \\
\hline
\end{tabular}

\subsection{System requirements and performance criteria}

$A$ reliable and valid attitudinal measure of commitment (R1) The literature on organizational commitment has recently taken a turn in terms of how it is conceptualized. That is, organizational commitment was previously defined either as a behavioral construct (specifically related to turnover behavior) or as an affective construct in case of the affective commitment scale (see chapter 2). Organizational commitment has been recently redefined as 'an attitude of an employee vis-à-vis the organization reflected in a combination of affect (emotional attachment, identification), cognition (identification and internalization of its goals, norms and values), and action readiness (a generalized behavioral pledge to serve and enhance the organization's interests)' (Solinger et al., 2008, p. 80; see also Roe, Solinger, \& Van Olffen, 2009). A measure of organizational commitment should therefore reflect the complete coverage of its attitudinal domain, consisting of a measure of the affective, the cognitive, and the behavioral element (R1.2).

The measurement of OC comes with a number of specifications, namely it should be measured as purely as possible. This implies two things. First, it should be measured with a single item per dimension ( $\mathrm{S} 1$ in the PoR) to avoid dangers of temporal divergence of measures tapping into the same dimension (see Appendix A). Second, affect, cognition, and action readiness should be measured separately and contain as little overlap with the other attitudinal dimensions as possible ( $\mathrm{S} 2$ in the PoR). The idea of measuring attitudinal 
components separately has been forwarded 40 years ago (Summers, 1969) but has not taken root in the commitment literature (see Appendix A, for an analysis).

The quality of the newly formed attitudinal OC items (R1.2) should be judged with an inspection of the dynamic correlation between the three attitudinal dimensions (PC-R1.2). In general, if OC consists of affective, cognitive, and behavioral processes, their separate temporal movement should show some overlap, but also demonstrate temporal uniqueness. From a temporal perspective, dynamic movement should overlap because we expect an underlying phenomenon steering and guiding these processes. More precisely, the phenomenon is reflected in affective, cognitive, and behavioral processes. However, attitudinal facets are also partly independent processes. The dynamic correlation should therefore not be too low (say, $>.20)$ and not too high $(<.90)$.

The measure should yield reliable OC trajectories, which - in our definition - is the precision by which a trajectory is (re)produced. Note that this definition differs from the conventional internal consistency reliability approach (for a short elaboration on reliability in a temporal research context, see Appendix B). We approximated this idea by looking at the predictability of the trajectory, using the proportion of explained variance $\left(\mathrm{R}^{2}\right)$ obtained from curve fitting analyses (PC-R1.1 in the PoR) in the MATLAB program.

Additionally, the measure should have adequate construct validity, which is examined by assessing the dynamic relation with event occurrences (R1.3) and its criterion-related validity by assessing concurrent temporal trajectories of other phenomena: mood (R1.4) or job satisfaction (R1.5). We expect the temporal relation (i.e., the dynamic correlation; PCR1.3) between event occurrences and $\mathrm{OC}$ and between job satisfaction and $\mathrm{OC}$ to be significant, given that fact that these relationships - though hardly studied with HDRM designs - are widely assumed to exist in commitment literature. The dynamic correlation measuring the concurrent/criterion-related validity of $\mathrm{OC}$ - between $\mathrm{OC}$ and job satisfaction should therefore be significant (PC-R1.5). Dynamic OC trajectories should resemble mood trajectories somewhat, but not too highly as OC is conceptually different. Moods are generalized affective states, lasting for a couple of hours to a day, while OC is an attitude which is expected to exert a different temporal character. How OC temporally differs from mood is still open for scientific exploration. The dynamic correlation between OC and mood may not exceed .80 (PC-R1.4).

Temporal sensitivity (R2) If change occurs, the instrument should pick it up. If an instrument does not capture nuances and differences across time moments, it can be considered temporally insensitive. In dynamic research temporal sensitivity is especially 
important since these kinds of measures eventually give the information necessary to answer research questions on development, growth or decline of a certain phenomenon. A self-report measure is temporally sensitive when it registers any change that is meaningful in the mind of the respondent, no matter how small the change.

Temporal sensitivity is subjectively assessed by the researcher when inspecting the relation between event occurrences and large as well as tiny disruption in individual OC trajectories. If LOCUST is able to pick up on meaningful small variation in OC, its temporal sensitivity is sufficient.

Robustness against re-use (R3) Measured attitude values should be insensitive to measurement frequency and time interval between measurement moments. Distortion due to too rapid re-use can be of systematic and non-systematic nature (Roe, 2008c). Systematic distortion is occurrence of response-shifts, like scale recalibration and construct redefinition. As time goes by, and experiences and information accumulate, systematic differences may emerge in the interpretation of the questions at hand or the scale anchors may occur. Nonsystematic distortions can have two sources: distortions that occur 'naturally' due to the passage of time and those that occur because of a particular method of measurement. Distortions due to the method can happen when the time interval interacts with the fallibility of human memory (Roe, 2008c). False recall of previous answers can make the observed longitudinal patterns unreliable. Measurement frequency can also have detrimental effects when respondents start 'satisficing' as a result of lack of motivation (Krosnick, 1999). If the number of repetitions is large, observed responses can become instantiations of routines (e.g., 'I am always scoring 5 on this item') rather than indicators of attitude levels.

Perhaps an example from aviation might help to clarify the issue of response distortion as a function of the method. After an airplane takes off from the runway, the air is temporarily moving. This instability in the air is dangerous for subsequent planes, increasing the risk of crashing during takeoff. Some time is needed for the air to stabilize before a next plane can take off. The instability in the air is called the 'vortex-effect' ${ }^{27}$. Likewise, selfreport measures may have their own unique 'vortex-effect' indicating the minimum amount

\footnotetext{
${ }^{27}$ We define the 'vortex-effect' of temporal measurement as the impact on measurement validity and reliability of item $\mathrm{X}$ on time $\mathrm{t}$ as a result of its closeness in time to its predecessor Xt-1. A minimal 'cooling down' time (Tc) may be required before acceptable validity and reliability of Xt can be ascertained again. For example, the question 'Do you love me?' should not be asked too many times. The answer decreases in reliability and certainly in validity, as it will start to become a measure of the degree of exasperation.
} 
of time required in between administrations ${ }^{28}$. If the time between measurements is too short, the next answer gets 'caught up' in the vortex of the former.

Robustness against re-use is tested by inspecting LOCUST's ability to perform well in terms of criterion-related validity - in different HDRM designs, in our case (1) two measures per day for duration of 4 weeks, (2) weekly measures for 7, 9, or 11 consecutive weeks, or (3) 25 weekly measures (PC-R3.1). There are no standards or threshold levels to judge LOCUST's performance on this criterion. Evaluation remains subjective.

Usability (R4) Critical issues that make a survey system appealing on the respondent side are simplicity, comprehensibility, aesthetic attractiveness, a positive 'feel', fun, and meaningfulness (i.e., facilitates self-inspection in a way that would otherwise not have been possible). In short, the respondent should be intrinsically motivated to use the instrument. To reach this kind of motivation the measure should, first of all, be non-intrusive (R4.1). The level of non-intrusiveness is tested by looking at the attrition rate. Dropout rates exceeding fifty percent are quite common in longitudinal research, even if measures were taken years apart from each other (see Table 3.1 in chapter 3). In HDRM designs attrition is expected to be even more problematic. Therefore, if attrition remains below $50 \%$ of the initial sample we assume that our system is sufficiently non-intrusive. We also look at compliance rates, which is the number of completed sessions relative to the total number of sessions (PCR4.1). Second, the system should have sufficient appeal to the user to keep participating in the entire time frame of the study (R4.2). Appeal to the user is assessed by looking at attrition rates, the number of complaints, and number of positive reactions while interacting with the system (PC-R4.2).

Monitoring of responses (R5) Longitudinal measurement in an HDRM environment calls for extra attention to response compliance. Naturally, a researcher wishes to obtain a time series which is as complete as possible. Timely detection of non-response should facilitate attempts to increase compliance again. Based on information assembled by the monitoring system the researcher can choose to change the kind, the number or the time interval of the prompting. The prompting procedure must be effective in the sense that it creates the optimum degree of compliance from respondents, and it must be time-efficient to the researcher. Unlike R1 - R4, R5 was considered only desirable. That is, we devoted most of our attention to R1 - R4 and R5 was considered important, but not crucial. The quality of

\footnotetext{
${ }^{28}$ This in itself is an interesting area of experimental research on temporal methodology. It may also serve as yardstick to compare the competitive advantage of one measure over another in high-density longitudinal designs.
} 
the response monitoring was assessed subjectively by evaluating the researcher's satisfaction with the system.

A usable database (R6) The database should contain reliable and valid time series data. The values in the database should be ordered in a time series format, easily accessible, and ready-to-use for subsequent analysis by the researcher (R6.1). This requirement is assessed subjectively by evaluating researcher satisfaction (PC-R6.1). Second, there should be a reliable translation from the input values (entered in the user interface) to the values retrieved from the database (R6.2). This translation is regarded sufficient if reliability and criterion-related validity of OC trajectories can be demonstrated (PC-R6.2).

The requirement of a usable database (R6) was considered a desirable system property. The 'desirable' weighting does not reflect the 'true' importance of a usable database in temporal research, but the relative importance. We assigned this weighting only when we first set out to construct the LOCUST system. In our experience at the time, this aspect did not lend itself for a conceptual contribution. Hence, it did not need extra attention from us.

To save space we will only discuss $\mathrm{C} 1$ and $\mathrm{S} 1$ as they were essential - and potentially the most controversial - to the design of the measurement system. Other constraints are presented in Table 4.1 and are self-explanatory.

Response time (C1) A practical - though crucial - issue in longitudinal survey research is the time needed to complete the survey. The higher the frequency and the smaller the time interval, the more completion time starts to weigh. This can be explained by a simple cost-benefit analysis: when the costs of expending cognitive effort in answering questions outweigh the benefits (e.g., money, insight, altruism, academic interest, compliance), motivation to comply decreases sharply (Krosnick, 1999). Response motivation is key to all problems associated with lengthy questionnaires, like lack of participation, lack of legitimacy, lack of score reliability, and response biases. It is therefore crucial to restrain the length of the survey to an absolute minimum. We set the requirement to 4 minutes ${ }^{29}$.

Single-item questions (S1) We propose a simple solution to the 4 minute completion time constraint: use single-item measures. For multi-dimensional constructs, like organizational commitment, a single question per facet is sufficient to cover the conceptual domain. The use of single-items measurements lessons respondent refusal, selection bias, attrition, intrusiveness, and it increases the face-validity of the research (i.e., no 'scientific

\footnotetext{
${ }^{29}$ This is the amount of time we thought it would take to get a cup of coffee from a nearby coffee machine in the workplace. Typically, this activity is not very intrusive.
} 
nit-picking' by posing redundant questions which waste the respondent's time; Wanous et al., 1997). Moreover, they have been used before in high-density longitudinal research on job satisfaction (Fuller et al., 2003). We therefore give preference to single-item measurement.

The more fundamental issue is, that using single-item questions is congruent with the 'spirit' of temporal thinking where the emphasis is not on individual differences within a single snapshot, but on temporal patterns and developmental trajectories (see also chapter 1). This means that we can stand to lose some units of individual-difference reliability of isolated snapshots if we can win reliable change across a temporal pattern. In temporal research we are dealing with patterns, not with singular, isolated points. In addition, single-item measures should be encouraged in HDRM designs because it lowers complexity, considering the fact that every additional item runs the risk of showing a different trajectory over time. These heteromorphic trajectories over time are unwanted as they endanger temporal convergent validity (see Appendix B, for a short and preliminary elaboration on the concept of validity in a temporal context). Moreover every parallel measure has different semantic connotations and is, thus, in different ways susceptible to systematic response shifts. A single item is therefore the most pure measure possible in temporal-dynamic research settings. On the other hand, the choice of which single item to choose therefore becomes of paramount interest, as it needs to show high content and face validity.

\section{$4 \quad$ Instrument design}

Our measurement system comes in three forms: (1) an internet-based work experience monitor called LOCUST, (2) another internet-based fallback option, called LOCUST-alt ${ }^{30}$ in case LOCUST did not live up to the operational reliability constraint (S3.1 in the PoR), and (3) a 'paper and pencil' alternative, LOCUST-PP, in case the use of internet is not a feasible option (S3.2 in the PoR) in a researcher's repertoire.

The actual design of LOCUST, that is the synthesis, can be divided into three phases (Roozenburg \& Eekels, 1995): architectural, conceptual, and detailed design. In the architectural design we discuss the basic structures of the LOCUST system. In the conceptual design - in which we aimed to make a conceptual contribution to the field of longitudinal measurement - the main innovative features of LOCUST are discussed and explained. In the

\footnotetext{
${ }^{30}$ Most important of the three systems are LOCUST and its paper-and-pencil alternative LOCUST-PP. The backup option, LOCUST-alt, was only created when we got serious doubts whether LOCUST would be able to function without technical problems at all. It was created in an already existing online questionnaire environment (NetQuestionnaires). LOCUST-alt lacks interactive features and is therefore not much different from conventional measures.
} 
detailed design we show screenshots of the LOCUST system's user interface and explain these system properties in more detail.

\subsection{Architectural design}

LOCUST consists of three systemic elements: the 'front', the 'inside' and the 'back' of the system. The 'front' of the system is its interface with the respondent. The inside of the system comprises the translation from the user interface, the front, to the database, the back of the system. It also involves monitoring of response and prompting. In Figure 4.2 the basis structure of LOCUST is presented.

Figure 4.2 Basic architectural design of the LOCUST system

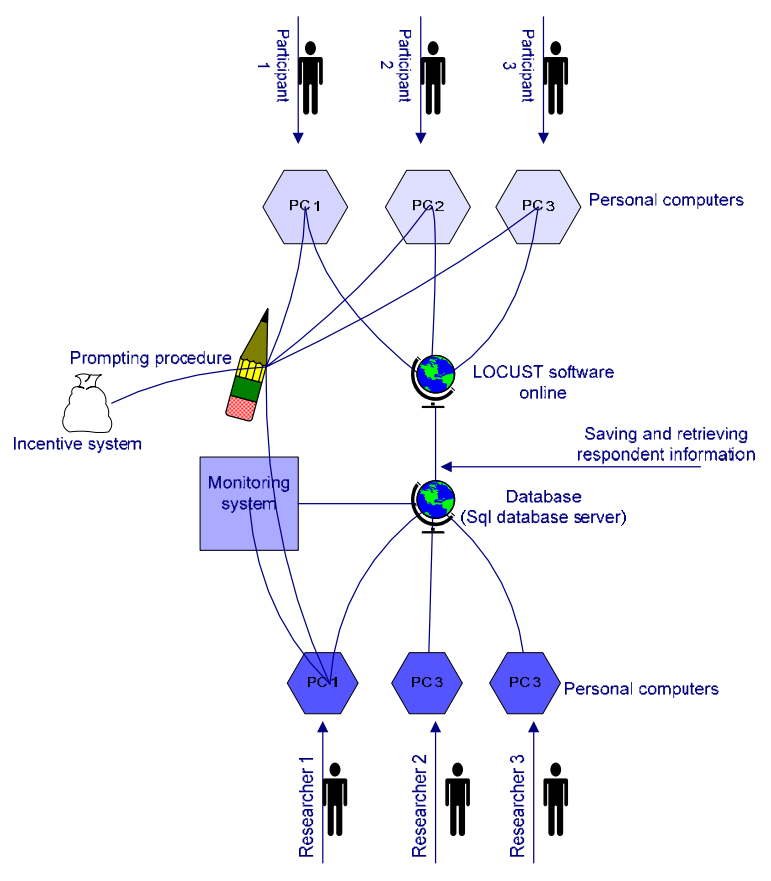

In the 'front' of the system (i.e., the input side) respondent cognitions of current attitudes are translated into numerical input values. The front of the system to researchers has to meet three main requirements: reliable and valid construct measurement, sensitivity to pick up longitudinal change, and robustness against re-use. On the side of the user (respondent), we aim to create a positive attitude towards interacting with the instrument, which can be reached by making sure the instrument is easy to use and minimally intrusive. 
A critical function of the 'back' of the system (i.e., the output side) is a usable database, which is easily accessible to the researcher. The database should contain time series data which are characterized by temporal reliability, and temporal criterion-related validity (see Appendix B for a discussion of these concepts). Arguably, reporting and communicating with respondents after the data collection period also belongs to the 'back' of the system. However, we chose to leave this aspect aside, because it does not differentiate a longitudinal from a conventional measurement system.

A critical function 'inside' the system is a flawless (and reliable) translation of input to output. That is, what a particular respondent indicates when interacting with the system must be translated flawlessly to a particular time series in the database. Another required feature inside the system is the monitoring of response compliance. We think of this function as a sort of 'cockpit' where the researcher follows week-by-week (or day-by-day) compliance of the participants using the system. This allows for a timely detection and management of attrition. Based on information assembled by this 'cockpit' the researcher can choose to change the kind, the number or the time interval of the prompting. The prompting procedure must be effective in the sense that it creates the optimum degree of compliance from respondents, and it must be time-efficient to the researcher.

IT-architecture We have opted for an internet-based design as this is the most flexible and time-efficinent option and potentionally aids the ease of communication between the researcher and the respondent. The main programming languages in LOCUST are JavaScript and ASP.NET2. The program rests on two main servers: the survey system (LOCUST) in our case - running on our faculty server - and the database server - running on the university server. These two servers communicate and exchange information with each mouse click. 'Cookies' are the main interactive communication devices between the LOCUST software and the database (see Figure 4.2). The choice to use cookies as communication devices between LOCUST and the database server will turn out to be unfortunate. This is because cookies were not user-specific so information gets corrupted as soon as more than one respondent logs on to LOCUST. As yet, we have not had enough opportunity to change the entire architecture. This remains to be done in a beta version (update) which is still to be developed. Our second (student) programmer has spent most of his time trying to cure bugs and problems caused by the exchange of cookies in a multi-user environment. 


\subsection{Conceptual design}

The conceptual design reflects the main design choices we have made to answer the elements in the PoR, it reflects the most important contribution we aimed to make with our LOCUST instrument. The eight respective elements in the conceptual design (i.e., design choices) are discussed one by one, and presented in Table 4.2 at the end of this section.

Verbalizations and temporal specificity (1) It was already decided in the PoR that we will use single items for measuring the respective dimensions of OC as well as any other construct. A first choice to be made concerns the way in which items are formulated. Following the temporal approach, we decided that items should be phrased in verbs and specify to a time interval. For example, we ask: 'What is your mood at the moment?', or 'Write down a work-related event that happened since the last session'. This feature is necessary because temporally unspecific phrasing can create unreliable change in temporal research settings. For example, the question 'In general, how hungry are you?' is temporally unspecific, and yields unreliable recordings of change. In this respect, verbs and active phrasing - in combination with a specific time frame to which the question applies - is to be preferred (Rescher, 1996; Roe, 2008a).

Design choice 1: items measuring commitment should be phrased in verbs and specify to a time interval.

Scaling method (2) The choice of a proper rating scale is also an important factor in sensitive longitudinal self-report measurement. If test items only have a few anchors, recording nuances and micro-changes over time is difficult. In differential research settings, typically, means are calculated out of a great number of respondents in order to represent the 'typical' respondent. Precision is achieved by the averaging process. This is not an option for individual-level temporal designs, where greater precision is reached by attempts to measure more precisely. One of the ways in which greater precision can be reached is by allowing more scaling options. In differential experimental research it was shown that the precision of measurement seems to increase with the number of scale points up to at least 20 scaling options (Nunnaly \& Bernstein, 1994, and the sources they cite).

A downside of increasing the number of scale points is an increased error variance. However, Nunnaly argued that 'the error variance increases, but at the same time, the truescore variance increases at an even more rapid rate' (Nunnaly \& Bernstein, 1994, p. 609). All 
in all, psychometric theory seems in favor of using more rather than fewer scale points. Unfortunately, there is no evidence regarding the impact of scaling method on temporal reliability for the simple reason that a temporal test theory is yet to be developed (see Appendix B). We would expect that indicating changes on an intuitive 0-100 scale (due to being known as temperature and percentage scales) is easier and more sensitive to microchanges than most other scales. Note that allowing respondents to score zero on a particular attribute deviates from conventional attitude measurement metrics. This is in line with temporal thinking as a commitment is temporally conceived of as having a finite existence and is expected to reach a zero value at some point in time (see chapter 1 and 3).

Design choice 2: answering scales should be continuous and ranging from 0-100

Choosing organizational commitment items (3)

To our knowledge, organizational commitment has never been measured as an attitude, using one item per dimension (affect, cognition, action readiness). We have taken great care as to which specific item to choose to represent each of the three dimensions. We will discuss the measures for affect, cognition, and action readiness consecutively. In our search for the right verbs we mainly based ourselves on the verbs and adjectives already used in existing measures of commitment. Semantic similarity with previous OC measures is important as it allows the creation of a homologous body of knowledge. For this purpose we classified items in one of the three attitudinal dimensions (see Appendix A, for the exact classification).

The adjective that was most widely used in different operationalizations of the affective facet of organizational commitment in dynamic studies was 'proud' (Hailey, Farndale, \& Truss, 2005; Kramer, Doughery, \& Pierce, 2004; Mowday, Steers, \& Porter, 1979; O'Reilly \& Chatman, 1986). For example, 'I am proud to tell others that I am part of this organization' and 'I talk up to this organization to my friends', or mixtures of happiness with pride: 'I am glad to tell others that I am part of this organization'. Words like 'happy', 'glad', 'enjoy' and 'care', and 'emotionally attached' also resound the affective attitudinal dimension of commitment. We concluded that being proud of one's organization is an appropriate single-item formulation of the affective dimension of organizational commitment. This resulted in the item 'What I feel about my organization: I am proud'.

The cognitive dimension is a set of beliefs and valuations regarding the organization which consists of two highly overlapping processes: identification and internalization (cf. Solinger, Van Olffen, \& Roe, 2008). Identification and internalization have appeared in 
different adjectives in the measures of OC. As for identification, 'part of the family', 'sense of belonging', or 'personal meaning', or 'ownership' are dominant phrases in the literature (Allen \& Meyer, 1990; Kramer, Doughery, \& Pierce, 2004; O'Reilly \& Chatman, 1986). As for internalization, 'thinking', 'agreeing' on policies, personal 'importance' are dominant, as well as seeing similarity in values (in Mowday, Steers, \& Porter, 1979; in O'Reilly \& Chatman, 1986) and the belief that the firm is the 'best of all possible organizations to work for' (Mowday et al., 1979).

The challenge in this dimension is to find a single formulation which taps the cognitive basis underlying identification and internalization processes. We have chosen to formulate the common ground on the cognitive dimension as follows: What I think about the organization: I belong to it. Belonging alludes to the cognitive process of self-categorization, which has been regarded as the 'basis' for both identification and internalization processes before (Hogg \& Terry, 2000; van Dick, 2001). Belonging is also colloquial, and occurs literally in the widely used Affective Commitment Scale (Meyer \& Allen, 1990).

We should be especially critical in judging adjectives used to describe action readiness, because authors have erroneously used the incidence of overt and specific behaviors as indicators of action readiness (e.g., leaving, talking, decision making, extra-role behavior, high performance). This is objectionable as it potentially leads to inflated correlations if these very behaviors are predicted from OC, see Appendix A and Solinger et al., 2008). Additionally, this practice may lead to poor construct validity if behaviors other than these indicators are predicted from OC (Solinger et al., 2008; Bollen \& Lennox, 1991). Some formulations are general enough to qualify. For example, the word 'loyalty' is common in existing measures (Allen \& Meyer, 1990; Mowday, Steers, \& Porter, 1979) and is also highly semantically associated with organizational commitment (Valk, 2006). However, this word violates the principle of non-redundancy, because it covers the meaning of both affect and action readiness. Other frequently used formulations, like 'effort', 'inspire', and 'performance' (Mowday, Steers, \& Porter, 1979) are not general enough to qualify. Hence, we need to search for motivational formulations outside the pool of items used in previous commitment scales, like 'drive', 'morale', 'to engage', 'passionate'. In a semantic appropriateness study (see Appendix E; Valk, 2006) we found that 'drive' and 'passionate' are significantly more associated with the neighboring constructs job involvement and career commitment, which disqualifies their usefulness. We finally chose the word 'to engage', because it is a verb, intuitive, non-redundant, and etymologically linked to the concept of 
'pledge' (the Latin root is 'gage', which literally means 'pledge'). Thus, we come to the following phrase: What I do for my organization: I engage.

Design choice 3: organizational commitment is measured with 3 single-items

Affect What I feel about [my organization]: I am proud

Cognition What I think about [my organization]: I belong to it

Action readiness What I do for [my organization]: I engage ${ }^{31}$

Graphic trajectory registering (4) What is missing in standard longitudinal measurement practices is the perspective of the individual respondent regarding his or her own progression. After all, temporal patterns of work attitudes are essentially subsequent recordings of subjective experiences by the same actor. If this is the case, why not use the subjective experience as a leading concept to improve reliability of individual progressions? We propose a practice of reliability improvement by matching the subjective experience of change with the action of pattern scoring. We propose a medium where we provide respondents with a graphical representation of their own progressions of their work attitude from all previous measurement occasions. This is called person-specific, historically tailored display and represents the first (of three) element of graphic trajectory registering (GTR). The second element in GTR operates by presenting person-specific graphs of previous responses while they are scoring. This is called real-time, incremental trajectory scoring. As the graphic display in our case represents (dimensions of) the commitment attitude, we have also named this graphic display the 'attitudogram'. A third element of graphic trajectory registering is retrospective corrective adjustment, which is discussed in design choice 5.

Standard practices of reliability enhancement can only 'repair' the dataset by dropping a couple of individual unreliable cases (or considerably enhancing the number of survey items). Dropping survey items is a form of post-hoc reliability procurement by the researcher. Alternatively, GTR allows for real-time reliable change registering by each individual respondent as he/she fills out the survey. Specifically, in GTR the respondent adds a score to the pattern in every consecutive session. This is likely to enhance the meaningfulness of the trajectory to the individual respondent, because he/she is actively involved in creating it. Providing graphs of past responses is a way to procure reliable change

\footnotetext{
${ }^{31}$ In Dutch, these questions sounded the following:

- Wat ik voel t.o.v. mijn organisatie: Ik ben trots

- Wat ik denk over mijn organisatie: Ik hoor erbij

- Wat ik doe voor mijn organisatie: Ik doe mee
} 
by making use of the process of anchoring. Newly added scores should then to be conceived of as relative to the past trajectory, that is, as 'pattern scores'.

Figure 4.3 Our first prototype of graphic trajectory registering

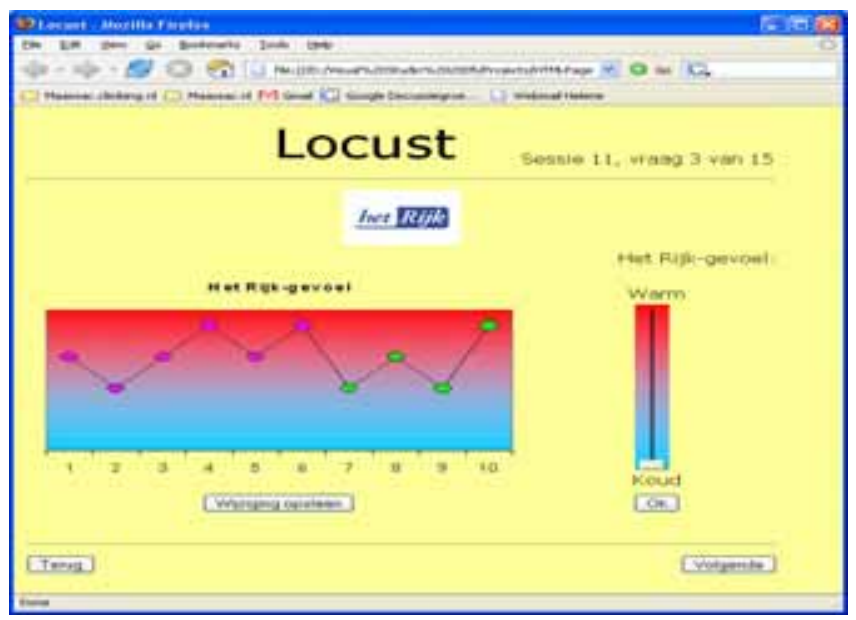

Having subjects repeatedly subscribe to their trajectory - instead of to a single score - has a number of advantages: (1) it eliminates false variation due to imperfections in memory, (2) it makes small adjustments meaningful because they are consciously scored relative to past scores, (3) it eliminates response routines and mindlessness as it forces the respondent to think about change and stability, (4) ascribing to a pattern is more consistent with the interest of the temporal researcher, (5) it is more congruent with the subjective experience of time as the present is always interpreted relative to one's past, (6) it makes participation in longitudinal research reflective and potentially insightful to participants, thereby minimizing unwanted response routines.

This procedure seems simple and straightforward but has dramatic consequences if applied consistently for measuring constructs in the area of work attitudes. As a rule of thumb, the more meaningful a particular progression is to the individual respondent, the more consistent and reproducible (i.e., reliable) the temporal pattern. Note that anchoring present scores to a previous series of scores (i.e. trajectory) directly ties into temporal sensitivity (R2), robustness against re-use requirement (R3). Aligning trajectory registering with the subjective experience of change and one's past is directly related to the 'usability' of the instrument (R4). Thus, the idea of graphic trajectory registering (in our specific case called an 'attitudogram') solves multiple problems at once. 
Design choice 4: At each measurement instance change is registered by means of real-time, incremental trajectory scoring in a person-specific, historically tailored graph (i.e., graphic trajectory registering - GTR)

The retrospective adjustable display (5)

As argued earlier, self-report surveys are vulnerable to scale recalibration (beta change), which limits an instrument's robustness against re-use. As a solution to this problem we suggest that subjects are free to repeatedly subscribe to their pattern. We use the term 'subscribed pattern' because we believe that temporal recording instruments should allow respondents to judge whether their trajectory matches their experience: 'Yes, this is how it went'. If the pattern (visible in their own trajectory in the user-interface) does not match their experience, subjects should be able to correct it. This feature of GTR is called retrospective adjustable display (RAD).

RAD is similar to a corrective grading procedure by a professor consecutively grading student papers. The professor might (and should) reconsider the grade given to the first corrected student paper if he is later confronted with student papers which are of much higher (or lower) quality than expected. In this instance, the scale of 'good paper' is recalibrated based on new information. Thus, reliable change can be enhanced by allowing respondents to adjust scores retrospectively (like the professor did when grading student papers).

Threats posed by scale recalibration (beta change) are cured instantly without loss valuable data, time and money. In a way, this corrective survey procedure is an elegant restoration of the 'Retrospective-Then measure' introduced by Terborg and colleagues (Terborg, Howard, \& Maxwell, 1980). This procedure was meant as a measure of beta change, by adding an extra question on what respondents think their attitude level was before the intervention ('Then-measure). Beta change was calculated by the difference between the actual previous measure and the 'Then-measure'. Later, the measure was criticized for taking too much energy from the respondent and enhancing memory-related biases (Armenakis \& Bedeian, 1982) and fell out of favor. But our corrective survey procedure does not suffer from 'Then-measure illnesses' because all past responses are simply given (no need to remember) and retrospective adjustments pertain to the entire pattern (no separate questions for all consecutive iterations). For every (single-item) measurement the entire pattern is visible and open for correction, which is a matter of seconds. Moreover, via this procedure the degree of beta change can be inferred and the amount of true longitudinal change (alpha change) is maximized. 
Thus, graphic trajectory registering (GTR) consists of three basic elements: (1) person-specific, historically tailored display of longitudinal change, (2) real-time, incremental trajectory scoring based on these graphical displays, and (3) corrective retrospective adjustments (which implies repeated confirmation) of individual graphs in each measurement occasion (i.e. retrospective adjustable display - RAD).

Design choice 5: at each measured instance, subjects should subscribe to their trajectory and be able to adjust their own scores retrospectively in a retrospective adjustable display.

Capturing 'movement' in a conceptual domain (6) The problem of change in the conceptual meaning of measures is usually assessed by means of Structural Equation Modeling techniques (Schmitt, 1982; Vandenberg \& Lance, 2000), which asses the stability of factorial structures in multi-item scales between consecutive time moments. We find this methodology not sufficiently insightful, because it does not allow inspection of the actual content of the re-conceptualization. Moreover, the existing technique is only applicable to meaning at the level of the group- or population average, but does not provide insight at the individual level (Li, 2009b; Terborg, Howard, \& Maxwell, 1980). Figure 4.4 shows how the content of construct redefinition (gamma change) can possibly be detected and predicted by using a 'semantic map' which represents the conceptual domain of organizational commitment. The map is populated with adjectives which refer to underpinning values and activities (Thompson \& Hunt, 1996), which each have their unique distance to each other. If we are able pinpoint the 'location' of meaning given by particular subjects within the semantic map and track their unique 'movement' over time, we should be better able to capture the nuances of gamma change than existing techniques. We do this by asking participants repeatedly to give their preference regarding these adjectives. This results in a respondent-specific typology of gamma change, relative to a general interpretation of commitment ${ }^{32}$.

Design choice 6: the measurement system should capture respondent-specific movement on a general semantic map of organizational commitment.

\footnotetext{
${ }^{32}$ We have created such a 'semantic map' of OC by first finding 37 adjectives typically associated with OC, than calculating semantic distances between these adjectives by means of Multidimensional Scaling. For inspection of this semantic map, please see Appendix E.
} 
Figure 4.4 Gamma change as movement over time on a semantic map

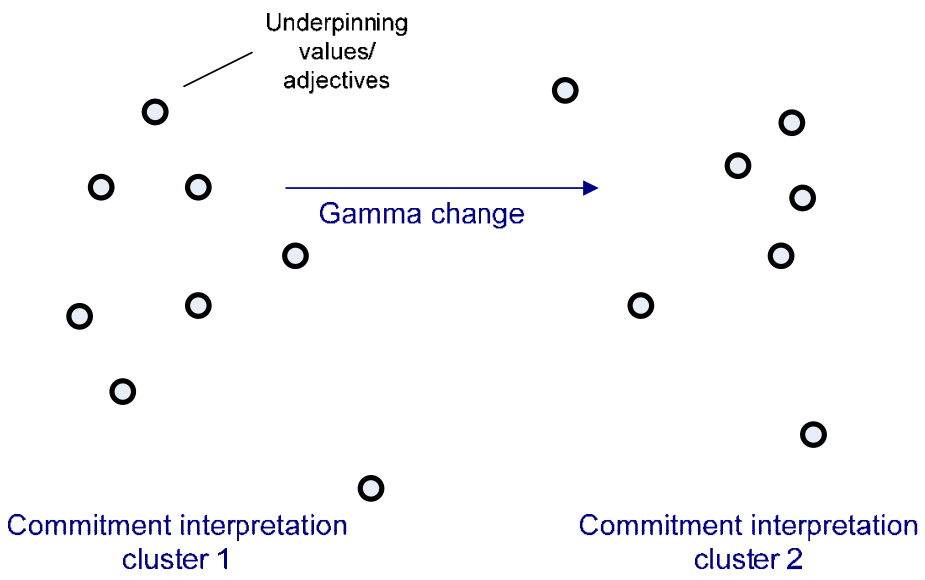

An event tracking system (7) Along with trajectories of commitment, we also intend to include concurrent measures of mood and organizational events. We included measures of mood to capture potential instances of mood-congruent responding and investigate the discriminant validity of our commitment measure. Event recordings were included to search for obvious explanations for temporal dynamics in $\mathrm{OC}$ and to investigate their 'causal' influence on potential 'shocks' in the commitment trajectory.

The investigation of the effect of events may be spurious if path-dependency is not taken into account. Consistent with the metaphor of the vortex-effect (i.e., air is temporarily unstable after an airplane takes off), the impact of organizational events may also linger 'in the air' for a particular period of time. This potentially causes carry-over effects across time moments and path-dependency in causality relationships. For example, an attempt by the management team to improve organizational climate is unlikely to increase OC if the announcement of an impending downsizing is still fresh in the memory of employees. In such cases, a researcher needs to know how long the influence of the downsizing announcement will last. How long this period of potential influence takes, is uncertain and probably contingent upon the type of event and the person experiencing the event. According to George and Jones (2000) the 'time bracketing' (i.e., duration) of organizational events is an important - but neglected - issue in temporal-dynamic research. Due to the fact that the duration of event impact is highly subjective, we choose to integrate it in the LOCUST system. In each consecutive week (or day) LOCUST retrieves events entered in the previous weeks and asks the respondent whether each of the particular events is still seen as important. 
As long as the respondent clicks 'yes' (still important) the event keeps on coming back. As soon as the respondent clicks 'no' (no longer important) the event disappears from the user interface.

Design choice 7: The system should keep track of important events - and their subjective duration - that may have had an instantaneous effect on commitment.

An interactive user interface We believe that the main feature which makes an instrument appealing is that it is interactive. Specifically, we allow the respondent to work with his/her own responses entered in previous measurement occasions; what is depicted in the user-interface should be a result of the respondent's own actions. This way, the respondents 'interacts' with him/herself over time. The GTR survey procedure, including the RAD (i.e., adjusting past scores), and the event tracking system are used as interactive features in dynamic measurement system. All contribute to user-interaction with the system.

Design choice 8: The system should contain an interactive user interface

In Figure 4.5 all the design choices (except 6 and 7) are displayed in a single internet page. This page is our implementation of the GTR, and includes design choices $1-5$, and 8 .

(Continued on next page) 
Figure 4.5 Integration of design choices 1-5, and 8

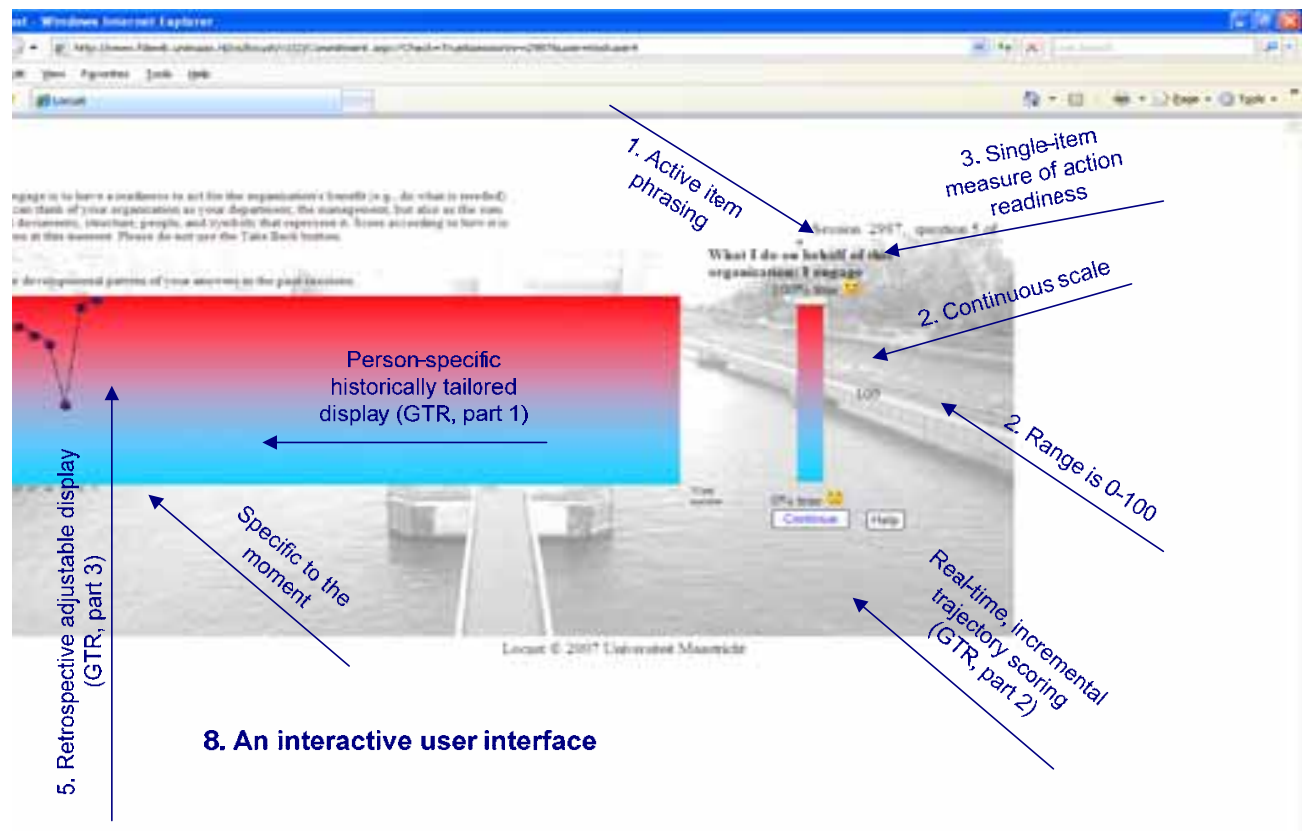




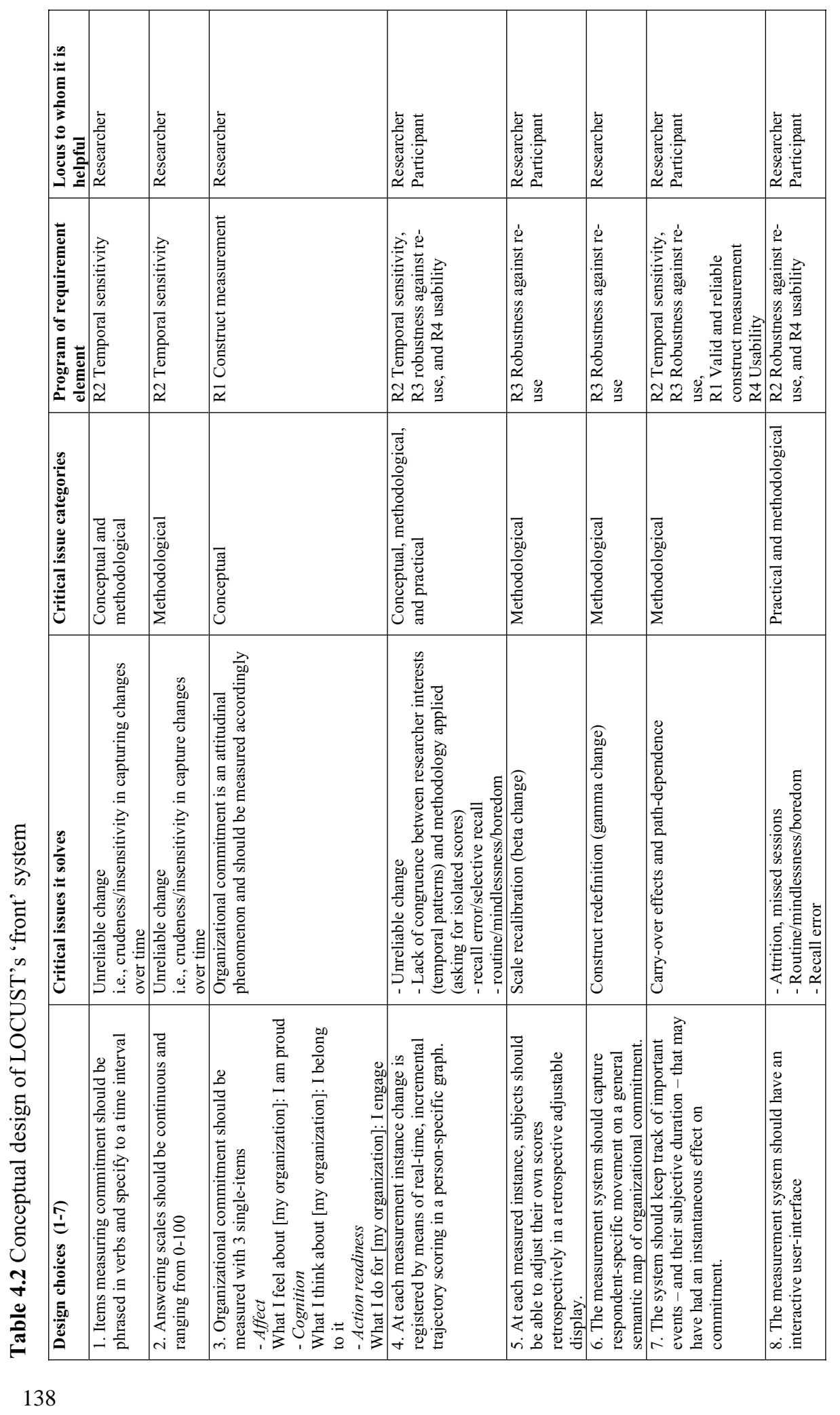




\subsection{Detailed design}

After designing the basic architecture, we designed the user interface (LOCUST's front) which represents the most important properties of LOCUST. We started out by creating a 'storyboard', which indicates the subsequent pages in the user-interface: log in, mood-check, past events (i.e., events which happened since last session), future events (i.e., events expected in the future), gamma check (i.e., the page that aims to detect changes in the understanding of the measured phenomenon, gamma change), commitment pages, 'thank you'-page, with room for comments. To control for order effects, we posed the three commitment questions randomly. We were able to keep this basic structural order throughout the entire process, although there were a couple of add-ons along the way. When users logged in for the first time, they were directed to a separate page where they had to enter and confirm their passwords. They were also referred to an online user-manual and received a document with 'frequently asked questions'. If users had missed a session, the first screen they saw asked them why they had missed a session in a multiple-choice format. We also made a LOCUST-demo (video-clip) where subjects could get acquainted with the system by looking at a video going through all the LOCUST pages ${ }^{33}$.

Below we show screenshots of all the pages - in the original order - in the LOCUST's user interface. Note that the lay-out is from the final version of LOCUST (December, 2007). Extra page-by-page information is provided in 'notes' below the figures.

Figure 4.6 LOCUST log in page

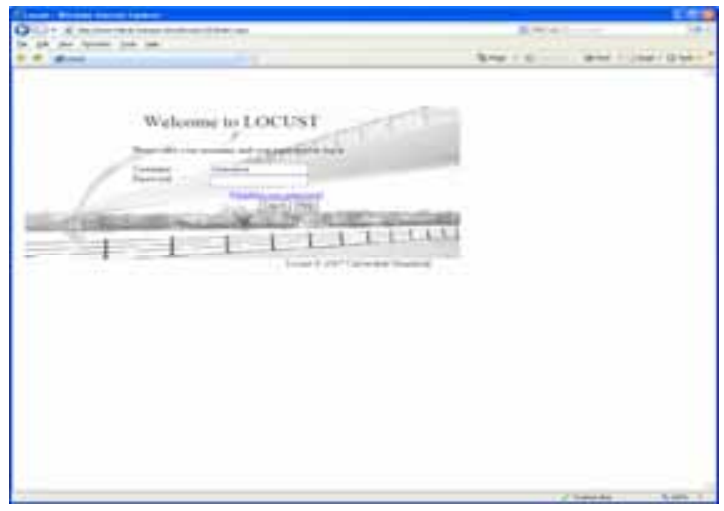

${ }^{33}$ see http://www.fdewb.unimaas.nl/os/locust/V2/site/demo.swf 
Figure 4.7 Mood-check using graphic trajectory registering (GTR)

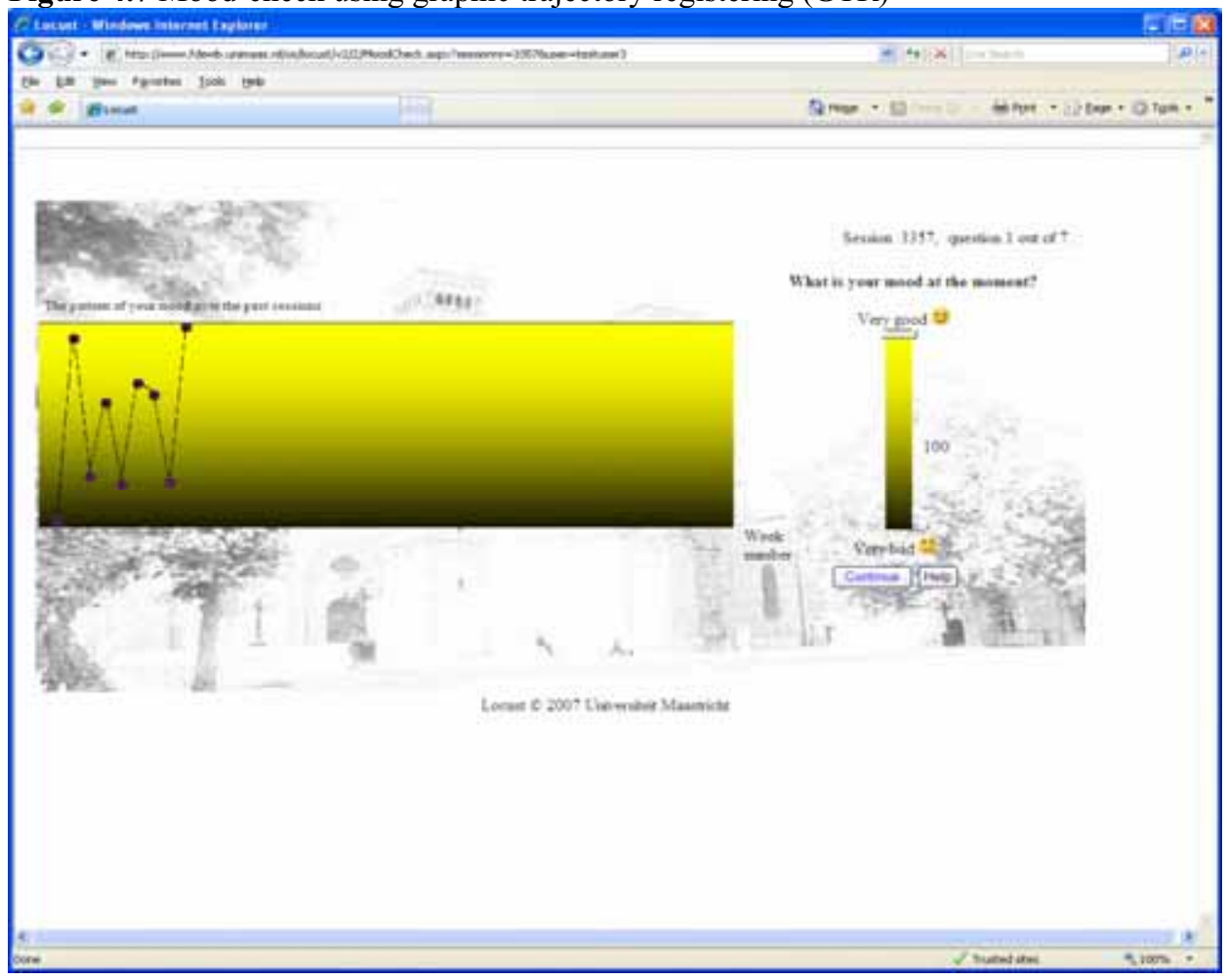

Note 1: To assist real-time, incremental trajectory scoring, some extra system properties were added. If the respondent slides down with the bar (now positioned at 100), the last point in the graphic display slides down with it.

Note 2: To increase precision, on the right side of the bar an integer indicated the position of the lever. The lever is now showing 100 (initial position).

Note 3: This graph is subject-specific and displays the subject's unique developmental history. Below the graphic display are the week numbers in which the subject filled out the questions. By moving over it with the mouse, the exact date of entry appears. This serves to assist person-specific, historically tailored display of longitudinal change.

Note 4. We fixed the position of the week numbers in the graphic display on purpose. If spatial distance between the weeks differs with the number of sessions in the attitudogram, it would give a non-equivalent impression of development in different iterations of measurement.

Note 5. In this item we used the first two elements of GTR, (1) person-specific, historically tailored display, and (2) real-time, incremental trajectory scoring. To save response time, we chose not to use RAD (retrospective adjustable display; the third element in GTR) in this item. 
Figure 4.8 Sketch of a clicking route in the event-tracking system

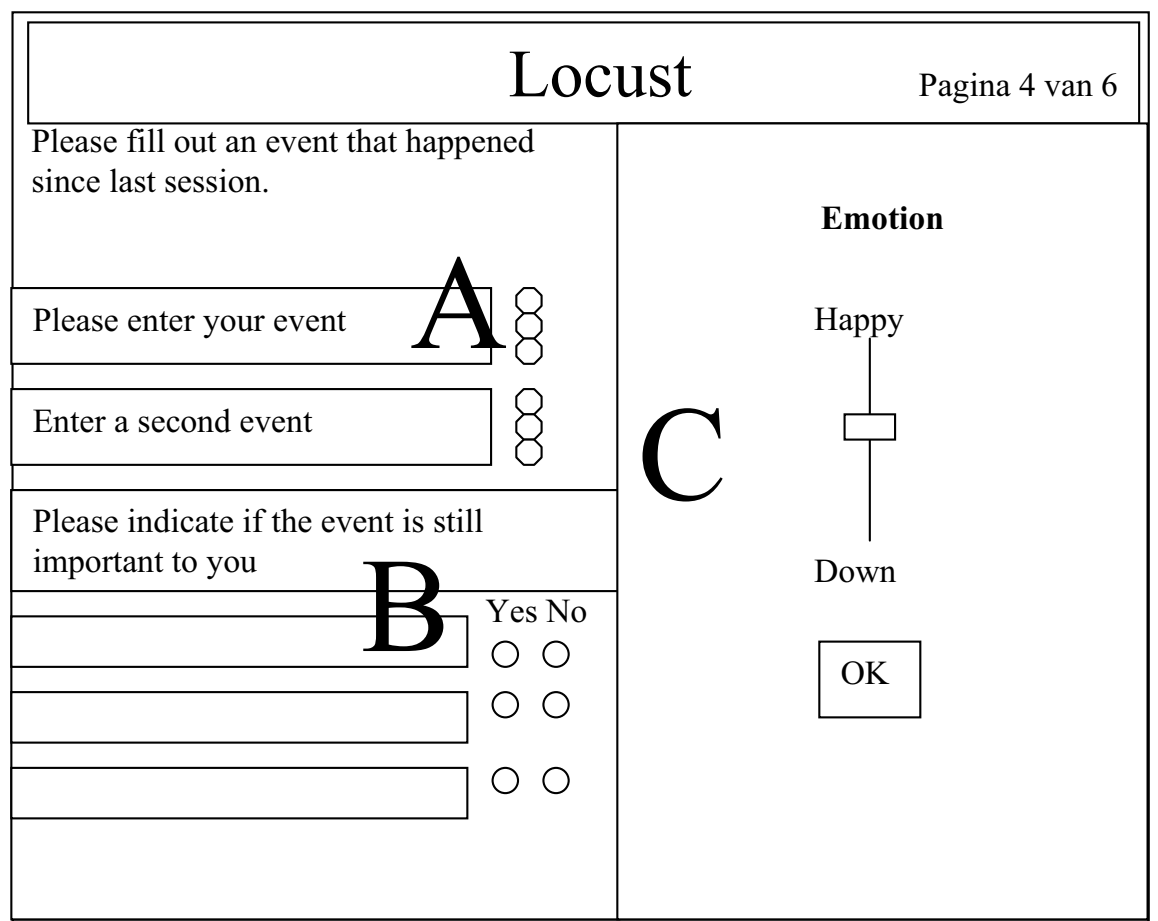

Note 1: $\mathrm{A}, \mathrm{B}$, and $\mathrm{C}$ indicate a clicking route through an event screen.

Note 2: If the respondent is still entering information at $\mathrm{A}, \mathrm{B}$ and $\mathrm{C}$ are invisible (see Figure 4.7)

Note 3: If the respondent is entering information at $\mathrm{B}$ or $\mathrm{C}$, previous elements on the page turn grey (see Figure 4.9).

Note 4: At B events entered in the previous sessions appear on the screen to be judged on whether they are still important (yes or no).

Note 5: At $\mathrm{C}$ the subject rates to what degree the most recently entered event had emotional impact 
Figure 4.9 Entering events (upper figure), event tracking (middle figure), event-related question (lower figure)

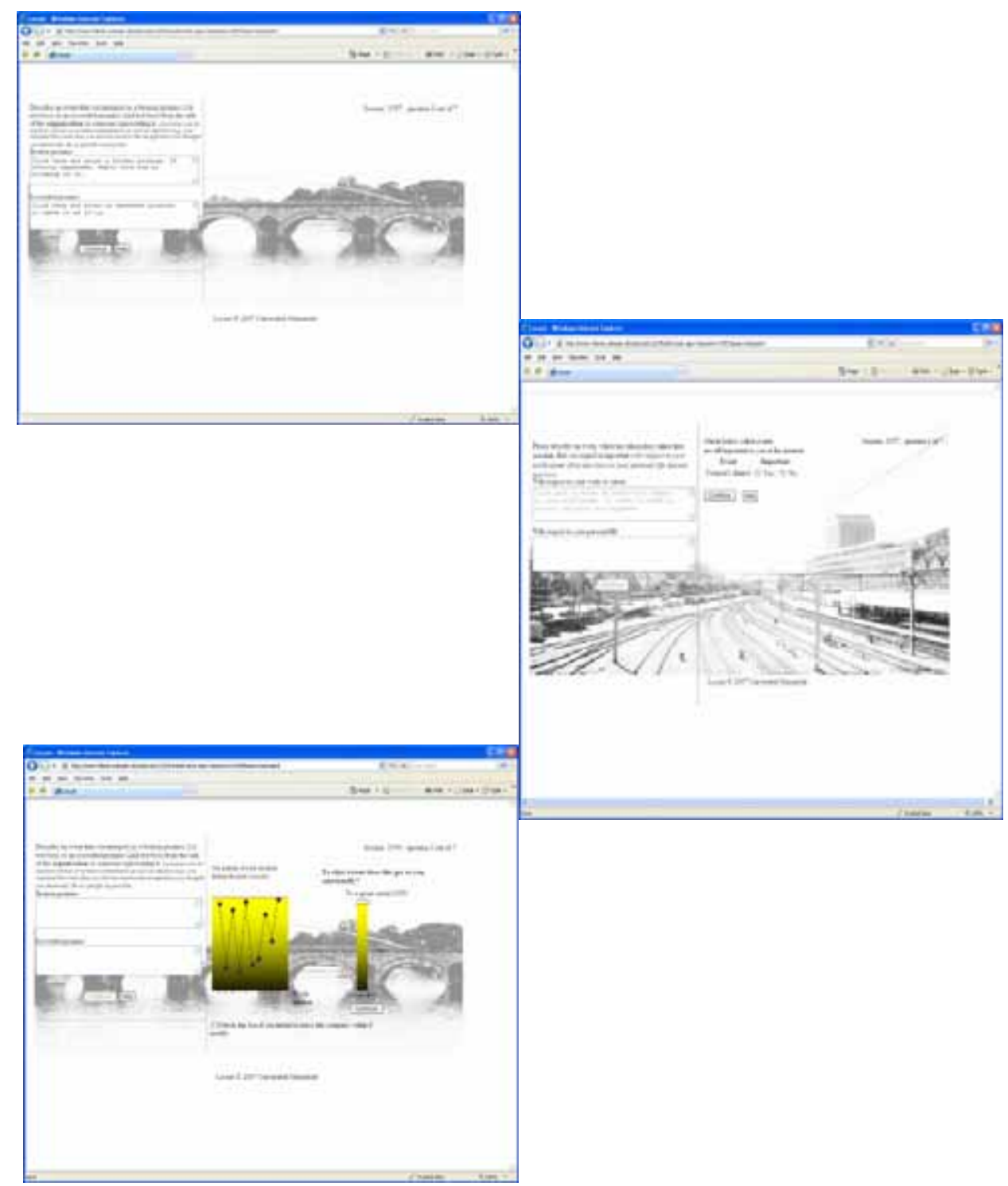

These three pages are three consecutive features on the same page, as explained under Figure 4.8. First the respondent enters an event. Then previous events (entered in the previous sessions) re-appear. After the respondent has entered whether each of the events is still important to him/her, she goes to the next page where LOCUST asks the respondents to what extent the most recently entered event is still having impact. In the latter we used the first two elements of GTR, person-specific, historically tailored display, and real-time, incremental trajectory scoring. To save response time, we chose not to use RAD (the third element in GTR) in this item. 
Figure 4.10 Gamma change check - three drop boxes with adjectives

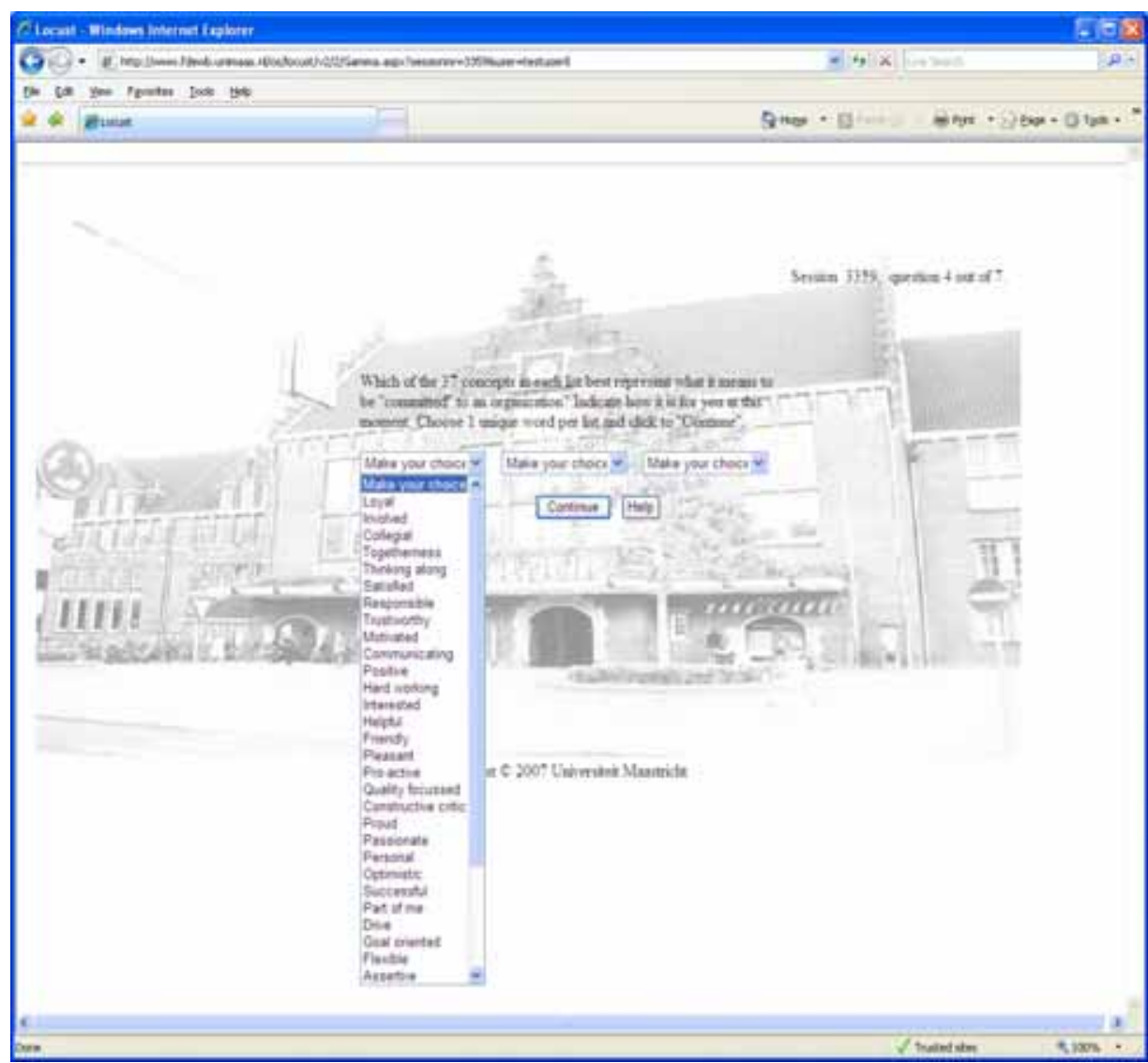

Note 1: the adjectives in the drop-box came out of a free-association task in Pilot project (Valk, 2006, see Appendix E)

Note 2: the order of the adjectives is the same in the three boxes; the order of the adjectives in the drop boxes is set according to their degree of perceived association with commitment (Valk, 2006)

Note 3: we gave respondents three opportunities to respond to this question. The purpose of this question was to explore what adjectives would highlight early in the response period and if that would differ from adjectives highlighted later on in the response period. Three response options were asked in order to get a more refined picture of potential gamma change. Thus, the three options have nothing to do with the three-component attitudinal operationalization of OC. 


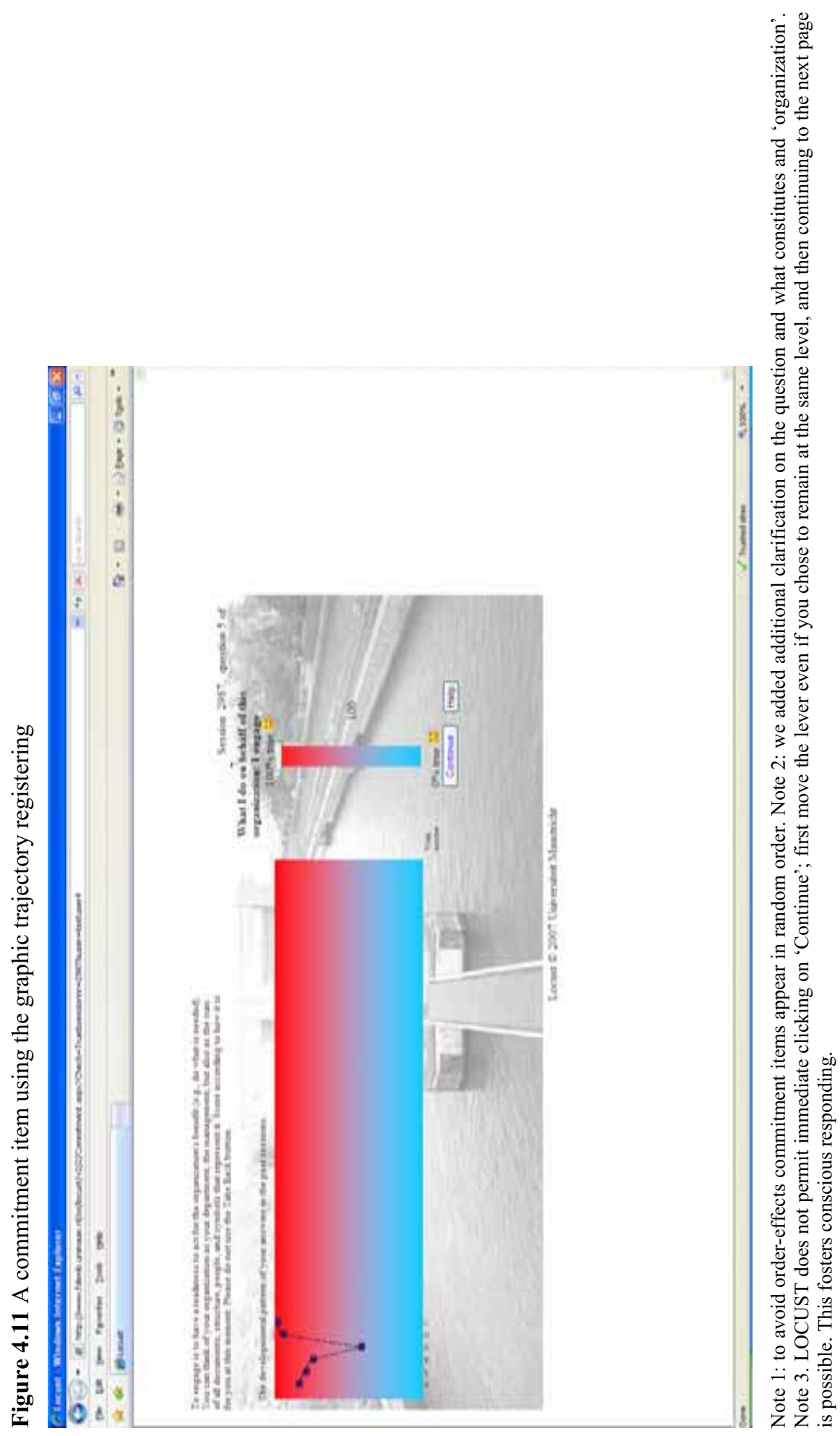




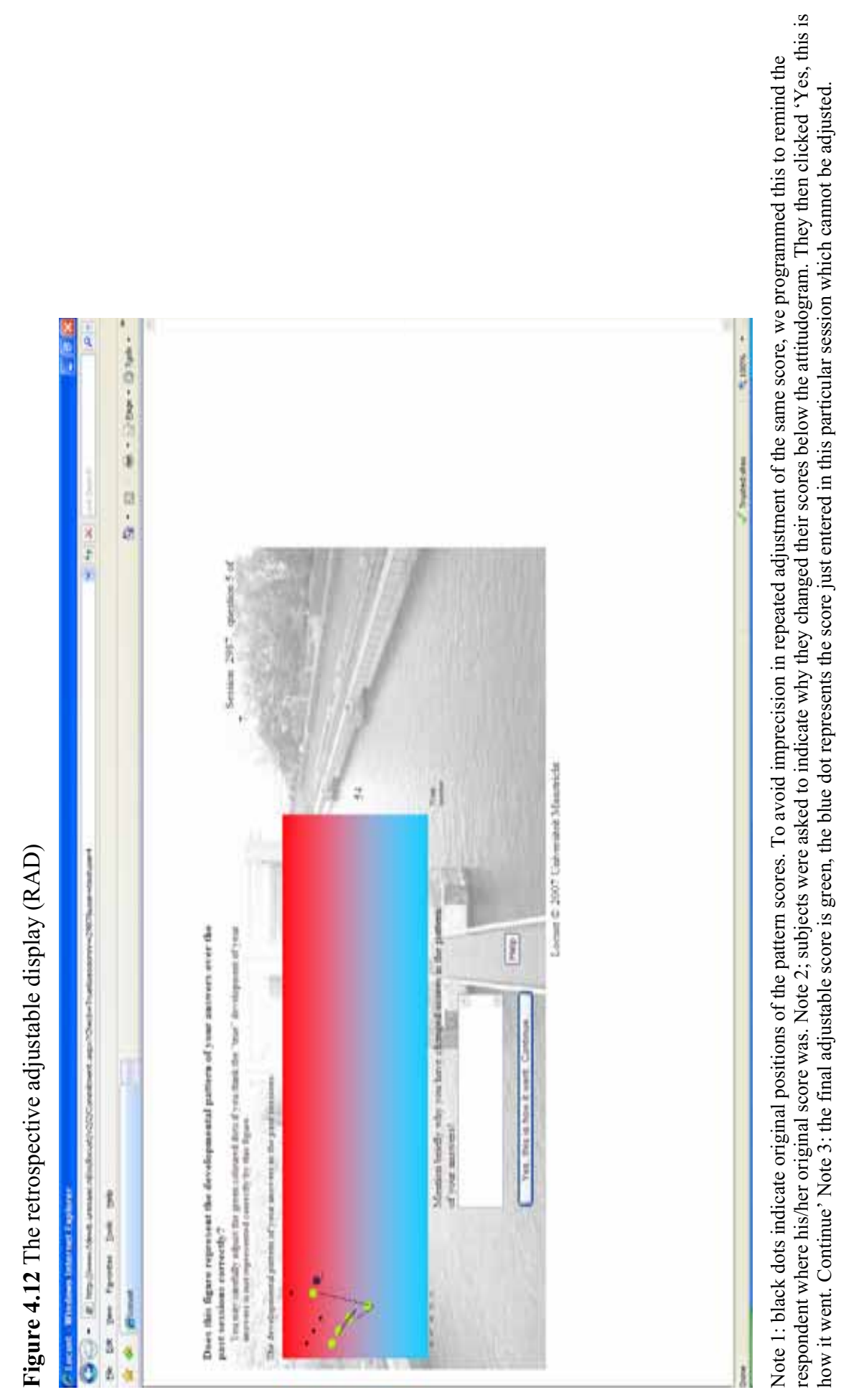


Figure 4.13 'Thank you'-page with room for comments

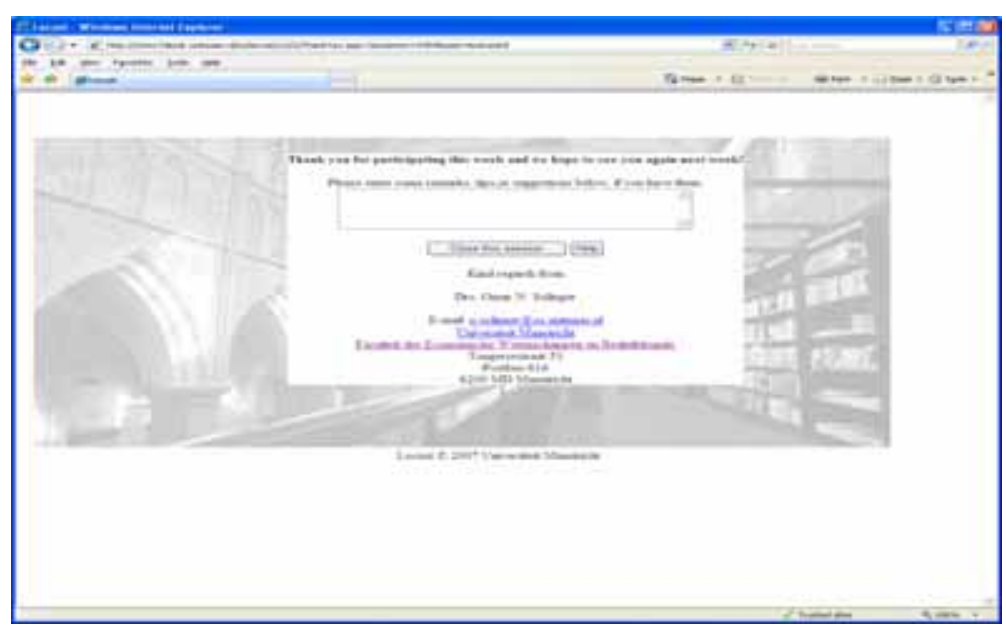

\subsection{Alternative LOCUST variants}

LOCUST-PP The paper-and-pencil version of LOCUST is easy to construct and apply. It comes close to the 'diary method' (Bolger, Davis, \& Rafaeli, 2003), but contains a number of innovative adjustments which brings the methodology close to the conceptual design of LOCUST. Figure 4.14 shows the format we have use in a study by Selders (2009). We will discuss some results of this study in the next section on simulations and try-outs. As shown in Figure 4.14, we have used the same measure of commitment, the same scaling method, visualized as 'thermometers'. Each thermometer indicates one administration ${ }^{34}$.

We approximated the idea of GTR by placing all the consecutive measures in a week next to each other. This is in itself an innovation to paper-and-pencil measures. Optionally, retrospective adjustment of scores is possible as subjects can use pencils and wipe out their previous answers and replace them for new ones. Or the researcher could have respondents confirm their trajectory and correct false hiccups in the trajectory at the end of the time frame. In the latter case, RAD is applied only once, namely at the end of the administration period.

\footnotetext{
${ }^{34}$ Note that this study took two measures during the consecutive days of the week during four weeks.
} 


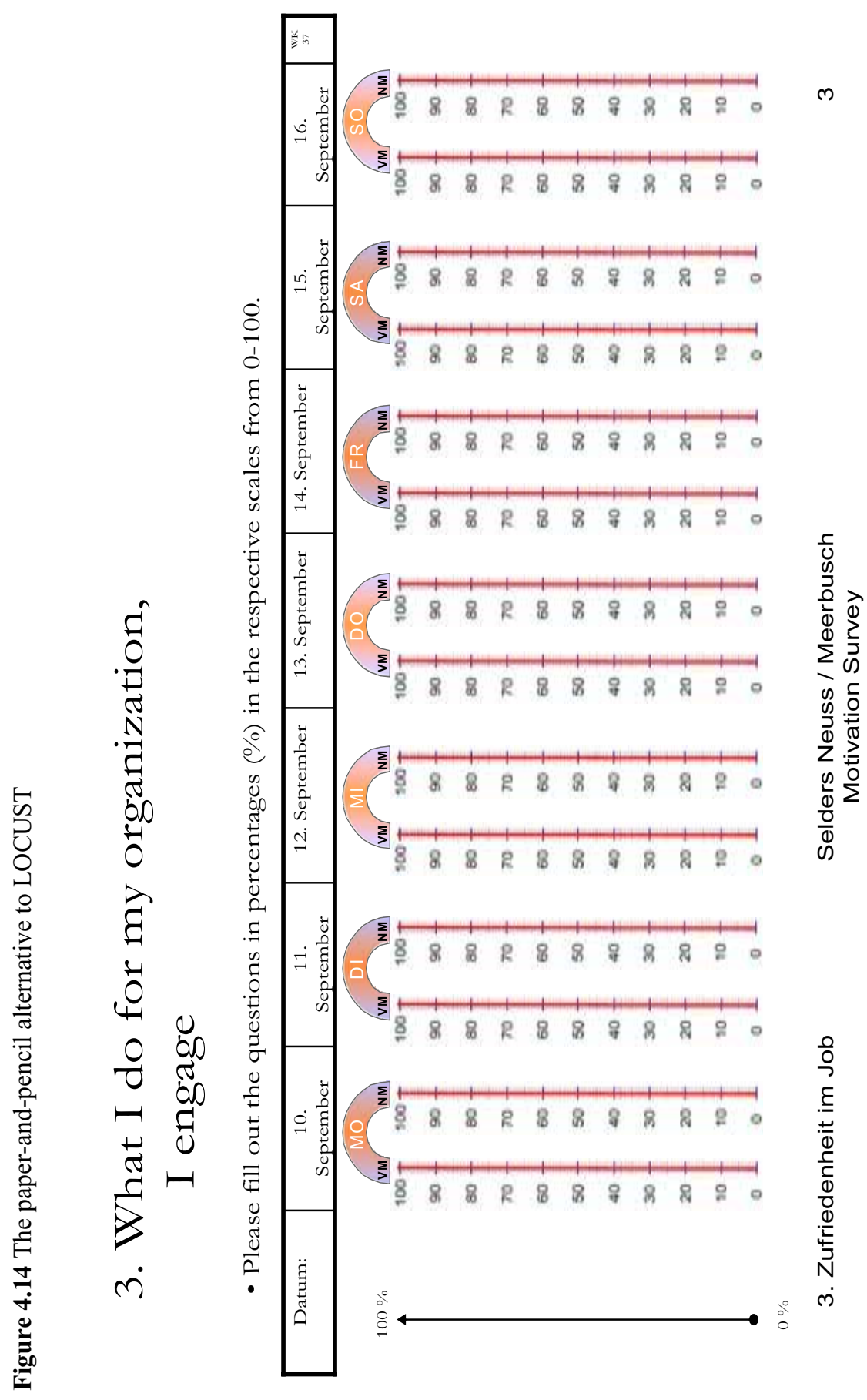


GTR variants As a general note, a researcher is free to decide how to apply the GTR feature. That is, different variants are thinkable: applying all elements $(1 / 2 / 3)$ - which, naturally, is to be preferred - or only the first and second (1/2) or the first and third element $(1 / 3)$. Note that the person-specific, historically tailored display (element 1) always needs to be part of these variants in order not to lose the crucial idea of GTR, which is scoring based on visual information of one's own historical development. For example, one could choose not to allow corrective adjustment (third element) at all and only use real-time, incremental trajectory scoring (element 2) on person-specific graphs (element 1). This is optional when the researcher suspects that incorrect memories of past events may distort retrospective adjustments, based on unique conditions in the research setting. For example, in longitudinal designs on human development through several age cohorts, retrospective adjustment is likely to lead to false recall as previous measures are simply too far away in time ${ }^{35}$.

Another alternative is to use the first and the third element of GTR. In this particular variant of GTR, subjects fill out their items in conventional ways, but get to inspect their unique trajectory (element 1) only at the end of the administration period. Subjects are then asked to adjust (parts of) their trajectory retrospectively (element 3). This is the least desirable variant of GTR because trajectories have not been scored incrementally. Still, it may be a workable option when technical of administrative difficulties have hampered or hindered the real-time, incremental trajectory scoring option. This is the variant we kept in mind when constructing LOCUST-alt, which is basically a conventional online questionnaire, constructed to back-up the LOCUST system.

Another reason to use the $1 / 3$ variant is when a researcher has conceptual reasons to expect stable patterns (e.g., when repeatedly measuring personality characteristics in a particular longitudinal design). The retrospective adjustable display (RAD) can then be applied to increase the reliability of discrete measures of personality and 'cure' false hiccups due to distortions typical to longitudinal measurement, such as learning effects, or false recall of previous responses.

\footnotetext{
${ }^{35}$ On the other hand, even in this type of design, corrective retrospective adjustment may still be applied as it could be used to control for scale recalibration which is likely to occur when time intervals are long.
} 


\section{Simulations}

\subsection{Introducing the simulations}

We will discuss the simulations according to the system properties to which they pertain. The operational performance of the LOCUST system was the main bottleneck to its success so we start with this issue. Then we will discuss the requirement of usability, monitoring and prompting, the database-interface, and the performance in the context of high-density repeated measurement (HDRM) in try-outs with varying degrees of measurement density. When discussing LOCUST's performance regarding these aspects we use information gathered in four studies, three of which are pilots, and one of which is the main study in this dissertation. The three pilots were set out to learn about the properties of the system and test whether it was sufficiently robust to continue using it in our main study.

As the amount of work which has been done in separate projects exceeds the limit of this chapter, we have chosen to refer to summaries which are in the respective appendices at the end of this dissertation. In total, we did four studies with were directly related to the performance of the LOCUST system. We call these studies Pilot 1 to 3, and the main study. Pilot 1 was a four-week pre-pilot (weekly measures) among 15 friends and colleagues, which was meant to increase knowledge on how respondents relate to the system in general and how its innovative features (e.g., the attitudogram) would 'land' with the users. Pilot 2 was a stress-test where we assessed the LOCUST system's performance in an unrelated research area, namely the development of language proficiency among 171 non-native students following a Dutch course at the Maastricht University Language Centre ${ }^{36}$ (Berenbroek, 2007, see Appendix C for a summary). Students in the Language Centre could take a 7, a 9, or an 11 week course. The final sample consisted of 17 students in the 7-week course, 13 students in the 9-week course, and 26 students in the 11-week course. Thus, the sample consists of these particular sub-groups. In all sub-groups we took weekly. In Pilot 3 we used the paperand-pencil version to LOCUST-P to assess its performance under a highly fine-grained and lengthy temporal design: we took measures on commitment, job satisfaction, mood and organizational events twice a day, 7 days per week, for a total period of 4 weeks (56 repeated measures in total). The sample consisted of 18 German horticulture workers (Selders, 2009, see Appendix D for a summary). The fourth simulation constituted our main study, where we

\footnotetext{
${ }^{36}$ The project was initiated and set out by Omar Solinger, executed by Omar Solinger and Auke Berenbroek (thesis student) and supervised by Daniela Kirchberg, who specializes in the management of multiple goals over time. The project was executed from March to June, 2007
} 
followed $72 \mathrm{PhD}$ graduates entering new firms for a period of 25 weeks. Results of the latter study will be described in chapter 5 . An overview of the simulation studies is provided in Table 4.3.

Table 4.3 Overview of simulation studies

\begin{tabular}{|c|c|c|c|c|}
\hline & Pilot 1 & Pilot 2 & Pilot 3 & Main study \\
\hline $\begin{array}{l}\mathrm{N}=\text { number of } \\
\text { subjects }\end{array}$ & $\begin{array}{l}15 \\
\text { acquaintances }\end{array}$ & $\begin{array}{l}\text { Final sample: } \\
\text { - } 7 \text { weeks: } N=17 \\
-9 \text { weeks: } N=13 \\
\text { - } 11 \text { weeks: } N=26\end{array}$ & $\begin{array}{l}18 \\
\text { horticulture } \\
\text { workers in } \\
\text { German } \\
\text { SME firm } \\
\text { (final } \\
\text { sample) }\end{array}$ & $\begin{array}{l}72 \mathrm{PhD} \\
\text { graduates } \\
\text { entering a new } \\
\text { organization } \\
\text { (final sample) }\end{array}$ \\
\hline $\begin{array}{l}\mathrm{N}^{*} \mathrm{t}=\text { total number } \\
\text { of observations }\end{array}$ & & $\mathrm{N} * \mathrm{t}=514$ & $\mathrm{~N}^{*} \mathrm{t}=742$ & $\mathrm{~N}^{*} \mathrm{t}=1032$ \\
\hline HDRM design & $\begin{array}{l}\text { Four weekly } \\
\text { measures }\end{array}$ & $\begin{array}{l}\text { Weekly measures for } \\
7 / 9 / 11 \text { consecutive } \\
\text { weeks }\end{array}$ & $\begin{array}{l}\text { Two } \\
\text { measures a } \\
\text { day during } \\
\text { four weeks }\end{array}$ & $\begin{array}{l}25 \text { weekly } \\
\text { measures }\end{array}$ \\
\hline $\begin{array}{l}\text { More } \\
\text { information } \\
\text { available }\end{array}$ & $\begin{array}{l}\text { No further } \\
\text { information }\end{array}$ & Appendix C & Appendix D & Chapter 5 \\
\hline
\end{tabular}

\subsection{Operational performance}

As said, the operational performance of the LOCUST system was the bottleneck to its success. We underestimated how many temporal, energetic and monetary resources we would need in order to make the LOCUST system operationally reliable (C2 in the PoR, Table 1). In Pilot 1 the operational reliability was insufficient. Sometimes participants were not able to $\log$ in, levers did not move with the mouse, and 'system errors' occurred abundantly. This is why many respondents quit their participation. The biggest lesson we learnt was that once there is only a tiny malfunction, compliance motivation drops dramatically. Technical lessons for our IT-programmer were multiple.

Unfortunately, in Pilot 2 the operational reliability of LOCUST was again insufficient. Problems encountered earlier were solved, but this pilot revealed major unanticipated weaknesses in LOCUST IT-architecture: if multiple users logged on to LOCUST at the same, their information got mixed-up (28 of 70 users). For example, respondent passwords got exchanged so they could not log in a second time (10 out of 70 
users) or the event-tracking system presented goals that belonged to other users, leading to malfunctions (18 out of 70). It does not come as a surprise that these malfunctions and negative 'word of mouth' accounted for a dramatic drop in compliance. Another technical malfunction in the system was that somehow adjusted scores were saved with numbers higher than 100. As a result, we could not use the data. It was concluded that the constraint of operational reliability was again not met and required extra attention.

In the period after Pilot 2 we spent 4 months of intensive testing mainly to get rid of 'bugs' in the software. After 6 testing rounds with 4 computers and 2 testing rounds in a computer laboratory, the LOCUST system was finally ready for a final and ultimate stresstest which took place on December 15, 2007. We invited 20 colleagues to fill out LOCUST in a laboratory, and asked them to do everything we thought would stress the system. Fortunately, LOCUST survived. And so it happened that LOCUSTv1 was officially born and champagne bottles were opened. LOCUST was ready to be used in the large scale study (the main study) that would start in January 2008. In the main study LOCUST performed well. In less than $2 \%$ of the cases we encountered malfunctions, which we considered satisfactory.

\subsection{Usability}

In the first try-out of LOCUST (Pilot 1) we had 15 friends, colleagues, and acquaintances fill out LOCUST for four weeks alongside a paper-and-pencil survey with open questions tapping into what thoughts and feelings were raised by using the different artifacts of our system. We were especially interested in what kind of responses our interactive features (i.e., GTR and event-tracking) would raise. We learned that respondent reactions were extremely diverse. Some thought that their stable patterns were 'boring' and were inclined to change them (e.g., 'this is a boring curve', 'I feel like changing the curve to make it more volatile'; 'If I enter the same thing over and over again, I feel like I did not enter truthfully'). Other users had the opposite reaction. ('I feel like I did not change my scores because of laziness'). There were also those who hated the interactive features ('I feel like the system does not hear me and I have to tell my story all over again', or 'Again??!'), and those who loved it ('good idea') or were neutral ('Nothing special'). Because of the erratic nature of the responses, we could not draw any conclusions on whether we were on the right track towards meeting our PoR. What did follow from this try-out was that we changed some of the instructions and added a document of 'frequently asked questions', which would be administered to each participant to whom LOCUST was new. 
Additionally, LOCUST allowed participants to leave comments after each session (see Figure 4.13). We used these comments to investigate the number of complaints and compliments (PC-R4.2). In total, we received 21 complaints of technical nature (i.e., complaints on the operational reliability of LOCUST), and 29 complaints related to the usability of LOCUST. These numbers amount to $2 \%$ and $3 \%$ (respectively) of the total number of 1032 completed sessions. We used the complaints to repeatedly update our file of 'frequently asked questions' sent around to users who were new to the system. We had the impression that, as the information in the file of 'frequently asked questions' became more and more sophisticated, the number of usability complaints decreased.

We received 8 compliments of different users ( 5 in writing, and 3 through personal communication), which is considerable given the fact that it is generally uncommon to leave positive feedback in self-report surveys. After all, 8 comments from different users imply that $9 \%$ (out of 72 participants) had such a positive 'feel' with the instrument that they felt the need to compliment the researchers.

Attrition and compliance rates

In Pilot 1 we had almost complete attrition due to operational malfunctions - only 2 out of 15 respondents continued participation until the last week. In Pilot 2 we recorded an attrition rate of $60 \%$ after sign-up. That is, only $40 \%$ of the students actually participated in the study after signing up for it. This may have been due to the procedure. We collected the sign-up sheets during Dutch classes in a classroom. Students signed up because of the desire not to lose face to the group. Among students who started participating in the study (i.e., those who logged on to LOCUST at least once) $38 \%$ dropped out before the third week. Among those who filled out more than three LOCUST sessions attrition rates amounted to $11 \%$ in the 7 -week course, $45 \%$ in the 9 -week course, and $55 \%$ in the 11-week course. The non-compliance rate - which is the average number of missing sessions relative to the average total duration of participation - is relatively good: .27 in the 7 week course, .24 in the 9 week course, and .09 in the 11 week course. The latter compliance rate (i.e., in the 11-week Dutch course) is upwardly biased because of the high attrition rate. That is, we only measured compliance of 'survivors'.

In Pilot 3 attrition and compliance rates were very good. There was no attrition at all and the compliance rate amounted to .26. (266 missed sessions out of 1008). Finally, we regarded 'attrition' as having less than 6 completed sessions, or dropping out before the $8^{\text {th }}$ week of participation in the main study. Attrition rate amounted to $23 \%$, which equals 19 of 81 initial participants. We learned that attrition and compliance are heavily influenced by the 
operational reliability of the system. We also learned that attrition does not need to drop dramatically in a HDRM design when LOCUST is used.

\subsection{Monitoring, prompting, and incentive systems}

During Pilot 1 and Pilot 2 the only way to monitor participation compliance was to check the MSAccess database server whether participants had logged in to LOCUST. This was tedious because the database presents the sessions in chronological order, and does not primarily distinguish user information. That is, the database was not ordered according to participant information, but according to session numbers (LOCUST assigns a session number to each new session no matter who it is). Hence, monitoring response compliance had to be done by hand, keeping log books for every participant. Monitoring in Pilot 3 (the paper-and-pencil study) was not possible as we gave participants a 'booklet' which they would hand over only at the end of the data collection period. In the main study we tried to automate response monitoring with a newly added program called 'Locustmanager'. This program had an option where $\log$ information could be requested for each particular user. It allows for checking what information is known about a particular user in the database. Observing response compliance was made easier when we created a separate user monitoring system in MSAccess. But keeping the monitoring system up-to-date still had to be done by hand, using the 'locustmanager' as input. In sum, the monitoring system is still in its early stages and tedious to operate for researchers. Automation is highly desirable. The creation of this system has been a classical example of 'learning-by-doing' and 'design-as-you-go' .

In all studies prompting (i.e. inviting respondents to a session) was done via e-mail, except in Pilot 3 where no prompting was used at all. In Pilot 1 and 2 we always used the same e-mails. We noticed that in Pilot 1 and 2 the practice of keeping on sending the same reminder e-mails after repeated neglect from the side of the respondent did not improve or prevent attrition. Therefore we used tailor-made prompting e-mails in the main study. Those who participated every week always got the same reminder e-mail. Those who missed 2 or more sessions in a row got a different e-mail addressing respondents on a first name basis (e.g., 'Dear Gina, LOCUST misses you'). By sending tailor-made e-mails we had the feeling that we managed improve the degree of compliance. However, sending these tailor-made emails was done by hand and, thus, a time consuming activity. A subsequent innovation was to use the mail-merge option in Word 2007. This allowed us to send out tailor-made promptings to all participants, that is, including first name, username and password. 
Compliance was stimulated by the use of diverse incentive systems (see Figure 4.2). Participation in Pilot 1 was voluntary and no incentive systems were used. In Pilot 2 we held a lottery. The first prize was a voucher for a dinner-for-two in a local restaurant (100 Euro's), the second prize was a ticket for two persons to go to the cinema. In Pilot 3 we did not use an incentive system as the student carrying out the research was familiar with many of the participants who - consequently - complied out of personal favor . In the main study we took a lesson from our experiences in Pilot 2 which had dramatic attrition rates. In the main study each participant could earn 1 Euro per completed session which would be paid if he/she had filled out at least $80 \%$ (i.e., a minimum of 20) sessions. Thus, participants could earn a total of 25 Euro's by participating in our study. In addition, we awarded those who filled out all required sessions (25) with a chance to win a weekend-for-two in lovely Maastricht.

\subsection{Database}

As said, the database was structured according to session numbers, not according to participants. This structure was chosen for optimal data-exchanges spread during a session between the user and the database. The structure was meant to save a considerable amount of waiting time in between the consecutive LOCUST pages. After all, we thought it was 'essential' (see PoR in Table 4.1) that a LOCUST-session should not take more than 4 minutes. Thus, the database had to be constructed in a way that minimized the amount of communication back and forth with LOCUST software (i.e., the user-interface; see Figure 4.2). However, we found in Pilot 2 that retrieving information usable to the researcher was highly tedious. To give an impression, creating a full database (by hand) of 50 participants costed a total amount of 3 weeks of full-time work. This experience taught us that there is a need for a 'locustmanager' to retrieve the needed information in a workable time-series format. In the main study the locustmanager was ready and the original database was converted to a time-series format in Excel. Conversion to Excel with the locustmanager was easier said than done. For example, we were still unable to retrieve information on changed scores (i.e., from the RAD). Moreover, the amount of columns needed exceeded the amount which Excel 2003 permits. Thus we could not see the 'full picture' and had to make selections.

Database performance The transfer of numerical values from the online user interface to the database generally functioned well, although we encountered some problems. The first problem was the counting of the number of 'pixels' in our graphic response 
medium, which was sometimes unreliable. For example, an indicated score of ' 50 ' would sometimes appear in the database as ' 51 ' or ' 49 '. Deviations larger than 1 were never encountered. This degree of unreliability is inherent to the JavaScript component that we used. The second problem was that in Pilot 2 we discovered that some events were not saved in the database. This was due to a 'bug' in the LOCUST software. After Pilot 2 we quickly repaired this malfunction. Thirdly, halfway the main study we discovered that LOCUST did not save all retrospective adjustments from the RAD database. Luckily we discovered the problem and were able to save retrospective adjustment of most subjects who entered after. These experiences clarify that a well-functioning database is a crucial property of a measurement system.

\subsection{Reliability and validity of LOCUST measures}

Until now we have discussed technical properties of the LOCUST system which are critical for operation, but the bottom line is whether it delivers reliable and valid trajectories of organizational commitment in the context of high-density repeated measurement. We had only one opportunity to assess the classical internal consistency reliability of our commitment measure, which was at the moment when potential participants signed up for participation in the main study (Cronbach alpha $=.78$, see chapter 5 ). To assess the reliability of the OC trajectory, we inspected the predictability of individual patterns (PC-R1.1). In an exploratory analysis of the main study trajectories (Odink, 2009, personal communication) 39 trajectories were analyzed using a curve fitting analysis, using the exponential function $y=a^{*} \exp \left(b^{*} x\right)+$ $\mathrm{c}^{*} \exp \left(\mathrm{d}^{*} \mathrm{x}\right)$. Adjusted R-squares varied between .50 and .99 .29 out of 39 patterns yielded an adjusted correlation higher than .70, 17 out of which showed fit indices higher than .90 . Had we not used the 'attitudogram' medium we doubt we could have obtained such a high degree of predictability of change. This shows that there is some preliminary evidence of temporal reliability - in the sense of the precision by which a pattern is (re)produced (see Appendix B).

The dynamic relationships among attitudinal commitment facets (affect, cognition, action readiness) lived up to our requirement (PC-R1.2) which was that dynamic correlations between attitudinal dimensions should be higher than .20 and lower than .90 . In Pilot 3 the dynamic correlation between affect and cognition was .42 , the dynamic correlation between affect and action readiness was .40 , and the dynamic correlation between cognition and action readiness was .61 . All these correlations were significant $(p<.01)$. In the main study these correlations were .76 for affect and cognition, .68 for affect and action readiness, and 
.83 for cognition and action readiness. Again, all these correlations were significant $(p<.01)$. All in all, these findings show that our attitudinal measure of commitment has sufficient construct validity in a temporal research context.

In many of the cases (in the main study) small as well as large 'hiccups' in observed patterns could be meaningfully related to organizational events. As an illustration, Figure 4.15 shows two particular cases in which large as well as small discontinuities can indeed be linked to the incidence of events in our sample: 'Christmas holidays' to entrant 87 and 'illness' to entrant 98. In these particular cases, the LOCUST system had performed well in what we called 'temporal sensitivity' ( $\mathrm{R} 2$ in the PoR, Table 4.1). This is evident when comparing the picture on the left, which indicates a major disruption, to the picture on the right, which shows only a minor - though, meaningful - disruption. It indicates that although evaluated subjectively - LOCUST is sufficiently sensitive to capture even small changes in OC. The measure also performed well on construct validity (R1.3 in the PoR) as it captured what we intended to measure: person-specific change in commitment. LOCUST also demonstrated concurrent validity in Pilot 3 by yielding significant dynamic correlations between the incidence of affective events and OC trajectories (dynamic $r=.36$, in Selders, 2009). This confirms earlier findings by Bentein et al. (Bentein, Vandenberg, Vandenberghe, \& Stinglhamber, 2005) who demonstrated similar findings across a time frame of six months, taking commitment measures every three months.

Figure 4.15 Relating large and small discontinuities to events.
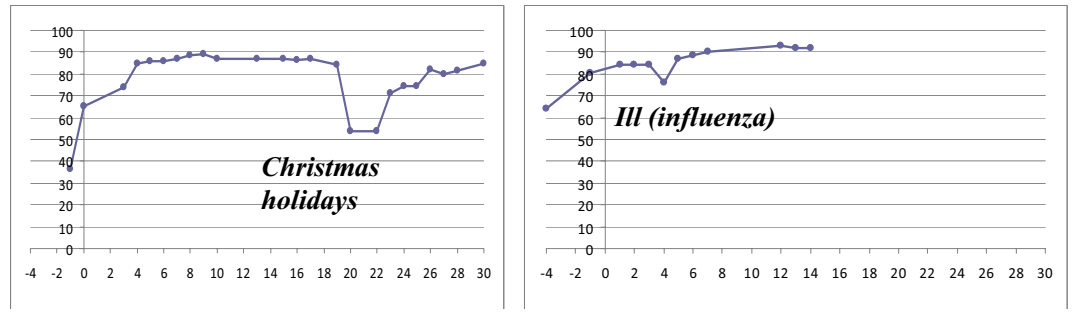

In Pilot 3 the commitment measure under HDRM displayed satisfactory concurrent validity (R1.4 and R1.5). That is, individual patterns of organizational commitment were highly related to individual patterns of mood (dynamic $r=.68$ ) as well as individual patterns of job satisfaction ( $\mathrm{r}=.74$, Selders, 2009, see Appendix D). The data on mood trajectories also showed interesting dynamic relations with separate attitudinal components. Mood correlates strongly with the affective and behavioral component, but shows only weak relations with the 
cognitive component of organizational commitment. Interestingly, the relationship between affective events and mood disappeared when time-lagged relations were analyzed; they were predominantly insignificant (Selders, 2009). This suggests an immediate effect only, as would be expected of a mood impact which is transient by definition. The strong dynamic relationship between individual patterns of mood and job satisfaction (measured with the LOCUST system) confirm findings in previous literature (Fuller et al., 2003). Moreover, the strong dynamic relationship between organizational commitment and job satisfaction is congruent with findings in previous literature where these two work attitudes are portrayed as concurrent phenomena that are related in an ongoing reciprocal influence relationship (Currivan, 1999; Farkas \& Tetrick, 1989).

Interestingly, the main study showed considerably lower dynamic correlations between commitment and mood trajectories (dynamic $r=.43$ ). This is probably largely due to the fact that in this study we used weekly measures. Thus, the degree of temporal relatedness with mood trajectories seems largely contingent upon the temporal design which is employed. That is, the more fine-grained the design, the closer commitment trajectories match mood trajectories. This is only logical as in Pilot 3 both variations in mood and OC were measured twice a day.

\section{$6 \quad$ Evaluation and decision making}

\subsection{An evaluation of the system's properties}

Reflecting on to the Program of Requirements, the main impression is that our conceptual design has been successful on requirements that we designated as 'essential', but less successful on elements that were only 'desirable', or 'not really needed'. Table 4.4 provides an overview of the results of our simulations in the Pilot 2, Pilot 3, and the main study held against the Program of Requirements (PoR) and its translation into 'measurables'. Had we not used the LOCUST system we doubt we could have gathered so many responses from our users in Pilot 2, 3, and the main study $(\mathrm{N}=514,741$, and 1032, respectively). Pilot 1 and Pilot 2 have been plagued by technical malfunctions. Therefore we cannot interpret LOCUST's usability from these particular simulations.

LOCUST does a good job on the requirement of sensitivity to change (R2) as observed change in commitment was related to change in mood and job satisfaction. 
Moreover, change could be meaningfully related to reported events in Pilot 3 and the main study. From these studies we can conclude that the GTR's - showing past responses in a graph - is an adequate feature to improve the reliability of observed change. Next, it makes the measurements sufficiently robust against re-use in high-density/high-frequency longitudinal designs (R3), because LOCUST has yielded OC patterns with significant concurrent relationships. That is, both in Pilot 3 (where measures were taken twice a day during four weeks) and in the main study (25 weekly measures) criterion-related validity could be demonstrated (PC-R3.1). What is more, the 3 single-item measures indicating affect, cognition, and action readiness have shown acceptable validity in a temporal context (R1). These findings challenge the dominant skepticism regarding single-items measurement as options for valid and reliable measurement as these measures have shown adequate concurrent validity with job satisfaction (PC-R1.5), discriminant validity with mood measures (PC-R1.4), construct validity in relation to event occurrences (PC-R1.3), and adequate inter-component relations in the attitudinal measurement of OC (PC-R1.2). In fact, single-item measurement is practically imperative rather than dangerous in the context of high-density repeated measurement. Last - but not least - an appealing and interactive userinterface in combination with the (relative) non-intrusiveness of the system has served well to diminish attrition below the 50\% threshold (PC-R4.1) in Pilot 3 and the main study.

In contrast to its high performance on the usability and on the reliable and valid measurement of commitment trajectories, LOCUST performed badly on the time-efficiency of monitoring response compliance (R5 and S2.2) and on the performance of the database (R6.2). Too many activities still had to be computed by hand, which is tedious and prone to human error. Moreover, crucial information got lost (e.g., retrospective adjustments in Pilot 2 and the main study) or got distorted (e.g., an error band of $1 \%$ ).

On the other hand, LOCUST functioned well on completion time and the operational use of the alternative systems (S3). For example, see the good performance of the paper-andpencil alternative in Pilot 3. The effectiveness of the prompting procedure improved across the four pilot studies, but its efficiency still needs considerable further improvement. Lastly, the operational reliability improved across the four studies but it still needs attention and improvement in following iterations of product design.

The beta change detection feature could not yet be tested due to the fact that LOCUST was plagued by technical malfunctions. Our gamma change detection feature worked well in the sense that proper measures were recorded, but not yet analyzed. 
Table 4.4 Evaluation of LOCUST performance against the PoR and its criteria

\begin{tabular}{|c|c|c|c|c|}
\hline \multirow[t]{3}{*}{$\begin{array}{l}\text { Program of } \\
\text { Requirements } \\
\text { element } \\
(\text { PoR; Table } 4.1)\end{array}$} & $\begin{array}{l}\text { Performance } \\
\text { criteria } \\
\text { (Table } 4.1)\end{array}$ & $\begin{array}{l}11 \text {-week Pilot at the } \\
\text { Language Centre }\end{array}$ & $\begin{array}{l}\text { Paper-and- } \\
\text { pencil study: } 56 \\
\text { time moments in } \\
4 \text { weeks }\end{array}$ & $\begin{array}{l}25 \text {-week } \\
\text { organizational entry } \\
\text { study }\end{array}$ \\
\hline & & $\begin{array}{l}\text { Sample: } 51 \text { foreign } \\
\text { students learning } \\
\text { Dutch }\end{array}$ & $\begin{array}{l}\text { Sample: } 18 \\
\text { German } \\
\text { horticulture } \\
\text { workers }\end{array}$ & $\begin{array}{l}\text { Sample: } 72 \text { Belgium } \\
\text { and Dutch PhD } \\
\text { graduates }\end{array}$ \\
\hline & & $\mathrm{N} * \mathrm{t}=514$ & $\mathrm{~N} * \mathrm{t}=741$ & $\mathrm{~N}^{*} \mathrm{t}=1032$ \\
\hline \multirow[t]{5}{*}{$\begin{array}{l}\text { R1 Reliable and } \\
\text { valid person- } \\
\text { specific } \\
\text { measurement of } \\
\text { change in OC }\end{array}$} & $\begin{array}{l}\text { PC-R1.1 } \\
\begin{array}{l}R^{2} \text { of individual } \\
\text { trajectories must } \\
\text { exceed } .30\end{array} \\
\end{array}$ & $\begin{array}{l}\text { Not applicable } \\
\text { (Henceforth: n.a.) }\end{array}$ & $\begin{array}{l}\text { Very good: OC } \\
\text { relates } \\
\text { significantly to } \\
\text { job satisfaction, } \\
\text { mood, and } \\
\text { critical events }\end{array}$ & $\begin{array}{l}\text { Very good: OC } \\
\text { level relates to } \\
\text { conventional } \\
\text { predictors exactly as } \\
\text { observed in } \\
\text { previous studies } \\
\text { (chapter 5) }\end{array}$ \\
\hline & $\begin{array}{l}\frac{\mathrm{PC}-\mathrm{R} 1.2}{\text { Dynamic }} \\
\text { correlation among } \\
\text { OC facets is not too } \\
\text { low }(>.20) \text { and not } \\
\text { too high }(<.90)\end{array}$ & & $\begin{array}{l}\text { Very good: } \\
\text { Dynamic } \\
\text { correlations }>.40 \\
\text { and }<.61(p< \\
.01) .\end{array}$ & $\begin{array}{l}\text { Very good: } \\
\text { Dynamics } \\
\text { correlations }>.68 \\
\text { and }<.83(p<.01)\end{array}$ \\
\hline & $\begin{array}{l}\text { PC-R } 1.3 \\
\text { Temporal variation } \\
\text { in OC must be } \\
\text { significantly } \\
\text { associated with } \\
\text { event occurrence }\end{array}$ & n.a. & $\begin{array}{l}\text { Very good. OC } \\
\text { is significantly } \\
\text { related to the } \\
\text { occurrence of } \\
\text { affective events } \\
\text { (Appendix D) }\end{array}$ & $\begin{array}{l}\text { Very good. Change } \\
\text { is OC could easily } \\
\text { be related to the } \\
\text { occurrence of } \\
\text { events. }\end{array}$ \\
\hline & $\begin{array}{l}\text { PC-R } 1.4 \\
\text { The dynamic } \\
\text { correlation between } \\
\text { OC and mood must } \\
\text { not exceed } 90\end{array}$ & n.a & $\frac{\text { Good: Dynamic }}{r \text { is } .68}(p<.01)$ & $\begin{array}{l}\text { Good: Dynamic } r \text { is } \\
.43(p<.01) .\end{array}$ \\
\hline & $\begin{array}{l}\text { PC-R } 1.5 \\
\text { The dynamic } \\
\text { correlation between } \\
\text { OC and job } \\
\text { satisfaction must be } \\
\text { significant }\end{array}$ & n.a & $\begin{array}{l}\frac{\text { Very good: }}{\text { Dynamic } r \text { is } .74} \\
(p<.01) .\end{array}$ & n.a \\
\hline $\begin{array}{l}\text { R2 Sensitivity to } \\
\text { change }\end{array}$ & $\begin{array}{l}\text { In individual cases, } \\
\text { changes in OC can } \\
\text { be meaningfully } \\
\text { linked to the } \\
\text { incidents of events - } \\
\text { no matter how small } \\
\text { the change }\end{array}$ & n.a. & $\begin{array}{l}\text { Very good: The } \\
\text { dynamic } r \text { of } \\
\text { affective events } \\
\text { - OC is } .36(p< \\
.01) .\end{array}$ & $\begin{array}{l}\text { Very good: Minor } \\
\text { as well as major } \\
\text { discontinuities can } \\
\text { be meaningfully } \\
\text { linked to events }\end{array}$ \\
\hline & & & & \\
\hline
\end{tabular}




\begin{tabular}{|c|c|c|c|c|}
\hline $\begin{array}{l}\text { R3 Robustness } \\
\text { against re-use }\end{array}$ & 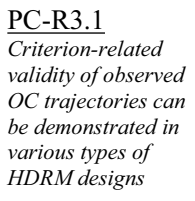 & $\begin{array}{l}\text { Unable to analyze } \\
\text { due to technical } \\
\text { malfunctions } \\
\text { during experiment }\end{array}$ & $\begin{array}{l}\text { Not part of this } \\
\text { design }\end{array}$ & $\begin{array}{l}\text { See PC-R1.1- } \\
\text { R1.5 in Pilot } \\
2,3 \text { and the } \\
\text { main study }\end{array}$ \\
\hline \multirow[t]{4}{*}{ R4 Usability } & $\begin{array}{l}\text { PC-R4.1 } \\
\text { Low attrition (< } \\
50 \%)\end{array}$ & $\begin{array}{l}\text { Poor: } \\
\text { Attrition after sign- } \\
\text { up: } 60 \% \\
\text { Attrition among } \\
\text { subjects with T }<3 \text { : } \\
38 \% \\
\text { Attrition rates } \\
\text { among participants } \\
\text { with T }>3 \text { : } \\
-7 \text { week course: } 11 \% \\
-9 \text { week course: } 15 \% \\
-11 \text {-week course: } 55 \%\end{array}$ & $\begin{array}{l}\text { Very good: No } \\
\text { attrition at all }\end{array}$ & $\begin{array}{l}\text { Good: Attrition rate } \\
\text { (i.e., less than } 6 \\
\text { measurements) is } \\
23 \% \text {, that is, } 19 \text { out } \\
\text { of } 81\end{array}$ \\
\hline & $\begin{array}{l}\text { High compliance } \\
\text { rate }\end{array}$ & $\begin{array}{l}\frac{\text { Good: }}{-7 \text { week course }} \\
\text { no attrition } \\
-9 \text { week course } \\
.24(2.2 \text { out of } 9 \text { ) missed } \\
-11 \text { week course: } \\
.09 \text { (1 out of } 11) \text { missed }\end{array}$ & $\begin{array}{l}\text { Very good } \\
\text { A compliance rate } \\
\text { of } .27(1.94 \text { out of } \\
7) \text { missed: } .26 \\
\text { (266 out of } 1008)\end{array}$ & $\begin{array}{l}\text { Satisfactory: } \\
\text { A compliance rate } \\
\text { of .41(1081out of } \\
\text { out of } 2590 \text { missing } \\
\text { sessions. }\end{array}$ \\
\hline & Complaints & $\begin{array}{l}\text { Poor: All } \\
\text { participants } \\
\text { complained }\end{array}$ & $\begin{array}{l}\text { No complaints } \\
\text { recorded }\end{array}$ & $\begin{array}{l}\text { Moderate: } 29 \\
\text { usability-related } \\
\text { complaints }(3 \%)\end{array}$ \\
\hline & Compliments & $\begin{array}{l}\text { No compliments } \\
\text { recorded }\end{array}$ & $\begin{array}{l}\text { No compliments } \\
\text { recorded }\end{array}$ & $\begin{array}{l}\text { Good: } 8 \\
\text { compliments }\end{array}$ \\
\hline $\begin{array}{l}\text { R5 Monitoring of } \\
\text { response } \\
\text { compliance }\end{array}$ & $\begin{array}{l}\text { Researcher } \\
\text { satisfaction } \\
\end{array}$ & $\underline{\text { Poor }}$ & $\underline{\text { Poor }}$ & $\underline{\text { Poor }}$ \\
\hline R6 Database & $\begin{array}{l}\text { PC-R6.1 researcher } \\
\text { satisfaction } \\
\text { PC-R6.2 (see PC- } \\
\text { R1.4) }\end{array}$ & $\underline{\text { Poor }}$ & $\underline{\text { Poor }}$ & Moderate \\
\hline
\end{tabular}

\subsection{Lessons learnt and future projections}

Aspects where LOCUST performed poorly were the monitoring of response compliance (R5 and S3), the functioning of the database (R6), the operational reliability (C2), the time constraint for the construction of LOCUST (C3), and the monetary constraint (C4). In 
retrospect, relatively poor performance on the functioning of the database and response monitoring could have been avoided if more research attention had been devoted to these aspects earlier in the process. Although our aim was to make a conceptual contribution to the field of longitudinal measurement, the latter aspects are important practical system properties that should - in hindsight - not be overlooked.

The first lesson we take away is that the initial IT-architecture on which LOCUST was based was flawed from the beginning. The use of 'internet cookies' as main communicators between the LOCUST server and the SQL database is highly dangerous in an online survey because cookies can get mixed-up in multi-user environment. Thanks to intensive testing and de-bugging we have managed to 'kill' most of the symptoms, but we could never completely cure the problem. The system as it is only permits up to 20 active users at the same time, which was sufficient for our current purposes.

Other points to take into account regarding the technical improvement of the system is the use of ASP.net and JavaScript as programming languages, which gives troubles in web browsers other than Internet Explorer. For example, the Safari browser and the newest versions of Mozilla Firefox sometimes do not support JavaScript. Or in some large companies the 'slider' does not work due to strong firewalls. Moreover the use of 'pixelcounts' to calibrate the degree of change is vulnerable to a (although very modest) degree of unreliability. Finally, according to our second IT-programmer the use of a professional SQL database server is not necessary; in hindsight we might have used MySql, which is free of charge and just as reliable.

The second lesson learnt is that - in hindsight - we did a poor job on project planning in terms of setting the time frame and the budget. For example, by setting such a low budget we were forced to work with student IT programmers. Had we set a realistic budget (e.g., around 6000 Euro's) we could have hired a professional software developing firm and spared ourselves two years of troubles, de-bugging and emotional despair. On the other hand, working with a student 'on site' has also enriched us as he was able to assist the brainstorming on how to implement an interactive user-interface in the making our measurement system.

The first future steps LOCUST should take is making it researcher-friendly (i.e., more automated and time-efficient), as well as multi-user. Making LOCUST researcher-friendly is necessary since the use of LOCUST has been highly time-consuming for the researcher because reminder e-mails are still sent by hand. Thus, the monitoring as well as the prompting system is unsatisfactory and still open for improvement. Moreover, if the 
researcher wishes to alter the text in LOCUST he/she needs to learn how to cope with software developer language and find his/her way in the 'original code'. Altering the text in LOCUST can easily take up to a couple of days work.

In short, our simulations have opened our eyes for fundamental flaws mainly in the technical design of the system, and in the functioning of the database and response monitoring system. In next versions of the LOCUST system we will try to solve the problems we encountered. Thus, the crafting process has been truly 'cyclical' in terms of operational technicalities.

A potential conceptual objection to that the graphic trajectory registering (GTR) design is that it introduces consistency bias through the process of anchoring. Depicting one's past might prompt respondents to be consistent with it (hence reducing time-related variance). However, to our knowledge consistency bias (as a phenomenon) has never been studied over time. Available research on the need for consistency demonstrates that people are inclined to reconcile to conflicting attitudes at one moment in time. In contrast, GTR measures attitudes as an unfolding process over time where change and 'stickiness' over time is only natural. We do not see the process of anchoring as a problem, but an opportunity to improve longitudinal survey procedures.

A last point we like to make on the alleged 'anchoring problem' is that (1) we do not know whether it really happens in our research context and (2) neither do we know how strong its effect is. As a general note, if there are objections against a new form of test design, their validity can be tested in comparative studies. For example consistency-bias can be tested by comparing the traditional methodology to the GTR design and see if there are significant differences in within-subject variance ${ }^{37}$. This is an interesting area of future research for scientists interested in psychological testing and highly relevant to the study of work attitudes.

We are also aware of potential objections against the corrective survey procedure. Retrospective adjustments of pattern changes could also introduce memory-related biases, embellishment of recollections, regression to the mean, etcetera (Armenakis \& Bedeian, 1982). Many of these objections can and should be studied in future research. For example, it is easy to investigate embellishment of recollections by correlating positive adjustments with the temporal lag between the time of administration and the adjusted score. Thus, if embellishment of recollections exists we should observe more upward adjustments when the

\footnotetext{
${ }^{37}$ We have already done such a study on the subjective development of language proficiency and found no significant difference in time-related variance.
} 
time lag between the previous score and the present is larger. If such a correlation is found the embellishment of recollections can be either proven or falsified. Recall bias can be tested with similar procedures. Comparative studies using a traditional versus a retrospective adjustable design (RAD) can be conducted to judge temporal reliability in either option.

The interesting finding that commitment trajectories match with those of mood when assessed on a daily basis as a function of the temporal design warrants further research and replication. It also poses questions as to what degree of dynamic correlation is still acceptable in the context of assessing a measure's discriminant validity in a certain time grid. Note that Pilot 3 was a study in which we took measures of these constructs twice a day. The fact that these measures pick up some of the 'variance' that is related to mood states is not surprising. In fact, it is even desirable as moods are one of the most basic affective states in the psychological system, affecting not just commitment, but also degrees of happiness, attraction to one's partner, even degrees of appetite. The question is how the dynamic moodcommitment relation can be explained, which calls for further research.

All in all, we can conclude that our dynamic measurement system is successful and that it should be 'valorized' as attractive system for researchers interested in doing temporaldynamic research.

\subsection{Conclusion}

The main distinguishing features of LOCUST are that the role of time and the interests of respondents are taken seriously. Time is taken seriously by consistently focusing on patterns instead of single scores, which is an holistic treatment of time (see chapter 1). Graphic trajectory registering (GTR), one of the most characterizing features in LOCUST, is a type of innovation which aims to apply a holistic treatment of time to the practice of attitude measurement. This measurement format makes different use of self-evaluation by applying it to one one's own change. That is, with person-specific, historically tailored graphs respondents can engage in real-time, incremental trajectory scoring. This does not only increase reliability and validity of the observed temporal patterns, it also creates a positive 'feel' with the instrument. After all, after lengthy usage the instrument may serve as a valuable interactive diary, a tool to increase insight and self-care for respondents. Further, users are taken seriously by setting heavy constraints on response time (i.e., maximum four minutes) and the type of measurement (i.e., single-item questions). 
None of these design choices endangered conventional standards of reliable and valid measurement. In fact, we have been able to obtain highly reliable and valid trajectories. Our decision on the usage of LOCUST is therefore positive. The product up to this point is a workable 'alpha version', in design terminology. Future attempts to create a beta version are advised to pay extra attention to practical design aspects, such as the construction of a readyto-use database and a better response monitoring system.

The measurement system has been developed to fit the specific case of high-density and high-frequency longitudinal measurement of organizational commitment in real-life work situations. But its applicability is not confined to these settings. We believe that LOCUST can be tested and applied in a wide variety of temporal research settings, such as the study of learning curves, company training effectiveness (e.g., relapse), repercussions of organizational interventions, role and job transitions, culture change, and so forth. Even outside of the realm of organizations, LOCUST could be useful. We think of health sciences, such as tracking those who quit smoking, or tracking subjectively experienced pain patterns in various medical disciplines, like anesthesiology, orthopedics or physiotherapy. We can also think of usage in fields like criminology, marriage counseling (attraction patterns; development of conflict), and so forth. In fact, in one of our try-outs we have even applied LOCUST to study the development of language proficiency among non-native Dutch speakers following a Dutch course at Maastricht University Language Centre. We hope that the LOCUST system will inspire other researchers to perform temporal-dynamic research. 


\title{
5 On the temporal form of newcomer commitment: A 25-week study
}

\begin{abstract}
Recently the within-person (temporal) development of organizational commitment among newcomers has interested scholars in the literature on organizational socialization. To extend this work, we take on a temporaldynamic approach and investigate temporal 'aspects of form' in week-by-week individual- and group-level patterns of commitment in a sample of young academics in their first 6 months (25-weeks) of work. We identify five latent trajectory groups and seven parameters of within-person variability (i.e., within-subject mean, initial level, slope, SD, change intensity, change frequency, and pattern ruggedness) and demonstrate that the seven parameters represent three underlying factors of temporal form - level, trend, and variability - and that they are each related to experiential, personal, and historical predictors (in their order of relative importance). Dynamic indicators show promising interrelations: low and decreasing commitment trajectories are significantly more 'rugged' than high and increasing ones, which casts a different perspective on the nature of low and declining commitment. 'Honeymoon-effects' did occur but only in distinct sub-groups. We also found an opposite pattern shape where people are affectively 'warming up' to the organization. All of this suggests that temporal development is not as 'universal' as is often assumed.
\end{abstract}




\section{Introduction}

The first six months of socialization into a new organization are often seen as crucial to the process of newcomer adaptation. Finding adequate entry practices to help new incumbents cope with their new environment, demands, and transitions is not an easy task. Organizational commitment (henceforth: OC) is an established indicator of successful socialization into a new firm environment (Baker \& Feldman, 1990; Bauer, Bodner, Erdogan, Truxillo, \& Tucker, 2007; Saks \& Ashforth, 1997). In addition, creating commitment early on in the process of newcomer adjustment has great strategic value, as it serves to prevent the incidence of voluntary turnover and increases organizational adaptability in the long term (Angle \& Perry, 1981).

From the entrant's perspective, it is often said that 'learning the ropes' in a new organization is characterized by ambiguity and insecurity. Finding one's way is not only finding out who to talk to, what to expect, and what is expected, but also finding out how to relate to the new organization (Vandenberg \& Seo, 1992): Do I belong here? Can I identify with organizational brands and goals? Am I willing to take 'that extra step' for this organization? Questions like these exemplify that entrants are in a process of 'attitudinal repositioning'. This process, by which new incumbents define and revise their stance toward the organization, is a process that evolves over time (Bentein, Vandenberg, Vandenberghe, \& Stinglhamber, 2005; Lance, Vandenberg, \& Self, 2000). In this process, new experiences, surprises, and disappointments require continuous re-evaluation of the attitude towards the organization (Bown, 1996; Louis, 1980). Thus, patterns of newcomer adjustment in general, and patterns of 'attitudinal repositioning' in particular, are unlikely stationary over time.

The question how the these kinds of temporal development in OC can be described and predicted - has interested an increasing number of scholars in the last 20 years (Bentein, Vandenberg, Vandenberghe, \& Stinglhamber, 2005; Lance, Vandenberg, \& Self, 2000; Vandenberg \& Self, 1993). However, the temporal development of OC is highly complex to describe, let alone to predict. For example, some individuals may start off high and then follow an erratic decline, while others start their jobs with low OC and then increase smoothly. Again others start off high, remain stable for a while, then to drop drastically to medium levels of commitment. To date, studies investigating temporal development in OC during organizational entry have reduced this complexity in temporal forms by (1) employing longitudinal designs with only few measurements, typically spanning large time intervals between measurements, and (2) sticking to (mostly linear) proxies of development, defined at 
the aggregate sample level. Thus, OC change has predominantly been described by reducing the complex nature of temporal OC development to aggregate proxies of development, namely a particular starting point (i.e., initial level) and a general linear trend (i.e., rate of change). In this approach, deviations from the 'average development' are seen as theoretically uninteresting.

We argue that reducing temporal development to two parameters only can only provide limited knowledge of temporal development. It is a 'universalistic' approach to temporal form as it obscures the fact that people can have quite different trajectories. Moreover, this approach is also crude because it remains unclear how the process of repositioning and re-evaluation of one's relationship with the organization translates into various forms of micro-level increases and decreases in commitment. We work from a more detailed approach by taking all ensuing temporal forms seriously without reducing them to two parameters only. That is, we demonstrate that other 'aspects of form' are theoretically interesting and explain variance in OC change over and above what is explained by the initial level and the rate of change. Moreover, we aim to study aspects of form shown in individual trajectories or sub-group level trajectories, in contrast to the conventional practice of only studying the aggregate mean of the sample. In short, we ask ourselves the question: What aspects of form can be observed in the temporal (individual and group-level) development of commitment other than the initial level and the rate of change? And how can they be explained?

To this end, we need to take a temporal-dynamic approach, which (among other things) implies the application of a high-density (in our case, weekly measures) and highfrequency (in our case, 25 measurement moments) temporal design. This study takes an exploratory approach, primarily by observing 'what happens' (Roe, 2008a) over a course of 25 weekly measurements within individuals (as opposed to aggregate means) and within different groups of individuals. The first aim of this paper is simply to report what temporal trajectories can be observed with such a fine-grained temporal design, and secondly to explain what we see using conventional predictors. 


\section{The development of commitment after entering the organization}

\subsection{Commitment taking shape}

Newcomers are typically insecure about a large scope of aspects of work life, such as what is expected, who to contact for support (Ostroff \& Kozlowski, 2006), how to 'read between the lines' and understand the organization's culture, how to interpret ambiguous signals, finding out whether they have what it takes to live up to new role expectations (Bauer, Bodner, Erdogan, Truxillo, \& Tucker, 2007), whether they will fit in the new environment (CooperThomas, Van Vianen, \& Anderson, 2004; Saks \& Ashforth, 2002), and the list goes on. Additionally, there is a host of aspects that can potentially affect the newly forming employment relationship. The interpretation of events and social signals in this phase highly influences the formation of attitudes (Salancik \& Pfeffer, 1978). Newcomers are generally vigilant in picking up on even small signals and events that would aid their adaptation process (Louis, 1980). If there is one time frame where job attitudes would be susceptible to change and influence, this is it.

Typical of the process of newcomer adaptation is that the interpretation of events, information, and social cues is expected to be uncertain at the start of the employment relationship and starts taking shape over time. What this particular shape looks like is our main focus of investigation.

\subsection{Literature on commitment change and newcomer adaptation}

Organizational commitment ${ }^{38}$ (OC) is one of most widely studied attitudinal phenomena in the context of newcomer adaptation. It is often regarded as a positive indicator of newcomer adjustment in the context of various socialization programs (Baker \& Feldman, 1990; Ng \& Feldman, 2006). The goal of most research on commitment and newcomer adaptation is to find causal antecedents and consequences of OC (e.g., Williams \& Hazer, 1986). This has resulted in an impressive list of antecedent variables associated with OC (Allen \& Meyer, 1996; Mathieu \& Zajac, 1990; Meyer, Stanley, Herscovitch, \& Topolnytsksy, 2002, for general meta-analyses). For example, role clarity and social acceptance are strongly related to levels of organizational commitment after entry (Bauer, Bodner, Erdogan, Truxillo, \&

\footnotetext{
${ }^{38}$ When referring to organizational commitment, we mean the conceptualization as defined by Solinger, Van Olffen, \& Roe (2008), that is, not regarding normative or continuance commitment as valid components of commitment.
} 
Tucker, 2007). This type of research typically involves a search for psychological 'states' (e.g. perceived support, organization-based self-esteem, job satisfaction, work ethics, and so forth) that correlate positively with high post-entry commitment, presumably because they 'cause it' to be high. A usual motive for this type of research is to explain and prevent the incidence of unwanted turnover. Implied in this branch of literature on newcomer adaptation is that commitment can be enhanced - or, more specifically, that ups and downs in employee commitment can be 'managed' - if appropriate managerial action is taken. However, the degree of commitment change is not explicitly investigated.

Recently, research attention has been focused more explicitly on explaining upward and downward changes in commitment during newcomer adaptation (Bentein, Vandenberg, Vandenberghe, \& Stinglhamber, 2005; Kammeyer-Mueller, Wanberg, Glomb, \& Ahlburg, 2005; Lance, Vandenberg, \& Self, 2000). In this approach positive adjustments are upward and negative adjustments downward revisions of the OC attitude (Mowday, Porter, \& Steers, 1982; Vandenberg \& Seo, 1992). Statistical variance in commitment change is approached as within-subject differences over time, and in between-subject differences in within-subject differences (Chan \& Schmitt, 2000). In this approach parameters of growth trajectories are the main focus of interest. ${ }^{39}$ This approach - which we will call the growth modeling approach - has led to a number of interesting and valuable observations. Common parameters used are the aggregate within-subject mean, initial level and the rate of change (slope) of a growth trajectory, defined on sample level.

With regard to the proportion of variance explained within individuals, KammeyerMueller et al. (2005) reported that $50 \%$ of the total variance could be attributed to withinsubjects variance. Note that this was a study which showed a stable mean trajectory across 5 longitudinal waves (chapter 3). Moreover, the authors show that time-varying models were considerably better able to show the nuances of withdrawal processes (i.e., withdrawal acting as a mediator between OC and turnover) than time-constant models. This shows that - even in relatively stable populations - within-person variability plays an important role in the prediction of turnover from organizational commitment.

High OC levels at Day 1 (i.e., the first day of work) has been explained by a wide range of predictors: high expectations (Lance et al, 2000), volitional job decision (O’Reilly \&

\footnotetext{
${ }^{39}$ Growth modeling has two main analytical traditions: one is based on the random coefficient modeling tradition, called Hierarchical Linear Modeling (HLM; Singer \& Willett, 2003) and the other on a structural equation tradition, known by the name of Latent Growth Modeling (Duncan, Duncan, \& Strycker, 2006). Both traditions work with estimating and predicting standard normal deviations of growth parameters (i.e. intercept and slope).
} 
Caldwell, 1981), high rank (Lee et al, 1992), high pre-entry fit perceptions (Saks \& Ashforth, 2002), high task competence (Adkins, 1995), to name a few. But the level of OC at the start of the job is not only affected by concurrent psychological states, situations and dispositions, but also by history. Interestingly, factors relating to the previous job (i.e., attitudinal levels in the previous job) are predictive of initial levels in the sense that initial attitudinal levels at the new job will generally be higher than the ones exerted at the previous job (Boswell, Tichy, \& Boudreau, 2005). Initial level is found to be predictive of subsequent turnover, in some cases up to 4 years after entry (Lee, Ashford, Walsh, \& Mowday, 1992; Porter, Crampon, \& Smith, 1976). Additionally, studies have demonstrated that differences in initial level are related to differences in the rate of change. More specifically, if low OC at Day 1 is due to high revocability of the job choice or realistic job previews, decline tends to be less steep (Griffeth \& Hom, 2001; Lance, Vandenberg, \& Self, 2000; Wanous, Poland, Premack, \& Davis, 1992). This finding was explained by the fact that people who received a realistic preview, and who can easily drawback, take more responsibility for their own decisions and cannot blame their experience to factors outside themselves (Lance, Vandenberg, \& Self, 2000; Meglino, Ravlin, \& DeNisi, 2000; O'Reilly \& Caldwell, 1981; Salancik, 1977). Thus, individuals with a highly revocable job choice are less prone to disappointments and therefore have a more 'robust' commitment pattern.

Although there have been relatively few studies specifically investigating antecedents of commitment trends (i.e., the rate of change), the literature seems to converge on a small number of determinants. High expectations on the first day are related to steeper declines in commitment (Lance, Vandenberg, \& Self, 2000). More specifically, it is not high expectations per se, but unmet expectations that lead to declining commitment after entering the organization. In a more general sense, there is converging evidence that unmet expectations and the related absence of fulfillment of promises (i.e., psychological contract breach) lead to a decline in job attitudes after entry (Boswell, Tichy, \& Boudreau, 2005; Irving \& Meyer, 1994). Declining OC is also very likely to be related to critical events ${ }^{40}$ (Bentein, Vandenberg, Vandenberghe, \& Stinglhamber, 2005). In fact, negative 'work experiences' are seen as even more predictive of OC change than unmet expectations (Irving \& Meyer, 1994; Lee, Ashford, Walsh, \& Mowday, 1992; Meyer, Irving, \& Allen, 1998). Qualitative evidence by Van Maanen indicates that decreases in OC could be ascribed to an adjustment to the level that was perceived as 'normal' among colleagues. This confirms the

\footnotetext{
${ }^{40}$ The authors do not specifically focus on this issue, but from their results this relationship can be inferred.
} 
more general contention made earlier by Salancik and Pfeffer (1978) that employee attitudes are influenced and shaped by 'social information'. Other explanations of decline are decreases in supervisor support (Jokisaari \& Nurmi, 2009) or the inability to attain personal goals (Maier \& Brunstein, 2001). Interestingly, declining OC can also be explained from general attitudinal levels held vis-à-vis the previous job. Boswell et al. (2009) argue that work attitudes in the previous job are seen 'as 'baggage' that individuals bring with them, that serves as a referent for the new job and thus an important part of the temporal pattern of newcomer attitudes....Notably, individuals react on the basis of their remembered experiences...even when these memories are biased' (p. 845). According to the authors job attitudes will taper off over time toward the levels held toward the prior job (job satisfaction) or organization (OC).

Declining OC is generally associated with impending employee turnover (and turnover intention). This has been demonstrated quite convincingly by showing that leaver OC trajectories show markedly steeper declines than those of stayers (Bentein, Vandenberg, Vandenberghe, \& Stinglhamber, 2005; Cohen \& Freund, 2005; Kammeyer-Mueller, Wanberg, Glomb, \& Ahlburg, 2005; Porter, Crampon, \& Smith, 1976). There is also evidence that leavers already started their job with a lower commitment compared to stayers (e.g., Lee et al., 1992; Porter et al., 1976).

The honeymoon-hangover effect The formation of a new employment relationship can be characterized by a paradoxical blend of exuberance and vulnerability. Once the choice to join a particular organization is made and previous employment bonds are broken, expectations regarding the new job and the new organizational context are generally high (Griffeth \& Hom, 2001; Lance, Vandenberg, \& Self, 2000). In addition, the socialization literature describes the initial exuberance in newcomers entering organizations as a 'honeymoon period'41 where 'initial assets' such as goodwill, enthusiasm, commitment and investments shield the new employment relationship from setbacks and conflicts (Boswell, Tichy, \& Boudreau, 2005; Chang \& Choi, 2007; Finchman \& Levinthal, 1991; Jokisaari \& Nurmi, 2009). From the perspectives of Finchman and Leventhal (1991) and Burt (Burt, $2000,2001,2002)$ this honeymoon period functions as a protective 'shield' to counteract the

\footnotetext{
${ }^{41}$ The honeymoon-hangover effect is an empirically established phenomenon in the literature on job satisfaction. Considering the fact that organizational commitment and job satisfaction are explained by similar types of antecedents, they are often found to influence each other reciprocally (Currivan, 1999; Farkas \& Tetrick, 1989). Therefore, it can be reasonably assumed that this phenomenon takes place in organizational commitment as well. In fact, the data by Lee et al. (1992) show a honeymoon-hangover effect in organizational commitment after organizational entry, although it was not identified as such at the time.
} 
vulnerability to early dissolvement of the relationship typically characterizing newly formed relationships.

Honeymoons do not last forever. Some authors argue that - based on research on job turnover - the honeymoon period generally lasts about 3 to 6 months (Jokisaari \& Nurmi, 2009 , and the sources they cite). After the honeymoon period, decline generally sets in. Longterm (i.e., longer than 6 months) longitudinal studies on OC generally confirm a declining mean trajectory, although stable mean trajectories are also frequently observed. The shape (e.g., linear, convex, concave, parabolic) of declining trajectories is of an erratic nature, thus, OC decline after entry comes in many forms (see chapter 3 , for a comparative review of pattern shapes).

To date most of the longitudinal studies on OC change have adopted a population level of analysis. There are a couple of exceptions that are worth mentioning. We are aware of three studies mentioning different pathways to adjustment comparing high-ranked to lowranked recruits (Van Maanen, 1975), high versus low job choice difficulty (Lance, Vandenberg, \& Self, 2000), and high versus low commitment propensity (Lee, Ashford, Walsh, \& Mowday, 1992). In all three cases, high-ranked recruits, individuals with low job choice difficulty, and those with high commitment propensity had higher levels of commitment, with pathways running roughly parallel to each other. Apart from these studies, there are no organizational entry studies explicitly investigating distinctive longitudinal progressions in subsets of the data. This is a pity, because the identification of meaningful subgroups can be very fruitful add considerable value to current organizational entry literature (cf. Dayton, 2008; Muthen, 2001; Nagin, 2005).

\subsection{Limitations of the growth modeling methodology}

Although the growth modeling approach has brought the understanding of employee adjustment a giant step ahead - and it will probably continue doing so - it is rather 'crude' in identifying and explaining temporal patterns. First of all, the locus of variance in growth modeling parameters resides in deviations from the group mean trajectory. The focus on the group mean potentially obscures - or even misrepresents - rich, interesting, and potentially useful heterogeneity in longitudinal data (Nagin, 2005) and obscures the fact that individuals can have quite different growth trajectories. Using only mean commitment trajectories is often too broad and too general a description of what really happens over time (see also Angle \& Lawson, 1993). For example, Thompson \& Van de Ven (2002) found three patterns 
underlying a relatively stable mean trajectory: a sharply declining, a stable and an increasing pattern. As a result, opportunities for better prediction of organizational outcomes (e.g., performance, information sharing, turnover intention, absenteeism, and so forth) are lost when deviations from a single population mean are the units of analysis.

Second, growth modeling tends to take a narrow a focus with regard to within-subject variability. That is, the parameters used in both Hierarchical Linear Modeling (HLM) and Latent Growth Modeling approaches (i.e., initial level and rate of change) allow a limited range of growth trajectories. This approach works fine if the individual trajectories are generally simple and similar to each other. However, if individual differences in time-based change are large, the growth modeling approach falls short. In those cases, more refined techniques are required. Growth modeling is insufficiently sensitive to answer questions regarding how often these adjustments occur (Child, 1972; Wholey \& Brittain, 1989), how the shape of sub-trajectories influences outcomes (Muthen, 2001; Nagin, 2005), at what level they generally occur, how intense these changes are (cf. Wholey \& Brittain, 1989), and what the variability of these changes is (i.e., pattern volatility).

Third, for the sake of interpretation growth modeling techniques start from the assumption of linear growth (Duncan, Duncan, \& Strycker, 2006; Singer \& Willett, 2003). Imposing such linearity reduces potentially meaningful fluctuation in the data to measurement error. For instance, Boswell et al. (2009) were able to estimate the temporal pattern of job satisfaction with more precision by specifying a curvilinear trajectory over time. That is, compared to their earlier study where linear trajectories were specified (Boswell, Tichy, \& Boudreau, 2005), the specification of curvilinear patterns was of great aid in coming to greater understanding of the effects of specific job change conditions on temporal patterns. In addition, extrapolating linear trajectories over longer periods of time gives results (e.g., infinite increase) that cannot be explained theoretically.

This problem of relative 'crudeness' with regard to patterns is exacerbated by the state of affairs in the current entry literature as it comes to building longitudinal designs. Longitudinal studies on organizational entry with more than 3 repeated measures are rare (see chapter 3, for a literature review). Moreover, moments of measurement are generally spaced by $1,3,6$ months or even years. It is unlikely that these kinds of designs allow for reliably picking up systematic downward or upward adjustments in the process of newcomer adjustment. Or put differently, why would growth curves develop in parallel fashions and exactly have their marking points (e.g., transition, disruption moments) at 1, 3, and 6 months after entering the organization? In short, the types of longitudinal designs typically employed 
do not match with the aim of research on dynamic patterns (Collins, 2006; Dormann, 2007; Roe, 2008a; Zaheer, Albert, \& Zaheer, 1999).

\subsection{The temporal-dynamic approach}

In this chapter we propose a temporal-dynamic approach, which has the same theoretical aim as the growth modeling approach: explaining and predicting temporal (i.e., within-subject) variability (Roe, 2008a). But the temporal-dynamic approach differs from the growth modeling approach in its operational aim. Growth modeling approaches - and panel data approaches alike - aim to predict a certain point in time based on an aggregate (linear) function. In contrast, the temporal-dynamic approach describes and predicts dynamic shape or 'aspects of form'. We call this approach 'temporal-dynamic' because upward and downward changes in OC translate into dynamic patterns of increases and decreases in OC levels when laid out over time. It is different from growth modeling as it is more sensitive to observing and predicting micro-level changes - say, from day to day, or week to week. The temporal-dynamic approach (1) starts from a high-density (i.e., fine-grained) and highfrequency (i.e., lengthy, say, $>20$ repeated measures) longitudinal design, (2) does not impose linearity or any other a priori function, and therefore (3) starts from individual level trajectories as units of analysis. The temporal-dynamic approach will help us to reach our goals which is to take a detailed (fine-grained) and lengthy look at dynamic OC behavior during the first 6 months of newcomer adjustment. A detailed and lengthy look can add value to existing literature by discovering 'aspects of form' in dynamic behavior other than the two that we already know (initial level and the rate of change).

In the temporal-dynamic approach commitment change during newcomer adaptation is defined as a process of continuous 'repositioning' which takes shape across a specified period of time. More specifically, commitment change can be represented as a commitment trajectory of a particular individual across a particular time span of time. Change in commitment can be studied on different levels of aggregation: on the population-, the group-, and the individual level of analysis. However, it is important to keep in mind that commitment change is by definition an individual-level phenomenon (cf. Molenaar, 2004; Roe, 2008a). This means that the individual-level should be seen as the most basic (and valid) unit of analysis in the study of commitment change. Aggregation to higher-order units of analysis will always result in some degree of distortion (Nagin, 2005). In this chapter we will 
discuss two levels of analysis: the individual level, and the group (also subgroup or cluster) level.

Approach As we know little of the dynamic behavior of commitment we first take a descriptive approach ${ }^{42}$, where we describe and (try to) predict observed aspects of temporal shapes. Then - post-hoc - we will revert back to theory to explore the implications of the observations in current theoretical perspectives. We categorize our observations in two types: analytical and holistic. In analytical observation we specify 'form parameters' that describe aspects of individual trajectory shapes. This kind of observation typically answers questions like: How high does OC start off? Does OC rise fast, or gradually? How often does change occur? How intense are these changes generally? How volatile is the trajectory? What is the average level of the trajectory? Note that this is an analysis at the individual level. In holistic observation we look at complete trajectories at once and categorize them based on predefined clustering principles. This type of observation answers research questions like: What 'typical' forms of trajectories exist? Do people who start high, generally end up high? Can you start low, and end up with high commitment? Is there a honeymoon-effect? And so forth. Note that this is - in our particular case - a group-level analysis.

After the observation of dynamic behavior in $\mathrm{OC}$ we try to describe the phenomenon by interrelating its aspects. For instance, are high trajectories smoother than low trajectories? Are rising trajectories more or less volatile compared to declining trajectories? Only a few of these questions have been answered in previous literature.

As a second step we will relate conventional predictors ${ }^{43}$ to OC either to (1) form aspects parameters or to (2) clusters membership. We have chosen to include only conventional predictors, which include explanatory variables that have often occurred in the commitment literature and are themselves well-established and well-researched constructs. The predictors we have chosen are displayed in Table 5.1. We have ordered them according to a classic dichotomy between dispositional and situational perspectives on Organizational Behavior in the literature. Commitment history is taken separately, because it can be seen both as reflective of dispositions and situational developments (Boswell, Tichy, \& Boudreau,

\footnotetext{
${ }^{42}$ There are other reasons not to rely on theory: (1) Temporal information in existing theories is too scant to rely upon. A theory that allows for explaining various forms of micro-level temporal variation in organizational attitudes is still to be developed, (2) starting from theoretical paradigms in unexplored areas should be discouraged. Theory can blind the watchful eye to detect unanticipated observations.

${ }^{43}$ Note that in analyses of form parameter interrelationships and the prediction of OC dynamics we will deviate from strictly analyzing within-subject information and will make use of between-subject differences in withinsubject OC development (i.e., interindividual differences in intraindividual changes, Chan \& Schmitt, 2000).
} 
2005). Among the dispositional variables we have included gender, personality (i.e., the Big5 domains), Positive and Negative Affectivity, and dutifulness. Motivational variables included are prior job expectations and motivational force (i.e., expectancy-value type motivation). Situational variables are divided into experiential predictors and contextual contingencies. Experiential variables include well-researched predictors such as met expectations, perceived organizational support, person-organization fit, job satisfaction, psychological contract breach, and psychological contract violation. Among contextual contingencies we included transition smoothness (i.e., the relative ease of transitioning from one organization to another), organization size, job mobility, and volition of the job choice. Historical predictors are less common in the commitment literature, but have recently gained attention from researchers interested in the dynamics of job attitudes during and after job change (Boswell et al., 2005; Boswell et al., 2009). As historical predictors we included organizational commitment to the previous employer, job satisfaction in the previous job, satisfaction with supervision in the previous job, and past achievements.

Dutifulness requires some extra attention, as this construct is highly related to the controversial concept of 'normative commitment'. The latter concept has received quite some conceptual critiques recently (Bergman, 2006; Cohen, 2007; Gonzalez \& Guillen, 2008; Solinger, Van Olffen, \& Roe, 2008) and is in urgent need of conceptual refinement (see Meyer et al., 2002). In the spirit of Cohen (2007) and González and Guillén (2008), we reconceptualize 'normative commitment' as 'dutifulness': a work value which is not specified to a particular organization. Dutifulness can be seen as the moral and dispositional element of normative commitment. It involves the part of normative commitment which is more central to the person's self-identity, as opposed to the element that comes from felt obligations to reciprocate (see Solinger et al., 2008, for a detailed conceptual analysis). We infuse this predictor in the study for exploratory purposes and also because 'normative commitment' has received quite some research attention in previous literature on commitment (Meyer et al., 2002). 
Table 5.1 Overview of main conventional predictors to OC development in our study

\begin{tabular}{|c|c|c|}
\hline Disposition & Situation & History \\
\hline Stable individual characteristics & Experiential predictors & $\begin{array}{l}\text { Job attitudes in the previous } \\
\text { organization } \\
\text { Organizational commitment } \\
\text { to the previous employer }\end{array}$ \\
\hline Gender & $\begin{array}{l}\text { Met expectations (combining } \\
\text { prior expectations with met expectations) }\end{array}$ & \\
\hline Big-5 personality domains & & $\begin{array}{l}\text { Job satisfaction in the } \\
\text { previous job }\end{array}$ \\
\hline - Extraversion & Perceived organizational support & \\
\hline - Agreeableness & & $\begin{array}{l}\text { Satisfaction with supervision } \\
\text { in the previous job }\end{array}$ \\
\hline - Conscientiousness & Person-organization fit & \\
\hline - Emotional stability & & General personal history \\
\hline - Openness to experience & Job satisfaction (current job) & Past achievements \\
\hline Positive Affectivity & $\begin{array}{l}\text { Psychological contract } \\
\text { breach/violation }\end{array}$ & \\
\hline \multicolumn{3}{|l|}{ Negative Affectivity } \\
\hline \multirow{3}{*}{$\begin{array}{l}\text { Dutifulness (i.e., the dispositional } \\
\text { counterpart of normative commitment) }\end{array}$} & Contextual contingencies & \\
\hline & Transition smoothness & \\
\hline & Organization size & \\
\hline Job expectations and motivation & Job mobility & \\
\hline $\begin{array}{l}\text { - Prior expectations } \\
\text { - Motivational Force (= expectancy } * \\
\text { value) }\end{array}$ & Volition of the job choice & \\
\hline
\end{tabular}

\section{$3 \quad$ Methods}

\subsection{Temporal design}

Our sample of newcomers has been chosen as an integral part of a larger research plan where we wished to assess the dynamic behavior of organizational commitment during the transition from one job/organization to another. The transition from one organization to another involves both a process of exit and a process of entry, which are typically unfolding at the same time (Ashforth, 2001; Boswell, Tichy, \& Boudreau, 2005; Solinger, 2004). To serve this research purpose we chose PhD graduates leaving their 'mother organizations' as target group as these people generally have a predictable exit date and are supposed to scatter out to become employed by new organizations ${ }^{44}$. In addition, there is a relatively large number of $\mathrm{PhD}$ candidates graduating in The Netherlands and Flanders ${ }^{45}$ each year as approximately around $4000 \mathrm{PhD}$ candidates graduate each year. As said, a

\footnotetext{
${ }^{44}$ Another reason to choose this target group is that some of them decide to stay with their mother organization and possibly get promoted. This allows us to compare three processes: entering, staying, or leaving.

${ }^{45}$ We chose to include Flanders because this is a region which geographically (being a region of the neighboring country Belgium) and linguistically close as it is a Dutch speaking region.
} 
temporal-dynamic approach requires a fine-grained (high-density) and lengthy (high-frequency) longitudinal design to allow for picking up OC changes as they unfold over time. We decided to take weekly measures of OC. As we estimated that the first 6 months of work would be most turbulent to newcomers, we chose 6 months as a time frame. Moreover, we figured that a period of 6 months would still sound 'manageable' to potential participants in our study. We set the time frame of the study to 25 weeks. Additionally, we were interested in how a commitment develops prior to entering an organization. This was inspired by the life cycle perspective of behavioral phenomena (Roe, 2008a, chapter 3) which contends that any behavioral phenomenon must have an onset, a duration, and an offset. After onset (i.e., the point in time where commitment is no longer zero) the phenomenon gradually emerges (see chapter 3 ). Considering converging evidence that commitment generally starts off high (see chapter 3) we were interested in knowing where these high levels come from and whether OC would reach a 'peak' at the first week of employment. We therefore started measuring OC 4 weeks prior to entering the organization.

\subsection{Procedure}

To get access to $\mathrm{PhD}$ candidates in their final year, we first approached all university boards in the Netherlands and Flanders. Most university boards granted access to approach their $\mathrm{PhD}$ candidates for participation. If boards did not grant us access we approached the separate university faculties and research schools. In case these separate faculties and research schools could not grant us access, we tried to find $\mathrm{PhD}$ candidate e-mail addresses online. In the end, 17 universities cooperated in our study. Participants were recruited by e-mail and asked to voluntarily participate in a longitudinal research on the process of transitioning from one job/organization to another. We only sent out emails to $\mathrm{PhD}$ candidates who were in the final year of their project. To increase legitimacy - and the likelihood of participation - we included a 'board of recommendation' of 8 rectores magnifici (board members), a reference to our project website ${ }^{46}$, a video preview of the newly developed LOCUST measurement system they would use ${ }^{47}$ and an explication of our incentive system. We offered participants 1 Euro for every completed session, which was only paid if respondents filled out at least $80 \%$ of all required sessions, thus after filling out 20 sessions or more. In addition, subjects who delivered complete patterns ( 25 sessions) could win a weekend trip for two persons to Maastricht.

The e-mail which we used to recruit participants contained two hyperlinks which directed respondents to sign-up questionnaires. The first hyperlink stated 'Yes, I belong to the target population, and I want to participate', the other resounded 'Yes, I belong to the target population, but I do not want to participate'. The sample of $\mathrm{PhD}$ candidates who did not wish to cooperate amounted to 92 respondents out of a potential pool of approximately 4.000 candidates. This 'non-response'

\footnotetext{
${ }^{46}$ http://www.fdewb.unimaas.nl/os/locust/V2/site/index.html

${ }^{47}$ http://www.fdewb.unimaas.nl/os/locust/V2/site/demo.swf; see chapter 4
} 
hyperlink directed respondents to a 5-item survey measuring organizational commitment to the 'mother organization' (explained later on in the Methods section), satisfaction with the supervisor, and general job satisfaction. We added the 'non-response' hyperlink to control for selection bias on our focal variable (i.e., organizational commitment). An independent sample T-test showed that there was no significant difference between non-responders and initial participants $(\mathrm{N}=277)$ on organizational commitment toward the 'mother organization' $(t=.65 ; d f=367 ; p=.51)$, supervisor satisfaction $(t=-1.5 ; d f=367 ; p=.11)$, or overall satisfaction $(t=.26 ; d f=367 ; p=.80)$. Considering the large sample size, we can confidently conclude that participants in our study did not systematically differ from non-participants. In total $277 \mathrm{PhD}$ candidates signed up for participation, which roughly corresponds to $7 \%$ of the total population getting their $\mathrm{PhD}$ each year in the Netherlands and Flanders. By the time of signing up (Fall, 2007) they were still working in their final year as $\mathrm{PhD}$ candidates for their 'mother' organizations. Note that, in the Dutch system, $\mathrm{PhD}$ candidates are officially recognized as 'employee', including all employee rights and benefits. In Flanders $\mathrm{PhD}$ candidates also employed by the university, but - in contrast to the Dutch system - do not have employee rights and benefits. However, this difference in employee status did not have an effect on mean organizational commitment toward the 'mother organization' $(F=.99 ; p>$ .1). Thus, for empirical and simplicity's sake, we regard Dutch and Belgium $\mathrm{PhD}$ graduates as equals.

During the data collection period subjects got weekly reminders to participate via a hyperlink which directed them to our online work experience monitor, called LOCUST (Longitudinal OcCUpational State Tracker; see chapter 4). Before starting the first session we had an additional questionnaire $(\mathrm{N}=69)$ inquiring after stable personal characteristics (i.e. the gender, Big-5 personality traits, Positive and Negative Affectivity, dutifulness, and job expectations). Upon completion of all 25 sessions, participants filled out a second additional questionnaire asking for experiential and situational information (i.e., job satisfaction, perceived organizational support, met expectations, P-O fit, and so forth). The latter questionnaire was filled out by 53 respondents. The reason for such a decline in response compliance is that many of the subjects who dropped out were unwilling to complete another survey. A summary of the total of 5 surveys is presented in Table 5.2.

(Continued on next page) 
Table 5.2 Overview of the 5 surveys used in the study

\begin{tabular}{|c|c|c|c|c|c|}
\hline & $\begin{array}{l}\text { Non-response } \\
\text { survey }\end{array}$ & Sign-up survey & $\begin{array}{l}\text { LOCUST } \\
\text { measurement } \\
\text { system }\end{array}$ & $\begin{array}{l}\text { First additional } \\
\text { questionnaire }\end{array}$ & $\begin{array}{l}\text { Second } \\
\text { additional } \\
\text { questionnaire }\end{array}$ \\
\hline Date & Fall 2007 & Fall 2007 & $\begin{array}{l}\text { January } 2008- \\
\text { April } 2009\end{array}$ & $\begin{array}{l}\text { January } 2008 \text { - April } \\
2009\end{array}$ & $\begin{array}{l}\text { January } 2008- \\
\text { April } 2009\end{array}$ \\
\hline Timing & $\begin{array}{l}\text { Filled out in the } \\
\text { final year of } \mathrm{PhD} \\
\text { project, while still } \\
\text { working for former } \\
\text { employer }\end{array}$ & $\begin{array}{l}\text { Filled out in the } \\
\text { final year of PhD } \\
\text { project, while still } \\
\text { working for } \\
\text { former employer }\end{array}$ & $\begin{array}{l}\text { Start: } 4 \text { weeks } \\
\text { prior to the start } \\
\text { of the new job } \\
\text { End: } 25 \text { weeks } \\
\text { later }\end{array}$ & $\begin{array}{l}4 \text { weeks prior to the } \\
\text { start of the new job; } \\
\text { Before using LOCUST }\end{array}$ & $\begin{array}{l}1 \text { week after using } \\
\text { LOCUST }\end{array}$ \\
\hline $\begin{array}{l}\text { Number of } \\
\text { respondents }\end{array}$ & $\begin{array}{l}\mathrm{N}=92 \text { non- } \\
\text { participants }\end{array}$ & $\begin{array}{l}\mathrm{N}=277 \\
\text { participants }\end{array}$ & $\begin{array}{l}\mathrm{N}=72 \\
\text { participants }\end{array}$ & $\mathrm{N}=69$ participants & $\begin{array}{l}\mathrm{N}=53 \\
\text { participants }\end{array}$ \\
\hline $\begin{array}{l}\text { Constructs } \\
\text { observed in } \\
\text { surveys }\end{array}$ & $\begin{array}{l}\text { 1. OC to former } \\
\text { organization } \\
\text { 2. Satisfaction with } \\
\text { the former job } \\
\text { 3. Satisfaction with } \\
\text { supervision }\end{array}$ & $\begin{array}{l}\text { 1. OC to former } \\
\text { organization } \\
\text { 2. Satisfaction } \\
\text { with the former } \\
\text { job } \\
\text { 3. Satisfaction } \\
\text { with supervision }\end{array}$ & $\begin{array}{l}\text { OC to the new } \\
\text { organization, } \\
\text { mood, and } \\
\text { organizational } \\
\text { events. }\end{array}$ & $\begin{array}{l}\text { Gender } \\
\text { Big-5 personality } \\
\text { domains } \\
\text { Positive Affectivity } \\
\text { Negative Affectivity } \\
\text { Dutifulness } \\
\text { Volition } \\
\text { Prior expectation and } \\
\text { motivation } \\
\text { Organization size } \\
\text { Prior performance }\end{array}$ & $\begin{array}{l}\text { POS } \\
\text { P-O fit } \\
\text { Job satisfaction } \\
\text { Psychological } \\
\text { contract } \\
\text { breach/violation } \\
\text { Transition } \\
\text { smoothness }\end{array}$ \\
\hline
\end{tabular}

\subsection{Sample}

Participants qualified as 'entrants' (i.e., newcomers entering an organization) if they would start working for new organization between January and October 2008. Out of the initial pool of 277 participants who signed up for the research, $81 \mathrm{PhD}$ graduates finally qualified as 'entrants', 72 of which rendered usable data (i.e., 2 or more repeated measures). The 72 participants in our final sample were drawn from a wide range of scientific disciplines (31\% behavior \& society; $22 \%$ nature; $15 \%$ health; $12 \%$ economics; $12 \%$ technology; $3 \%$ language $\&$ culture; $1 \%$ agriculture; $1 \%$ law) from all the different universities (17) in the Netherlands (74\%) and Flanders (26\%). The vast majority of them were native Dutch speakers $(81 \% ; 19 \%$ other native tongues); $53 \%$ were female, and $45 \%$ male. They were all in the age category between 26 and 35. There was no significant effect of 'scientific discipline' on the mean score of commitment toward their new organizations $(F=.22 ; p>.1)$. Likewise, membership of one of the 17 different universities did not have a significant effect on the mean level of OC $(F=1.5 ; p>.1)$.

Due to administrative difficulties and initial non-compliance (for between-job holidays), not all participants started their cooperation exactly 4 weeks prior to entering their new organizations. Thus, we have a dataset running for a total time of 35 calendar weeks, with asynchronous starting points. The overall number of active participants shows a parabolic shape across the time moments with the highest levels between 5 to 10 weeks of participation. The average response of was 36 subjects per week $(S D=7.9$ ), with a minimum of 21 (week 28) and a maximum of 49 (week 9). 
Missing data In the end, $36 \%$ of the participants filled out more than 20 weekly sessions. On average participants filled out 14 sessions $(\mathrm{SD}=7.7)$. The highest frequency in the number of completed sessions was 4 (12 subjects), closely followed by 22 (11 subjects) and 23 completed sessions (10 subjects). For a distribution of the number of completed sessions across all participants, see Figure 5.1. The minimum number of completed sessions was $2(3 \%)$, and the maximum $25(3 \%)$. Across 35 weeks our total number of observations is 1032 (with 1558 missed sessions); across 30 weeks - deleting the last 5 weeks where the number of active participants was less than 20 - our total sample size is 998. Among missing data points we distinguish intra-period noncompliance (i.e., skipping one or more sessions within the participation period), and extra-period noncompliance (i.e., missed sessions outside of the compliance period, i.e., due to fact the respondent did not start or had ended participation. If respondents skipped a session (i.e., intra-period), our LOCUST measurement system prompted a multiple-choice question on the reason of non-compliance: forgot/ no time $46 \%$; I was not on the job (e.g., vacation/time off) $34 \%$; something else $20 \%$.

To check for systematic non-response-effects on our dependent variable, we correlated the person-specific organizational commitment mean score (i.e., the mean of all time moments within each person) with the degree of participation compliance (i.e., the number of completed sessions each subject filled out). There was no significant correlation $(r=-.01, p=.46)$. Thus, with respect to our dependent variable ${ }^{48}$, we can reasonably assume that non-response did not occur as a function of a low degree of OC.

Figure 5.1 The distribution of participation compliance in the sample $(\mathrm{N}=72)$

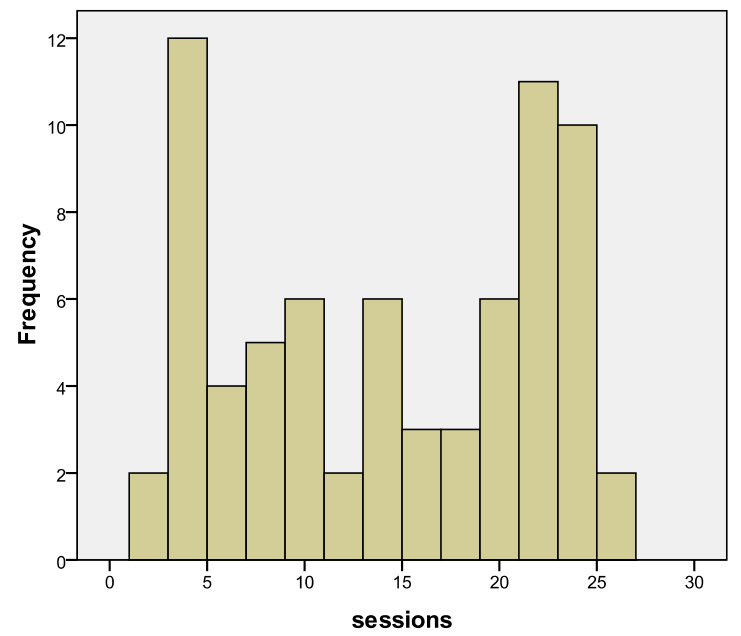

\footnotetext{
${ }^{48} \mathrm{We}$ also performed an exploratory correlational analysis of the relationship between the degree of response compliance and predictor variables. Confirming our intuition, response compliance correlated positively with agreeableness $(r=.25, p<.05)$, and high prior job expectations $(r=.21, p<.05)$.
} 
As explained in chapter 4, the LOCUST measurement program we devised makes use of an innovation in questionnaire administration: it displays all previous time points in a response format called graphic trajectory registering (GTR, see chapter 4). $\mathrm{GTR}^{49}$ functions by depicting personspecific graphs of previous attitudes measurements, the 'attitudogram', to respondents while they fill out the survey in order to facilitate real-time, incremental trajectory scoring. To avoid imprecision, we included an integer counting along from 0 to 100 with each adjustment made. The crucial point of the GTR technique is that self-inspection is applied to assess one's degree of change as subjects truly subscribe to a pattern, not to a single point. In this way, change - in particular small adjustments becomes more meaningful, resulting in increased reliability of the trajectory as a whole. This is particularly relevant to the purpose of this research because we are especially interested in change in OC.

\subsection{Measures}

Organizational commitment We did not use existing measures because of inadequate construct validity (see chapter 2 and 5) and unsuitability of use in a temporal (HDRM) context. Instead, we adopted the attitudinal conceptualization of OC as recently described in Solinger et al. (2008; see chapter 2 and 4). Single-item questions were used to measure each attitudinal component of OC. The affective component was measured by 'What I feel about my organization: I am proud'. The cognitive component was measured by 'What I think about my organization: I belong to it'. The action readiness component was measured by 'What I do for my organization: I engage'. We used a continuous 'thermometer' scale ranging from 0 to 100 (see chapter 4 ). We used the total score of the three elements as a measure of $\mathrm{OC}$, which is the net sum affect, cognition, and action readiness.

Personal characteristics On the whole, we have chosen for brief questionnaires to limit the compliance burden as much as possible. (1) The Big-5 personality domains were measured with the TIPI (Ten-item Personality Inventory) developed by Gosling and colleagues (Gosling, Rentfrow, \& Swann, 2003). A 7-point Likert response format was used. The instrument has adequate psychometric properties (Ibid.). According to the authors, performing internal consistency reliability and factor analyses on TIPI data is inappropriate because of the small number of items.

(2) The Positive and Negative Affectivity questions were obtained from a 10-item PANAS scale (Watson, Clark, \& Tellegen, 1988). Participants were asked to what extent they generally experienced a number of positive emotions (i.e., inspired, alert, excited, enthusiastic, and determined)

\footnotetext{
${ }^{49}$ GTR consists of three basic elements which were incorporated in the LOCUST system: (1) person-specific, historically tailored graphs, (2) real-time, incremental trajectory scoring, and (3) corrective retrospective adjustment of pattern scores. Through the application of these three elements even small 'hiccups' in the trajectory must be meaningful, as they are affirmed time after time and thus are unlikely ascribed to 'measurement error'. In this chapter we only used the first and the second element in this study, which means that we worked with trajectory scores that have not been adjusted retrospectively. See chapter 4 for more information on GTR.
} 
and negative emotions (afraid, upset, nervous, scared, and distressed) on a 7-point Likert scale. The internal consistency reliability statistic was good for Positive Affectivity (Cronbach $\alpha=.83$ ) and Negative Affectivity (Cronbach $\alpha=.91)$.

(3) Dutifulness was measured by a 6-item scale combining 3 questions by Wiener and Vardi (Wiener \& Vardi, 1980): 'One should be loyal to his/her organization', 'One should not criticize his/her organization ${ }^{, 50}$, and 'One should make sacrifices for his/her organization', and 3 questions of our own making: 'I am the type of person an organization can count upon'; 'I hold my conduct toward organizations to high moral standards'; and 'I generally feel a sense of duty toward organizations I work for'. We extended the scale because items by Wiener and Vardi (1980) did not completely cover the conceptual domain that we had in mind. That is, the three items reflect particular normative beliefs on how to behave toward organizations in general. We extended the conceptual domain of this construct by adding the element of self-identity to it (see Solinger et al., 2008, chapter 2, for a placement of these two normative concepts in a 'theory of reasoned action' framework). The internal consistency reliability of the extended scale was satisfactory (Cronbach $\alpha=.82$ ), which was an improvement compared to the reliability of the 3-item Wiener \& Vardi scale (Cronbach $\alpha=.57$ ). More specifically, our added items generally improved the item-total correlations of the Wiener \& Vardi items from $.42, .31$ and .43 to $.67, .41$ and .39 , respectively. The item-total correlations of our three additional items showed higher item-total correlations compared to the Wiener and Vardi items: $.67, .68$, and .75 . We concluded that our newly formed scale had improved compared to its predecessor.

\section{Prior expectations and motivation (1) Participant's prior expectations regarding their} future job were measured according to how likely they thought the following 10 job characteristics would be present on the new job: autonomy, job security, opportunities to learn, interesting work, new challenges, promotional opportunities, time for leisure activities, usefulness to the community, social status, and possibility to combine work and family. These items were obtained from ROA, a socioeconomic research centre in Maastricht University (de Grip, 2007, personal communication). All questions were answered on a 7-point Likert scale. As 'prior expectations' is a formative measure ${ }^{51}$, a Cronbach alpha metric is inappropriate. (2) In addition to the likelihood of encountering the 10 job characteristics in their future job, subjects were also asked how important each of these characteristics is to them. The resulting measure, 'Motivational Force' (Van Maanen, 1975), which is the squared root of the product of the likelihood times the importance per characteristic. As said, with formative measures Cronbach alpha statistics are inappropriate.

\footnotetext{
${ }^{50}$ The low item-total correlation of Wiener and Vardi's item 2 ('One should not criticize one's organization') is probably culturally bound. In the Netherlands, uttering constructive criticism is considered ' normal' and even appreciated. Therefore, one can criticize one's organization and still remain highly dutiful. We kept the item to allow accumulation of research evidence.

${ }^{51}$ In a formative measure the construct is determined by its indicators, which are not necessarily related to each other. In formative construct, the indicators are assembled and put together for conceptual, rather than empirical, reasons. An internal consistency reliability statistic is therefore inadequate.
} 
Experiential predictors Usually, 'Met expectations' (1) are measured only

retrospectively, which is sub-optimal considering all kinds of perceptual and recall biases (Wanous et al., 1992). This is why we have chosen for an operationalization which combines 'raw expectations' prior to entry with reflections on 'met expectations' afterwards. Our measure of met expectations is therefore the (square root of the) product of prior expectations and the 'met expectations' measure. The measure is based on the mean of the 10 job characteristics described before.

(2) Person-organization fit perceptions (P-O fit) were measured by the subjective 4-item scale as reported by Saks and Ashforth (1997). Sample items are: 'To what extent does your personality match the personality or image of the organization?'; and 'The organization fulfills my needs'. Cronbach $\alpha=.93$. (3) Perceived organizational support (POS) was measured by an 8 -item questionnaire by Rhoades and Eisenberger (2002). Sample items are: 'My organization would forgive an honest mistake from my part'; 'My organization cares about my well-being'. Cronbach $\alpha=.80$. (4) Psychological contract breach was measured by a 5-item questionnaire taken from Robinson and Rousseau (1994, found in Conway \& Briner, 2005). Sample items are: 'So far my employer has done an excellent job in fulfilling its promises to me'; 'I have not received everything promised to me in exchange for my contributions'. The internal consistency reliability coefficient was good (Cronbach $\alpha$ $=.92$ ). Violation of the psychological contract was based on a 4-item measure (in Conway \& Briner, 2005): 'I feel frustrated by how I have been treated by my organization'; 'I feel anger toward my organization'. The internal consistency reliability was good (Cronbach $\alpha=.85$ ). (5) Overall job satisfaction with the new job was measured with a single-item scale (Wanous \& Hudy, 2001; Wanous, Reichers, \& Hudy, 1997): 'In general, I am satisfied with my job'.

History (1) OC to the previous organization was measured using the same items as described before, including the 0-100 response format. Using the sign-up sample (i.e. 277 participants) combined with the non-response questionnaire (i.e., 92 non-participants) a satisfactory internal consistency reliability was reported (Cronbach $\alpha=.78, \mathrm{~N}=369$ ).

(2) Job satisfaction with the old job and (3) satisfaction with the supervisor (old job) were measured in the sign-up questionnaire in Fall 2007, when participants were still working in their former job. Both were measured with singe-items. 'All things considered, I am satisfied with my job' and 'I am satisfied with the supervision I have received during my $\mathrm{PhD}$ project'. The two job satisfaction items in the former job had correlation of $.48(p<.01)$.

(4) Performance was measured by a single open question: 'What is the number of submitted/in press/published papers with your name on it?' Responses ranged from 0 to 29 ( $M=6.6$; $S D=5.37)$. The number of publications reported was highly dependent on (differential customs in) academic disciplines $(F=2.7 ; p<.05)$.

Contextual controls (1) The transition from one job/organization to another can differ by the degree to which entrants need to span a gulf of contextual differences between organizations. Transitions are smooth when similar activities, coworkers, skills, and knowledge are involved in the 
job change. To control for this difference we created and used 3 items measuring professional transition smoothness: 'There is considerable similarity between my current activity and the ones that I performed during my $\mathrm{PhD}$ ', 'In my current organization many of my coworkers have a $\mathrm{PhD}$ ', 'My employer appreciates the added value a $\mathrm{PhD}$ can bring'. The internal consistency reliability was satisfactory (Cronbach $\alpha=.68$ ). To test the content validity of 'Transition smoothness' we compared the group of 'entrants' with a control group of stayers (i.e., $\mathrm{PhD}$ graduates who stayed with their 'mother organization'). An independent sample T-test showed that our focal sample of 'entrants' who filled out the final additional questionnaire at the end of the study $(\mathrm{N}=53 ; M=4.7)$ had significantly lower work-related transition smoothness compared to the pool of stayers $(\mathrm{N}=34 ; M=5.4) ; t(85)=-$ $2.5, p<.05)$. We therefore regard our measure of work-related transition smoothness as both valid and reliable.

(2) Organizational size. Our measure was a multiple-choice question on the number of people employed by the focal organization: $1=1-9 ; 2=10-24 ; 3=25-49 ; 4=50-99 ; 5=100-250 ; 6=250$ $999 ; 7=1000$ or more. The final measure we used was the exponent of the respective scores (i.e., the $\left.e^{1}, e^{2}, \ldots e^{7}\right)$. This is because organization size is growing exponentially with numbers on the 1-7 scale.

(3) Job mobility expectations. Our measure was single-item: 'How often do you expect to move from one organization to the next (assuming you keep working in the same field)?' Responses were set to a $1-100$ scale: $1=$ Never $^{52} ; 100=$ very often.

(4) Freedom of job choice. Unlike O'Reilly and Caldwell (1981), we decided to split the volition measure into two parts: situational (i.e., the objective number of job alternatives), and motivational (i.e., subjective volition). In our perspective, one can experience freedom of choice (which is a subjective, motivational state) without objectively having many alternatives in the situation at hand. Thus, objective and subjective volition are two different concepts. For job alternatives (objective volition) we used a single-item measure directly asking the number of job offers: 'How many job offers could you choose from before deciding to take on this job?' The subjective part of volition was measured by three items taken from O'Reilly and Caldwell (1981): 'My decision to take on this new job was based on my OWN feelings/considerations/intuition'; 'My decision to join this firm was based on external pressures (e.g., finances)' Reverse coded; 'My decision to take on this new job was based on satisfying needs of others' (Reverse coded). Then participants could indicate the percentage of agreement on a 1-100 scale. These are formative measures, thus, Cronbach alphas are inappropriate.

\footnotetext{
${ }^{52}$ Conceptually, choosing for the ' 0 ' option would have been a better lower limit than 1 . However, in try-outs the 0 gave technical difficulties in the online questionnaire system (NetQ).
} 


\subsection{Analytical procedures}

As said, we will use two ways of describing dynamic form aspects: first is the description of individual-level aspects of form, and second is the description of the overall shape of the trajectory, which is performed on group-level.

Individual-level form aspects Aspects of the trajectory form were assessed for each individual. We distinguished 7 form parameters: within-subject mean, initial level, rate of change (slope), standard deviation, intensity of change, frequency of change, and pattern ruggedness. To clarify the content of these parameters, we refer to Figure 3 and Table 3 in the Results section where we demonstrate how each of these parameters highlights unique aspects of trajectories in 12 exemplar individuals in our sample. (1) Within-subject mean answers the question 'What was the general level of the OC trajectory?'; it was computed by taking the mean across all time points for all 72 participants separately. It signifies a person-specific average level of OC across time. (2) Initial level answers the question 'How high does OC start?'; in our study initial level was not the first measurement, but the fifth, because we measured OC 4 weeks in advance. The initial level corresponds to the first week on the job. (3) Rate of change (slope) answers the question 'What was the linear degree of increase/decrease of the trajectory?'. This variable is computed by drawing a linear (regression) line through a series of time points, according to the least squares method. It signifies the beta-coefficient of the time variable in $\mathrm{OCt}, \mathrm{i}=\beta 0_{\mathrm{i}}+\beta 1_{\mathrm{i}} * \mathrm{t}$, for respondent $i$. A rate of change near zero signifies a 'stable' trajectory. To check whether the rate of change represents the actual overall decrease or increase we calculated all rates of change between all pairs of successive time points and then calculated the mean of all rates of change per trajectory. Indeed, there was a high correlation between the average rate of change connecting the separate time points and the overall rates of change $(r=.96)$.

(4) The standard deviation $(S D)$ answers the question: 'What was the degree of variability around the individual base level of the trajectory?' The individual standard deviation is taken as the degree of variability from the within-subject mean. It is worth noting that the use of the SD as the only parameter of variability - as is done by some researchers - is unjustified, as the metric does not necessarily distinguish smooth increase from erratic variability around the mean. (5) Change intensity answers the question: 'What was the general degree/amplitude/intensity of the change in the trajectory?' It was measured by taking the mean of the absolute difference scores between sessions. To avoid bias caused by discontinuities that are disproportionate to the rest of the trajectory, we also took a more conservative measure: the median of absolute difference scores ${ }^{53}$.

(6) Change frequency answers the question: 'How often did change occur in the trajectory?'; it is measured by counting the number of slope changes relative to (i.e., divided by) the number of

\footnotetext{
${ }^{53}$ We deliberately omitted the often used 'coefficient of variation' (i.e., variation divided by the mean, Lee, Ashford, Walsh, \& Mowday, 1992; Wholey \& Brittain, 1989) as we thought it would not have added value over and above the form parameters we are using.
} 
completed sessions (Wholey \& Brittain, 1989). We did not count slope changes smaller than one, that is, changes back and forth from 50 to 51 were regarded as 'stable', because our LOCUST measurement system was vulnerable to exactly this degree of inaccuracy (see chapter 4).

(7) Finally, pattern ruggedness answers the question: 'What is the general degree of volatility in the pattern?' Its name, pattern ruggedness, was inspired by Sappington and colleagues (Sappington, Longshore, \& Thompson, 2007) who assessed the degree of ruggedness of a 3-D wildlife terrain in the Mojave desert landscape. We apply it to a 2-D trajectory. Pattern ruggedness is measured by the standard deviation of the slopes between all adjacent trajectory points. Missing values were interpolated. Compared to the standard deviation, pattern ruggedness is more informative about of the degree of volatility as variability in change (e.g., discontinuity) is taken into account. Its additional value over and above the standard deviation is depicted in Figure 5.2. Line 2 has a relatively high standard deviation, but only a low ruggedness score. In contrast, pattern 3 and 4 display higher ruggedness scores compared to the standard deviation.

Figure 5.2 Hypothetical trajectories contrasting standard deviation (SD) and pattern ruggedness

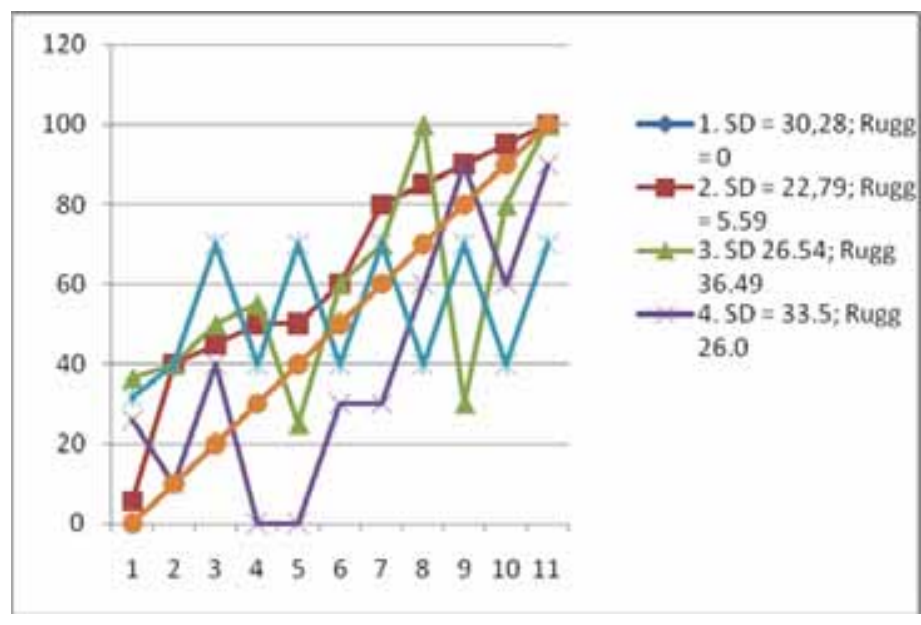

Group-based modeling of development To detect groups of similar trajectories in our data, we opt for the approach advocated and developed by Nagin and Jones (Jones \& Nagin, 2007; Jones, Nagin, \& Roeder, 2001; Nagin, 2005). The technique is known as 'finite mixture modeling' or 'group-based modeling of development'. The approach is 'finite' because the number of trajectory groups $(J)$ is limited and pre-specified, and 'mixture' because it is assumed that the population consists of a mixture of heterogeneous sub-populations (i.e., latent trajectory groups) that display different dynamic patterns and may reflect distinctive etiologies (Nagin, 2005). The technique follows a fixed order of analytical steps. First, it tries to detect $J$ classes of comparable trajectories based on trajectory level and shape characteristics. Second, it calculates the probability that an individual 
trajectory $i$ could belong to each latent group $j$; this metric is called the posterior probability $\pi_{j}$. The posterior probability 'collectively measures a specific individual's likelihood of belonging to each of the model's $J$ trajectory groups (Nagin, 2005, p. 78). It is a highly useful metric in the context of group-based modeling as it is used to create profiles of the trajectory group members and assess the model's fit to the data. Third, group-based modeling assigns individual trajectories to a particular latent trajectory group $j$. Subjects are then assigned to latent group $j$ on the basis of the highest posterior probability among the groups. This allocation results in the actual number of individuals assigned to latent group $j$. Fourth, it allows to use multinomial regression analyses to predict group membership.

Model choice Finite mixture modeling is a data-driven technique based on a maximum likelihood algorithm and requires pre-specification of the number of latent groups as well as the order of the polynomial (up to cubic). What is typically done in this technique is to compare models with 2 , $3,4,5$, to $j$ number of latent trajectories - all polynomials set to quadratic or all to cubic - and evaluate their relative performance and then make an informed decision on which model to pick. A caveat mentioned by the designer (Nagin, 2005) is that there is no 'right model' in terms of the number of latent trajectories. Choosing the right model relies heavily on the domain knowledge and expert judgment of the researcher. To decide on the number of latent groups we used 3 pre-set criteria for model selection: (1) non-redundancy of trajectories, (2) the balance between parsimony and explanatory power approached by the numerical Bayesian Information Criterion (BIC), Aikake Information Criterion (AIC) and/or - if sample size is small - the evidence ratio (Burnham \& Anderson, 2004). For an explanation on the interpretation of these information statistics, see Appendix F. (3) not too many small groups (i.e. $>5 \%$ of $\mathrm{N}$ ).

Assessing model performance Nagin (2005) suggests 4 diagnostics (see Table 5 in the Results section) to provide concrete guidance to assess a model's capacity to identify distinct trajectories in the data. He suggests the AvePP (i.e., average posterior probability of assignment). Ideally, the AvePP is 1, which means that all individuals have been assigned to their trajectory group with a probability of 1 and all other groups are 0 . As a rule of thumb, Nagin (2005) states that the AvePP should be at least .7. The second diagnostic, the OCC $j$, measures the odds of correct classification per group. An OCC $j$ of 1 means that assignment to group $j$ is completely at random; 5 and higher indicates high assignment accuracy (Nagin, 2005). The third metric $\left(\pi_{\mathrm{j}} / \mathrm{P}_{j}\right)$ measures whether there is a sufficiently close correspondence between a group's posterior probability, $\pi_{j}$, and the actual proportion of individuals in the sample classified to group $j$. The closer the metric approaches 1 , the better the correspondence. Finally, the fourth diagnostic indicates the confidence interval (98\%) around $\pi_{j}$, which is the relative accuracy of the posterior probability.

Explaining group membership After the initial step of finding the appropriate number of trajectory groups is taken, the challenge is to try and predict their occurrence through 'risk factors' (in Nagin's terminology). The main difference in prediction compared to standard growth curve modeling 
is that growth modeling is parameter-driven (e.g. depending on parameters such as the initial level, and the rate of change), while group-based modeling is trajectory-driven (i.e. allocating group membership based on similarity of the level and the shape of the trajectory). That is, group-based modeling aims to explain group membership. As our sample did not allow for a powerful multinominal test we used a non-parametric test (Kruskal-Wallis) to test for differences between $J$ identified groups. If this was the case, we performed a Bonferroni post-hoc test to examine the exact location of group differences. To asses form parameter interrelationships we examined bi-variate correlations. The prediction of form parameters with conventional predictors was also performed with simple correlations.

\section{Results}

Before reading further we advise the reader to first have a look at Appendix G, where we show our 72 commitment trajectories depicted over time. What is apparent is the heterogeneity of pattern shapes. Another apparent feature in the data is the smooth convex increasing patterns. Here and there we find discontinuities in otherwise smooth patterns. Then have a look at Appendix H, where we report descriptive statistics and a graphical representation of the mean (i.e., sample level) development of OC. Then contrast the mean development of $\mathrm{OC}$ with the individual patterns. The differences are conspicuous.

We will start discussing observations of individual-level patterns, including the description of 7 form parameters in 12 illustrations. Then we will address group-level form aspects. As a third step, we will describe form aspects of latent trajectory groups in terms of form parameters such as ruggedness, change intensity, or change frequency. In the analytical part of this section we will interrelate form parameters (based on between-subject differences in within-subject change), then predict them using conventional predictors. As a final step, we try to predict membership of latent trajectory groups.

\subsection{The observation of individual-level form aspects}

We have identified 7 parameters of trajectory form: within-subject mean, initial level, rate of change, standard deviation, intensity of change, frequency of change, pattern ruggedness. In the following we will illustrate how these parameters illuminate distinct features in temporal patterns. Figure 5.3 shows a series of individual patterns, ordered according to their ruggedness scores (from high to low). The cases have been selected to display optimal contrast between the different form parameters to facilitate illustration purposes. Table 5.3 shows their respective values on all form parameters. To aid interpretation we provided the mean sample score on each form parameter as well. The first two individuals in Figure 5.3 show a sharply declining pattern (participant A) and a sharply increasing 
pattern (participant B). Both participants are also examples of high ruggedness scores (18.78 and 9.72, respectively), and of very high standard deviations (30.77 and 32.41, respectively). The two participants differ markedly on their change frequency score (23.8 versus $61.5 \%$ ). Although, participant $\mathrm{A}$ has a higher ruggedness score than $\mathrm{B}$, her number of changes is substantially less frequent than B. This is because participant A shows a relatively consistent decline in after week 10, while B keeps on showing many slope changes.

Figure 5.3 Twelve participants as illustration (from high to low ruggedness scores)

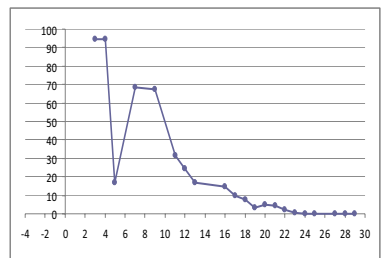

A

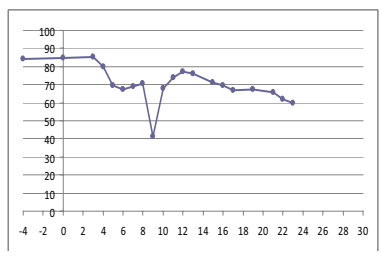

$\mathrm{D}$

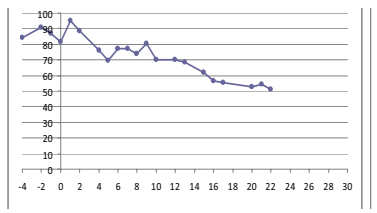

G

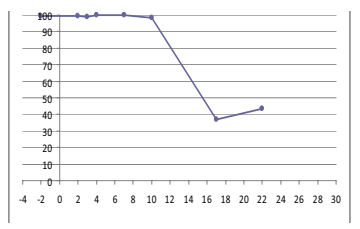

$\mathrm{J}$

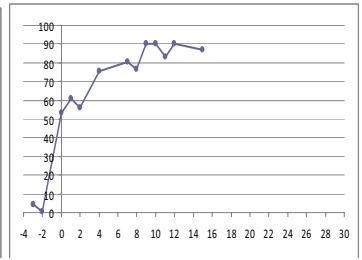

B

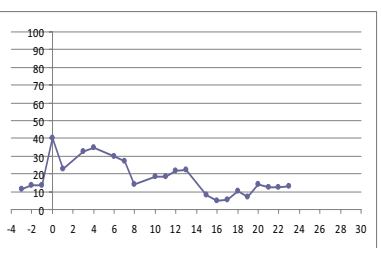

$\mathrm{E}$

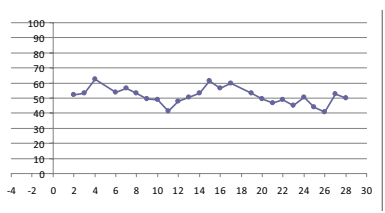

$\mathrm{H}$

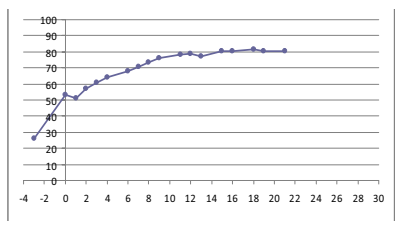

K

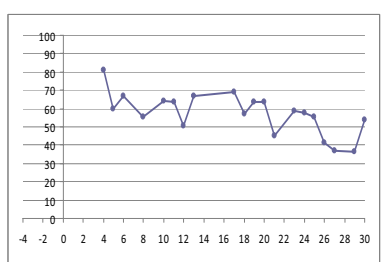

$\mathrm{C}$

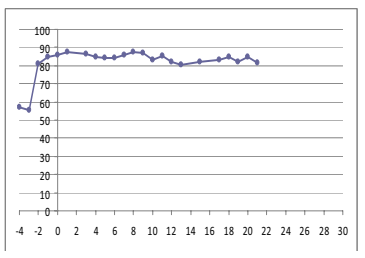

$\mathrm{F}$

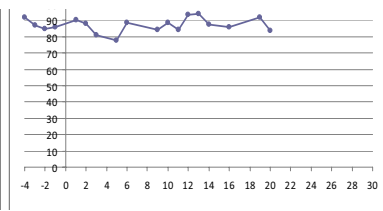

I

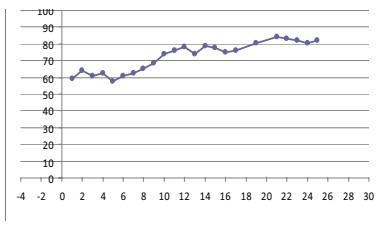

$\mathrm{L}$

Many features do not necessarily go hand in hand. For instance, participants $\mathrm{K}$ and $\mathrm{C}$ have similar trajectory means (69 and 61) while showing dramatically different forms in terms of pattern ruggedness ( 3.15 vs. 9.29), change frequency ( 28 vs. $56 \%$ ), change intensity ( 2.45 vs. 9.71 ), and general direction of change (rate of change $=1.85$ vs. - .88 ). Moreover, participant $\mathrm{K}$ is a noteworthy illustration of the difference between the standard deviation (i.e., SD around the trajectory mean) and 
the pattern ruggedness score (i.e., SD of all the rates of change connecting separate time points). While this participant $\mathrm{K}$ has a high standard deviation $(S D=14.8)$, her pattern ruggedness score is well below the sample mean $(3.14, M=4.19)$. SD captures the broadness of the range, whereas ruggedness better captures the variability within this range. SD is more a characteristic of form than variability. To illustrate this further, participant I has a low standard deviation $(S D=4.31$;), while having a relatively high ruggedness score (ruggedness $=4.53 ; M=4.19$ ).

Table 5.3 Form parameter values of twelve participants

\begin{tabular}{ccccccccc}
\hline & $\begin{array}{c}\text { Within- } \\
\text { subject } \\
\text { Mean }\end{array}$ & $\begin{array}{c}\text { Initial } \\
\text { level }\end{array}$ & Slope & SD & $\begin{array}{c}\text { Change } \\
\text { intensity: } \\
\text { mean }\end{array}$ & $\begin{array}{c}\text { Change } \\
\text { intensity: } \\
\text { median }\end{array}$ & $\begin{array}{c}\text { Change } \\
\text { frequency } \\
\text { (\%) }\end{array}$ & $\begin{array}{c}\text { Rugged- } \\
\text { ness }\end{array}$ \\
Participant & $\mathbf{M = 7 5 . 1}$ & $\mathbf{M = 6 8}$ & $\mathbf{M}=. \mathbf{4}$ & $\mathbf{M}=\mathbf{8 . 7}$ & $\mathbf{M}=\mathbf{3 . 9}$ & $\mathbf{M}=\mathbf{3 . 1}$ & $\mathbf{M = 3 1 \%}$ & $\mathbf{M}=\mathbf{4 . 1 9}$ \\
\hline A & 25.67 & $(94.00)$ & -3.21 & 32.41 & 7.86 & 2.00 & 23.81 & 18.78 \\
B & 65.15 & 53.00 & 4.61 & 30.77 & 5.88 & 6.00 & 61.54 & 9.72 \\
C & 61.13 & $(81.00)$ & -.88 & 8.29 & 9.71 & 9.50 & 55.00 & 9.29 \\
D & 70.40 & 85.00 & -.71 & 10.00 & 7.31 & 2.50 & 21.05 & 8.40 \\
E & 17.74 & 40.00 & -.61 & 9.79 & 5.18 & 2.50 & 50.00 & 7.95 \\
F & 74.00 & 86.00 & .18 & 8.27 & 3.26 & 2.00 & 39.13 & 5.44 \\
G & 72.43 & 35.00 & -1.56 & 13.25 & 5.43 & 5.00 & 42.86 & 5.38 \\
H & 51.77 & $(52.00)$ & -.28 & 5.43 & 4.76 & 3.50 & 50.00 & 5.29 \\
I & 87.28 & 86.00 & .07 & 4.31 & 5.17 & 5.00 & 55.56 & 4.53 \\
J & 84.50 & 100.00 & -2.99 & 27.52 & 0.50 & 0.50 & 37.50 & 4.27 \\
K & 68.89 & 51.00 & 1.85 & 14.80 & 2.45 & 2.00 & 27.78 & 3.15 \\
L & 72.26 & $(57.00)$ & 1.09 & 8.83 & 2.63 & 2.50 & 43.48 & 2.86 \\
\hline
\end{tabular}

Note: initial levels in parentheses are interpolated scores as these values were missing. Note that the data are ordered from high to low ruggedness scores. M's displayed in the first row represent sample means.

Participant D seems more 'rugged' because of the large 'dip' in the middle. Still, she has only a slightly lower ruggedness score than participant $C$ (8.4 vs. 9.7). Participant D also shows a remarkable difference in change intensity, depending on the metric used (i.e., 7.3 when using the mean - and 2.5 when using the median of absolute difference scores). Thus, the median is a more conservative measure of change intensity, disregarding the influence of isolated drastic changes in the pattern.

The use of these 7 parameters gives much more insight into the temporal nature of commitment progressions than what we would have seen by using only the rate of change and the initial level. This method allows for numerical comparison of different aspects of dynamic form. For example, participants $\mathrm{C}$ and $\mathrm{D}$ seem different at first glance, but have similar trajectory means (within-mean $=61$ and 70, respectively), rate of change signs (-.88 and -.71), standard deviations (8.29 and 10) and ruggedness scores (8.29 and 10); their distinguishing dynamic feature is the frequency of change (55 vs. $21 \%$ ). The trajectories of participant C and D also exemplify the fact that two trajectories with the same initial level and the same slope can still show substantially different patterns. 
Interestingly, the mean across all trajectory slopes amounts to 0.4 , which deserves the qualification 'stable'. When looking at individual-level data in Figure 3, however, stability is only one out of many trajectory options. Trajectories of participants A to $\mathrm{L}$ show that there is quite some variability in OC change patterns among new incumbents in the first 6 months of work It demonstrates the crudeness of the population mean, compared to individual-level trajectories. Thus, the combination of 7 parameters allows for analyses which are better able to address the meaningful nuances of change between individual trajectories.

\subsection{The observation of group-level form aspects}

Choosing the number of latent trajectory groups In group-based modeling of development (Nagin, 2005) model choice is the most sensitive issue. After visual inspection of the data we used the SAS Proc Traj software package to explore the number and the shape of latent trajectory groups. The first step is to determine the number of latent groups to include in the model. As is conventional in group-based modeling, we tested the relative performance of the 2 to 7 -group solution. To allow for comparison across groups, we initially fixed the order of the polynomials to cubic. As a first empirical yardstick to model selection we checked for empirical criteria, which is the relative performance of model $i$ compared to $j$ according to the Bayesian Information Criterion (BIC; see Appendix F for more information).

Table 5.4 Information criteria to aid model selection (T1-T30)

\begin{tabular}{cccccc}
\hline N groups & BIC $(\mathrm{N}=962)$ & PCM & BIC $(\mathrm{N}=72)$ & AIC $c$ & $\begin{array}{c}\text { Evidence } \\
\text { ratio }\end{array}$ \\
\hline 2 & -3879.61 & 0.00 & -3867.12 & -3854.94 & 0.00 \\
3 & -3775.28 & 0.00 & -3756.54 & -3738.19 & 116.75 \\
4 & -3735.02 & 0.00 & -3710.02 & -3685.44 & 169.50 \\
5 & -3694.76 & 0.00 & -3663.51 & -3632.61 & 222.33 \\
6 & -3684.96 & 0.00 & -3647.46 & -3610.18 & 244.76 \\
7 & -3612.45 & 1.00 & -3527.24 & -3524.97 & 329.97 \\
\hline
\end{tabular}

In our particular case, the BIC could not be interpreted because it kept increasing (i.e. becoming less negative, towards zero) with the number groups, which is a common problem noted by Nagin (2005). This means that in all our exploratory trials the highest number of groups had the highest probability to be the correct one (using the Probability Correct Model; PCM; see Appendix F). The fact that BIC was of no aid became especially clear to us when we specified models with up to 20 latent trajectory groups and BIC kept increasing. Note that such a large number of latent groups contains trajectories of even single participant-trajectories.

As we thought that a potential reason for a continuously rising BIC was the relatively 'small' sample size, we looked for an information criterion which corrects for sample size. We found the 
$\mathrm{AIC} c$, which is the corrected Aikake Information Criterion (Burnham \& Anderson, 2004). Using AIC $c$ the relative performance of model $i$ over $j$ is judged using the evidence ratio (Ibid., 2004), where any number above 150 is good evidence for choosing model $i$ over $j$ (which is the worst performing model - the 2-group solution - with to the lowest AICc score; see Appendix F). The evidence ratio was more informative in the sense that it consoled us that any model containing 4 groups or more would do fine. But even this criterion did not provide the ultimate answer what solution to pick. Thus, we mainly used the other criteria explained before to decide upon the model.

Of the 2, 3, 4, 6, and 7-group solutions, the 5-group solution yielded patterns that were the most robust in split-half tests (i.e., skipping even/uneven time points) and monthly time intervals, when taking out the last 5 weeks, and the first four weeks (see Appendix H). Information regarding these robustness-checks is available from the first author. Next, the 6- and 7-group solution yielded redundant patterns in comparison with the 5-group solution which is undesirable. Moreover, additional latent groups were only made up by less than 5 percent of the population, which equals around 2 or 3 participants in our sample. Therefore, we think that the 5-group solution gives a fair reflection of the data. Figures of the 4, 6, and 7-group solutions are presented in Appendix H.

Table 5.5 Model diagnostics for the 5-group solution

\begin{tabular}{|c|c|c|c|c|c|c|c|}
\hline Group number and name & $\pi_{i}$ & 98\% C.I. for $\pi_{i}$ & AvePPj & $\mathrm{OCC} j$ & $\boldsymbol{\pi}_{j} / \mathbf{P}_{i}$ & $\mathbf{P}_{i}$ & $\mathbf{N}_{j}$ \\
\hline 1 Low start; cubic decline & .07 & $(.04-.01)$ & .87 & 82.50 & 1.05 & .07 & 5 \\
\hline 2 Low start; parabolic increase & .22 & $(.16-.27)$ & .75 & 11.00 & .78 & .28 & 20 \\
\hline 3 High start; parabolic decrease & .29 & $(.22-.36)$ & .70 & 5.60 & 1.06 & .28 & 20 \\
\hline 4 Middle start; parabolic increase & .25 & $(.19-.31)$ & .57 & 4.00 & 1.506 & .17 & 12 \\
\hline 5 High stable & .17 & $(.12-.21)$ & .76 & 6.90 & .80 & .21 & 15 \\
\hline
\end{tabular}

Model performance As said, Nagin (2005) suggests 4 diagnostics to provide concrete guidance to assess a model's capacity to identify distinct trajectories in the data: (1) AvePP, (2) OCC $j$, (3) $\pi_{j} / \mathrm{P}_{j}$, and (4) confidence intervals for $\pi_{j}$. In our case the average posterior probability (AvePP) $=$ .80 , which according to Nagin is 'good' model performance. AvePP's on group-level are shown in Table 5. Subjects were assigned to groups with fairly high probabilities. Group 4 was the worst performing group in terms of the AvePP's. That is, subjects were assigned to group 4 with an average probability of .57. The second diagnostic, the OCC $j$, measuring the odds of correct classification per group, yields satisfactory results. All groups have high odds of correct classification, except for group 4 , which as has 'moderate' odds for correct classification. The third metric $\left(\pi_{j} / \mathrm{P}_{j}\right)$, measuring the degree of correspondence between a group's posterior probability, $\pi_{j}$, and the actual proportion of individuals in the sample classified to group $j$, also yields satisfactory results. Individuals have been under-assigned to group 4, while they have been over-assigned to group 5 and 2. Group 1 and 3 have excellent assignment accuracy. The actual numbers of individuals in the respective latent groups are displayed in Table 5.6 (see the end of this section). The fourth diagnostic indicates the confidence 
interval (98\%) around $\pi_{j}$. They have been taken from the standard errors around $\pi_{j}$, provided in the SAS Proc Traj output. For clarification purposes we also included $\mathrm{P}_{j}$, which is the actual propability of an individual to be allocated to each the groups. Finally, $\mathrm{N}_{j}$ represents the actual number of participants allocated to each of the groups.

Figure 5.4 Five commitment trajectories during the first 6 months of work.

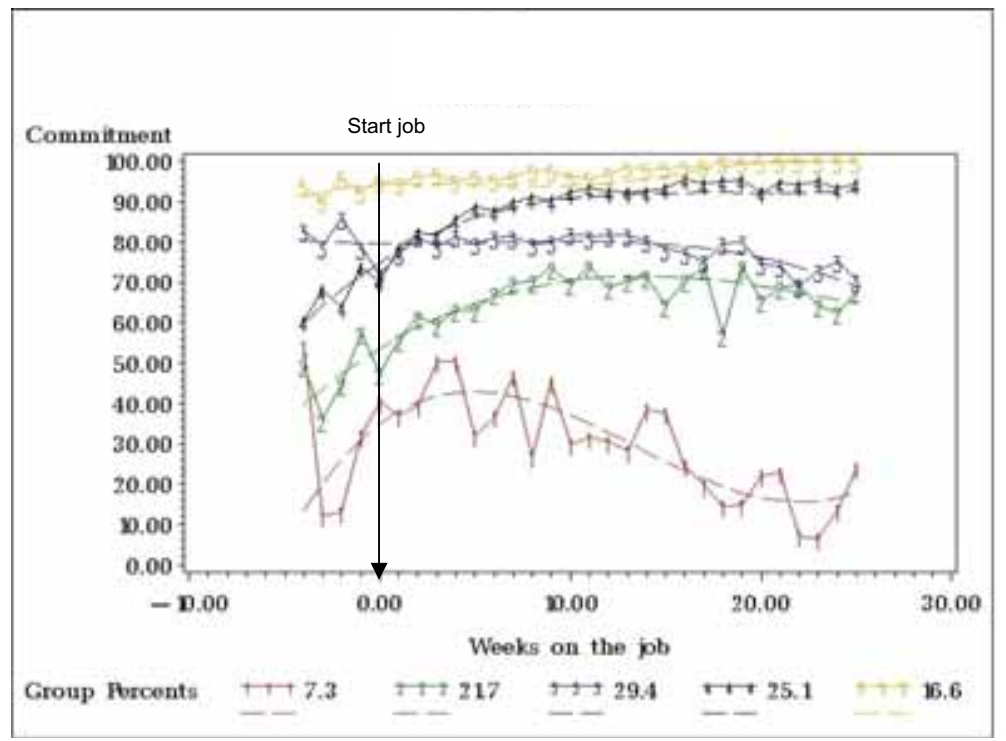

Note: the group percents are posterior probabilities, not the actual proportions assigned to these groups.

The patterns shapes of these 5-clusters are depicted in Figure 5.4. They are selected based on pattern similarity based on their shape and level (Nagin, 2005). Below we will describe what group-level trajectories we observe. The group percents as depicted in Figure 5.4 are the estimated posterior probabilities to belong to group $j\left(\pi_{j}\right)$. The first group starts off low, and then shows a cubic decline. The figure shows quite a volatile ('rugged') trajectory. The second group starts off low as well, but shows quite a sharp increase afterwards. The shape of the trajectory is parabolic, showing a modest decline after the fourth month on the job. The pattern seems volatile in the beginning as well in the end. In contrast to the second group, the third group starts off high, but gradually declines over time with convex shape. Just like the second group, this group shows some discontinuities in the beginning and in the end, although changes are less volatile. The fourth group starts around the middle point and then slowly 'warms up' to end up with high commitment levels. In contrast to the former trajectories, this pattern does not decline at the end. From the looks of it, the trajectory seems 'smooth', showing continuous logarithmic increase with an asymptotic end. The fifth and final group consists of individuals who start off high and stay high with a modest linear increase. 
There are a couple of aspects that we find conspicuous about these distinctive time-based progressions. First of all, we have observed a generally enthusiastic and committed sample of newcomers. Averages are generally high. Second, reasoning from the life cycle approach (chapter 3) one would expect rising $\mathrm{OC}$ before entering the organization. A rising pattern is indeed observed in group 1,2, and 4. But a substantial proportion displays high 'anticipatory' OC before entering the organization (group 3 and 5). Third, contrary to our expectations, OC does not 'peak' at the first week of employment. To the contrary, group 2, 3 and 4 display a 'micro-dip' (i.e., a relatively small temporary low point in OC) at the start of the job. Fourth, there is no evidence for a 'hangover-effect' during the first 6 months of employment. The general pattern of decline after entry is only one possibility, typically under low-commitment individuals (i.e., group 1). Whether our sample reflects a 'honeymoon' period is unsure because the picture is diverse. Only when extrapolating trajectories displayed by group 2 and 3 - which show a modest decline after the $12^{\text {th }}$ week - one might expect that a 'hangover' period is still to come. If that would be the case, group 2 and 3 would have experienced a 'honeymoon' in our time frame. Interestingly, group 4 displays the opposite pattern, starting off with some degree of hesitation (medium-high OC) but then quickly growing and ending up high, showing no signs of decline in the near future. In short, newcomers on the job do not uniformly experience honeymoons and hangovers; only some of them do and others even display the opposite pattern.

Fifth, some patterns start out at different levels, but converge over time. For example, group 4 (starting in the middle) and 5 (starting high) seem to converge around the 12th week on the job. Similarly, group 3 (starting high) and 4 (starting low) seem to converge around the $6^{\text {th }}$ month on the job. Sixth, individuals showing low levels of OC prior to entering can still end up in the high regions of OC, as seen in trajectory 2. Those who's OC does not rise after a slow start can be considered as good as 'lost' to the firm as 3 out of 5 individuals in group 1 reported that they are looking for another job. It should also be noted that some individuals do not follow the patterns as stated in Figure 5.4. For example participant A and B in Figure 5.3 are obvious exceptions to the general patterns on the group-level. This illustrates the difference between the observed individual patterns of commitment and the group-based curves depicted in Figure 5.4.

Form parameters and trajectory groups

In this section we answered the question: 'What distinguishing features do the latent trajectory groups have?' To aid understanding of the dynamic shapes of the five latent trajectory groups we have displayed means and standard deviations of the 7 form parameters specified to group-level. A Kruskal-Wallis test reveals that the withinsubject mean, initial level, the slope, and pattern ruggedness are features which distinguish grouplevel trajectories from one another. The chi-square of 'frequency of change' is marginally significant. What is remarkable is the decreasing ruggedness in higher in levels of commitment. It seems that within-person variability decreases when the trajectory group is positioned at a higher level of commitment. Table 5.6 also shows that there are considerable within-group differences in terms of form aspects. Especially in group 1 the standard deviation sometimes even exceeds the mean. Thus, 
individuals in the five groups display substantial differences with respect to aspects of form. This is helpful as the group-based modeling approach does not assume within-group variability (Nagin, 2005).

Table 5.6 Means and standard deviations of form parameters in 5 latent groups

\begin{tabular}{|c|c|c|c|c|c|c|c|c|c|c|}
\hline \multicolumn{3}{|c|}{$\begin{array}{l}\text { Latent trajectory groups } \\
N=72\end{array}$} & \multirow{2}{*}{\begin{tabular}{|c|}
$\begin{array}{c}\text { Within } \\
\text { subject } \\
\text { mean }\end{array}$ \\
31.67
\end{tabular}} & \multirow{2}{*}{$\begin{array}{c}\text { Initial level } \\
39.00\end{array}$} & \multirow{2}{*}{$\begin{array}{c}\text { Slope } \\
-.74\end{array}$} & \multirow{2}{*}{$\frac{\text { SD }}{10.58}$} & \multirow{2}{*}{$\begin{array}{c}\begin{array}{c}\text { Change } \\
\text { intensity } \\
\text { mean }\end{array} \\
3.86 \\
\end{array}$} & \multirow{2}{*}{$\begin{array}{c}\begin{array}{c}\text { Change } \\
\text { intensity } \\
\text { median }\end{array} \\
2.10\end{array}$} & \multirow{2}{*}{$\begin{array}{c}\begin{array}{c}\text { Frequency } \\
\text { of change }\end{array} \\
24.83\end{array}$} & \multirow{2}{*}{$\begin{array}{c}\begin{array}{c}\text { Rugged } \\
\text { ness }\end{array} \\
6.45\end{array}$} \\
\hline $\begin{array}{l}\text { Group 1 } \\
(N=5)\end{array}$ & $\begin{array}{l}\text { Low } \\
\text { declining }\end{array}$ & $M$ & & & & & & & & \\
\hline & & $(S D)$ & (10.36) & $(4.58)$ & (1.44) & (12.53) & $(2.71)$ & $(1.24)$ & (15.19) & (7.39) \\
\hline \multirow{2}{*}{$\begin{array}{l}\text { Group } 2 \\
(N=\mathbf{2 0})\end{array}$} & $\begin{array}{l}\text { Low } \\
\text { increasing }\end{array}$ & $M$ & 62.59 & 46.30 & .21 & 10.21 & 5.35 & 4.83 & 30.41 & 5.63 \\
\hline & & (SD) & $(8.62)$ & (11.27) & (1.88) & $(7.51)$ & (5.59) & (5.73) & (22.47) & (4.99) \\
\hline \multirow[t]{2}{*}{$\begin{array}{l}\text { Group } 3 \\
(N=\mathbf{2 0})\end{array}$} & $\begin{array}{l}\text { High } \\
\text { declining }\end{array}$ & $M$ & 79.27 & 77.55 & -.08 & 7.83 & 3.75 & 2.95 & 34.40 & 3.98 \\
\hline & & (SD) & $(4.69)$ & $(8.32)$ & $(1.20)$ & $(5.60)$ & (1.87) & $(1.45)$ & (15.92) & $(2.20)$ \\
\hline \multirow[t]{2}{*}{$\begin{array}{l}\text { Group } 4 \\
(N=12)\end{array}$} & $\begin{array}{l}\text { Middle } \\
\text { increasing }\end{array}$ & $M$ & 82.06 & 63.75 & 2.19 & 13.47 & 3.72 & 2.18 & 21.39 & 4.16 \\
\hline & & (SD) & $(8.62)$ & (8.73) & (3.61) & (10.48) & (2.63) & (2.09) & (22.33) & (2.68) \\
\hline \multirow[t]{3}{*}{$\begin{array}{l}\text { Group } 5 \\
(N=15)\end{array}$} & $\begin{array}{l}\text { High } \\
\text { stable }\end{array}$ & $M$ & 95.35 & 92.88 & .44 & 3.36 & 2.29 & 2.07 & 16.52 & 1.85 \\
\hline & & $(S D)$ & $(2.80)$ & $(7.30)$ & $(.45)$ & $(1.77)$ & $(1.54)$ & $(1.97)$ & $(18.07)$ & $(1.16)$ \\
\hline & & $\begin{array}{l}\text { Kruskal- } \\
\text { Wallis } \chi^{2}\end{array}$ & $60.16^{* * * *}$ & $32.65^{* * * *}$ & $18.65^{* *}$ & $24.91 * * *$ & 6.01 & 7.48 & 8.37 & $13.77^{* *}$ \\
\hline
\end{tabular}

Note: the $\mathrm{M}$ and the SD are group-level means and standard deviations. ${ }^{* * *} p<.001 ;{ }^{* *} p<.01$; $* p<.05$.

\subsection{Prediction of individual-level form aspects}

In this section we will try to explain/predict the individual- and group-level form aspects that we have identified in the previous section. We will now deviate from strictly describing within-subject change and will make use of between-subject differences in within-subject change (Chan \& Schmitt, 2000). As in the previous section, we start out with the prediction of the individual level form aspects and will then discuss the prediction of the latent trajectory groups.

Form parameter interrelationships It is unlikely that form parameters are orthogonal characteristics as they all describe how OC in a particular individual evolves over time. Level, decline, and fluctuation may be interlinked. Table 5.7 shows that this is indeed the case: pattern ruggedness correlates negatively with the trajectory mean as well as with slope, that is, ruggedness increases with decline in OC. Most form aspects are related to each other (Table 5.7). Change frequency is a noteworthy exception. It correlates with ruggedness and slope, but not with the mean, $\mathrm{SD}$, initial level, and change intensity.

Further, one can observe that initial level and within-subject mean are highly related. This is in line with previous literature: initial level is predictive of OC level further on in time (Lee et al., 2008). Initial level is remarkably unrelated to the rate of change (slope). That is, the OC level in the first week of employment is not predictive of the general dynamic direction afterwards. 
Table 5.7 Form parameter interrelationships

\begin{tabular}{|c|c|c|c|c|c|c|c|c|c|c|}
\hline Parameters of change & $N$ & $M$ & $S D$ & 1 & 2 & 3 & 4 & 5 & 6 & 7 \\
\hline 1. Within-subject mean & 72 & 75.10 & 17.90 & 1 & & & & & & \\
\hline 2. Initial level & 72 & 68.00 & 19.90 & $.78^{* *}$ & 1 & & & & & \\
\hline 3. Rate of change & 72 & .40 & 2.10 & .20 & .00 & 1 & & & & \\
\hline 4. SD & 72 & 8.70 & 7.80 & $.42 * *$ & .10 & $.42 * *$ & 1 & & & \\
\hline $\begin{array}{l}\text { 5. Change intensity: } \\
\text { mean }\end{array}$ & 72 & 3.90 & 3.50 & $-.30^{* *}$ & $-.36^{*}$ & -.20 & $.33 * *$ & 1 & & \\
\hline $\begin{array}{l}\text { 6. Change intensity: } \\
\text { median }\end{array}$ & 72 & 3.10 & 3.40 & $-.23 *$ & $-.36^{*}$ & -.20 & .20 & $.92 * *$ & 1 & \\
\hline 7. Change frequency (\%) & 72 & 30.50 & 33.00 & -.10 & -.10 & $-.22 *$ & .10 & .10 & .20 & 1 \\
\hline 8. Ruggedness & 72 & 4.20 & 3.80 & $-.37 * *$ & $-.45 * *$ & $-.27 *$ & $.48 * *$ & $.79 * *$ & $.60 * *$ & $.42 *$ \\
\hline
\end{tabular}

To simplify the data on form aspects we performed an Exploratory Principal Component Factor Analysis. We chose for the Oblimin extraction method because the factors are correlated (see Table 5.8). A scree-plot shows a clear 'elbow' after two factors. However, we choose to adapt the threefactor solution as this solution can be better interpreted.

Figure 5.5 Scree-plot of eigenvalues exploring the dimensional space of 7 form parameters

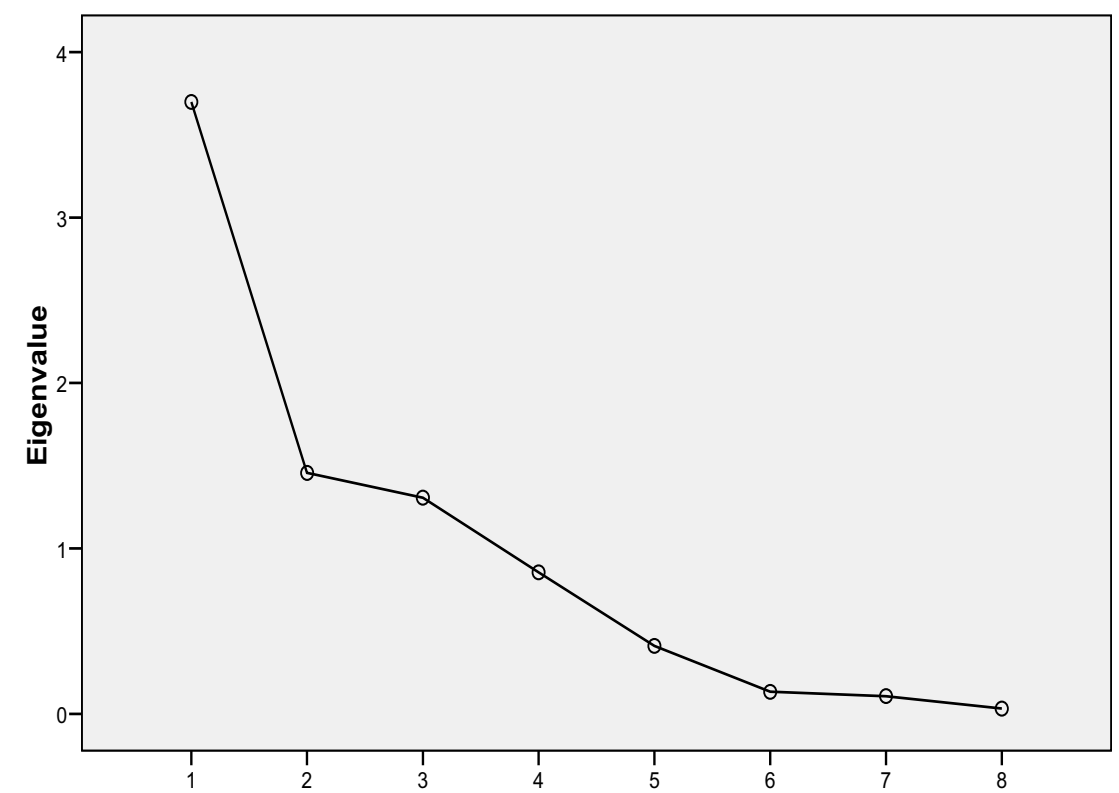


Table 5.8 A three-factor structure of form parameters

\begin{tabular}{lcccc}
\hline Aspects of form & \multicolumn{3}{c}{ Factor loadings } & $\begin{array}{c}\text { Communality } \\
\text { estimates } \\
\left(h^{2}\right)\end{array}$ \\
\cline { 2 - 4 } $\mathrm{N}=72$ & Factor 1 & Factor 2 & Factor 3 & \\
\hline Within-subject mean & .05 & .13 & $\mathbf{. 5 1}$ & .90 \\
Initial level & .03 & -.06 & $\mathbf{. 5 0}$ & .92 \\
Slope & -.08 & $\mathbf{. 6 3}$ & .06 & .85 \\
SD & .13 &. $\mathbf{4 5}$ & -.11 & .81 \\
Change intensity: mean & $\mathbf{. 3 3}$ & -.03 & .03 & .93 \\
Change intensity: median & $\mathbf{. 3 2}$ & -.10 & .04 & .89 \\
Change frequency & .13 &. $\mathbf{2 3}$ & .05 & .28 \\
Ruggedness & $\mathbf{. 2 9}$ & .05 & -.05 & .90 \\
& & & & \\
Initial eigenvalues & 3.70 & 1.46 & 1.31 & \\
Percentage of variance & 46.23 & 18.21 & 16.33 & \\
explained by factor & & & & \\
Factor correlations & & & & \\
& & & & \\
Factor 1 & 1 & & & \\
Factor 2 & .17 & 1 & & \\
Factor 3 & -.34 & -.02 & 1 & \\
\hline
\end{tabular}

In Table 5.8 we have displayed the three-factor ${ }^{54}$ structure of form parameters. It shows a distinction into three factors. Factor 1 contains measures of 'variability', including change intensity (mean and median) and ruggedness. Change frequency displays a cross-loading on Factor 2. Results on this variable should be interpreted with caution as the communality estimates of this variable are particularly low. Hence, change frequency will not be considered for the interpretation of the factor structure. Factor 2 captures a pattern's trend containing the parameters of slope and the standard deviation. Finally, Factor 3 captures the pattern's level containing the within-subject mean and the initial level. Interestingly, Factor 2 and 3 represent the kinds of parameters common to the growth modeling approach, namely the level and the trend, while Factor 1 introduces a new dimension in the description of time-based change in OC. Our interpretation of this exploratory analysis is that the data show that the standard growth modeling approach only taps into two particular dimensions of timebased change, that is, the level and the direction of change (trend), and omits the dimension of variability of change.

As visible in Table 5.8 factor 1 ('variability') is negatively correlated with Factor 3 (level). This suggests that lower commitment patterns go hand in hand with variable commitment patterns. Factor 1 and 2, variability and trend, are only weakly (and positively), which is explained by the fact

\footnotetext{
${ }^{54}$ The two-factor solution consisted of a factor tapping into all parameters that are conventional to growth modeling (i.e. within-subject mean, slope, and the initial level) and another factor tapping into 'variability' which contains the $\mathrm{SD}$, change intensity, change frequency and ruggedness.
} 
that the standard deviation (Factor 2) and pattern ruggedness and change intensity (Factor 1) are positively associated, while the latter variables are negatively associated with the rate of change (see Table 5.7). The fact that the standard deviation loads on Factor 2 (trend) tells that the standard deviation is influenced by the rate of change to such an extent that is does not qualify as a measure of variability (Factor 1).

Predicting trajectory levels To start off the search for explanations, we first checked whether the results in our sample could replicate findings in earlier studies. Earlier studies have mainly predicted OC levels, either in cross-sectional, or serial cross-sectional studies. Therefore we expected to find high associations of common predictor variables with the trajectory mean and the initial level. Associations of stable individual characteristics with commitment level indeed replicate findings from earlier studies: high commitment is related to conscientiousness, emotional stability, negative affectivity, positive affectivity, dutifulness (this is, in fact, new), and past achievements (see Table 5.9). Further, all types of raw prior expectations and met (prior) expectations, POS and P-O fit, job satisfaction, and volition of the job choice correlated highly positively with general OC level (i.e., trajectory mean). Job satisfaction (with the current job) closely matches the corrected correlation coefficient found in previous meta-analyses (i.e., .61, see Meyer et al., 2002).

All this did not come as a surprise; and it clearly confirms the nomological validity of the measures we had used, which gave us confidence in facing the rest of the analyses. In contrast to earlier findings (O'Reilly \& Caldwell, 1981), initial level is only marginally significant ( $p=.052)$.

Predicting the rate of change As a general note, the rate of change is best explained by experiential variables as it correlates most often (5 times) and highest (correlations around .40) with experiential variables. Table 5.9 shows that rate of change correlates with motivation, met expectations, P-O fit, and job satisfaction with the current job, psychological contract breach, psychological contract violation, and dutifulness. Considering the correlation levels, job satisfaction and $\mathrm{P}-\mathrm{O}$ fit, and meeting expectations can be seen as the main experiential predictors of increases in commitment, while 'dutifulness', and psychological contract breach/violation tends to push commitment downwards. The significant association with dutifulness is surprising. We will elaborate on the meaning of this finding in the Discussion section.

As for prior motivation, there was one variable that did correlate with trajectory rate of change: situation-based volition of the job choice (i.e., a high number of job offers). In other words, a 'positive choice' for the organization leads to increasing commitment. This is congruent with findings by Lance and colleagues (2000) who found that having low job choice difficulty (i.e. few job alternatives) is related to decreases in commitment. The authors argue that individuals experiencing high job choice difficulty take personal responsibility for their decision and are less likely to attribute causes of negative events to factors outside themselves. Our results show that the reverse of this effect is also true: having many job alternatives mitigates declining $\mathrm{OC}$ due to disappointments and is related to growing OC. 
Table 5.9 Prediction of 7 form parameters with disposition, situation, and history

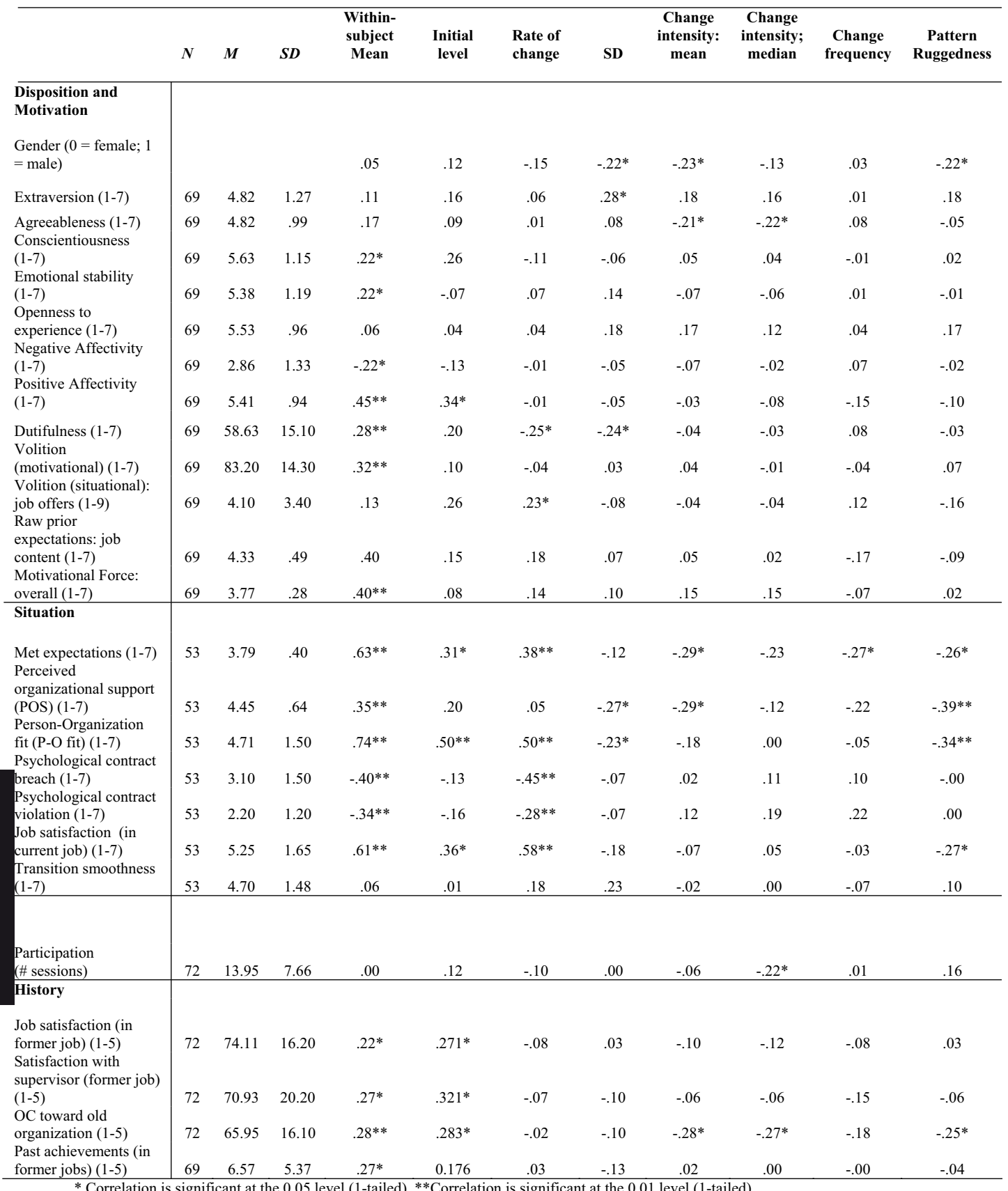

* Correlation is significant at the 0.05 level (1-tailed). ${ }^{* *}$ Correlation is significant at the 0.01 level (1-tailed)

Predicting pattern variability

related to pattern variability as these variables correlate most often and show the highest correlation 
coefficients. Historical predictors (mainly OC to the old organization) have the second-best explanatory value to pattern variability. Contrary to our expectation, emotional stability does not relate to any of the pattern variability parameters. The same generally holds for other dispostional variables, with gender and agreeableness as notable exceptions.

Among the variability parameters (change intensity, change frequency, and pattern ruggedness), pattern ruggedness is relates most often and highest with conventional OC predictors. Pattern ruggedness is related to variables mainly of experiential kind (unmet expectations, POS, P-O fit, and job satisfaction) of also to dispositional characteristics (gender), and history (high commitment toward the old organization). The relationship of gender with both pattern ruggedness and change intensity is remarkable. That is, women's commitment patterns are more rugged, and their changes are more intense compared to men. This is interesting because gender has never been found to be a significant predictor of OC levels in previous studies (Meyer et al., 2002; Mathieu \& Zajac, 1990). The findings indicate that an unpleasant job situation (unmet expectations, low POS, low P-O fit, and low job satisfaction) is associated with a volatile and discontinuous, that is 'rugged', OC pattern.

Change intensity is generally higher among women than men. Moreover, change intensity is lower among agreeable individuals, entrants who held high OC levels toward the old organization, who had high expectations prior to entering, whose expectations were met and received high organizational support in the first six months on the job. The relationship between the intensity of change and agreeableness is remarkable. It shows that a stable personality characteristic is capable of explaining the intensity of change unfolding over time. Change frequency is only explained by met expectations. That is, meeting expectations is associated with a low frequency of change in OC.

Interestingly, job attitudes regarding the previous organization (i.e., $\mathrm{OC}$ to the former organization, overall job satisfaction and supervisor satisfaction in the former job) are strongly related to the trajectory mean in the current organization. Apparently, individuals tend to bring a similar attitude they had toward their old organization when starting to relate to their new organization. What is more, high commitment toward the previous organization is also related to low change intensity and low pattern ruggedness. The meaning of this finding is discussed in the Discussion.

Contextual contingencies did not play as much of a role as we expected them to: transition smoothness, organization size, and (expected) job mobility do not play a major role in explaining OC dynamics during organizational entry. Transition smoothness was only marginally significantly associated $(p<.10)$.

\subsection{Prediction of trajectory group membership}

In the prediction of latent trajectory groups we came across some noteworthy findings. A nonparametric Kruskal-Wallis test revealed that the following predictors showed significantly different 
mean levels across latent groups 1 to 5 (Table 5.10): Positive Affectivity, prior expectations, motivational force, met expectations, P-O fit, psychological contract breach, psychological contract violation, job satisfaction in the current job, and job satisfaction in the former job. Group means in these respective predictor variables generally rise with the level of the group-based trajectory. An interesting exception is psychological contract breach which displays higher means in group 3 compared to group 2 and 4 . This finding makes sense as group 3 starts high but declines over time, whereas group 2 and 4 both are rising trajectories.

A Bonferroni post-hoc test found that Positive Affectivity displays significantly higher means in group 5 compared to group $1(p<.01)$ and $2(p<.01)$. Prior expectations are higher in group 5 compared to group 1,2 , and 3 (all $p<.05$ ). Motivational force is significantly higher in group 5 compared to group $1(p<.01)$. Met prior expectations displays higher means in group 5 compared to group $1(p<.01)$, group $2(p<.05)$, and group $3(p<.05)$.

Interestingly, Person-Organization fit displayed significantly higher means in group 2 ( $p<$ $.05), 3(p<.05), 4(p<.05)$, and $(p<.05)$, compared to group 1 . The results set apart group 1 as 'misfits' in their organizations. This is confirmed by the fact that 3 out 5 members of group 1 reported to look out for other jobs. Group 5 displayed higher means on P-O fit compared to group $2(p<.05)$, the low increasing group. Similar results are found in job satisfaction levels where group $2(p<.05)$, group $3(p<.05)$, group $4(p<.01)$, and group $5(p<.05)$ all display higher job satisfaction means compared to group 1. Job satisfaction levels in group 2 to 5 are not significantly different.

Group mean differences in the Bonferroni post-hoc test were no longer significant (on a .05 significance level) for psychological contract breach and psychological contract violation. Group mean differences on OC toward the old organization and job satisfaction in the previous job were only significant on a .1 level in a One-Way ANOVA. Post-hoc tests did no longer reveal significant differences across groups for these variables. This is mainly due to the high standard deviations around their means.

All in all, the analysis shows that the predicting of group-membership does not provide much added value to prediction of commitment levels alone. After all, most pronounced differences in prediction were encountered between group 1 (the low declining group) and group 5 (the high stable group). Inspection of means in the group-level trajectories shows that the general pattern of means (i.e., group 1 scoring lowest versus the rest) is replicated by inspecting the prediction of the withinsubject mean, and the initial level. This confirms our analysis discussed earlier (see Table 5.6), where we found that group-based trajectories are significantly distinguished from one another by the withinsubject mean, the initial level, the slope, and pattern ruggedness, and that the distinguishing effect of within-subject mean and the initial level was most pronounced. We must conclude that - contrary to our intention - this particular group-based representation of OC change mainly taps into groupdifferences in levels of commitment patterns. 
Table 5.10. Prediction of five latent trajectory groups with disposition, job situation, and history

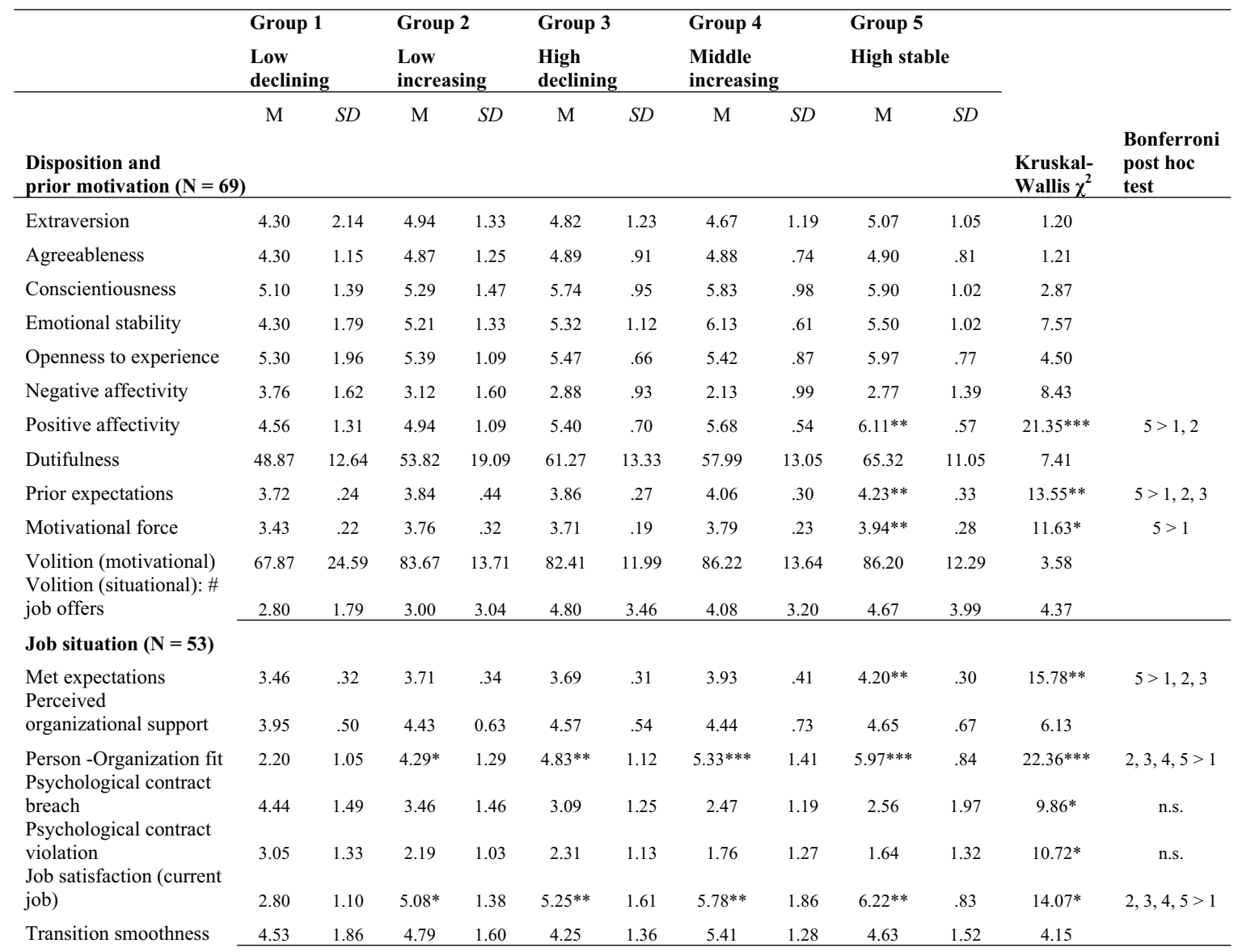

History $(\mathbf{N}=72)$

Satisfaction with

supervisor (old job)

Job satisfaction (old

job)

$\begin{array}{lccccccccccc}53.00 & 27.29 & 65.00 & 28.27 & 75.50 & 11.53 & 76.58 & 16.86 & 73.93 & 14.65 & 3.96 & \\ 68.40 & 22.48 & 68.47 & 15.17 & 71.40 & 17.17 & 81.83 & 18.12 & 79.80 & 9.86 & 12.54 * & \text { n.s. } \\ 19.20 & 5.76 & 11.80 & 8.21 & 15.60 & 7,04 & 15.75 & 8.04 & 11.40 & 7.32 & 6.16 & \\ 57.00 & 18.87 & 58.95 & 17.99 & 68.40 & 14.11 & 69.06 & 10.92 & 72.73 & 16.85 & 8.25 & \end{array}$

$\begin{array}{lllllllllll}57.00 & 18.87 & 58.95 & 17.99 & 68.40 & 14.11 & 69.06 & 10.92 & 72.73 & 16.85 & 8.25\end{array}$

compliance (\# sessions)

Commitment to the old

organization

*Test is significant at the 0.05 level. ** Test significant at the 0.01 level. *** Test significant at the 0.001 level.

Asterisks in the respective groups reveal significant mean differences compared to group 1 (on a 0.05

significance level) 


\section{Discussion}

This research has attempted to investigate 'what happens' to newcomers' OC in the organization during the first 25 weeks on the job. We have worked from a temporal-dynamic perspective where 'aspects of form' in within-subject OC change are examined using a finegrained and lengthy longitudinal design. We have demonstrated that it can add value to existing approaches and literally open up an entire new dimension of time-based change. This was demonstrated by the data which showed a clear three-factor structure showing 'variability parameters' (change intensity and ruggedness), trend parameters (SD and the rate of change), and level parameters (initial level and the within-subject mean). In other words, growth modeling approaches (typically investigating only the trend and level) leave an entire dimension ('variability' of change) unexplored.

Our descriptive analysis on the individual level form parameters has revealed that newcomers in the organization display highly heterogeneous temporal pathways in OC. Breaking down trajectories in 7 distinct aspects of form has served to enrich our understanding of newcomers' OC trajectories. Our descriptive analysis of form parameters at the individual level can potentially be useful in the prediction at the intraindividual level. For example, one could start from form parameters and try to 'draw' individual trajectories. The combination of 7 form parameters is capable of giving quite a detailed description of individual trajectory's form. Thus, prediction is likely substantial. Still, there remains a range of potential trajectories that are equally likely, given a certain profile of form parameters. This is only normal as prediction of temporal development can never be deterministic.

On the group-level, our observations indicate that pathways to adjustment in the process of socialization are far from homologous, which contrasts the usual implicit assumption of uniform growth. Our study provides a nice illustration of potential divergent findings in population versus cluster-levels of analysis. We found no evidence for the presence of a universal honeymoon-hangover effect (Boswell, Tichy, \& Boudreau, 2005). Instead, honeymoons occur only to distinct groups of individuals, namely those who start high and then decline or those who start low, quickly rise, and then decline again. Other groups of individuals display the opposite of honeymoons, starting out with medium commitment levels, but then rising and retaining high commitment. This type of a pattern could be qualified as form of slowly 'warming up' for the new organization. For these people there was no honeymoon-effect, but rather a 'learning-to-love' effect. 
Figure 5.6 Our findings in terms of honeymoons and arranged marriages

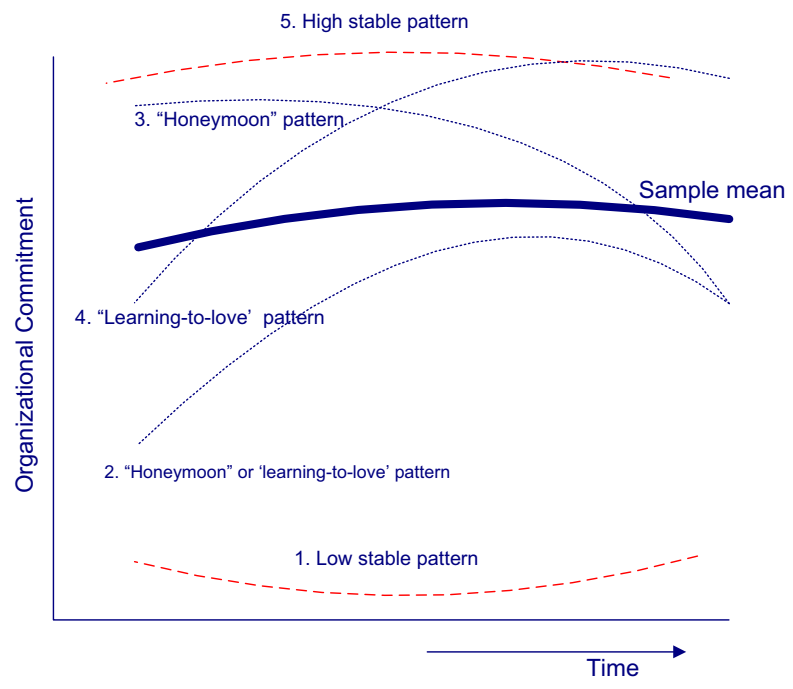

Taken together, these 5 patterns combine to form a relatively stable sample mean. Our sample mean only reveals a very slight increase (average slope is .04) it is best characterize as 'stable'.

Considering the evidence from previous research indicating that $\mathrm{OC}$ generally starts off high (see chapter 3) we wanted to see whether OC 'peaks' at the first week of employment. There was no evidence of a peak. Instead, OC showed a small 'dip' in three groups which lasted only a week. We interpret this finding as the phenomenon of 'getting cold feet' when newcomers are confronted with new situations. The choice to start a new chapter in their working lives has become 'reality', which may invite feelings of apprehension or even melancholia. Commitment prior to entering generally rises, but there is a substantial percentage of individuals who already have high 'anticipatory' OC.

A caveat to the interpretation of these latent trajectory groups is that it gives post hoc descriptions of observed patterns that cannot be used deterministically to predict individual patterns. In other words, one should watch out for reification in the interpretation of trajectory groups (Nagin, 2005). In reality a critical event (e.g., downsizing) may dramatically alter the trajectory and, hence, alter latent composition and group membership of individual employees. Thus, latent groups should be interpreted probabilistically (as is the analytical approach in group-based modeling), not deterministically. The same principle holds for using form parameters to 'predict' an individual's trajectory. Form parameters have been 
established post-hoc; as such prediction should not be interpreted as 'forecasting' but rather conceived of as explanation.

\subsection{Interpretations of form aspect predictions}

Interpretation of form parameter predictions

The fact that we were able to predict general 'aspects of form' (e.g., rate of change, ruggedness, change intensity) from conventional predictors of $\mathrm{OC}$ is promising. Experiential variables were the strongest predictors (e.g., person-organization fit, psychological contract breach/violation, meeting expectations, job satisfaction), followed by stable personal characteristics (gender, dutifulness, positive/negative affectivity, and agreeableness). History appears to be highly important as well (i.e., job attitudes in previous organizations, past successes). Situational contingencies played no role of significance which defied our expectation. It suggests that experiences generally have more impact on commitment dynamics than the situation per se. Other variables which were used to predict rate of change in previous literature, were unrelated. For example, high prior expectations are unrelated to declining OC (contradicting Lance et al., 2000). This may be due to the fact that our sample has a relatively high percentage of increasing commitment trends, while this was not the case in the sample by Lance and colleagues (2000).

A couple of findings deserve some more attention as they are open to inductive reasoning. One of the most intriguing findings is that dutifulness is highly associated with declining $O C$ trajectories. How can this relation be explained? Reasoning from Social Exchange Theory, one could argue that dutiful individuals hold their own conduct (toward organizations in general) to high moral standards. As a consequence, they tend to hold the organization's conduct to equally high standards. These standards may be unrealistic, or - at least - hard to live up to by organizational actors. Therefore, dutiful individuals get more easily upset by negatively perceived organizational events. The incidence of disappointment in the organization could be exacerbated by errors in the attribution of negative events: dutiful individuals tend view themselves as dependable, trustworthy and are therefore more likely to attribute causes of negative events to factors outside themselves (e.g., 'I am always dependable, so it must be the organization's fault').

The finding that 'change frequency' is explained by a lack of 'met expectations' suggests that a subjectively 'predictable' job situation to newcomers results in relative few ups and downs in OC. Conversely, 'reality shocks' create an unpredictable environment, 
resulting in the experience of many ups and downs in OC. If changes in the OC pattern are frequent, expectations and experience must be more often 'realigned'. This causes OC to fluctuate more as subjects make sense again and again. The data suggest that having an accommodating (i.e., agreeable) personality, expecting a lot from the new job, experiencing a supportive environment, absence of reality shocks, and having a history of high commitment all contribute to experiencing changes in $\mathrm{OC}$ with little intensity. The fact that the data show that agreeableness is related to low levels of change intensity makes sense as individuals who are generally demanding and quarrelsome may be emotionally more reactive to conflicts in the workplace. It is surprising that 'neuroticism' did not explain a change frequency nor change intensity. After all, neuroticism - by definition - conveys dispositional differences in the temporal instability of affective states. Unrelatedness to pattern variability potentially questions the construct validity of the neuroticism construct as it is currently operationalized. Replication is warranted. We encourage other researchers to investigate the role of the Big-5 personality traits in relation to 'variability' parameters.

A similar logic could explain the remarkable finding that gender predicts both mood and change intensity. Women may be emotionally more reactive to organizational events (e.g., shocks and disappointments) which translate into more intense changes and a 'rugged' commitment trajectory. We highly recommend other researchers to try and replicate these findings and explore when and to what types of events women react differently than men do.

Finally, the high predictive value of experiences in the former job calls for some further elaboration and induction. OC toward the old employer is highly predictive of the trajectory, initial level, change intensity, and pattern ruggedness. We have theoretical reasons to believe that the main influence that $\mathrm{OC}$ in the former job has on $\mathrm{OC}$ in subsequent organizations trough the presence of an affective 'set point', which is a dispositional attitude level around which reactions occur. These findings call for a historical and 'path-dependent' perspective to the commitment dynamics. That is, the explanation of current developments in organizational socialization depends on historical developments in the previous employment relationships (Boswell, Tichy, \& Boudreau, 2005).

What could explain the high predictive value of job satisfaction and $\mathrm{OC}$ to the old organization? First, past experiences are 'sticky'. That is, bad experiences in past relationships impact on developments in the new relationships (Boswell, Tichy, \& Boudreau, 2005). Second, the findings may point toward a dispositional view on attitudinal dynamics (Boswell, Tichy, \& Boudreau, 2005; Sutton \& Staw, 1995). That is, the strong relationship between past and current commitments in different organizations is congruent with the 
contention that commitment - and perhaps attitudes in general - are at least to some extent composed of a permanent, person-specific, say 'dispositional' element. This idea was mentioned earlier by Tisak and Tisak (2000) who claimed that organizational commitment measures are composed of a permanent element (i.e., a trait characteristic) and an ephemeral element (i.e., a state characteristic). What we may have captured - at least in some part - is a dispositional or preferred 'commitment-style' which is transferred from one organization to the other. This contention is consistent with research on affective 'set points', which are dispositional attitude levels around which adjustments in attitude levels occur (Avant, 1977; Boswell, Tichy, \& Boudreau, 2005; Diener \& Diener, 1996; Heady \& Wearing, 1992).

The dispositional view can also explain our findings that positive and negative affectivity, conscientiousness, emotional stability are all related to the within-subject mean in OC. All these personality aspects seem to contribute to a certain 'set point level' in the commitment attitude. The finding that stable dispositions correlate highly with time-based dynamics is remarkable and calls for replication in other samples. The fact that gender correlates with pattern ruggedness, dutifulness with decreases in OC, Positive Affectivity with membership of high-level, stable trajectories, agreeableness with change intensity, and extraversion with the standard deviation, calls for further research on the relations between dispositions and OC dynamics.

Notwithstanding the dispositional influence on OC, we have also demonstrated that variability around alleged affective set points is considerable, which suggests that crosssectional research may still come to erroneous conclusions as set points can only be discovered in temporal analyses.

Form parameter interrelationships A truly promising observation is that pattern ruggedness (trajectory volatility) is typically found in low levels of commitment. The link between $\mathrm{OC}$ level and pattern ruggedness (i.e. high patterns tend to be smooth, while low patterns tend to be rugged) can also be understood from 'attitudinal dissonance theory', known from theory on attitude change (Eagly \& Chaiken, 1993). In case of organizational commitment negative events can be seen as events that are incongruent with the positive attitude. To resolve this state of dissonance, entrants need to either deny the negative event or 'integrate' it in their associative network, by adjusting the commitment levels proportional to the severity of the event. Rugged patterns in OC are then functions of oscillating denial and acceptance based on the experience of organizational events. We contend that with highly positive attitudes, negative (thus incongruent) events are more likely to be denied. The 'threshold level' to fully assimilate the meaning of negative events is therefore higher among 
individuals with high commitment compared to those with low commitment. This makes high commitment temporally more 'robust'. Linking the concept of attitudinal dissonance with the incidence of organizational events is new and could potentially enrich theory on attitude change.

Pattern ruggedness is also related to declining OC. That is, increasing OC tends to develop 'smoothly', whereas decreasing OC trajectories are rugged. Possible explanations of this difference could be found in Social Identity Theory (Ashforth, 2001; Ashforth \& Mael, 1989): the development of a social identity is typically a slow and cumulative process where experiences in certain roles and affiliations are slowly affecting one's definition of self. Compared to developing a social identity, letting go of a social identity is more resistant to change (Solinger, 2004). Individuals tend to strive for self-consistency and are therefore motivated to keep up their initial attachment levels (Ashforth, 2001). Thus, compared to increasing commitment progressions, declining progressions are subject to more opposing forces trying to steer commitment levels back to initial levels. Letting go of a social identity has been earlier referred to as a mourning process, where denial and acceptance oscillate to eventually lead to full acceptance of the loss. It could be this oscillation of denial and acceptance that results in an association of 'rugged' patterns and declining OC. Thus, while increasing commitment is like a slow and almost undeliberated process of 'identification', decreasing OC is a more like 'mourning process', which comes with 'ups and downs' and which cannot stay unnoticed.

This is in line with the concept of 'attractor nodes' in nonlinear dynamics of behavioral systems (Halasz, 1970, 1995; Lewin, 1936). Oscillation, as a phenomenon, is known from magnetic field theory, previously applied to behavioral systems by Kurt Lewin (1936). In terms of field theory one could say that decreasing OC is subject to oscillation in the context of two opposing attractor nodes, (in our interpretation) the organization and the self. Rising OC is smooth because there is only a single salient attractor - the organization. In contrast, when OC declines the subject is pulled back and forth between two salient attractor nodes: the organization and the self. All in all, these findings cast different perspectives on the nature of low and declining commitment.

Individual and group-levels of analyses Our results show that the combination of holistic (trajectory groups) and particular aspects of change in OC (form parameters) results in non-redundant and complementary analyses of dynamic processes. That is, the holistic approach can cure 'blind spots' in the analytical approach, and vice versa. For example, the observation that honeymoons only occur in distinctive trajectory groups could be found in 
group-based modeling approaches. On the other hand, gender is not predictive of membership of any latent group, but it shows significant correlations with pattern ruggedness and change intensity. This shows that group-level and individual level analysis provide unique information and can be used, combined and contrasted in a single study.

Latent trajectory group membership was harder to predict with conventional predictors than individual form parameters. That is, in the prediction of trajectory group membership only few predictors had a significant effect in contrast to the prediction of individual form parameters. This is no surprise as one tries to explain group-level developmental instantiations with individual-level data. Moreover, trajectories identified with group-based modeling are in fact constellations of several latent dimensions: initial level, rate of change, ruggedness, and so forth. If predictors relate to only one dimension but not with others, prediction of latent pattern classes is hampered. For example, perceived organizational support relates to pattern ruggedness, and trajectory mean, but not with initial level and rate of change; hence its limited value in predicting membership of trajectory groups.

\subsection{Limitations of this study}

A possible threat to the generalization of our findings is that we used a highly specific targetgroup: $\mathrm{PhD}$ graduates. These types of individuals - often classified as professionals or knowledge-workers - are not necessarily comparable to other workers. For example, blue collar workers have to do their jobs under stricter managerial controls than academic professionals. Another threat to the generalizability of our findings comes from the groupbased method we have chosen. Clustering techniques have often been criticized for samplespecific groupings. The validity of this concern however can only be tested through empirical replication. Psychological mechanisms we have revealed that honeymoon effects, learningto-love effects, and getting 'cold feet' in the first week of work are perhaps broad human inclinations which generally occur in many types of individuals in new positions. Another reason replication in future studies is warranted is that we had a relatively large number of predictors and only a relatively small sample size (72 participants).

Second, the group-based modeling approach by Nagin (2005) has statistical limitations. For example, it does not take into account effects of the temporal relatedness of individual scores (i.e., autocorrelation). Nagin argues that this would complicate an already highly complex model. His counter-argument is that the group-based approach accounts for previous scores by the concept of group-based path-dependence. Although this is comforting 
for the time being, it is not entirely convincing. Nor does the 'finite mixture modeling approach' we used (i.e., the 'SAS Proc Traj technique by Nagin and Jones) take into account individual deviations from the group mean. Table 5.6 shows that deviations from the mean can be larger in one group compared to another. There are alternatives to finite mixture modeling which do take into account deviations from the group mean in the tradition of Structural Equation Modeling (Muthen, 2001), but these approaches are computationally highly complex and generally end up with similar results.

A perhaps more disturbing inconvenience in the group-based modeling approach, as forwarded by Nagin and Jones, is that the main distinguishing feature between group-based trajectories is the level of the trajectory group (i.e., within-person mean and the initial level; Table 5.6). This undermines the potential added value of group-based modeling of trajectory shapes over sole prediction of levels of commitment. We recommend the creation of different algorithms for group-based modeling to better distinguish trajectory shapes over and above their differences in level, and in their rate of change.

Nevertheless, the group-based modeling approach is promising, both for descriptive and for explanatory purposes. It provides a holistic approach to temporal development and exposes 'blind spots' which form parameters alone are unable to illuminate. We await statistical improvements on finite mixture modeling with enthusiasm.

Related to the former critique is the fact that we have analyzed highly complex longitudinal data by reducing them back to form 'variables' again. The exploratory tests we used suffer from the very element we tried to fight: the assumption of temporal invariance. Thus, still, a load of temporal richness has remained unexplored. For example, future studies could research the impact of time-lagged relations, the interplay of organizational events, commitment dynamics, time-lagged effects, and so forth. Despite our method of 'aggregation' - we acknowledge the limitations of it - we have been able to show interesting new relations and have gained insight in the process of 'attitudinal repositioning' in a way that was not done before. In addition, we have formulated these types of individual-level variables for a reason, namely to demonstrate that different types of variability, other than the initial level and the slope are of substantive theoretical interest. This study should be considered as a first attempt to comprehend basic structures of highly complex temporal data. Compared to the state of the literature, the creation of group-based modeling of development and the identification of temporal form parameters is new and (hopefully) opens new ventures for others researchers. 


\section{Conclusion}

In the last 40 years of research on organizational socialization, there has been a marked shift from cross-sectional to 'longitudinal' approaches, the most recent of which is the popular growth modeling approach. As an extension of the latter, we have demonstrated that a temporal-dynamic approach opens up a new dimension in the study of time-based change, namely the study of variability in change. Change intensity and pattern ruggedness have shown to be non-redundant descriptions of trajectory variability and are applicable to the individual level of analysis. The form parameters have proven to be of substantive theoretical interest and can be explained from conventional predictors. This contrasts the dominant growth modeling approach where any type of variability in temporal development other than the initial level and the rate of change is disregarded.

The analysis of trajectory groups revealed meaningful temporal heterogeneity in a seemingly 'stable' population. That is, honeymoon-effects do occur but their effects were not observed on the sample level as they were offset by opposite pattern shapes resembling 'learning-to-love' effects where individuals affectively 'warm up' to the new partner (i.e., the organization) in the relationship. Thus, temporal patterns in OC are not as 'universal' as is often assumed.

All of this challenges current practices of taking the population mean as the only locus of variance in longitudinal analyses. We have demonstrated that 'stepping down' from population levels of analysis and diving into the - more complex - group- and individual level realms is highly rewarding. Plus, its potential added value to prediction of a host of outcome variables, such as fluctuations in performance, is enormous. For example, prediction of performance trajectories such as task performance levels over time, learning curves, signs of citizenship behavior, counterproductive work behavior, changes in customer satisfaction can benefit from a temporal-dynamic approach. In this approach (aspects of) individual trajectories of OC are linked to (aspects of) individual trajectories of performance.

Implications for practice OC seems to be susceptible to change (and possibly to managerial influence) as individuals with medium OC entry levels can end up in high stable trajectories (i.e., a 'learning-to-love' effect). Even individuals who start with low OC can end up with medium and - on a case by case basis - even high levels of commitment after a couple of months on the job. Others who start with high anticipatory commitment can also show decline later on (i.e., a honeymoon-hangover effect). Our data have shown that this 
decline is related to unmet expectations and frustrations of newcomers due to unmet commitments and obligations by the employer in the form of psychological contract breach and violation.

The observation that commitment development among organizational newcomers is multi-faceted (e.g., 5 different temporal modes of development) rather than universal, implies that not all newcomers would benefit equally from standard newcomer orientation programs. For some, who already have high anticipatory commitment, such programs are of little use, while for others (who still need to 'warm-up' affectively to the organization) orientation programs might be more useful.

It should be noted that - if one wishes to 'manage' OC development - we suggest two important footholds. First, work experiences, dispositions, and history are all important factors to consider - in their consecutive order of importance. Second, 'management' should be done early on in the process (say, the first 10 weeks on the job) as this is the time frame where patterns diverge the most and subsequent development is possibly decided. If one tries to manage OC only after the first 10 weeks, one has to deal with path-dependency, meaning that if newcomers are already disappointed in the first 10 weeks, trying to increase OC again is probably fruitless.

More specifically, creating satisfying work, meeting expectations, choosing newcomers who 'fit' in the organization, and providing emotional support and care to newcomers has proven value not only to instill high commitment levels, but also to ensure growing commitment in the first 10 weeks, and - last but not least - temporally stable employee commitment patterns (i.e., low change intensity and low volatility). If stability in performance is crucial on the job, this research may serve as a foothold for practitioners on what can be done to ensure it from an attitudinal perspective. Moreover, gender, personality, work values, and motivaton are factors to take into account in management practices as these factors are predictive of temporal OC development in terms of level (e.g, positive affectivity relates to high OC levels), trend (dutifulness is related to declining OC), and stability (e.g., women generally have more volatile trajectories and more intense OC changes then men). From an ethical perspective, we do not recommend adopting recruitment and selection practices based on personality or gender, but we advocate that supervisors and managers be aware that individuals do not react to work experiences and job situations in the same way. As such, a personally tailored, small-scale management approach is warranted. Organizational agents responsible for selection and recruitment practices could rather take away another practical foothold from our research as we have demonstrated that high OC 
toward the previous employer is predictive of high and stable OC patterns in the new organization.

All of this suggests that the temporal development of organizational commitment can be scientifically predicted and practically managed as long as persons as such, instead of their aggregations, are taken seriously. 


\section{Concluding the dissertation}

In this dissertation we promote a temporal approach to studying dynamic aspects of organizational behavior. A temporal approach implies a detailed study of patterns of historical development within a particular individual. It contrasts the more common differential approach where one studies the covariance between two or more static variables based on differences between individuals. We describe how placing phenomena in time can add value to existing knowledge by applying a consistent temporal perspective to a particularly well-studied phenomenon in the field of Organizational Behavior: the organizational commitment (OC) attitude. We explore how OC can be conceived of (and measured) temporally, how its development can best be captured, and how the resulting developmental patterns can be analyzed.

As the way we think impacts the way we conceptualize, measure, and analyze phenomena, we start in the introductory Chapter 1 with systematically assessing the underlying philosophical tenets of two particular modes of thought, namely differential and temporal thinking. Differential thinking constitutes the currently dominant perspective in the field of Organizational Behavior (OB), which dictates that phenomena and their interrelationships can be understood by assessing differences between individuals. Temporal thinking, in contrast, assumes that knowledge is gained by studying historical development within individuals over a certain time span. We demonstrate that the two modes of thought derive from doctines that differ fundamentally in their ontology (particularly in the definition of the role of time, the definition of content, and the conceptualization of cause-effect relationships) as well as in their epistemology (particularly regarding observation, capturing causation effects, the level of analysis typically applied, and the treatment of time). We continue to explore how the temporal doctrine can benefit the study of OC. Answers to the questions raised in this introductory overview chapter are given in chapter 2, 3, 4, and 5.

In Chapter 2 we argue that the currently dominant three-component model of OC fails to qualify as a general model of $\mathrm{OC}$ and should rather be seen as a specific model for predicting turnover behavior. Instead, OC should be conceived of as a strictly attitudinal phenomenon consisting of affect, cognition, and action readiness - three classic facets in standard attitudinal theory. Throughout the dissertation it becomes clear that the attitudinal perspective is compatible with the temporal approach as the three attitudinal facets can be seen as three separate underlying processes that reflect a commitment. 
In Chapter 3 we argue that the temporal perspective dictates that OC, like any other phenomenon, has finite existence and follows a life cycle of ascendance, subsistence, descendance and eventual disappearance. The degree of (aggregate mean) trajectory instability seems to be contingent upon the phase in the OC life cycle: unstable patterns are common during ascendance and descendance while stable patterns are common during subsistence. Also, our results confirm that OC indeed seems to grow at a very early point of ascendance, but often declines after the newcomer has entered the organization. OC is remarkably stable and resilient during periods of organizational upheaval in the subsistence phase, and it naturally declines during the descendance phase. Growing commitment trends are rare, which challenges the dominant managerial rhetoric of 'raising employee commitment'. Upholding commitment at high levels seems in itself quite a managerial achievement.

We argue in Chapter 4 that capturing patterns of historical development in OC implies a fine-grained type of longitudinal measurement where measures follow densely after each other in high frequencies (i.e., typically more than 20 time moments). The type of longitudinal measurement is called high-density repeated measurement (HDRM). As existing instruments are insufficiently adapted to HDRM environments, we have developed a measurement system (LOCUST), which tracks historical development in OC in HDRM research contexts. The instrument reconciles conflicting interests of researchers and respondents and consistently focuses on creating reliable and valid patterns of development. One of its defining features is graphic trajectory registering, which is the graphic display of historical development to respondents to allow for real-time, incremental trajectory scoring and repeated trajectory confirmation (including the possibility to make retrospective adjustments). Results of various simulations (with up to 56 time moments) are promising in terms of attrition rates, reliability, and validity of measured patterns.

All of this culminates in Chapter 5, where we apply our approach to studying OC development among 72 young academics during the first six months of work, while taking 25 weekly measurements. We investigate temporal 'aspects of form' in group- and individuallevel patterns of commitment. We observe meaningful heterogeneity in temporal development which challenges the dominant assumption of uniform growth. In a seemingly stable population (a stable aggregate mean) we observed a 'honeymoon-hangover' pattern (i.e., high anticipatory OC followed by decline), but this pattern was compensated by an opposite 'learning-to-love' pattern (medium entry levels but then climbing to high and stable OC levels). We observed five distinct latent trajectory groups in total. On the individual-level 
of analysis we identified seven pattern characteristics, namely within-subject mean, initial level, slope, standard deviation, change intensity, change frequency, and pattern ruggedness. The seven characteristics represent three underlying factors of temporal form: level, trend, and variability. They also showed interesting interrelationships: low and decreasing OC trajectories tend to be 'rugged' while high and growing trajectories tend to be 'smooth', which casts a different perspective on the nature low and declining commitment. Each of these underlying form aspects could be related with experiential, dispositional, and historical predictors, in their order of relative importance.

In sum, we demonstrate that $\mathrm{OC}$ is best viewed as a strictly attitudinal phenomenon and its underlying processes should be measured separately as they unfold over time. Moreover, we argue that the temporal perspective dictates that $\mathrm{OC}$ emerges at some point, exists for a while, and then declines to eventually disappear, which - as our data indicate influences what OC patterns are typically observed in the respective phases. In our approach, capturing historical development in OC is characterized by using a fine-grained longitudinal design, called high-density repeated measurement (HDRM), for which we advise the use of a new methodology that adopts a holistic focus where complete patterns of historical development are assessed, rather than the discrete, separate scores which make up the pattern. We have demonstrated the benefits of measuring temporal development with HDRM designs and assessing them at the individual- and group-level of analysis.

\section{Implications}

Although the adoption of a temporal perspective requires some extra effort, it is practically feasible and scientifically rewarding as it aids to gain a better understanding of how organizational attitudes emerge, how they develop in response to the daily and weekly hustles-and-bustles in organizational life, and how they eventually decay. By adopting highdensity repeated measurement designs we come close to the attitudinal dynamics typically experienced in 'real life'. We have also demonstrated that the assumption of universal growth is not warranted and that temporal development is, in fact, heterogeneous. This challenges the dominant mode of analysis where only the grand mean development is studied and only deviations from population averages are taken as units of analysis. Moreover, conflating heterogeneous temporal patterns into a single 'mean development' potentially obstructs opportunities for prediction due to path dependency effects. If we observe that one can start off with low levels and gradually grows (a 'learning-to-love' pattern), but others start with high levels and gradually get disappointed and decline (a 'honeymoon-hangover effect'), the 
effect of a managerial intervention is likely to lead to different results. Put simply, an already disappointed person is hard to convince while a person who is gradually 'warming up' for the organization is more receptive. These kinds of path-dependent effects are lost if all subjects are conflated under a 'mean'. In group-based modeling of development one can take into account such forms of 'historical connectivity'. We therefore encourage other researchers to step down from the common population level of analysis when analyzing growth.

We have demonstrated that temporal variability is more than transient fluctuation or measurement error; it is of substantive interest and can be predicted with conventional predictors (e.g., women tend to have more 'rugged' patterns than men). Our approach of focusing on patterns of historical development in measurement, including innovative features of making use of graphical display in response formats, is promising and applicable to a wide range of areas from scientific research to business consultancy, and from marriage counseling to criminology, and even physiotherapy. On a conceptual level, there is still a pressing need for a thorough analysis of what constitutes reliability and validity in a temporal research context. When is a pattern reliable? When is a trajectory valid? How can it be assessed? Conventional standards of assessment, based on Classical Test Theory or Item Response Theory, may no longer be sufficient as these theories are based on the differential doctrine. Instead, we need a temporal theory of measurement. In the Appendix we have given some preliminary suggestions by advocating the prominence of patterns, rather than the points that make up the pattern.

In our view, the temporal perspective has also proven its potential practical value. For example, we found that subsequent temporal development of newcomer commitment is possibly decided in the first 10 weeks on the job. If one should try to manage commitment, it should happen in this span of time. Another time where management is needed is immediately (up to around two months) after the announcement of organizational upheaval. Drastic declines in OC can be prevented if appropriate managerial action is taken and it is done at the right time. 


\section{$7 \quad$ Samenvatting}

In dit proefschrift staan wij een temporele benadering voor bij het bestuderen van organisatiegedrag. Een temporele benadering behelst het zoeken naar patronen van ontwikkeling van een fenomeen binnen individuen over de tijd. Dit contrasteert de meer gangbare differentiële benadering waarbij men de covariantie tussen twee of meer variabelen bestudeert, gebaseerd op verschillen tussen individuen. We passen de temporele zienswijze consequent toe op het fenomeen van verbondenheid met de werkgever (d.i. 'organisatiecommitment') - een zeer breed onderzochte werkhouding (attitude) in de organisatiewetenschappen. Op deze manier tonen wij aan hoe het plaatsen van fenomenen in de tijd een vermeerdering van kennis en inzicht oplevert. We onderzoeken hoe op fundamenteel niveau organisatiecommitment (OC) begrepen en gemeten kan worden vanuit een temporele zienswijze. Ook exploreren we hoe de gemeten patronen van ontwikkeling geanalyseerd kunnen worden.

Aangezien onze denkwijze directe consequenties heeft voor de manier van conceptualiseren, meten en analyseren, beginnen we in hoofdstuk 1 met een systematische uiteenzetting van de filosofische basisassumpties van twee denkkaders, differentieel en temporeel denken. Differentieel denken is het meest gangbare denkkader in het onderzoeksveld van organisatiewetenschappen en organisatiegedrag. In dit denkkader gaat men ervan uit dat fenomenen en hun samenhang kunnen worden bestudeerd door verschillen tussen individuen te analyseren. Temporeel denken, echter, gaat ervan uit dat men alleen tot begrip kan komen door de ontwikkeling van fenomenen binnen individuen te beschrijven. We laten zien dat de twee denkkaders op fundamenteel verschillende gedachtewerelden gestoeld zijn wat betreft hun ontologie (betreffende de rol van het temporele, hoe de inhoud van fenomenen wordt gedefinieerd en hoe oorzaak-gevolgrelaties worden geconceptualiseerd) en wat betreft hun epistemologie (betreffende hoe geobserveerd wordt, hoe causaliteit bepaald wordt, welk niveau van analyse gebruikt wordt en tenslotte hoe men omgaat met veranderingen over tijd). Vervolgens passen wij deze inzichten toe op het fenomeen van organisatiecommitment. Daarbij onderzoeken wij hoe elk van de hierboven genoemde aspecten van temporele ontologie en epistemologie onze kennis en ons inzicht aangaande commitment zou kunnen vergroten.

In hoofdstuk 2 stellen wij dat het gangbare 'drie componentenmodel' van organisatiecommitment (OC) niet kan dienen als algemeen model van OC maar veeleer gezien moet 
worden als een specifiek model dat dient om personeelsverloop te voorspellen. OC moet in plaats daarvan gezien worden als een attitudinaal fenomeen, bestaande uit een affect, een cognitie, en een actiebereidheid, goed bekend als drie klassieke facetten in gangbare attitudetheorie. Verderop in de dissertatie zal duidelijk worden dat dit attitudeperspectief zich uitstekend laat verenigen met de temporele zienswijze, aangezien de drie klassieke facetten gezien kunnen worden als drie onderliggende - doch separate - processen die tezamen een 'commitment' jegens de organisatie vormen.

In hoofdstuk 3 leggen wij uit dat het temporele perspectief onherroepelijk het begrip van eindigheid met zich meebrengt. Dit houdt in dat OC, net als overigens alle andere fenomenen, een beperkte levensduur heeft en een 'levenscyclus' doorloopt van opgang, doorgang, neergang en verdwijning. Onze bevindingen ondersteunen deze zienswijze in de zin dat - kijkend naar het steekproefgemiddelde - instabiele patronen de bovenhand hebben in de opgang- en neergangfasen, terwijl stabiele patronen de bovenhand hebben tijdens de doorgangfase. Onze resultaten laten ook zien dat OC op een vroeg moment tijdens de opgangfase begint te stijgen en dat het veelal daalt vlak na binnenkomst in de organisatie. OC is opmerkelijk stabiel en veerkrachtig in turbulente tijden in de doorgangfase en het vertoont een natuurlijke daling tijdens de neergangfase. Stijgende trends komen zelden voor, wat noopt om vraagtekens te zetten bij de gangbare retoriek in managementkringen die het bevorderen van betrokkenheid vooropstelt. Het behouden van het huidige niveau van commitment lijkt realistischer en is op zich al een behoorlijke managementprestatie.

In hoofdstuk 4 stellen wij dat het in kaart brengen van de ontwikkeling van OC een fijnmazige manier van longitudinaal observeren vereist, waarbij metingen elkaar snel opvolgen in hoge frequenties (met doorgaans meer dan 20 meetmomenten). Dit type design noemen wij HDRM. Deze afkorting staat voor "High-density repeated measurement". Aangezien het gangbare instrumentarium niet is toegesneden op het doen van fijnmazige herhaalde metingen (HDRM), hebben we een meetinstrument ontworpen, LOCUST, dat juist voor dit doel is toegerust. Het instrument integreert tegengestelde belangen van onderzoekers en respondenten en richt zich op consistente wijze op het creëren van betrouwbare and valide temporele patronen. Eén van karakteristieke eigenschappen van dit instrument is grafische trajectregistratie: het grafisch weergeven van de individuele historische ontwikkeling van respondenten in de enquête, zodat zij terplekke (en incrementeel) hun eigen patroon kunnen vormgeven en (waar nodig) kunnen aanpassen.

Dit alles culmineert in hoofdstuk 5, waar we onze benadering toepassen op de ontwikkeling van OC onder 72 jonge academici gedurende de eerste zes maanden op het 
werk, bij wie we in totaal 25 wekelijkse metingen hebben verricht. We onderzoeken temporele 'vormaspecten' op groeps- en individueel niveau. Onze bevindingen duiden op betekenisvolle heterogeniteit in temporele ontwikkeling wat in schril contrast staat met de gangbare assumptie van uniforme groei. In een op het eerste oog stabiele groep nieuwkomers (wegens een stabiel steekproefgemiddelde) hebben we tegengestelde patronen waargenomen die elkaar op geaggregeerd niveau uitdoven. Zo hebben we onder andere een zogenaamd 'honeymoon-hangover effect' aangetoond (d.i. een groep die zich kenmerkt door een hoge OC aan het begin, gevold door een daling) en een tegenhanger van dit patroon, namelijk een 'learning-to-love effect' (OC begint laag of in het midden en stijgt dan gestaag tot hoge en stabiele niveaus). In totaal konden we vijf latente trajectgroepen van elkaar onderscheiden. Op individueel niveau hebben wij zeven patroonkenmerken kunnen identificeren, namelijk het trajectgemiddelde, het beginniveau, de standaarddeviatie, de intensiteit, de frequentie en de grilligheid van veranderingen in het patroon. In de zeven patroonkenmerken kunnen drie onderliggende dimensies worden onderscheiden, namelijk niveau, trend, en variabiliteit. Deze vertonen onderling interessante relaties. Zo blijken lage en dalende OC patronen over het algemeen grilliger dan hoge en stijgende patronen, hetgeen een ander licht werpt op de aard van lage en dalende commitment. Elk van de patroonkenmerken kan worden gerelateerd aan predictoren die te maken hebben met ervaringen op het werk, disposities en persoonlijke geschiedenis, in volgorde van belangrijkheid.

Al met al hebben we kunnen aantonen dat OC het best gezien kan worden als een attitude waarvan de onderlinge processen separaat gemeten kunnen worden, zoals zij zich ontvouwen over de tijd. Onze bevindingen wijzen uit dat deze 'tijdigheid' van het OCfenomeen relevant is, gezien de verschillen in dynamiek die men doorgaans in elk van de fasen van de levenscyclus aantreft. Onze benadering impliceert het in kaart brengen van ontwikkelingen binnen personen middels fijnmazig herhaald meten volgens het HDRMdesign. Wij adviseren bij dit design een nieuwe temporele meetmethodiek te gebruiken, gebaseerd op een holistische benadering, waarbij de aandacht primair uitgaat naar het patroon en minder naar de afzonderlijke punten in het patroon. We hebben laten zien dat deze benadering voor theorievorming en praktijk verstrekkende gevolgen heeft. 


\section{Bibliography of the dissertation}

Abbott, A. (1988). Transcending general linear reality. Sociological Theory, 6, 189-196.

Abbott, A. (1990). A primer on sequence methods. Organization Science, 1(4), 375-392.

Abbott, A. (2001). Time matters: On theory and method. Chicago: Chicago University Press.

Adkins, C. L. (1995). Previous work experience and organizational socialization: A longitudinal examination. Academy of Management Journal, 38(3), 839-862.

Adler, A., \& Adler, P. (1988). Intense loyalty in organizations: A case study of college athletes. Administrative Science Quarterly, 33(3), 401-417.

Ajzen, I. (1991). The theory of planned behavior. Organizational Behavior and Human Decision Processes, 50, 179-211.

Ajzen, I. (2001). Nature and operation of attitudes. Annual Review of Psychology, 52(1), $27-$ 58.

Ajzen, I., \& Fishbein, M. (1980). Understanding attitudes and predicting social behavior. Upper Saddle River, NJ: Prentice Hall.

Allen, N. J., \& Meyer, J. P. (1990). The measurement and antecedents of affective, continuance, and normative commitment to the organization. Journal of Occupational Psychology, 63, 252-276.

Allen, N. J., \& Meyer, J. P. (1996). Affective, continuance, and normative commitment to the organization. Journal of Vocational Behavior, 49, 252-276.

Allen, T. D., Freeman, D. M., Russell, J. E. A., Reizenstein, R. C., \& Rentz, J. O. (2001). Survivor reactions to organizational downsizing: Does time ease the pain. Journal of Occupational and Organizational Psychology, 74, 145-164.

Alliger, G. M., \& Williams, K. J. (1993). Using signal-contingent experience sampling methodology to study work in the field: A discussion and illustration examining task perceptions. Personnel Psychology, 46, 525-549.

Allport, G. W. (1960). Personality and social encounter. Boston: Beacon.

Ambrose, M. L., \& Cropanzano, R. (2003). A longitudinal analysis of organizational fairness: An examination of reactions to tenure and promotion decisions. Journal of Applied Psychology, 88(2), 266-275.

Ancona, D. G., Goodman, P. S., Lawrence, B. S., \& Tushman, M. L. (2001). Time: A new research lens. Academy of Management Review, 26(4), 545-663.

Angle, H. L., \& Lawson, M. B. (1993). Changes in affective and continuance commitment in times of relocation. Journal of Business Research, 26(1), 3-15.

Angle, H. L., \& Perry, J. L. (1981). An empirical assessment of organizational commitment and organizational effectiveness. Administrative Science Quarterly, 27, 1-14.

Armenakis, A. A., \& Bedeian, A. G. (1982). On the measurement and control of beta change: Reply to Terborg, Maxwell, and Howard. Academy of Management Review, 7(2), 296-299.

Armstrong-Stassen, M. (2002). Designated redundant but escaping lay-off: A special group of lay-off survivors. Journal of Occupational and Organizational Psychology, 75, 113.

Armstrong-Stassen, M. (2006). Determinants of how managers cope with organizational downsizing. Applied Psychology: An International Review, 55(1), 1-26.

Ashforth, B. E. (2001). Role transitions in organizational life: An identity-based perspective. Mahwah, NJ: Lawrence Erlbaum. 
Ashforth, B. E., \& Mael, F. (1989). Social identity theory and the organization. Academy of Management Journal, 39, 149-178.

Avant, L. L. (1977). Psychophysics and scaling. In M. H. Appley (Ed.), Adaptation level theory (pp. 19-25). New York: Academic Press.

Avital, M. (2000). Dealing with time in social inquiry: A tension between method and lived experience. Organization Science, 11(6), 665-673.

Bai, J., \& Perron, P. (2003). Computation and analysis of multiple structural change models. Journal of Applied Econometrics, 18, 1-22.

Baker, E. H., \& Feldman, D. C. (1990). Strategies of organizational socialization and their impact on newcomer adjustment. Journal of Managerial Issues, 2(2), 198-212.

Bass, B. M. (1962). Further evidence on the dynamic character of criteria. Personnel Psychology, 15, 93-97.

Bauer, T. N., Bodner, T., Erdogan, B., Truxillo, D. M., \& Tucker, J. S. (2007). Newcomer adjustment during organizational socialization: A meta-analytic review of antecedents, outcomes, and methods. Journal of Applied Psychology, 92(3), 707-721.

Bauer, T. N., \& Green, S. G. (1994). Effect of newcomer involvement in work-related activities: A longitudinal study of socialization. Journal of Applied Psychology, 79(2), 211-223.

Bauer, T. N., Maertz Jr., C. P., Dolen, M. R., \& Campion, M. A. (1998). Longitudinal assessment of applicant reactions to employment testing and test outcome feedback. Journal of Applied Psychology, 83(6), 892-903.

Bargh, R., Chaiken, S., Govender, R., \& Pratto, F. (1993). The generality of the automatic attitude activation effect. Journal of Personality and Social Psychology, 62(6), 893912.

Becker, H. S. (1960). Notes on the concept of commitment. American Journal of Sociology, $66,32-42$.

Bentein, K., Vandenberg, R. J., Vandenberghe, C., \& Stinglhamber, F. (2005). The role of change in the relationship between commitment and turnover: A latent growth modeling approach. Journal of Applied Psychology, 90(3), 468-482.

Beal, D. J., \& Weiss, H. M. (2003). Methods of ecological momentary assessment in organizational research. Organizational Research Methods, 6(4), 440-464.

Beck, K., \& Wilson, C. (2000). Development of affective organizational commitment: A cross-sequential examination of change with tenure. Journal of Vocational Behavior, 56, 114-136.

Bedeian, A. G., \& Armenakis, A. A. (1989). Promise and prospects: The case of the alpha, beta, gamma change typology. Group \& Organization Studies, 14(2), 155-160.

Bedeian, A. G., Armenakis, A. A., \& Gibson, R. W. (1980). The measurement and control of beta change. Academy of Management Review, 5(4), 561-566.

Bentein, K., Vandenberg, R. J., Vandenberghe, C., \& Stinglhamber, F. (2005). The role of change in the relationship between commitment and turnover: A latent growth modeling approach. Journal of Applied Psychology, 90(3), 468-482.

Berenbroek, A. (2007). The pursuit of multiple parallel goals over time: Longitudinal investigation of language proficiency development. Unpublished master's thesis. Maastricht: Maastricht University.

Bergkvist, L., \& Rossiter, J. R. (2007). The predictive validity of multiple-item versus singleitem measures of the same construct. Journal of Marketing Research, 94(May), 175184.

Bergman, M. E. (2006). The relationship between affective and normative commitment: Review and research agenda. Journal of Organizational Behavior, 27, 645-663. 
Blau, G. L., \& Ryan, J. (1994). On measuring work ethic: A neglected work commitment facet. Journal of Vocational Behavior, 51, 435-446.

Bluedorn, A. C. (1982). A unified model of turnover from organizations. Human Relations, $35(2), 135-153$.

Bluedorn, A. C. (2002). The human organization of time: Temporal realities and experience. Stanford, CA: Stanford University Press.

Bolger, N., Davis, A., \& Rafaeli, E. (2003). Diary methods: Capturing life as it is lived. Annual Review of Psychology, 54, 579-616.

Bollen, K., \& Lennox, R. (1991). Conventional wisdom on measurement: A structural equation perspective. Pschological Bullitin, 110(2), 305-314.

Bordens, K. S., \& Abbott, B. B (2002). Research design and methods: A process approach. ( $5^{\text {th }}$ ed.). Boston: McGraw-Hill

Borsboom, D., Mellenbergh, G. J., \& van Heerden, J. (2003). The theoretical status of latent variables. Psychological Review, 110(2), 203-219.

Boswell, W. R., Tichy, J., \& Boudreau, J. W. (2005). The relationship between employee job change and job satisfaction: The honeymoon-hangover effect. Journal of Applied Psychology, 90(5), 882-892.

Boswell, W. R., Shipp, A. J., Payne, S. C., \& Culbertson, S. S. (2009). Changes in newcomer job satisfaction over time: Examining the pattern of honeymoons and hangovers. Journal of Applied Psychology, 94(4), 844-858.

Bozeman, D. P., \& Perrewe, P. L. (2001). The effect of item content overlap on organizational commitment questionnaire-turnover cognitions relationships. Journal of Applied Psychology, 86, 161-173.

Brickman, P. (1987). Commitment. In C. B. Wortman \& R. Sorrentino (Eds.), Commitment, conflict, and caring. Englewood Cliffs, NJ: Prentice Hall.

Brickman, P., Janoff-Bullman, R., \& Rabinowitz, V. C. (1987). Meaning and value. In C. B. Wortman \& R. Sorrentino (Eds.), Commitment, conflict, and caring. Englewood Cliffs, NJ: Prentice Hall.

Brickman, P. (1987). Commitment. In C. B. Wortman \& R. Sorrentino (Eds.), Commitment, conflict, and caring. Englewood Cliffs, NJ: Prentice Hall.

Brown, R. B. (1996). Organizational commitment: Clarifying the concept and simplifying the existing construct typology. Journal of Vocational Behavior, 49, 230-251.

Buchanan, B. (1974). Building organizational commitment: The socialization of managers in work organizations. Administrative Science Quarterly, 19(4), 533.

Bunjens, A. M. (2009). Applying design methodology is a strong example of learning by doing. In F. R. H. Zijlstra, A. Van Iterson \& L. A. Ten Horn (Eds.), Time changes work: Liber amicorum for Robert A. Roe. Maastricht: Datawyse/Universitaire Pers Maastricht.

Burnham, K. P., \& Anderson, D. R. (2004). Multimodel inference: Understanding AIC and BIC in model selection. Sociological Methods \& Research, 33(2), 261-304.

Burt, R. S. (2000). Decay functions. Social Networks, 22, 1-28.

Burt, R. S. (2001). Attachment, decay, and social network. Journal of Organizational Behavior, 22, 619-643.

Burt, R. S. (2002). Bridge decay. Social Networks, 24, 333-363.

Cameron, K. S., Dutton, J. E., \& Quinn, R. E. (Eds.). (2003). Positive organizational scholarship: Foundations of a new discipline. San Francicso, CA: Berrett-Koehler Publishers.

Camilli, G., \& Hopkins, K. D. (1978). Applicability of Chi-square to 2 x 2 contingency tables with small expected cell frequencies. Psychological Bulletin, 85(1), 163-167. 
Cattell, R. B., \& Ross, K. (1952). Comparisons of the ergic and self-sentiment structures found in dynamic traits by R- and P-techniques. Journal of Personality, 21, 205-271.

Chan, D. (1998). The conceptualization and analysis of change over time: An integrative approach incorporating longitudinal means and covariance structures analysis (LMACS) and multiple indicator latent growth modeling (MLGM). Organizational Research Methods, 1, 421-483.

Chan, D., \& Schmitt, N. (2000). Interindividual differences in intraindividual changes in proactivity during organizational entry: A latent growth modeling approach to understanding newcomer adaptation. Journal of Applied Psychology, 85(2), 190-210.

Chang, J. Y., \& Choi, J. N. (2007). The dynamic relation between organizational and professional commitment of highly educated research and development (R\&D) professionals. The Journal of Social Psychology, 147(3), 299-315.

Case, J. (2000). Employee theft: The profit killer. Del Mar, CA: John Case \& Associates.

Child, J. (1972). Organizational structure, environment, and performance: The role of strategic choice. Sociology, 6, 2-21.

Churchill, G. A. (1979). A paradigm for developing better measures of marketing constructs. Journal of Marketing Research, 16, 64-73.

Coffin, B. (2003). Breaking the silence on white collar crime. Risk Management, 50, 8.

Cohen, A. (1991). Career stage as a moderator of the relationships between organizational commitment and its outcomes: A meta-analysis. Journal of Occupational Psychology, 64, 253-268.

Cohen, A. (2003). Multiple commitments in the workplace: An integrative approach. Mahway, NJ: Lawrence Erlbaum.

Cohen, A. (2007). Commitment before and after: An evaluation and reconceptualization of organizational commitment. Human Resource Management Review, 17, 336-354.

Cohen, A., \& Freund, A. (2005). A longitudinal analysis of the relationship between multiple commitments and withdrawal cognitions. Scandinavian Journal of Management, 21, 329-351.

Collins, L. M. (1991). Measurement in longitudinal research. In J. L. Horn (Ed.), Best methods for the analysis of change: recent advances, unanswered questions, future directions. Washington, DC: American Psychological Association.

Collins, L. M. (2001). Reliability for static and dynamic categorical latent variables: Developing measurement instruments based on a model of the growth process. In L. M. Collins \& A. G. Sayer (Eds.), New methods for the analysis for the analysis of change (pp. 273-288). Washington, DC: American Psychological Association.

Collins, L. M. (2006). Analysis of longitudinal data: The integration of theoretical model, temporal design, and statistical model. Annual Review of Psychology, 57, 505-528.

Collins, L. M., \& Cliff, N. (1990). Using the longitudinal Guttman simplex as a basis for measuring growth. Quantitative Methods in Psychology, 108(1), 128-134.

Conway, N., \& Briner, R. B. (2002). A daily diary study of affective responses to psychological contract breach and exceeded promises. Journal of Organizational Behavior, 23(3), 287-302.

Conway, N., \& Briner, R. B. (2005). Understanding psychological contracts at work: A critical evaluation of theory and research. Oxford: Oxford University Press.

Cook, T. D., \& Campbell, D. T. (1979). Quasi-experimentation: Design \& analysis issues for field settings. Chicago: Rand McNally.

Cooper-Hakim, A., \& Viswesvaran, C. (2005). The construct of work commitment: Testing an integrative framework. Psychological Bullitin, 131(2), 241-259. 
Cooper-Thomas, H. D., Van Vianen, A., \& Anderson, N. (2004). Changes in personorganization fit: The impact of socialization tactics on perceived and actual P-O fit. European Journal of Work and Organizational Psychology, 13(1), 52-78.

Coyle-Shapiro, J. A. M. (1999). Employee participation and assessment of an organizational change intervention: A three-wave study of total quality management. Journal of Applied Behavioral Science, 35(4), 439-456.

Cronbach, L. J. (1961). Essentials of psychological testing (2nd ed.). New York: Harper \& Row.

Cronbach, L. J., Gleser, G. C., Nanda, H., \& Rajaratnam, N. (1972). The dependability of behavioral measurements: Theory of generalizability of for scores and profiles New York: Wiley.

Cronbach, L. J., \& Meehl, P. E. (1955). Construct validity in psychological tests. Psychological Bullitin, 52, 93-96.

Csikszentmihalyi, M., \& Reed, L. (1987). Validity and reliability of the Experience-Sampling method. The journal of nervous and mental disease, 175(9), 537-544.

Cude, R. L., \& Jablin, F. M. (1992). Retiring from work: The paradoxical impact of organizational commitment. Journal of Managerial Issues, 4, 31-45.

Currivan, D. B. (1999). The causal order of job satisfaction and organizational commitment in models of employee turnover. Human Resource Management Review, 9(4), 495524.

Davis, M. W. (1971). That's interesting. Philosophy of the Social Sciences, 1, 309-344.

Dayton, C. M. (2008). An introduction to latent class analysis. In S. Menard (Ed.), Handbook of longitudinal research: Design, measurement, and analysis (pp. 357-372). Amsterdam: Elsevier.

DeShon, R. P., Ployhart, R. E., \& Sacco, J. M. (1998). The estimation of reliability in longitudinal models. International Journal of Behavioral Development, 22(3), 493515.

Diener, E., \& Diener, C. (1996). Most people are happy. Psychological Science, 7, 181-185.

DiMaggio, P. J. (1995). Comments on "What theory is not". Administrative Science Quarterly, 40, 391-397.

Dirks, K. T., \& Ferrin, D. L. (2002). Trust in leadership: Meta-analytic findings and implications for research and practice. Journal of Applied Psychology, 87(4), 611628.

Dormann, C. (2007). Sustainable WO-psychology research - An illusion? Why short-term effects matter more. Paper presented at the The XIIIth European Congress of Work and Organizational Psychology, Stockholm, May 9-12.

Duncan, T. E., Duncan, S. C., \& Strycker, L. A. (2006). An introduction to latent variable growth curve modeling: Concepts, issues, and applications (Second ed.). Mahwah, NJ: Lawrence Erlbaum.

Dunham, R. B., Grube, J. A., \& Castaneda, M. B. (1994). Organizational commitment: The utility of an integrative definition. Journal of Applied Psychology, 79(3), 370-380.

Dutton, J. E., Dukerich, J. M., \& Harquail, C. V. (1994). Organizational images and member identification. Administrative Science Quarterly, 39, 239-263.

Eagly, A. H., \& Chaiken, S. (1993). The psychology of attitudes. Orlando, FL: Harcourt.

Earl, J. K., \& Bright, J. E. H. (2007). The relationship between career decision status and important work outcomes. Journal of Vocational Behavior, 71, 233-246.

Ebaugh, H. R. F. (1988). Becoming an ex: The process of role exit. Chicago: University of Chicago Press.

Edelman, G. M. (1987). Neural darwinism: The theory of neuronal group selection. New York: Basic. 
Edwards, J. R. (2001). Multidimensional constructs in organizational behavior research: An integrative analytical framework. Organizational Research Methods, 4(2), 144-192.

Edwards, J. R., \& Bagozzi, R. P. (2000). On the nature and the direction of relationships between constructs and measures. Psychological Methods, 5(2), 155-174.

Eekels, J. (2000). On the fundamentals of engineering design science: The geography of engineering design science. Part 1. Journal of Engineering Design, 11(4), 377-397.

Farkas, A. J., \& Tetrick, L. E. (1989). A three-wave longitudinal analysis of the causal ordering of satisfaction and commitment on turnover decisions. Journal of Applied Psychology, 74(6), 855-868.

Farrell, D. (1983). Exit, voice, loyalty, and neglect as responses to job dissatisfaction: A multidimensional scaling study. Academy of Management Journal, 26(4), 596-607.

Faulconer, J. E., \& Williams, R. N. (1985). Temporality in human action. American Psychologist, 40(11), 1179-1188.

Fazio, R. H., \& Towles-Schwen, T. (1999). The MODE model of attitude-behavior processes. In S. Chaiken \& Y. Trope (Eds.), Dual-process theories in social psychology. New York: The Guilford Press.

Finchman, M., \& Levinthal, D. A. (1991). Honeymoons and the liability of adolescence: A new perspective on duration dependence and organizational relationships. Academy of Management Review, 16, 442-468.

Fishbein, M., \& Ajzen, I. (1974). Attitudes toward objects as predictors of single and multiple behavioral criteria. Psychological Review, 81, 59-74.

Fishbein, M., \& Ajzen, I. (1975). Belief, attitude, intention, and behavior: An introduction to theory and research. Reading, MA: Addison-Wesley.

Ford, J. D., Ford, L. W., \& McNamara, R. (2002). Resistance and background conversations of change. Journal of Organization Change Management, 15: 105-121.

Fuller, J. A., Fisher, G. G., Jeffrey, M. S., Spitsmüller, C., Russell, S. S., \& Smith, P. C. (2003). A lengthy look at the daily grind: Time series analysis of events, mood, stress, and satisfaction. Journal of Applied Psychology, 88(6), 1019-1033.

George, J. M., \& Jones, G. R. (2000). The role of time in theory and theory building. Journal of Management, 26(4), 657-684.

Ghiselli, E. E., \& Haire, M. (1960). The validation of selection tests in the light of dynamic character character of criteria. Personnel Psychology, 13, 225-231.

Giacalone, R. A., \& Thompson, K. R. (2006). From the guest co-editors: Special issue on ethics and social responsibility. Academy of Management Learning and Education, 5(3), 261-265.

Gluckman, M. (1963) Gossip and scandal. Current Anthropology, 4: 307-316.

Golembiewski, R. T., Billingsley, K., \& Yeager, S. (1976). Measuring change and persistence in human affairs: Types of change generated by OD designs. Journal of Applied Behavioral Science, 12, 133-157.

Gollwitzer, P. M., \& Brandstätter, V. (1997). Implementation intentions and effective goal persuit. Journal of Personality and Social Psychology, 73(1), 186-199.

Gollwitzer, P. M., Heckhausen, H., \& Steller, B. (1990). Deliberative and implementational mind-sets: Cognitive tuning toward congruous thoughts and information. Journal of Personality and Social Psychology, 59(6), 1119-1127.

Gonzalez, T. F., \& Guillen, M. (2008). Organizational commitment: A proposal for a wider ethical conceptualization of 'normative commitment'. Journal of Business Ethics, 78, 401-411.

Gosling, S. D., Rentfrow, P. J., \& Swann, W. B. (2003). A very brief measure of the Big-Five personality domains. Journal of Research in Personality, 6(6), 504-528.

Gottman, J. M. (Ed.). (1995). The analysis of change. Mahway, NJ: Lawrence Erlbaum. 
Greenberg, J. (1990). Employee theft as a reaction to underpayment inequity: The hidden cost of pay cuts. Journal of Applied Psychology, 75(5), 561-568.

Greenberg, J., \& Baron, A. B. (2003). Behavior in organizations (8 ed.). Upper Saddle River, NJ: Prentice Hall.

Griffeth, R. W., \& Hom, P. W. (2001). Retaining valued employees. Thousand Oaks, CA: Sage.

Grunberg, L., Moore, S., Greenberg, E. S., \& Sikora, P. (2008). The changing workplace and its effects: A longitudinal examination of employee responses at a large company. Journal of Applied Behavioral Science, 44(2), 215-236.

Hackett, R. D., Bycio, P., \& Hausdorf, P. A. (1994). Further assessments of Meyer and Allen's (1991) three component model of organizational commitment. Journal of Applied Psychology, 79, 15-23.

Hagedoorn, M., Van Yperen, N. W., Van de Vliert, E., \& Buunk, B. P. (1999). Employee's reactions to problematic events: A circumplex structure of five categories of responses, and the role of job satisfaction. Journal of Organizational Behavior, 20(309-321).

Hall, D. T., \& Nougaim, K. E. (1968). An examination of Maslov's need hierarchy in an organizational setting. Organizational Behavior and Human Performance, 3, 12-35.

Hailey, V. H., Farndale, E., \& Truss, C. (2005). The HR department's role in organisational performance. Human Resource Management Journal, 15(3), 49-66.

Hair, J. F., Black, W. C., Babin, B. J., Anderson, R. E., \& Tatham, R. L. (2006). Multivariate data analysis (6th ed.). Upper Saddle River: Pearson Prentice Hall.

Halasz, M. F. (1970). Transitions of conditioned delay in a behavioral phase-plane: Nodes, foci, and limit cycles. International Journal of Psychobiology, 1, 43-47.

Halasz, M. F. (1995). Nonlinear dynamics in behavioral systems. American Psychologist, February, 107-108.

Hambrick, D. C. (2007). The field of management's devotion to theory: Too much of a good thing? Academy of Management Journal, 50(6), 1346-1352.

Harrison, D. A., Newman, D. A., \& Roth, P. L. (2006). How important are job attitudes? Meta-analytic comparisons of integrative behavioral outcomes and time sequences. Academy of Management Journal, 49(2), 305-325.

Harter, J. K., \& Schmidt, F. L. (2008). Conceptual versus empirical distinctions among constructs: Implications for discriminant validity. Industrial and Organizational Psychology, 1, 36-39.

Heady, B., \& Wearing, A. (1992). Understanding happiness: A theory of subjective wellbeing. Melbourne, Australia: Longman Chesire.

Henle, C., Giacalone, R., \& Jurkiewicz, C. (2005). The role of ethical ideology in workplace deviance. Journal of Business Ethics, 56(3), 219-230.

Herscovitch, L., \& Meyer, J. P. (2002). Commitment to organizational change: Extension of a three-component model. Journal of Applied Psychology, 87(3), 474-487.

Hinkin, T. R., \& Tracey, J. B. (1999). An analysis of variance approach to content validation. Organizational Research Methods, 2(2), 175-187.

Hirschman, A. O. (1970). Exit, voice, and loyalty: Responses to decline in firms, organizations, and states. Cambridge, Mass.: Harvard University Press.

Hogg, M. A., \& Terry, D. J. (2000). Social identity and self-categorization processes in organizational contexts. Academy of Management Review, 25, 121-140.

Hollander, E.P. (1971). Principles and methods of social psychology. New York: Oxford University Press.

Hom, P. W., \& Griffeth, R. W. (1995). Employee turnover. Cincinatti, OH: South/Western. 
Hom, P. W., Griffeth, R. W., \& Gaertner, S. (2000). A meta-analysis of antecedents and correlates to turnover: Update, moderator tests, and research implications for the next millennium. Journal of Management, 26(3), 463-488.

Horn, J. L., \& McArdle, J. J. (1992). A practical and theoretical guide to measurement invariance in aging research. Experimental Aging Research, 3, 424-453.

Howard, G. S. (1994). Why do people say nasty things about self-reports? Journal of Organizational Behavior, 15, 399-404.

Howard, G. S., \& Dailey, K. M. (1979). Response-shift bias: A source of contamination of self-report measures. Journal of Applied Psychology, 64, 144-150.

Howard, G. S., Ralph, K. M., Gulanick, N. A., Maxwell, S. E., Nance, D. W., \& Gerber, S. R. (1979). Internal validity in pretest-posttest self-report evaluations and a re-evaluation of retrospective pre-tests. Journal of Applied Measurement, 3, 1-23.

Hunt, J. G., \& Ropo, A. (2003). Longitudinal organizational research and the third scientific discipline. Group \& Organization Management, 28(3), 315-340.

Irving, P., \& Meyer, J. P. (1994). Reexamination of the met-expectations hypothesis: A longitudinal analysis. Journal of Applied Psychology, 79(6), 937-949.

Jaccard, J., \& Dittus, P. (1990). Idiographic and nomothetic perspectives on research methods and data analysis. In C. Hendrick \& M. Clark (Eds.), Research methods in personality and social psychology. Newbury Park, CA: SAGE.

Jacques, E. (1982). The form of time. London: Heinemann.

Jaros, S. J., Jermier, J. M., Koehler, J. W., \& Singigh, T. (1993). Effects of continuance, affective, and moral commitment on the withdrawal process: An evaluation of eight structural equation models. Academy of Management Journal, 36(5), 951-995.

Jokisaari, M., \& Nurmi, J.-E. (2009). Change in newcomers 'supervisor support and socialization outcomes after organizational entry. Academy of Management Journal, 52(3), 527-544.

Jones, B. L., \& Nagin, D. S. (2007). Advances in group-based trajectory modeling and a SAS procedure for estimating them. Sociological Methods \& Research, 35(542-571).

Jones, B. L., Nagin, D. S., \& Roeder, K. (2001). A SAS procedure based on mixture models for estimating developmental trajectories. Sociological Research and Methods, 29, 374-393.

Kammeyer-Mueller, J. D., Wanberg, C. R., Glomb, T. M., \& Ahlburg, D. (2005). The role of temporal shifts in turnover process: It's about time. Journal of Applied Psychology, 90(4), 644-658.

Kanter, R. M. (1968). Commitment and social organizations: A study of commitment mechanisms. American Sociological Review, 33, 499-517.

Kanungo, R. N. (1982). Measurement of job and work involvement. Journal of Applied Psychology, 67, 341-349.

Kaplan, R. M., \& Saccuzzo, D. P. (2005). Psychological testing: Principles, applications, and issues. Belmont, CA: Thomson Whadsworth.

Katz, R. (1997). Managing professional careers: The influence of job longevity and group age. In M. L. Tushman \& P. Anderson (Eds.), Managing strategic innovation and change: A collection of readings. Oxford: University Press.

Kelly, K. S. (1998). Effective fund-raising management. Mahwah, NJ: Lawrence Erlbaum.

Ko, J.-W., Price, J. L., \& Mueller, C. W. (1997). Assessment of Meyer and Allen's threecomponent model of organizational commitment in South Korea. Jounal of Applied Psychology, 82(6), 961-973.

Kockelmans, J. J. (1984). On the truth of being: Reflections on Heidegger's later philosophy. Bloomington: Indiana University. 
Kramer, M. W., Doughery, D. S., \& Pierce, T. A. (2004). Managerial uncertainty during a corporate acquisition: A longitudinal study of communication during an airline acquisition. Human Communication Research, 30(1), 71-101.

Krosnick, J. A. (1999). Survey research. Annual Review of Psychology, 50, 537-567.

Kuvaas, B. (2006). Work performance, affective commitment, and work motivation: The roles of pay administration and pay level. Journal of Organizational Behavior, 27, 365-385.

Kunda, G. (1992). Engineering culture: Control and commitment in a high-tech corporation. Philadelphia: Temple University Press

Labouvie, E., \& Ruetsch, C. (1995). Testing for equivalence of measurement scales: Simple structure and metric invariance reconsidered. Multivariate Behavioral Research, 30(1), 63-76.

Lance, C. E., Vandenberg, R. J., \& Self, R. M. (2000). Latent growth models of individual change: The case of newcomer adjustment. Organizational Behavior and Human Decision Processes, 83(1), 107-140.

Latham, G. P., \& Pinder, C. C. (2005). Work motivation theory and research at the dawn of the twenty-first century. Annual Review of Psychology, 56, 485-516.

Leik, R. K., Owens, T. J., \& Tallman, I. (1999). Interpersonal commitment: The interplay of social networks and individual identities. In J. M. Adams \& W. M. Jones (Eds.), Handbook of interpersonal commitment and relationship stability. New York: Kluwer Academic/Plenum.

Lee, J. A., \& Chulguen, Y. (2005). Factor structure of organizational commitment: Differences between U.S. and South Korean samples. Psychological Reports, 96(3), 595-602.

Lee, K., Allen, N. J., Meyer, J. P., \& Rhee, K.-Y. (2001). Cross-cultural generalizability of the three-component model of organizational commitment: An application to South Korea. Applied Psychology: An International Review, 50, 596-614.

Lee, T. W., Ashford, S. J., Walsh, J. P., \& Mowday, R. T. (1992). Commitment propensity, organizational commitment, and voluntary turnover: A longitudinal study of organizational entry processes. Journal of Management, 18(1), 15-32.

Lee, T. W., \& Mitchell, T. R. (1994). An alternative approach: The unfolding model of voluntary employee turnover. Academy of Management Review, 19(1), 51-89.

Lewin, K. (1936). Principles of topological psychology. New York: McGraw Hill.

Li, J. (2009a). The impacts of conflict dynamics and temporal orientation on team performance and team cohesion. (Working paper). Maastricht: Maastricht University.

Li, J. (2009b). Testing the stability of temporal characteristics over time (working paper). Maastricht University, Maastricht.

Lord, F. M. (1984). Standard errors of measurement at different ability levels. Journal of Educational Measurement, 21, 239-243.

Louis, M. R. (1980). Surprise and sense making: What newcomers experience entering unfamiliar settings. Administrative Science Quarterly, 25, 226-251.

Lunt, P. K. (1991). The perceived causal structure of loneliness. Journal of Personality and Social Psychology, 61(1), 26-34.

Lynn, S. A., Le Thi Cao, S. A., \& Horn, B. C. (1996). The influence of career stage on the work attitudes of male and female accounting professionals. Journal of Organizational Behavior, 17(2), 135-149.

Mael, F., \& Ashforth, B. E. (1992). Alumni, and their alma mater: A partial test of the reformulated model of organizational identification. Journal of Organizational Behavior, 13, 103-123. 
Maier, G., \& Brunstein, J. C. (2001). The role of personal work goals in newcomers' job satisfaction and organizational commitment: A longitudinal analysis. Journal of Applied Psychology, 86(5), 1034-1042.

March, J. G., \& Simon, H. A. (1958). Organizations. New York: Wiley.

Mathieu, J. E., \& Zajac, D. M. (1990). A review and meta-analysis of the antecedents, correlates, and consequences of organizational commitment. Psychological Bulletin, 108(2), 171-194.

McDonald, R. P. (1999). Test theory: A unified treatment. Mahwah, NJ: Lawrence Erlbaum.

McGee, G., \& Ford, R. C. (1987). Two (or more?) dimensions of organizational commitment: Reexamination of the affective and continuous commitment scales. Journal of Applied Psychology, 72(4), 638-641.

McGrath, J. E., \& Kelly, J. R. (1986). Time and human interaction. New York: Guilford Press.

McGrath, J. E., \& Tschan, F. (2004). Temporal matters in social psychology: Examining the role of time in the lives of groups and individuals. Washington, DC: American Psychological Association.

Meglino, B. M., Denisi, A. S., Youngblook, S. A., \& Williams, K. J. (1988). Effects of realistic job previews: A comparison using an enhancement and a reduction preview. Journal of Applied Psychology, 73(2), 259-266.

Meglino, B. M., Ravlin, E. C., \& DeNisi, A. S. (2000). A meta-analytic examination of realistic job preview effectiveness: A test of three counterintuitive propositions. Human Resource Management Review, 4, 407-434.

Menard, S. (Ed.). (2008). Handbook of longitudinal research: Design, measurement, and analysis. Amsterdam: Elsevier.

Mehta, C. R., Patel, N. R. (1999). Exact permutational inference for categorical and nonparametric data. In R. H. Hoyle (ed.), Statistical strategies for small sample research, (pp. 134-167). Thousand Oaks, CA: Sage

Meyer, J. P., \& Allen, N. J. (1987). A longitudinal analysis of the early development and consequences of organizational commitment. Canadian Journal of Behavioral Science, 19(2), 199-215.

Meyer, J. P., \& Allen, N. J. (1988). Links between work experiences and organizational commitment during the first year of employment: A longitudinal analysis. Journal of Occupational Psychology, 1988(61), 195-209.

Meyer, J. P., \& Allen, N. J. (1991). A three-component conceptualization of organizational commitment. Human Resource Management Review, 1, 61-89.

Meyer, J. P., \& Allen, N. J. (1997). Commitment in the workplace: Theory, research, and application. London: Sage.

Meyer, J. P., Allen, N. J., \& Smith, C. A. (1993). Commitment to organizations and occupations: Extension and test of the three-component conceptualization. Journal of Applied Psychology, 78, 538-551.

Meyer, J. P., Becker, T. E., \& Van Dick, R. (2006). Social identities and commitments at work: Toward an integrative model. Journal of Organizational Behavior, 27, 665683.

Meyer, J. P., Becker, T. E., \& Vandenberghe, C. (2004). Employee commitment and motivation: A conceptual analysis and integrative model. Journal of Applied Psychology, 89(6), 991-1007.

Meyer, J. P., Bobocel, D. R., \& Allen, N. J. (1991). Development of organizational commitment during the first year of employment: A longitudinal study of pre-and post-entry influences. Journal of Management, 17(4), 717-733. 
Meyer, J. P., \& Herscovitch, L. (2001). Commitment in the workplace: Toward a general model. Human Resource Management Review, 11, 299-326.

Meyer, J. P., Irving, P., \& Allen, N. J. (1998). Examination of the combined effects of work values and early work experiences on organizational commitment. Journal of Organizational Behavior, 19, 29-52.

Meyer, J. P., Stanley, D. J., Herscovitch, L., \& Topolnytsksy, L. (2002). Affective, continuance, and normative commitment to the organization: A meta-analysis of antecedents, correlates, and consequences. Journal of Vocational Behavior, 61(1), 2052.

Miller, D. (2007). Paradigm prison, or in praise of atheoretic research. Strategic Organization, 5(2), 177-184.

Mitchell, T. R., Holtom, B. C., Lee, T. W., Sablynski, C. J., \& Erez, M. (2001). Why people stay: Using job embeddedness to predict voluntary turnover. Academy of Management Journal, 44(6), 1102-1121.

Moberg, D. J. (2006). Best intentions, worst results: Grounding ethics students in the realities of organizational context. Academy of Management Learning and Education, 5(3), 307-316.

Mohr, L. B. (1982). Explaining organizational behavior. San Francisco, CA: Jossey-Bass.

Molenaar, P. C. M. (1985). A dynamic factor model for the analysis of multivariate time series. Psychometrika, 50, 181-202.

Molenaar, P. C. M. (1999). Longitudinal analysis. In H. J. Ader \& G. J. Mellenbergh (Eds.), Research methodology in the social, behavioural, and life sciences (pp. 143-176). London: Sage.

Molenaar, P. C. M. (2004). A manifesto on psychology as idiographic science: Bringing the person back into scientific psychology, this time forever. Measurement, 40, 201-218.

Molenaar, P. C. M., Boomsma, D. I., \& Dolan, C. V. (1993). A third source of developmental differences. Behavior genetics, 23, 519-524.

Molenaar, P. C. M., \& Campbell, C. G. (2009). The new person-specific paradigm in psychology. Current directions in psychological science, 18(2), 112-117.

Molenaar, P. C. M., Huizinga, H. M., \& Nesselroade, J. R. (2003). The relationship between the structure of interindividual and intraindividual variability: A theoretical and empirical vindication of developmental systems theory. In U. M. Staudinger \& U. Lindenberger (Eds.), Understanding human development: Dialogues with lifespan psychology. Dordrecht: Kluwer Academic.

Monge, P. R. (1990). Theoretical and analytical issues in studying organizational processes. Organization Science, 1(4), 406-430.

Morgan, R. M., \& Hunt, S. D. (1994). The commitment-trust theory of relationship marketing. Journal of Marketing, 58, 20-38.

Mowday, R. T., Porter, L. W., \& Steers, R. M. (1982). Employee-organization linkages: the psychology of commitment, absenteeism and turnover. New York: Academic Press.

Mowday, R. T., Steers, R. M., \& Porter, L. W. (1979). The measurement of organizational commitment. Journal of Vocational Behavior, 14, 224-247.

Muthen, B. (2001). Second-generation structural equation modeling with a combination of categorical and continuous latent variables: New opportunities for latent class-latent growth mixture modeling. In L. M. Collins \& A. G. Sayer (Eds.), New methods for the analysis of change (pp. 289-322). Washington, DC: American Psychological Association.

Nagin, D. S. (2005). Group-based modeling of development. Cambridge, MA: Harvard University Press. 
Netemeyer, R. G., Johnston, M. W., \& Burton, S. (1990). Analysis of role conflict and role ambiguity in a structural equations framework. Journal of Applied Psychology, 75(2), 148-157.

Netemeyer, R. G., Bearden, W. O., \& Sharma, S. (2003). Scaling procedures: Issues and applications. Thousand Oaks, CA: Sage.

Ng, T. W. H., \& Feldman, D. C. (2006). Organizational embeddedness and occupational embeddedness across career stages. Journal of Vocational Behavior, 70, 336-351.

Noon, M., \& Delbridge, R. (1993). News from behind my hand: Gossip in organizations. Organization Studies, 14(1), 22-36.

Nunnally, J. C., \& Bernstein, I. H. (1994). Psychometric theory $\left(3^{\text {rd }}\right.$ ed.). New York: McGraw-Hill.

Oatley, K., Keltner, D., \& Jenkins, J. M. (2006). Understanding emotions (2nd ed.). Malden, MA: Blackwell.

O'Reilly, C. A., \& Caldwell, D. F. (1981). The commitment and job tenure of new employees: Some evidence of postdecisional justification. Administrative Science Quarterly, 26, 597-616.

O'Reilly, C. A., \& Chatman, J. (1986). Organizatinal commitment and psychological attachment: The effects of compliance, identification, and internalization of prosocial behavior. Journal of Applied Psychology, 71, 492-499.

O'Reilly, C. A., Chatman, J., \& Caldwell, D. F. (1991). People and organizational culture: A profile comparison approach to assessing person-organization fit. Academy of Management Journal, 34, 487-516.

Organ, D. W. (1988). Organizational citizenship behavior: The good soldier syndrome. Lexington, MA: D. C. Heath.

Organ, D. W., \& Ryan, K. (1995). A meta-analytic review of attitudinal and dispositional predictors or organizational sitizenship behavior. Personnel Psychology, 48, 775-802.

Orlikowski, W. J., \& Baroudi, J. J. (1991). Studying information technology in organizations: Research approaches and assumptions. Information Systems Research, 2(1), 1-28.

Ostroff, C., \& Kozlowski, S. W. J. (2006). Organizational socialization as a learning process: The role of information acquisition. Personnel Psychology, 45(4), 849-874.

Overall, J. E. (1980). Power of chi-square tests for $2 \times 2$ contingency tables with small expected frequencies. Psychological Bullitin, 87(1), 132-135.

Payne, S. C., \& Webber, S. S. (2006). Effects of service provider attitudes and employment statues on citizenship behaviors and customers' attitudes and loyalty behavior. Journal of Applied Psychology, 91(2), 365-378.

Perugini, M., \& Bagozzi, R. P. (2004). The distinction between desires and intentions. European Journal of Social Psychology, 34, 69-84.

Pierce, J. L., \& Dunham, R. B. (1987). Organizational commitment: Pre-employment propensity and initial work experiences. Journal of Management, 13(1), 163-178.

Pierce, J. L., \& Gardner, D. G. (2004). Self-esteem within the work and organizational context: A review of the organizational-based self-esteem literature. Journal of Management, 30(5), 591-622.

Pierce, J. L., Gardner, D. G., Cummings, L. L., \& Dunham, R. B. (1989). Organizational based self-esteem: construct definition, measurement, and validation. Academy of Management Journal, 32, 622-648.

Pinder, G. C. (1998). Work motivation in organizational behavior. London: Prentice Hall.

Powell, D. M., \& Meyer, J. P. (2004). Side-bet theory and the three-component model of organizational commitment. Journal of Vocational Behavior, 65, 157-177. 
Ployhart, R. E., Holtz, B. C., \& Bliese, P. D. (2002). Longitudinal data analysis: Applications of random coefficient modeling to leadership research. The Leadership Quarterly, 13, 455-486.

Poole, M. S., Van de Ven, A. H., Dooley, K., \& Holmes, M. E. (2000). Organizational change and innovation processes. New York: Oxford University Press.

Porter, L. W., Crampon, W. J., \& Smith, F. J. (1976). Organizational commitment and managerial turnover: A longitudinal study. Organizational Behavior and Human Performance, 15, 87-98.

Priestley, M. B. (1989). Nonlinear and nonstationary time series analysis. London: Academic.

Rabe-Hesketh, S., \& Skrondal, A. (2008). Multilevel and longitudinal modeling using stata $\left(2^{\text {nd }}\right.$ ed.). Lakeway drive, TX: Stata Press.

Randall, D. M. (1987). Commitment and the organization: The organization man revisited. Academy of Management Review, 12(3), 460-471.

Reichers, A. E. (1985). A review and reconceptualization of commitment. Academy of Management Review, 10, 465-476.

Reichers, A. E. (1986). Conflict and organizational commitments. Journal of Applied Psychology, 71(3), 508-514.

Rescher, N. (1996). Process metaphysics: An introduction to process philosophy. New York: State University of New York.

Rhoades, L., \& Eisenberger, R. (2002). Perceived organizational support: A review of the literature. Journal of Applied Psychology, 87(4), 698-714.

Riketta, M. (2002). Attitudinal organizational commitment and job performance: A metaanalysis. Journal of Organizational Behavior, 23, 257-266.

Robinson, S. L., \& Bennett, R. J. (1995). A typology of deviant workplace behaviors: A multidimensional scaling study. Academy of Management Journal, 38(2), 555-572.

Rodriguez Landeros, O. A. (2006). Beyond the three-component model of organizational commitment: Empirical support. Unpublished Master's thesis, Maastricht University, Maastricht.

Roe, R. A. (2004). The paradox of time and the future of W\&O-Psychology research [De paradox van de tijd en de toekomst van A\&O-Psychologisch onderzoek]. Gedrag en Organisatie, 17(5), 342-350.

Roe, R. A. (2005a). The design of selection systems: Context, principles, issues. In A. Evers, O. Smit \& N. Anderson (Eds.), Handbook of personnel selection. Oxford: Blackwell.

Roe, R. A. (2005b). No more variables, please! Giving time a place in work and organizational psychology. In F. Avallone, H. Kepir Sinangil \& A. Caetano (Eds.), Convivence in organizations and society (pp. 11-20). Milano: Guerini.

Roe, R. A. (2008a). Time applied psychology: The study of "what happens" rather than "what is". European Psychologist, 13(1), 37-52.

Roe, R. A. (2008b). Towards more dynamic research in IO Psychology, Master Tutorial. San Francisco, CA: SIOP, Annual Meeting, April 10-12, 2008.

Roe, R. A. (2008c). Time and the study of behavior in organizations. Implications for assessment, selection, and development. Seminar at SHL, Thames Ditton, September $9,2008$.

Roe, R. A. (2009). Perspectives on time and the chronometric study of what happens in organizations. In R. A. Roe, M. Waller \& S. Clegg (Eds.), It's about time: Perspectives on time in organizational research (pp. 291-313). Abingdon, UK: Routledge. 
Roe, R. A., Solinger, O. N., \& Van Olffen, W. (2009). Shaping organizational commitment. In S. Clegg \& C. L. Cooper (Eds.), The SAGE handbook of organizational behaviour: Macro Approaches (Vol. II). London: SAGE.

Roe, R. A., Ten Horn, L. A., Zinovieva, I. L., \& Dienes, E. (1997). Final report on the project "work motivation and quality of working life - social prerequisites for successful socio-economic change" (WMO-report 028-97-EXT-EN). Tilburg: Report to the European Commission.

Roe, R. A., \& Van Olffen, W. (2004). METEOR PhD project application. Unpublished manuscript, Maastricht.

Rogosa, D. R., Brandt, D., \& Zimowski, M. (1982). A growth curve approach to the measurement of change. Psychological Bullitin, 92(18-38).

Roozenburg, N. F. M., \& Eekels, J. (1995). Product design: Fundamentals and methods. Chichester: Wiley.

Roscoe, J. T., \& Byars, J. A. (1971). An investigation of the restraints with respect to sample size commonly imposed on the use of the chi-square statistic. Journal of the American Statistical Association, 66, 755-759.

Rusbult, C. E., \& Zembroth, I. M. (1983). Responses to dissatisfaction in romantic involvements: A multidimensional scaling analysis. Journal of Experimental Social Psychology, 19(274-293).

Rynes, S. L. (2005). Taking stock and looking ahead. Academy of Management Journal, 48, $732-737$.

Saks, A. M., \& Ashforth, B. E. (1997). Organizational socialization: Making sense of the past and present as a prologue for the future. Journal of Vocational Behavior, 51, 234-279.

Saks, A. M., \& Ashforth, B. E. (2002). Is job search related to employment quality? It all depends on the fit. Journal of Applied Psychology, 87(4), 646-654.

Salancik, G. R. (1977). Commitment and the control of organizational behavior and belief. In B. Staw \& G. Salancik (Eds.), New Directions in Organizational Behavior (pp. 5159). Chicago: St. Clair Press.

Salancik, G. R., \& Pfeffer, J. (1978). A social information processing approach to job attitudes and task design. Administrative Science Quarterly, 23, 224-253.

Salthouse, T. A., Nesselroade, J. R., \& Berish, D. E. (2006). Short-term variability in cognitive performance and the calibration of longitudinal change. Journal of Gerontology: Psychological Sciences, 61B(3), 144-151.

Sanchez, R. J., Bauer, T. N., \& Paronto, M. E. (2006). Peer-mentoring freshmen: Implications for satisfaction, commitment, and retention to graduation. Academy of Management Learning and Education, 5(1), 25-37.

Sappington, J. M., Longshore, K. M., \& Thompson, D. B. (2007). Quantifying landscape ruggedness for animal habitat analysis: A case study using bighorn sheep in the Mojave desert. Journal of Wildlife management, 71(5), 1419-1426.

Schaubroeck, J., \& Ganster, D. C. (1991). Beyond the call of duty: A field study of extra-role behavior in voluntary organizations. Human Relations, 44, 569-582.

Schaufeli, W. B., Salovana, M., Gonzáles-Romá, V., \& Bakker, A. B. (2002). The measurement of engagement and burnout: A two sample confirmatory factor analytic approach. Journal of Happiness Studies, 3, 71-92.

Scholl, R. W. (1981). Differentiating organizational commitment from expectancy as a motivating force. Academy of Management Review, 6(4), 589-599.

Schalk, R., \& Freese, C. (2000). The impact of organizational changes on the psychological contract and attitudes toward work in four health care organizations. In K. Isakson (Ed.), Health effects of the new labor market (pp. 129-143). New York: Kluwer/Plenum. 
Schmitt, N. (1982). The use of analysis of covariance structure to assess beta and gamma change. Multivariate Behavioral Research, 17, 343-358.

Schweiger, D. M., \& Denisi, A. S. (1991). Communication with employees following a merger: A longitudinal field experiment. Academy of Management Journal, 34(1), 110-135.

Schweiger, D. M., \& Goulet, P. K. (2005). Facilitating acquisition integration through deeplevel cultural learning interventions: A longitudinal field experiment. Organization Studies, 26(10), 1477-1499.

Selders, S. (2009). The temporal relation between affective events, mood and work attitudes: A high-density study. Unpublished master's thesis. Maastricht: Maastricht University.

Singer, J. D., \& Willett, J. B. (2003). Applied longitudinal data analysis: Modeling change and event occurrence. New York: Oxford University Press.

Slife, B. D. (1993). Time and psychological explanation. Albany, NY: State University of New York.

Shamir, B. (1991). Meaning, self, and motivation in organizations. Organization Studies, $12(3), 405-424$.

Sheldon, M. E. (1971). Investments and involvements as mechanisms producing commitment to the organization. Administrative Science Quarterly, 16, 637-643.

Skarlicki, D. P., \& Folger, R. (1997). Retaliation in the workplace: The roles of distributive, procedural, and interactional justice. Journal of Applied Psychology, 82(3), 434-443.

Slocum, J., \& Cron, W. L. (1985). Job attitudes and performance during three career stages. Journal of Vocational Behavior, 26(126-145).

Solinger, O. N. (2004). Outsourcing and HRM: Making sense of change. Unpublished master's thesis. Nijmegen: Radboud University.

Solinger, O. N. (2007). High density measurement of attitudinal phenomena. In S. U. Uitdewilligen (chair), Tools and Methods for Studying Temporal Aspects of Organizational Behavior (PDW), Academy of Management Annual Meeting, Anaheim, CA: Academy of Management, August 9, 2007.

Solinger, O. N., Van Olffen, W., \& Roe, R. A. (2008). Beyond the three-component model of organizational commitment Journal of Applied Psychology, 91(1), 70-83.

Somers, M. J. (1995). Organizational commitment, turnover, and absenteeism: An examination of direct and interaction effects. Journal of Organizational Behavior, 16, 49-58.

Spector, P. E. (1994). Using self-report questionnaires in OB research: A comment on the use of a controversial method. Journal of Organizational Behavior, 15, 385-392.

Spreitzer, G. M. (1995). Psychological empowerment in the workplace: dimensions, measurement, and validation. Academy of Management Journal, 38(5), 1442-1465.

Steers, R. M., \& Mowday, R. T. (1981). Employee turnover and postdecision accomodation processes. In L. L. Cummings \& B. M. Staw (Eds.), Research in organizational behavior (Vol. 3). Greenwich, CT: JAI Press.

Stumpf, S. A., \& Rabinowitz, S. (1981). Career stage as a moderator of performance relationships with facets of job satisfaction and role perceptions. Journal of Vocational Behavior, 18, 202-218.

Sturges, J., Guest, D., Conway, N., \& Mackenzie Davey, K. (2002). A longitudinal study of the relationship between career management and organizational commitment among graduates in the first ten years at work. Journal of Organizational Behavior, 23(23), 731-748.

Sturgis, P., Allum, N., \& Brunton-Smith, I. (2009). Attitudes over time: The psychology of panel conditioning. In P. Lynn (Ed.), Methodology of longitudinal surveys. Chichester, UK: Wiley. 
Summers, G. F. (Ed.). (1969). Attitude measurement. Chicago: Rand McNally.

Super, D. (1957). The psychology of careers. New York: Harper.

Sutton, R. I., \& Staw, B. M. (1995). What theory is not. Administrative Science Quarterly, 40, 371-384.

Terborg, J. R., Howard, G. S., \& Maxwell, S. E. (1980). Evaluating planned organizational change: A method for assessing alpha, beta, and gamma change. Academy of Management Review, 5(1), 109-121.

Tett, R. P., \& Meyer, J. P. (1993). Job satisfaction, organizational commitment, turnover intention, and turnover: Path analyses based on meta-analytic findings. Personnel Psychology, 46, 259-293.

Thompson, B. (Ed.). (2003). Score reliability: Contemporary thinking on reliability issues. Thousand Oaks, CA: Sage.

Thompson, J.A., \& Van de Ven, A.-H. (2002). Commitment shift during organizational upheaval: Physicians' transitions from private practitioner to employee. Journal of Vocational Behavior, 60, 382-404.

Thompson, R. C., \& Hunt, J. G. (1996). Inside the black box of alpha, beta, and gamma change: using a cognitive processing model to assess attitude structure. Academy of Management Review, 21(3), 655-690.

Tisak, J., \& Tisak, M. S. (2000). Permanency and ephemerality of psychological measures with application to organizational commitment. Psychological Methods, 5(2), 175198.

Triandis, H. C. (1977). Interpersonal behavior. Monterey, CA: Brooks/Cole.

Tsoukas, H., \& Chia, R. (2002). On organizational becoming: Rethinking organizational change. Organization Science, 13(5), 567-582.

Valk, S. (2006). A re-conceptualization of organizational commitment. Unpublished master's thesis. Maastricht: Maastricht University.

Van de Ven, A. H. (2007). Engaged scholarship: A guide for organizational and social research. New York: Oxford University Press.

Van de Ven, A. H., \& Poole, M. S. (2005). Alternative approaches for studying organizational change. Organization Studies, 26(9), 1377-1404.

Van de Vliert, E., Huismans, S. E., \& Stok, J. J. L. (1985). The criterion to unraveling beta and alpha change. Academy of Management Review, 10, 269-274.

Van Dick, R. (2001). Identification in organizational contexts: Linking theory and research from social and organizational psychology. International Journal of Management Reviews, 3(4), 265-283.

Van Maanen, J. (1975). Police socialization: A longitudinal examination of job attitudes in an urban police department. Administrative Science Quarterly, 20, 207-228.

Van Ravestein, A. C. (2008). Dynamics of organizational commitment and its attitudinal components. Unpublished master's thesis. Maastricht: Maastricht University.

Vandenberg, R., \& Seo, J. H. (1992). Placing recruitment effectiveness into perspective: A cognitive explication of the job-choice and organizational entry period. Human Resource Management Review, 2, 239-273.

Vandenberg, R. J., \& Lance, C. E. (2000). A review and synthesis of the measurement invariance literature: Suggestions, practices, and recommendations for organizational research. Organizational Research Methods, 3(1), 4-70.

Vandenberg, R. J., \& Self, R. M. (1993). Assessing newcomers' changing commitments to the organization during the first 6 months of work. Journal of Applied Psychology, $78(4), 557-568$. 
Vermunt, J. K., Tran, B., \& Magidson, J. (2008). Latent class models in longitudinal research. In S. Menard (Ed.), Handbook of longitudinal research: Design, measurement, and analysis (pp. 373-386). Amsterdam: Elsevier.

Wanberg, C., \& Kammeyer-Mueller, J. (2000). Predictors and outcomes of proactivity in the socialization process. Jounal of Applied Psychology, 85, 373-385.

Wanous, J. P., \& Hudy, M. J. (2001). Single-item reliability: A replication and extension. Organizational Research Methods, 4(4), 361-375.

Wanous, J. P., Poland, T. D., Premack, S. L., \& Davis, K. S. (1992). The effects of met expectations on newcomer attitudes and behaviors: A review and meta-analysis. Journal of Applied Psychology, 77(3), 288-297.

Wanous, J. P., Reichers, A. E., \& Hudy, M. J. (1997). Overall job satisfaction: How good are single-item measures? Journal of Applied Psychology, 82(2), 147-252.

Watson, D. (2000). Mood and temperament. New York: The Guilford Press.

Watson, D., Clark, L. A., \& Tellegen, A. (1988). Development and validation of brief measures of positive and negative affect: The PANAS scales. Journal of Personality and Social Psychology, 54(6), 1063-1070.

Weick, K. E. (1989). Theory construction as disciplined imagination. Academy of Management Review, 14(4), 516-531.

Weiss, H. M., \& Cropanzano, R. (1996). Affective Events Theory: A theoretical discussion of the structure, causes, and consequences of affective experiences at work. In B. M. Staw \& L. L. Cummings (Eds.), Research in organizational behavior: An annual series of analytical essays and critical reviews (Vol. 18, pp. 1-74). Greenwich, CA: JAI.

Wheaton, B., Muthen, B., Alwin, D. F., \& Summmers, G. (1977). Assessing reliability and stability in panel models. In D. R. Heise (Ed.), Sociological methodology (pp. 84136). San Francisco, CA: Jossey Bass.

Wholey, D. R., \& Brittain, J. (1989). Characterizing environmental variation. Academy of Management Journal, 32(4), 867-882.

Wiener, Y. (1982). Commitment in organizations: A normative view. Academy of Management Review, 7, 47-52.

Wiener, Y., \& Vardi, Y. (1980). Relationships between job, organization, and career commitments, and work outcomes: An integrative approach. Organizational Behavior and Human Performance, 26, 81-96.

Williams, L. J., \& Hazer, J. T. (1986). Antecedents and consequences of satisfaction and commitment in turnover models: A reanalysis using latent variable structural equation methods. Journal of Applied Psychology, 71, 219-231.

Wimbush, J. C., \& Dalton, D. R. (1997). Base rate for employee theft: convergence of multiple methods. Journal of Applied Psychology, 82(5), 756-763.

Wood, W., Quinn, J. M., \& Kashy, D. A. (2002). Habits in everyday life: Thought, emotion, and action. Journal of Personality and Social Psychology, 83(6), 1281-1297.

Wright, T. A. (2002). The importance of time in organizational research. Academy of Management Review, 27(3), 339-345.

Wyatt, P. K. (1999). Conceiving couple commitment. In J. M. Adams \& W. M. Jones (Eds.), Handbook of interpersonal commitment and relationship stability. New York: Kluwer Academic/ Plenum.

Zaheer, S., Albert, S., \& Zaheer, A. (1999). Time scales and organizational theory. Academy of Management Journal, 24(4), 725-741.

Zhao, H., Wayne, S., Glibkowski, B. C., \& Bravo, J. (2007). The impact of psychological contract breach on work-related outcomes: A meta-analysis. Personnel Psychology, 60(3), 647-680. 
Zijlstra, F. R. H., \& Rook, J. W. (2009). The weekly cycle of work and rest: A diary study. In R. A. Roe, M. Waller \& S. R. Clegg (Eds.), Time in organizational research. London: Routledge. 


\section{Appendix A}

\section{An attitudinal reclassification of commitment measures: A summary of Van Ravestein (2008)}

\section{Introduction}

Recent conceptual studies support the view that OC should be regrounded and measured as a truly attitudinal construct. Organizational commitment has been recently defined as 'an attitude of an employee vis-à-vis the organization reflected in a combination of affect (emotional attachment, identification), cognition (identification and internalization of its goals, norms and values), and action readiness (a generalized behavioral pledge to serve and enhance the organization's interests)' (Solinger, Van Olffen, \& Roe, 2008, p. 80, emphasis added). From an attitudinal point of view, existing measures of OC may no longer be appropriate because they were not initially constructed to reflect the three attitudinal dimensions ${ }^{55}$ (Bozeman \& Perrewe, 2001; Cohen, 2007; Solinger et al., 2008).

\section{Methodological approach}

In this study it was examined how well existing measures of organizational commitment reflect the attitudinal triplet. We did this by retrospectively classifying each item in the most widely used measures - i.e., the Organizational Commitment Questionnaire, the Affective Commitment Scale and the Psychological Attachment Scale - in one of the three attitudinal dimensions and a behavioral rest category (i.e., specific behaviors). We then examined how these retrospectively classified measures would behave over time. For this purpose we requested to inspect the data by Maier and Brunstein (2001)

\section{Results}

The Affective Commitment Scale Affective organizational commitment is frequently used in temporal studies on OC (Bauer \& Green, 1994; Beck \& Wilson, 2000; Cohen \& Freund,

\footnotetext{
${ }^{55}$ Note that we are NOT talking about the affective, normative, and continuance commitment dimensions (Meyer \& Allen, 1990), but about three attitudinal dimensions: affect, cognition, and action readiness (Solinger et al., 2008)
} 
2005; Vandenberg \& Self, 1993). It is defined as 'emotional attachment to, identification with, and involvement in the organization', Meyer \& Allen, 1990, p. 14). Many scholars before us have studied the psychometric properties of the Affective Commitment Scale empirically. It has been found that the scale has good internal consistency reliability and is unidimensional (Dunham, Grube \& Castañeda, 1994; Ko, Price \& Mueller, 1997; Meyer, Allen, \& Smith, 1993; McGee \& Ford, 1987). However, these kinds of analyses do not reveal whether the measure captures the conceptual domain it intends to measure (construct validity)

Table 6.1 Attitudinal classification of Affective Commitment Scale items

\begin{tabular}{|l|l|}
\hline 1. 'I would be very happy to spend the rest of my career in this organization' & S \\
\hline 2. 'I enjoy discussing my organization with people outside it' & T \\
\hline 3. 'I really feel as if this organization's problems are my own' & $\mathbf{A}$ \\
\hline 4. 'I think I could easily become as attached to another organization as I am to this one' & $\mathbf{C}$ \\
\hline 5. 'I do not feel like 'part of the family' at my organization' & $\mathbf{A}$ \\
\hline 6. 'I do not feel 'emotionally attached' to this organization' & $\mathbf{A}$ \\
\hline 7. 'This organization has a great deal of personal meaning for me' & $\mathbf{A}$ \\
\hline 8. 'I do not feel a strong sense of belonging to my organization' & $\mathbf{A}$ \\
\hline A = Affective component; $\mathrm{C}=$ Cognitive component; $\mathrm{S}=$ Staying; $\mathrm{T}=$ Talking &
\end{tabular}

This item classification exercise confirms that the Affective Commitment Scale fails to qualify as an attitudinal representation of the commitment construct (see also Solinger, Van Olffen, \& Roe, 2008). Although the word involvement in the definition bears an actionable notion, the affective commitment (AC) measure does not contain any item that qualifies as 'action readiness'. Two items focus on Talking and Staying, but are too specific to the respective kinds of behavior. The cognitive part (belief structures such as identification and involvement with the organization) is underrepresented. Only 'I think I could easily become as attached to another organization as I am to this one' can arguably be interpreted as a certain kind of cognitive involvement in the organization. But then again, it could also be interpreted as a consideration of leaving the organization. The operationalization is clearly top-heavy on the affective side. This is understandable because the authors wanted to measure 'affective commitment' (Allen \& Meyer, 1990), but from an attitudinal point of view, the operationalization is unbalanced and incomplete. From a conceptual point of view it is questionable whether this measure demonstrates sufficient construct validity.

Evaluation of the OCQ The most widely used - and mostly attitudinal measure of OC is the OCQ (Mowday, Steers, \& Porter, 1979). In this questionnaire the affective, cognitive and behavioral components of organizational commitment are measured, but only half of the items fit in one of these categories (see Table 2). Most items measure the 
attitude towards staying with the organization and the quality of the decision to join the organization. Bozeman \& Perrewé (2001) identified six retention-related items in the OCQ measure. These are item 4, 7, 9, 11, 14 and 15. These items correspond to the items that were categorized as Staying or Decision Quality in the present study. Bozeman \& Perrewé (2001) argue that these retention-related items should not be in a general OC measure.

Table 6.2 Classification of OCQ items

\begin{tabular}{|l|l|}
\hline $\begin{array}{l}\text { 1. 'I am willing to put in a great deal of effort beyond that normally expected in order to help } \\
\text { this organization be successful' }\end{array}$ & B \\
\hline 2. 'I talk up this organization to my friends as a great organization to work for' & T \\
\hline 3. 'I feel very little loyalty to this organization' & B \\
\hline $\begin{array}{l}\text { 4. 'I would accept almost any type of job assignment in order to keep working for this } \\
\text { organization' }\end{array}$ & S \\
\hline 5. 'I find that my values and the organization's values are very similar' & C \\
\hline 6. 'I am proud to tell others that I am part of this organization' & A \\
\hline $\begin{array}{l}\text { 7. 'I could just as well be working for a different organization as long as the type of work were } \\
\text { similar' }\end{array}$ & S \\
\hline 8. 'This organization really inspires the very best in me in the way of job performance' & B \\
\hline $\begin{array}{l}\text { 9. 'It would take very little change in my present circumstances to cause me to leave this } \\
\text { organization' }\end{array}$ & S \\
\hline $\begin{array}{l}\text { 10. 'I am extremely glad that I chose this organization to work for over others I was } \\
\text { considering at the time I joined' }\end{array}$ & D \\
\hline 11. 'There's not too much to be gained by sticking with this organization indefinitely' & S \\
\hline $\begin{array}{l}\text { 12. 'Often, I find it difficult to agree with this organization's policies on important matter } \\
\text { relating to its employees' }\end{array}$ & C \\
\hline 13. 'I really care about the fate of this organization' & A \\
\hline 14. 'For me this is the best of all possible organization for which to work' & S \\
\hline 15. 'Deciding to work for this organization was a definite mistake on my part' & D \\
\hline A = Affective component; B = Behavioral component; C = Cognitive component; D = Decision quality; S = Staying; T = Talking
\end{tabular}

When examining the relationship between OC and employee turnover, including retentionrelated items in the OCQ is particularly problematic. Bozeman \& Perrewé (2001) found an overlap of retention-related OCQ items and items of the turnover construct. This overlap results in an inflated relationship between $\mathrm{OC}$ and turnover. They suggest that the six items should be removed from the OCQ when examining employee turnover. Combining these arguments, if OC is seen as an attitude, it appears that the OCQ does not measure commitment accurately, because it does not represent the classic attitudinal triplet and there is a strong emphasis on 'staying'.

The Psychological Attachment Scale

The definition of O'Reilly \& Chatman's (1986) Psychological Attachment construct seems to reflect the affective and cognitive part of the definition used in the current study, but it does not reflect the behavioral component. Furthermore, it includes a compliance dimension, which does not belong to the OC definition. 
Table 6.3 Reclassification of Psychological Attachment scale items

\begin{tabular}{|l|l|}
\hline $\begin{array}{l}\text { 1. 'If the values of this organization were different, I would not be as attached to this } \\
\text { organization' }\end{array}$ & $\mathbf{C}$ \\
\hline $\begin{array}{l}\text { 2. 'Since joining this organization, my personal values and those of the organization have } \\
\text { become more similar' }\end{array}$ & $\mathbf{C}$ \\
\hline 3. 'The reason I prefer this organization is because of what it stands for, its values' & $\mathbf{C}$ \\
\hline $\begin{array}{l}\text { 4. 'My attachment to this organization is primarily based on the similarity of my values and } \\
\text { those represented by the organization' }\end{array}$ & $\mathbf{C}$ \\
\hline 5. 'What this organization stands for is important to me' & $\mathbf{C}$ \\
\hline 6. 'I am proud to tell others that I am a part of this organization' & $\mathbf{A}$ \\
\hline 7. 'I talk up the university to my friends as a great organization to work for' & $\mathbf{T}$ \\
\hline 8. 'I feel a sense of 'ownership' for this organization rather than being just an employee' & $\mathbf{A}$ \\
\hline $\begin{array}{l}\text { 9. 'Unless I'm rewarded for it in some way, I see no reason to expend extra effort on behalf } \\
\text { of this organization' }\end{array}$ & $\mathbf{C p}$ \\
\hline 10. 'How hard I work for the organization is directly linked to how much I am rewarded' & $\mathbf{C p}$ \\
\hline 11. 'My private views about the university are different than those I express publicly' & $\mathbf{C p}$ \\
\hline 12. 'In order for me to get rewarded around here, it is necessary to express the right attitude' & $\mathbf{C p}$ \\
\hline A = Affective component; B = Behavioral component; C = Cognitive component; Cp = Compliance; T = Talking
\end{tabular}

Reclassified commitment items over time We also used the data obtained from the authors Maier \& Brunstein (2001) who have used a 5-item version of the Organizational Commitment Questionnaire (OCQ) during a long-term time-frame of 5, 9, 13 months after organizational entry. This measure does no longer tap into all too specific OC drivenbehaviors. We first categorize the 5 items into the attitudinal categories and then plot them separately in graph. In Table 4 we see that the revised OCQ (stripped of all items that originally mentioned the behavior of leaving) taps into all three attitudinal dimensions: affect (2 items), cognition ( 1 item), and action readiness ( 2 items). Figure 1 depicts these items longitudinally over a period of 1,6 , and 11 months after entering a new organization. The figure shows that the two items reflecting 'affect' show a consistent dynamic. The two items reflecting 'action readiness' do not show a consistent dynamic: between T1 and T2 one item shows a significant decrease, while the other remains stable. Motivational verbalizations such as being 'inspired' cannot be regarded as equal representations of the same dimension, or the individuals in the sample were motivationally ambivalent. The 'cognition' item shows a consistent decrease, unlike the 'affect' and 'cognition' items, which show an increase between $\mathrm{T} 2$ and $\mathrm{T} 3$.

Table 6.4 The 5-item OCQ scale

\begin{tabular}{|l|l|}
\hline $\begin{array}{l}\text { 5-item Organizational Commitment } \\
\text { Questionnaire (in Maier \& Brunstein, 2001) }\end{array}$ & \\
\hline $\begin{array}{l}\text { 1. 'I am proud to tell others that I am part of this } \\
\text { organization' }\end{array}$ & A \\
\hline 'I really care about the fate of this organization' & A \\
\hline 'I find that my values and the organization's & C \\
\hline
\end{tabular}




\begin{tabular}{|l|l|}
\hline values are very similar' & \\
\hline $\begin{array}{l}\text { 'This organization really inspires the very best in } \\
\text { me in the way of job performance' }\end{array}$ & B \\
\hline $\begin{array}{l}\text { 'I am willing to put in a great deal of effort } \\
\text { beyond that normally expected in order to help } \\
\text { this organization be successful' }\end{array}$ & B \\
\hline
\end{tabular}

$\mathrm{A}=$ Affective component; $\mathrm{B}=$ action readiness; $\mathrm{C}=$ Cognitive component

Figure 6.1 Diverging patterns of separate OCQ items in the Maier \& Brunstein (2001) data

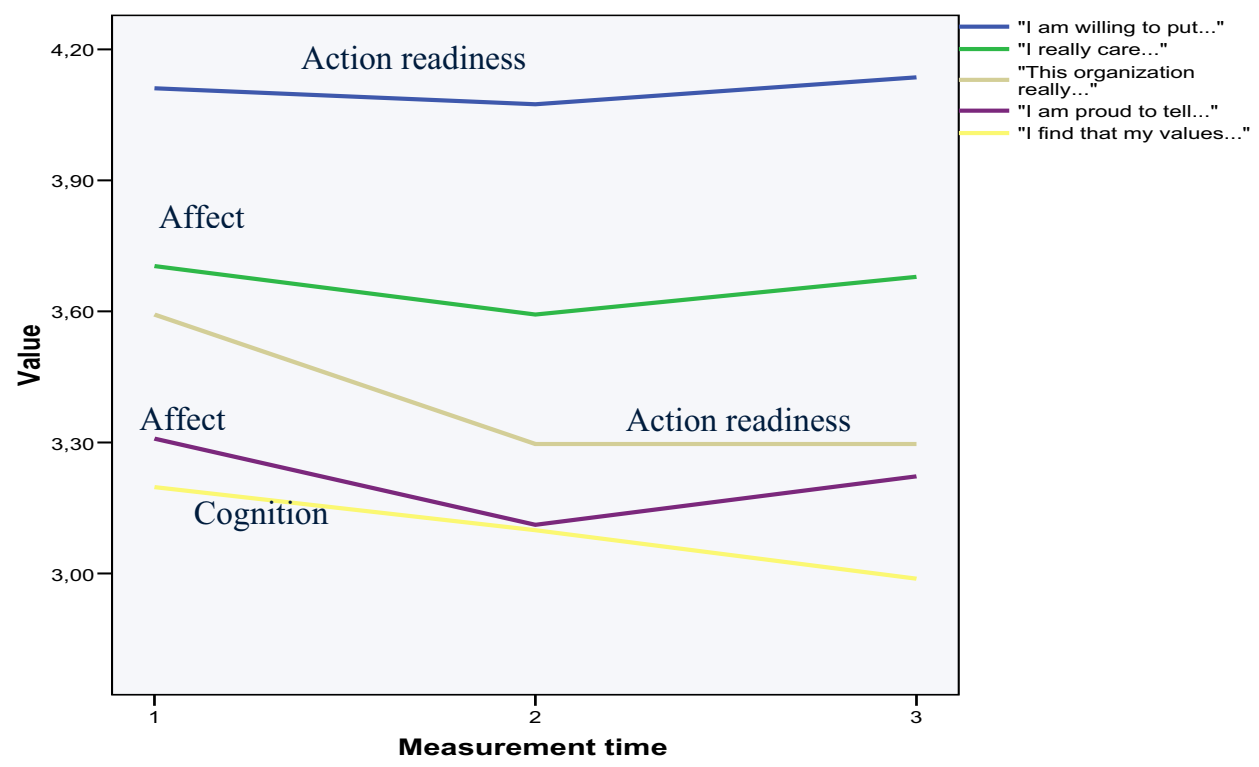

\section{Discussion}

These results are revealing because they show that items reflecting different attitudinal dimensions may show diverging trends between administrations - even on a sample level of analysis. The resulting 'stability' in mean levels of an attitudinal component between T2 and $\mathrm{T} 3$, is then in fact deceitful. If a measure of Affective Commitment had been used instead, the pattern could have been U-shaped instead of the stable pattern we observed with the 5- item OCQ. So it appears that measurement does make a difference. However, we should not overestimate its effect. An attitudinal measure of $\mathrm{OC}$ is the net sum (or the latent factor) of items reflecting affect, cognition, and action readiness. It is known from fundamental social psychological research that attitudes can be ambivalent (feelings can contradict each other) or internally inconsistent (e.g., feelings can contradict beliefs; Eagly \& Chaiken, 1993). Our 
conclusion from this exercise is that attitudes need to be measured 'purely', that is, with single-items.

In future research fine-grained and lengthy temporal designs are needed to see what patterns in separate attitudinal dimensions emerge - purely measured - and whether clusters of temporal trajectories can be identified. Existing measures clearly are inappropriate, conceptually (they do not reflect an attitudinal model) and empirically (attitudinal measures are not 'purely' measured and demonstrate questionable convergent validity over time). Future research should focus on OC as an attitude and measure it accordingly over time.

\section{Conclusion}

In this study we aim to find out how existing measures of $\mathrm{OC}$ fit to the attitudinal perspective where $\mathrm{OC}$ is conceived of as a combination of affective, cognitive and behavioral processes. From the most often used scales (affective organizational commitment, the organizational commitment questionnaire, and the psychological attachment questionnaire) we learn that they do not have equal emphasis on the three attitudinal components. That is, the affective organizational commitment scale heavily leans towards affect, and cognition, and does not refer to any behavioral aspect. The same holds for the psychological attachment questionnaire. The OCQ contains many references to specific behaviors like talking, decision quality, and leaving the organization. All in all, the OCQ seems the most appropriate measure from an attitudinal point of view. From inspection of the development of affective, cognitive and action readiness items we have observed that items measuring a single component can still show divergent patterns over time. We conclude that items measuring the separate attitudinal components should measure these aspects specifically (and not tap into the content of other components), and as purely as possible to avoid temporal divergence. This could be reached by using only single items scales. 


\section{References}

Allen, N. J., \& Meyer, J. P. (1990). The measurement and antecedents of affective, continuance, and normative commitment to the organization. Journal of Occupational Psychology, 63, 252-276.

Bauer, T. N., \& Green, S. G. (1994). Effect of newcomer involvement in work-related activities: A longitudinal study of socialization. Journal of Applied Psychology, 79(2), 211-223.

Beck, K., \& Wilson, C. (2000). Development of affective organizational commitment: A cross-sequential examination of change with tenure. Journal of Vocational Behavior, 56, 114-136.

Bozeman, D. P., \& Perrewe, P. L. (2001). The effect of item content overlap on organizational commitment questionnaire-turnover cognitions relationships. Journal of Applied Psychology, 86, 161-173.

Cohen, A. (2007). Commitment before and after: An evaluation and reconceptualization of organizational commitment. Human Resource Management Review, 17, 336-354.

Cohen, A., \& Freund, A. (2005). A longitudinal analysis of the relationship between multiple commitments and withdrawal cognitions. Scandinavian Journal of Management, 21, 329-351.

Mowday, R. T., Steers, R. M., \& Porter, L. W. (1979). The measurement of organizational commitment. Journal of Vocational Behavior, 14(224-247).

Solinger, O. N., Van Olffen, W., \& Roe, R. A. (2008). Beyond the three-component model of organizational commitment Journal of Applied Psychology, 91(1), 70-83.

Vandenberg, R. J., \& Self, R. M. (1993). Assessing newcomers' changing commitments to the organization during the first 6 months of work. Journal of Applied Psychology, $78(4), 557-568$. 


\section{Appendix B}

\section{Notes on reliability and validity in a temporal research context}

\section{Introduction}

Psychometricians agree that the measurement of change is different from the measurement of a single score (Nunnaly \& Bernstein, 1994). Classical Test Theory ${ }^{56}$ - which defines reliable measurement by the proportion of observed score variance that is made up of true score variance (Lord, 1984; McDonald, 1999; Thompson, 2003) - has been criticized for being is static and not suitable to the study of within-person change (Bass, 1962; Cattell \& Ross, 1952; Collins, 2006; Collins \& Cliff, 1990; Cronbach, Gleser, Nanda, \& Rajaratnam, 1972; DeShon, Ployhart, \& Sacco, 1998; Ghiselli \& Haire, 1960; Lord, 1984; Molenaar, 2004; Rogosa, Brandt, \& Zimowski, 1982; Salthouse, Nesselroade, \& Berish, 2006; Tisak \& Tisak, 2000). For example, almost 20 years ago, Collins and Cliff stated that 'The traditional definition of instrument reliability as the ratio of within-time interindividual true score variance to total within-time interindividual variance has little relevance to growth' (Collins \& Cliff, 1990, p. 129). Recently other developmental psychologists have reached the same conclusion: 'There is now considerable evidence that calls into question the adequacy of the classical notion of a fixed true score as an ideal focus of measurement efforts. Theoretical concepts and analytical methods should therefore reflect this shift of thinking if progress is to be made in describing, measuring, and explaining behavior and behavior change' (Salthouse, Nesselroade, \& Berish, 2006, p. 151).

In response to this shortcoming in Classical Test Theory, authors have put forward reliable change criteria (i.e., dynamic true scores) in the panel modeling tradition (Wheaton, Muthen, Alwin, \& Summmers, 1977), in the latent curve modeling tradition (Rogosa, Brandt, \& Zimowski, 1982; Tisak \& Tisak, 2000), in the latent class modeling tradition (Collins, 2001), or used the Guttman simplex (Collins \& Cliff, 1990) or restricted maximum likelihood

\footnotetext{
${ }^{56}$ Generalizability theory has received a similar critique (DeShon, Ployhart, \& Sacco, 1998).
} 
estimation methods (Ployhart, Holtz, \& Bliese, 2002). The problem with these kinds of approaches is that the calculation of true scores - or a dynamic true score - is based on a sample of individuals. An implicit assumption is that all individuals display uniform growth (Collins \& Cliff, 1990; Molenaar, 2004) - or at least have simple and comparable trajectories - and errors of within-subject growth can be calibrated with between-subject information. The assumption of uniform growth is often not warranted in the context of behavioral phenomena (Molenaar, 2004; Priestley, 1989). There is research on identical twins - having homologous neural and genetic compositions - displaying different developmental trajectories unfolding over time (Molenaar, 1999). Other research demonstrates heterogeneous time-based development in genetically identical organisms, even when reared in standardized environments (Edelman, 1987; Molenaar, Boomsma, \& Dolan, 1993). Thus, (dynamic) true score calibration based on information from a sample of individuals is flawed. We need an approach to reliability (and validity) which calibrates errors of measurement on the individual-level.

\section{Criteria for reliability and validity in a temporal research context}

Our definition of temporal reliability is the precision by which a pattern is reproduced. Before we elaborate on this definition and forward our suggestions as to what should constitute a temporal criterion of reliability and validity, we forward two criteria to which a temporal criterion of reliability and validity should answer. The first criterion we have just discussed: it must be calibrated at the individual level. A second requirement to a temporal theory of measurement - and a crucial difference between differential and temporal modes of thought - is that the object of scrutiny must be the temporal pattern. In the epistemology of differential thinking (Slife, 1993, see chapter 1 for an elaboration) it is assumed that time can be studied by analyzing its discrete 'parts'. Congruent with this particularistic treatment of time, differential measurement theory judges the reliability of isolated scores. In contrast, temporal thinking assumes 'connectivity of time', where path-dependency of development is assumed in a way that events, activities and processes are highly intertwined in time (see chapter 1). That is, the reliability of a temporal pattern exceeds analysis of the difference between two time moments. Although - yes - a pattern is a series of changes, it is a very distinct series of changes, which cannot randomly be reordered without destroying its meaning and informative message. A pattern is a unique Gestalt, so to speak, whose particular manifestation we are interested to assess. 


\section{Temporal reliability}

We regard temporal reliability as the precision and accuracy by which a pattern is (re)produced. Our concept of temporal reliability is depicted in Figure 3. Precision means 'the degree of refinement with which an operation is performed or a measurement stated' (Merriam Webster Online dictionary of English, 2009). Accuracy implies the range of imprecision which should be as small as possible for a pattern to be temporally reliable. If the range of imprecision in measurement around the temporal pattern is small (Figure 3A), temporal reliability is high. Temporal reliability is low when the range of imprecision around the trajectory is large. Note that the object of scrutiny in our definition is the pattern. The range of imprecision should therefore be evaluated on pattern-level (i.e., not for every single score), which means that the researcher should find a single metric for a pattern-specific degree of accuracy. Which metric would fit here (e.g., mean, median, maximum, minimum, and so forth) is open to discussion. Further, the definition is phrased in a passive way as to clarify that the locus of reliability is in the instrument, not in the agent. Also note that this conception of reliability can be produced at the population, group- and individual level. For all these different levels of analysis different metrics will apply.

We used the verb '(re)produce' on purpose as it denotes the precision and exactness by which a pattern is produced by a respondent using a particular measurement instrument, but it also denotes the exactness by which a particular researcher can reproduce a particular subset of a trajectory by another subset of the same trajectory. For instance, in Figure 3, the left trajectory (A) is more reliable because it has a lower range of imprecision and the right part of the trajectory can be accurately reproduced from the left part if the trajectory form is set to 'cubic'. One should not speak of 'prediction' in this case because the analysis is posthoc; reproduction is therefore more appropriate to describe the type of inquiry. Prediction is not an appropriate term as it blurs the distinction with predictive validity, which we will discuss later. Reliability can be assessed by reproducing a particular subset of a trajectory by means of another subset of the same trajectory. In contrast, temporal criterion-related validity deals with the prediction of the trajectory of another phenomenon. 
Figure 7.3 A concept of temporal reliability

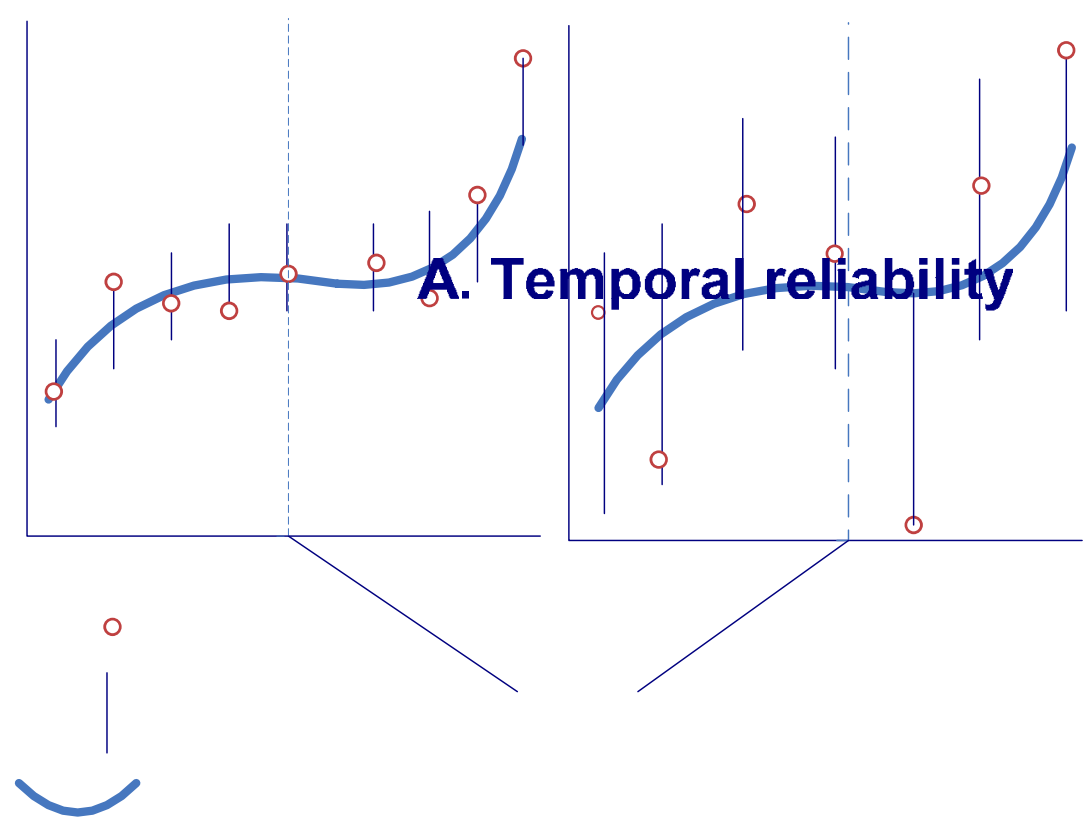

The notion of 'split-half testing' applies to this idea of endogenous reproduction in the sense that one could split the trajectory in half and try to predict the one half with the other. Note that the notion of the split-half test we use here has nothing to do with its meaning in Classical Test Theory. The classical notion of the split-half test deals with correlations between two subsets of a population; our notion of the split-half test deals with subsets of a single pattern.

\section{Temporal validity}

The issue of temporal reliability cannot be judged without considering the concept of validity. Where temporal reliability is about how precisely the pattern is (re)produced, one of questions temporal validity deals with: 'Is this the right pattern?' Temporal validity is the extent to which the trajectory represents the development of the phenomenon under study, and not something else. Thus, whereas reliability deals with the precision of measurement, validity deals with the meaning of marnget.of imprecision 
Types of criterion-related validity in literature There are many types validity (Cattell \& Ross, 1952; Cook \& Campbell, 1979; Cronbach \& Meehl, 1955; Kaplan \& Saccuzzo, 2005; Netemeyer, Bearden, \& Sharma, 2003) but we cannot discuss them all in detail here. We choose to deal with the main types of criterion-related validity which - in practice - is the most often used concept to study the construct validity of a measure (Netemeyer, Bearden, \& Sharma, 2003).

Essential to criterion-related validity is that the referential construct should be external to the focal construct (Cronbach \& Meehl, 1955; Nunnaly \& Bernstein, 1994). That is, the criterion measure has to be an indicator of another phenomenon. Definitions of this form of validity vary greatly. Criterion-related validity has been described as the degree to which a measure corresponds to another measure of interest (Kaplan \& Saccuzzo, 2005). In this definition criterion-related encompasses predictive validity (Nunnaly \& Bernstein, 1994), but also convergent and discriminant validity (Cronbach \& Meehl, 1955; Netemeyer, Bearden, \& Sharma, 2003). The criterion measure has to be theoretically prespecified as there has to be a plausible rationale why to choose a certain criterion. This is why some definitions of criterion-related validity resound: 'a theoretically specified pattern of relations between a measure and a criterion often referred to as a validity coefficient' (Netemeyer et al., 2003, p. $14)$.

Criterion-related validity encompasses a couple of more specific forms of validity, such as concurrent, post-dictive, convergent, discriminant, and nomological validity (Netemeyer, Bearden, \& Sharma, 2003). There is some confusion as to what exactly entails predictive validity as it is often used interchangeably with criterion-related validity. Nunnaly and Bernstein (1994) use predictive validity as the overarching concept which entails covariance between the instrument under study and external instruments which are either administered before (post-dictive validity), during (concurrent validity), or after the focal instrument is administered (predictive validity). In the context of this chapter we will use predictive validity only as 'the ability of a measure to effectively predict some subsequent and temporally ordered criterion' (Netemeyer, Bearden, \& Sharma, 2003, p. 76)).

Convergent validity is the degree to which two measures designed to measure the same construct are related (Netemeyer, Bearden, \& Sharma, 2003, p. 13). The criterion measure in convergent validity is often a previously validated 'golden-standard'. Discriminant validity 'requires that a measure does not correlate too highly with measures from which it is supposed to differ' (Churchill, 1979, p. 413). The last type of criterion validity is nomological validity which denotes the extent to which a measure operates within 
a set of theoretical constructs and their respective measures (Nunnaly \& Bernstein, 1994, p. 135). The latter assesses the extent to which a measure fits 'lawfully' into network of relationships (i.e., a so-called "nomological network", Cronbach \& Meehl, 1955) known in an established body of knowledge. In Table 7.2 we present all the definitions of the different types of criterion-related validity as defined in the classical sense and defined in a temporal sense. Criterion-related validity in temporal context will be discussed in the next section.

In Table 7.1 we present a typology of all the types of criterion-related validity in a temporal context. This typology is useful as it helps to classify and - more importantly simplify all the different kinds of validity. The time element serves to separate 7 different validity types (see Table 7.2) into three chunks: criterion-related validity with a negative lag of effect (when the criterion phenomenon unfolds before the predictor phenomenon), no lag (when the criterion phenomenon unfolds at the same time as the predictor phenomenon), and a positive lag of effect (the criterion phenomenon occurs after the predictor phenomenon).

Table 7.1. A typology of criterion-related validity in a temporal context

\begin{tabular}{cc|c}
\hline $\begin{array}{c}\text { Negative lag of effect (-) } \\
\text { Post-dictive validity }\end{array}$ & $\begin{array}{c}\text { No time lag (o) } \\
\text { Concurrent validity }\end{array}$ & $\begin{array}{c}\text { Positive lag of effect (+) } \\
\text { Predictive validity }\end{array}$ \\
\cline { 2 - 3 } & \multicolumn{2}{c}{ Nomological validity } \\
\cline { 2 - 3 } & $\begin{array}{c}\text { Convergent } \\
\text { validity }\end{array}$ & $\begin{array}{c}\text { Discriminant } \\
\text { validity }\end{array}$ \\
\hline
\end{tabular}




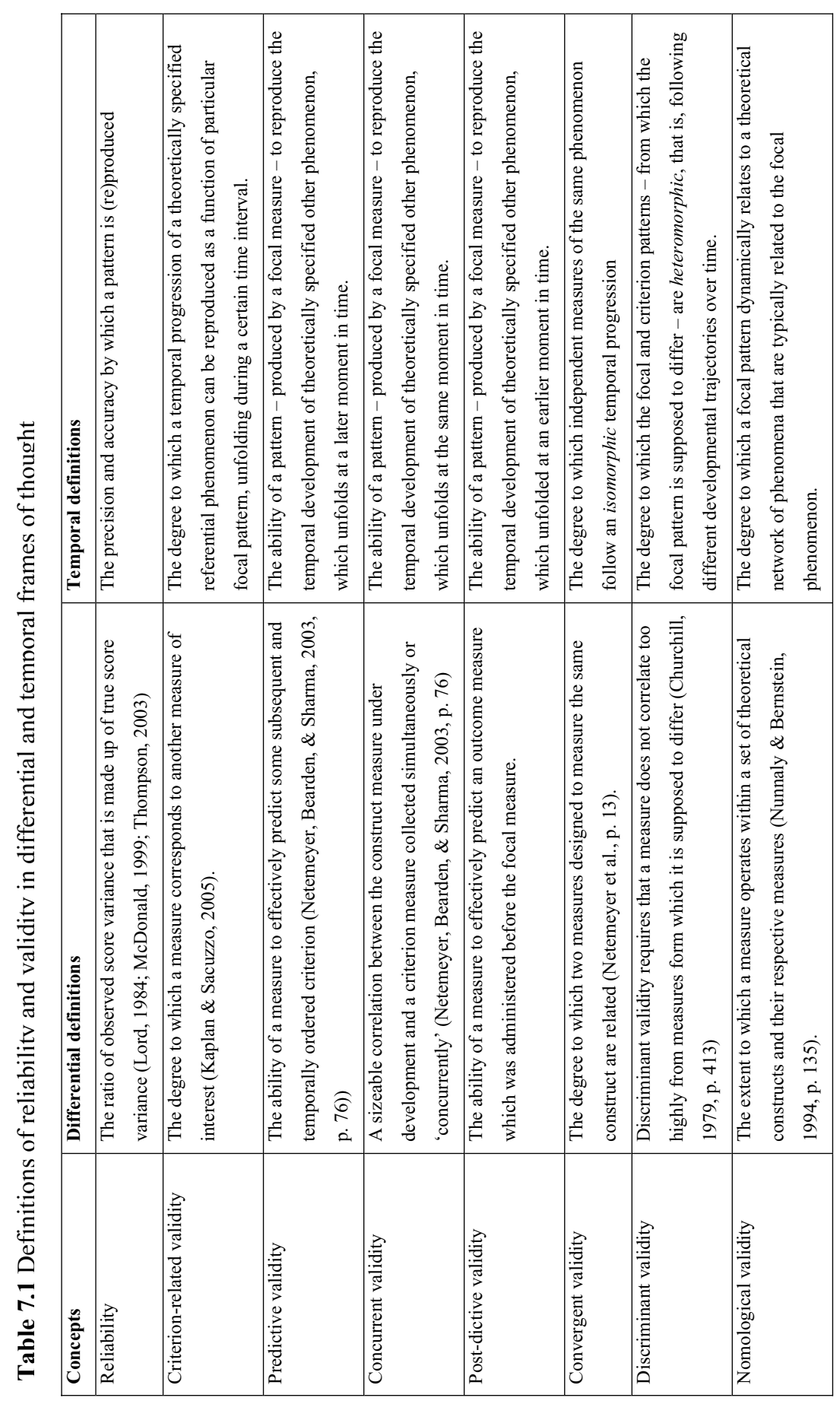


Criterion-related validity in a temporal context In a temporal research setting criterion-related validity is the degree to which a temporal progression of a theoretically specified referential phenomenon can be reproduced as a function of particular focal pattern, unfolding during a certain time interval. In other words, it is the extent to which the focal pattern is meaningfully related to a criterion pattern. Note a couple of specifications in this definition. Reproduction means that the trajectory as observed in the criterion phenomenon could be 'drawn' from the focal trajectory. Temporal criterion-related validity is therefore a 'morphic' type of validity, because one is 'matching' or 'mirroring' pattern forms and shapes. For example, one can draw the height, the direction, the shape, the volatility (to name a few) of the criterion pattern on the basis of a focal pattern (see Figure 7.4). Mind that 'reproduction' is always specified to a certain time frame and that the time gap in between the criterion and the focal phenomenon is of crucial importance (George \& Jones, 2000; Monge, 1990; Roe, 2008a). These types of predictions are unusual in our domain, but certainly applicable given the current progress in the field of statistics. Crucial in these types of analyses is that one should be able to predict and reproduce the developmental progression of theoretically meaningful criterion as a function pattern of the focal phenomenon. Note that we speak of reproduction and not about between-subject 'covariance'. This means that criterion-related validity can be demonstrated at the population, group, and individual level of analysis.

Figure 7.4 Example of temporal predictive validity

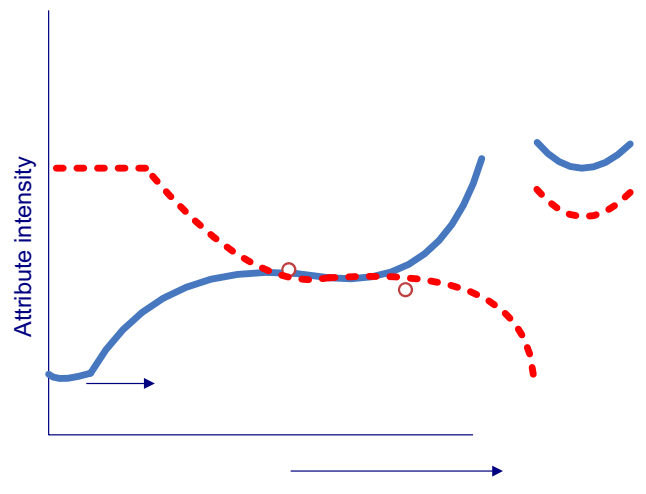

We define predictive validity as the ability of a pattern - produced by a focal measure - to reproduce the temporal development of theoretically specified other phenomenon, which unfolds at a later moment in time. Concurrent temporal validity is the same type of validity, 
specified to criterion pattern unfolding at the same time and post-dictive temporal validity is specified to a criterion pattern at an earlier moment in time. For an overview definitions, see Table 7.1.

Figure 7.4 shows how predictive temporal validity could look like in the case of organizational commitment predicting turnover intention. Turnover intention is a particularly good time-varying criterion to use when testing the temporal validity of a specific organizational commitment measure as dynamic activity in organizational commitment has been found to be inversely related to dynamic activity in turnover intention (Bentein, Vandenberg, Vandenberghe, \& Stinglhamber, 2005; Cohen \& Freund, 2005; KammeyerMueller, Wanberg, Glomb, \& Ahlburg, 2005). For explanatory purposes we have added a time lag of effect. It is as yet unsure whether this lagged effect really occurs. Strictly speaking, if there is no lag of effect, we should speak of concurrent validity instead of predictive validity.

Example of concurrent temporal validity is when the development of a focal phenomenon is isomorphic to a conceptually close other phenomenon from which the same trajectory shape can reasonably be expected (e.g., Figure 7.5A). For example, it should be expected that organizational commitment and job satisfaction should follow the same type of trajectory as these phenomena ${ }^{57}$ are explained by the same predictors (Currivan, 1999; Farkas \& Tetrick, 1989).

The same principle holds for assessing convergent, nomological, and discriminant validity of a measure in a temporal context. If developmental progressions of two measures are an exact match, it is likely that the measures tap into a single underlying phenomenon (see Figure 7.5A). Convergent validity is therefore the degree to which independent measures of the same phenomenon follow an isomorphic temporal progression during a certain time interval. The degree to which the focal and criterion patterns - from which the focal pattern is supposed to differ - are heteromorphic, that is, following different developmental trajectories over time (see Figure 7.5B).

If the trajectory of a criterion measure of another phenomenon (such as job satisfaction) is related to a measure of the focal phenomenon (organizational commitment) in a way that confirms earlier findings in literature, nomological validity has been demonstrated. Unfortunately, we know little about temporal interrelationships. Thus, it will take a while

\footnotetext{
${ }^{57}$ It should be noted that this has never been demonstrated. Predictors of job satisfaction and organizational commitment have found in differential 'covariance' studies.
} 
before we can realistically speak of demonstrating nomological validity in a temporal research context.

Figure 7.5 Temporal convergent and discriminant validity

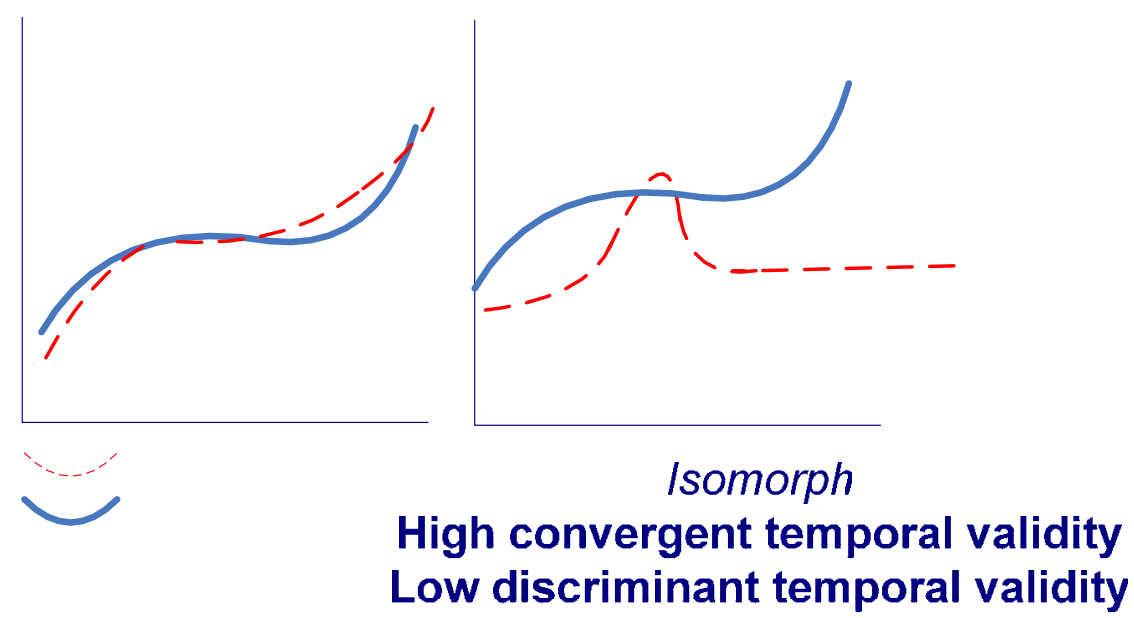

\section{A 5 Caveats}

A cautionary note on this heuristic approach is that in case of clear structural breaks in the time series (i.e., when the before and after the structural break patterns are fundamentally different), the determination of temporal reliability should be split into parts (Bai \& Perron, 2003). This means that temporal reliability could differ before and after the structural break. That is, temporal reliability is not a 'constant'. It should rather be seen as versatile, and can vary with the trajectory. Note that the same holds for the determination of temporal validity. As is common in literature on response-shift biases, like scale recalibration (beta change) or construct redefinition (gamma change) the validity of a particular trajectory can be different in the first half compared to the second half of the trajectory.

Additionally, the kind of trajectory specified in the 'calibration' of temporal reliability depends on the judgment of the researcher. We must acknowledge that there is also a 'range of imprecision' in the judgment of the researcher regarding which trajectory shape is specified. As a general note, the more data points available, the easier it gets to specify the

Observed focal pattern

Developmental pattern of a time-varying referenti: 
trend function. The use of rapid and frequent succession of observations is highly recommended - if not to say indispensable - in this kind of temporal-dynamic research.

As a general note, the generalizability of temporal progressions should also be assessed as patterns of the same individuals who belong to the same groups and samples may not remain identical over time (Roe, 2008b). For example, the cycle and intensity of weekly performance is expected to change as a function of aging. Likewise, we may see varying patterns of the same individuals measured at different calendar times. For instance, organizational commitment dynamics during Summer or Christmas leave may be different from samples in other time slots.

For construct validation purposes, it would be useful to detect phenomenon-specific 'temporal norms' (Roe, 2008b), which can be conceived of as temporal progressions that function as 'ideal pattern' with an error band, defined by the variation of earlier observations around trend functions (e.g., growth curves for children, learning curves for students, etcetera). Temporal norms can also be assessed differently according to the different levels of analysis: population, group, and individual level.

\section{References}

Bai, J., \& Perron, P. (2003). Computation and analysis of multiple structural change models. Journal of Applied Econometrics, 18, 1-22.

Bass, B. M. (1962). Further evidence on the dynamic character of criteria. Personnel Psychology, 15, 93-97.

Bentein, K., Vandenberg, R. J., Vandenberghe, C., \& Stinglhamber, F. (2005). The role of change in the relationship between commitment and turnover: A latent growth modeling approach. Journal of Applied Psychology, 90(3), 468-482.

Cattell, R. B. (1964). Validity and reliability: A proposed more basic set of concepts. Journal of Educational Psychology, 55, 1-22.

Churchill, G. A., \& Iaccobucci, D. (2002). Marketing research methodological foundations (8th ed.). Forth Worth, TX: Hartcourt College.

Cohen, A., \& Freund, A. (2005). A longitudinal analysis of the relationship between multiple commitments and withdrawal cognitions. Scandinavian Journal of Management, 21, 329-351.

Collins, L. M. (2001). Reliability for static and dynamic categorical latent variables: Developing measurement instruments based on a model of the growth process. In L. M. Collins \& A. G. Sayer (Eds.), New methods for the analysis for the analysis of change (pp. 273-288). Washington, DC: American Psychological Association.

Collins, L. M. (2006). Analysis of longitudinal data: The integration of theoretical model, temporal design, and statistical model. Annual Review of Psychology, 57, 505-528.

Collins, L. M., \& Cliff, N. (1990). Using the longitudinal Guttman simplex as a basis for measuring growth. Quantitative Methods in Psychology, 108(1), 128-134. 
Cook, T. D., \& Campbell, D. T. (1979). Quasi-experimentation: Design \& Analysis issues for field settings. Chicago: Rand McNally.

Cronbach, L. J., Gleser, G. C., Nanda, H., \& Rajaratnam, N. (1972). The dependability of behavioral measurements: Theory of generalizability of for scores and profiles New York: Wiley.

Cronbach, L. J., \& Meehl, P. E. (1955). Construct validity in psychological tests. Psychological Bullitin, 52, 93-96.

Currivan, D. B. (1999). The causal order of job satisfaction and organizational commitment in models of employee turnover. Human Resource Management Review, 9(4), 495524.

DeShon, R. P., Ployhart, R. E., \& Sacco, J. M. (1998). The estimation of reliability in longitudinal models. International Journal of Behavioral Development, 22(3), 493515.

Edelman, G. M. (1987). Neural darwinism: The theory of neuronal group selection. New York: Basic.

Farkas, A.-J., \& Tetrick, L.-E. (1989). A three-wave longitudinal analysis of the causal ordering of satisfaction and commitment on turnover decisions. Journal of Applied Psychology, 74(6), 855-868.

George, J. M., \& Jones, G. R. (2000). The role of time in theory and theory building. Journal of Management, 26(4), 657-684.

Ghiselli, E. E., \& Haire, M. (1960). The validation of selection tests in the light of dynamic character character of criteria. Personnel Psychology, 13(225-231).

Kammeyer-Mueller, J. D., Wanberg, C. R., Glomb, T. M., \& Ahlburg, D. (2005). The role of temporal shifts in turnover process: It's about time. Journal of Applied Psychology, 90(4), 644-658.

Kaplan, R. M., \& Saccuzzo, D. P. (2005). Psychological testing: Principles, applications, and issues. Belmont, CA: Thomson Whadsworth.

Lord, F. M., \& Novick, M. R. (1968). Statistical theories of mental test scores. Reading, MA: Addison-Wesley.

McDonald, R. P. (1999). Test theory: A unified treatment. Mahwah, NJ: Lawrence Erlbaum.

Merriam Webster Online dictionary of English. (2009). http://www.merriam-webster.com/ retrieved on June 1, 2008.

Molenaar, P. C. M. (2004). A manifesto on psychology as idiographic science: Bringing the person back into scientific psychology, this time forever. Measurement, 40, 201-218.

Molenaar, P. C. M., Boomsma, D. I., \& Dolan, C. V. (1993). A third source of developmental differences. Behavior genetics, 23(519-524).

Molenaar, P. C. M., \& Raijmakers, M. E. J. (1999). Additional aspects of third source variation for the genetic analysis of human development and behavior. Twin Research, 2, 49-52.

Monge, P. R. (1990). Theoretical and analytical issues in studying organizational processes. Organization Science, 1(4), 406-430.

Netemeyer, R. G., Bearden, W. O., \& Sharma, S. (2003). Scaling procedures: Issues and applications. Thousand Oaks, CA: Sage.

Nunnaly, J. C. (1978). Psychometric theory. New York: McGraw-Hill.

Nunnaly, J. C., \& Bernstein, I. H. (1994). Psychometric theory (3rd ed.). New York: McGrath-Hill.

Ployhart, R. E., Holtz, B. C., \& Bliese, P. D. (2002). Longitudinal data analysis: Applications of random coefficient modeling to leadership research. The Leadership Quarterly, 13, 455-486. 
Priestley, M. B. (1989). Nonlinear and nonstationary time series analysis. London: Academic.

Roe, R. A. (2008a). Time applied psychology: The study of 'what happens' rather than 'what is'. European Psychologist, 13(1), 37-52.

Roe, R. A. (2008b). Time and the study of behavior in organizations. Implications for assessment, selection, and development. Seminar at SHL, Thames Ditton, September 9, 2008.

Rogosa, D. R., Brandt, D., \& Zimowski, M. (1982). A growth curve approach to the measurement of change. Psychological Bullitin, 92(18-38).

Salthouse, T. A., Nesselroade, J. R., \& Berish, D. E. (2006). Short-term variability in cognitive performance and the calibration of longitudinal change. Journal of Gerontology: Psychological Sciences, 61B(3), 144-151.

Slife, B. D. (1993). Time and psychological explanation. Albany, NY: State University of New York.

Thompson, B. (Ed.). (2003). Score reliability: Contemporary thinking on reliability issues. Thousand Oaks, CA: Sage.

Tisak, J., \& Tisak, M. S. (1996). Longitudinal models of reliability and validity: A latent curve approach. Applied Psychological Measurement, 20(3), 275-288.

Wheaton, B., Muthen, B., Alwin, D. F., \& Summmers, G. (1977). Assessing reliability and stability in panel models. In D. R. Heise (Ed.), Sociological methodology (pp. 84136). San Fransisco, CA: Jossey Bass. 


\section{Appendix C}

\section{A summary of Pilot 2}

\section{Objectives}

Pilot 2 had four parallel purposes. First, we wanted to assess whether LOCUST would be suited to study phenomena other than attitudes in the workplace. Second, we wanted to check performance of our system in terms of operational reliability. Third, we intended to do a field experiment to see whether the GTR including the corrective response procedure (i.e., retrospective adjustments in the attitudogram) would create systematic differences in observed temporal patterns compared to 'conventional' response procedures (i.e., not showing past responses and lettering the researcher reconstruct the pattern). After all, this observation directly relates to the sensitivity to change and the robustness against re-use requirement (R2 and R3 in the PoR; Table 4.1). Fourth, we wanted to relate language proficiency development and the final grade to the time-varying pursuit of multiple goals (i.e., work-related goals, number of goals at the same time, duration of those goals), using (time-varying) commitment to the goal of learning Dutch as moderator (see Berenbroek, 2007). The effect of the pursuit multiple goals is investigated together with the role of commitment in this relationship. Commitment represents the degree to which a person considers a goal to be important, is determined to reach and is unwilling to abandon the goal. Reminders to participate were sent on a weekly basis to students following Dutch classes at the Language Center in Maastricht. 18 classes were approached and 57 students filled out the questionnaire more than three times (Berenbroek, 2007, p. 2).

\section{Application}

The perceived development of language proficiency (speaking, listening, reading) took the place that was originally meant for organizational commitment (affect, cognition, action readiness) in the LOCUST system. Work- and non-work related goals were entered as 'events' in the LOCUST system. The interactive event-tracking system on the events-page was used to track the duration of these goals. Finally, the mood-check page was used to 
measure the development of commitment to learning Dutch. So, LOCUST was used with a different set of constructs (see chapter 4 for the LOCUST architecture).

\section{Sample}

The total number of completed LOCUST sessions was 514. Students were spread out over 18 classes of different length, level, and nationality (of which 68\% German); $93 \%$ of the students studied at Maastricht University; mean age was 23 and 97\% was female. Despite all these technical problems, we still managed to get 51 participants to respond more than 3 times $(\mathrm{N}$ total $=514)$. Attrition was too high to perform the quasi-experimental study on the functionality of the GTR feature.

\section{Results}

Results of the study show that the level of language proficiency is affected by the number of goals an individual is engaged in. Multiple goals in parallel imply parallel processes, in which different phases overlap or are pursued consecutively. Resources as time and effort are divided among the number of goals that are pursued in parallel. In this process prioritization plays a key role. The higher the number of goals the more the performance on the other goal is negatively affected. Goal duration and the distinction between exam-related goals or not exam-related goals do not appear to affect the performance on the goals of learning Dutch.

Commitment towards the goal of learning Dutch is influenced by characteristics of other goals pursued in parallel. Short term compared to long term goals have a negative impact on the commitment towards learning Dutch. Commitment to learning Dutch in turn is positively related to the performance on language proficiency. Some moderating effect occurs between the number of goals and the final grade, but for the other variables the moderating effect is not significant. Interestingly, the grand mean development of both language proficiency and goal commitment display patterns that are congruent with substantive theory on these phenomena. That is, learning Dutch demonstrates a classic exponential learning curve and goal commitment shows a classic U-shaped pattern, which is congruent with literature on pacing styles in a context of working with a deadline (Gevers, Rutte \& van Eerde, 2006). 
Figure 8.15. Development language proficiency and goal commitment (Berenbroek, 2007)
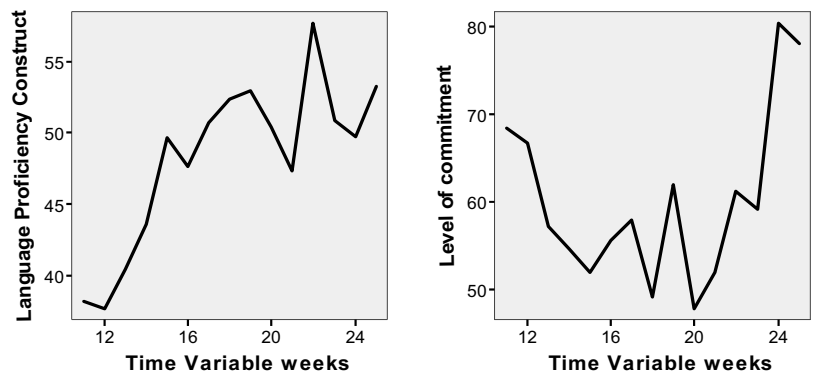

\section{Conclusion}

Although the quasi-experiment could not be executed due to technical malfunctions in the LOCUST system, we could still learn that LOCUST is potentially applicable to a wide range of temporal phenomena, one of which is the development of language proficiency, commitment towards learning Dutch, and tracking the real-time adding and dropping of personal goals. In a more general sense, this study has shown that LOCUST can be applied to discover the development of phenomena. Patterns have shown construct validity like the goal commitment pattern, which showed a U-shaped pattern which is supported by substantive theory on meeting deadlines (Gevers, Rutte \& van Eerde, 2006). Patterns have shown criterion-related validity in the sense that the development of language proficiency, goal commitment, and adding and dropping personal goals are meaningfully related.

\section{References}

Berenbroek, A. (2007). The pursuit of multiple parallel goals over time: Longitudinal investigation of language proficiency development. Unpublished master's thesis. Maastricht: Maastricht University.

Gevers, J. M. P., Rutte, C. G., \& van Eerde, W. (2006). Meeting deadlines in work groups: Implicit and explicit mechanisms, Applied Psychology: An International Review, $55(1), 52-72$. 


\section{Appendix D}

\section{A summary of Pilot 3}

\section{Objectives}

This study was performed in cooperation with Stefan Selders ${ }^{58}$ (2009). The study had three main purposes. The first purpose was to perform a 'stress-test' to test how the paper-andpencil LOCUST format (LOCUST-PP) performs in a context of very rapid and frequent longitudinal measurements (i.e., 2 measurements per day, 7 days a week, for a period of 4 weeks). The second purpose was to investigate how the attitudinal measure of commitment (affect, cognition, and action readiness) behaves temporally over time. Specifically, we wanted to validate the attitudinal conceptualization of commitment in a temporal research context (see R1 in the PoR; Table 4.1). The third purpose of this study was to look at the temporal validity of commitment patterns, that is, to see how commitment patterns relate to other time-varying constructs, like job satisfaction, mood, and critical events.

\section{Sample}

The study consisted of a sample of 18 employees working in two plants of a German horticulture and gardening services firm. The firm employs around 35 employees, some which are seasonal workers. Among the 18 participants, 10 were male, 8 were female. Their age ranged from 18 to $57(M=35.8)$ and their tenure from 1 to 28 years $(M=7.72$ years); 9 out 18 were higher educated (i.e., college of university); 15 worked full-time and 3 part-time. Participation was completely voluntary. Because Stefan Selders was acquainted to most of them, we took great care and extra measures to ensure anonymity (e.g. by having 3 other people judge the events, and letting another person collect the data). The timing of the sample was deliberately set one week prior to the opening of a new plant until three weeks afterwards. We did so to be able to see some 'movement' in the patterns. Measures were taken twice a day, 7 days per week for a total time of 4 weeks. This makes a total number of 56 time moments! The paper-and-pencil variant (LOCUST-PP; see chapter 4) were pasted

\footnotetext{
${ }^{58}$ This was project initiated and supervised by Omar Solinger and executed by student Stefan Selders in the context of a master's thesis. Unfortunately, he has not been able to hand in his thesis yet. We still refer to his work to credit his contributions.
} 
together in a nice booklet along with a pencil, to be collected at the end of the 4 weeks. Survey items were all translated to German.

\section{Analysis}

Critical events were rated according to the idea of 'affective events' (Fuller et al., 2003; Weiss \& Cropanzano, 1996). Three independent native German speakers coded the events according to the rating scheme defined in Table 5, with example verbatims. Coder ratings were highly similar. Two coders assigned identical values in $92.4 \%$ of the cases. In 56 cases coders did not agree; in these cases they were asked to reach a consensus rating. Temporal relations among constructs were assessed via dynamic correlations.

Table 9.5 Events Severity Rating Scheme (in Selders, 2009)

\begin{tabular}{|c|c|c|}
\hline Rating & Description & Example verbatims \\
\hline 3 & $\begin{array}{l}\text { Event described positively with high degree of severity, } \\
\text { use of thrilled language }\end{array}$ & $\begin{array}{l}\text { 'High volume contract won, yeah!', 'My } \\
\text { boyfriend proposed to me last night ;-)', } \\
\text { 'Strike! I finally got a new car' }\end{array}$ \\
\hline 2 & $\begin{array}{l}\text { Event described positively with a moderate degree of } \\
\text { severity, interpersonal issues }\end{array}$ & $\begin{array}{l}\text { 'Colleague(s) were nice to me', 'Boss patted } \\
\text { me on the back', 'Going out for a drink with } \\
\text { colleagues after work' }\end{array}$ \\
\hline 1 & $\begin{array}{l}\text { Event description positively with some/low degree of } \\
\text { severity }\end{array}$ & $\begin{array}{l}\text { 'Found a } 1-€ \text { coin on my way to work', } \\
\text { 'Weather is great' }\end{array}$ \\
\hline $\mathbf{0}$ & $\begin{array}{l}\text { Neither description of positive/negative event, nor } \\
\text { severity; Absence of a comment }\end{array}$ & $\begin{array}{l}\text { 'Nothing has happened', 'Served customers } \\
\text { today', 'Had to water flowers and plants' }\end{array}$ \\
\hline-1 & $\begin{array}{l}\text { Event described negatively with some/low degree of } \\
\text { severity }\end{array}$ & $\begin{array}{l}\text { 'My car wouldn't start', 'Forgot my cell } \\
\text { phone today', 'Mother-in-law visiting' }\end{array}$ \\
\hline-2 & $\begin{array}{l}\text { Event described negatively with moderate degree of } \\
\text { severity, interpersonal issues }\end{array}$ & $\begin{array}{l}\text { 'Researcher complained due to people on } \\
\text { coffee break', 'Bridging day holiday plans } \\
\text { cancelled, colleague called in sick' }\end{array}$ \\
\hline-3 & $\begin{array}{l}\text { Event described negatively with high degree of severity, } \\
\text { use of exasperated language }\end{array}$ & $\begin{array}{l}\text { 'I totally messed up a delivery, customer } \\
\text { complained to supervisor', 'Stressed OUT! }\end{array}$ \\
\hline
\end{tabular}

\section{Results}

Almost all the 18 employees in the horticulture firm participated well until the $56^{\text {th }}$ measurement. The total number of responses was 741 (out of 1008). This means that subjects filled out $73 \%$ of the sessions. This is remarkably high. Results were promising and full of insights rarely seen before. For example, there was a nice cyclical trend visible in the mean development of commitment across weeks - see the purple line in Figure 9.16. That is, on Monday commitment is high and generally declines to its lowest point on Friday and Saturday. On a Sunday commitment rises quickly to reach the observed high levels again on Monday. And then cycle repeats itself. These findings are in line with research on weekly cycles of work and rest (Zijlstra \& Rook, 2009). Had we not used the LOCUST methodology, 
we doubt we could have observed this kind of information. The figure also shows that the attitudinal three-facet operationalization of organizational commitment is a success as the facets are non-redundant over time (see dynamic correlations ${ }^{59}$, Table 9.5), yet combine to meaningfully represent a commitment toward the organization. Moreover, the facets behave as expected. For example, standard deviations of the affective component are significantly higher than cognition and action readiness (Van Ravestein, 2008) ${ }^{60}$.

Figure 9.16. Weekly cycles in organizational commitment (in van Ravestein, 2008)

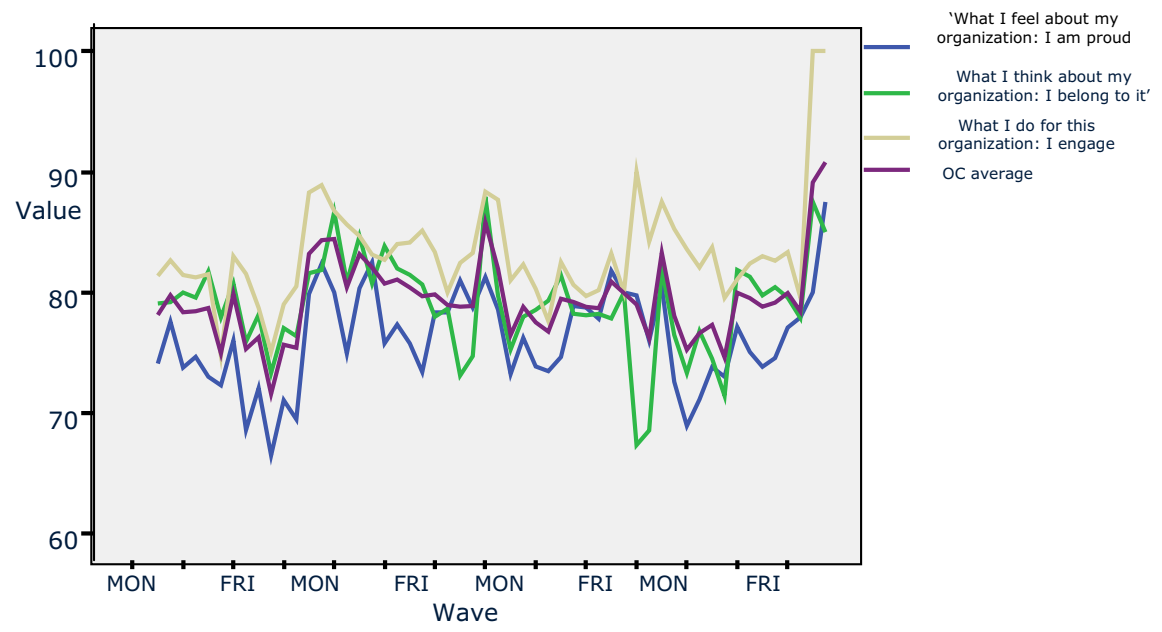

\section{Conclusion}

This study was executed using the LOCUST-PP variant. Results are highly promising as we have been able to successfully track eighteen employees for a period of four weeks with measures taken twice a day. A longitudinal design with such high density and high frequency (the essence of HDRM) has never been performed on the development of job attitudes before. The results show highly interesting temporal aspects of $\mathrm{OC}$ as we have discovered weekly cycles, significant temporal relations with the incidence of affective events, mood and job satisfaction trajectories. This indicates a high degree of criterion-related validity of the trajectories yielded by the LOCUST measurement system.

\footnotetext{
${ }^{59}$ Calculation of dynamic correlations is based on a person-period dataset $(\mathrm{N} * \mathrm{t}=741)$

${ }^{60}$ Carine van Ravestein analyzed some the data by Stefan Selders in the context of her master's thesis. The project was initiated and supervised by Omar Solinger.
} 
Table 9.6. Dynamic correlations between affect, cognition, and action readiness $(\mathrm{N}=741)$

\begin{tabular}{|c|c|c|c|c|c|c|c|}
\hline & 1 & 2 & 3 & 4 & 5 & 6 & 7 \\
\hline $\begin{array}{l}\text { 1. Organizational Commitment mean } \\
\text { 2. Affect }\end{array}$ & 1 & & & & & & \\
\hline $\begin{array}{l}\text { What I feel: I am proud of this } \\
\text { organization. }\end{array}$ & $.81 * *$ & 1 & & & & & \\
\hline $\begin{array}{l}\text { 3. Cognition } \\
\text { What I think: I am part of this } \\
\text { organization, I belong to it }{ }^{61} \text {. }\end{array}$ & $.82 * *$ & $.42 * *$ & 1 & & & & \\
\hline $\begin{array}{l}\text { 4. Action readiness } \\
\text { What I do: I engage for this } \\
\text { organization. }\end{array}$ & $.80 * *$ & $.40^{* *}$ & $.61^{* *}$ & 1 & & & \\
\hline 5. Affective events (critical incidents) & $.36^{* *}$ & $.42 * *$ & $.20 * *$ & $.21 * *$ & 1 & & \\
\hline $\begin{array}{l}\text { 6. How satisfied are you with your } \\
\text { Job? }\end{array}$ & $.74 * *$ & $.61^{* *}$ & $.57^{* *}$ & $.60^{* *}$ & $.40 * *$ & 1 & \\
\hline 7. Mood & $.68^{* *}$ & $.60^{* *}$ & $.49 * *$ & $.55^{* *}$ & $.60^{* *}$ & $.75^{* *}$ & 1 \\
\hline
\end{tabular}

** = significant at the .01 level

\section{References}

Fuller, J. A., Fisher, G. G., Jeffrey, M. S., Spitsmüller, C., Russell, S. S., \& Smith, P. C. (2003). A lengthy look at the daily grind: Time series analysis of events, mood, stress, and satisfaction. Journal of Applied Psychology, 88(6), 1019-1033.

Selders, S. (2009). The temporal relation between affective events, mood and work attitudes: A high-density study. Unpublished Master's thesis. Maastricht University: Maastricht.

Weiss, H. M., \& Cropanzano, R. (1996). Affective Events Theory: A theoretical discussion of the structure, causes, and consequences of affective experiences at work. In B. M. Staw \& L. L. Cummings (Eds.), Research in organizational behavior: An annual series of analytical essays and critical reviews (Vol. 18, pp. 1-74). Greenwich, CA: JAI.

Zijlstra, F. R. H., \& Rook, J. W. (2009). The weekly cycle of work and rest: A diary study. In R. A. Roe, M. Waller \& S. R. Clegg (Eds.), Time in organizational research. London: Routledge.

\footnotetext{
${ }^{61}$ Original items were in German. These are literal translations of German items.

Was ich gerade, d.h. genau in diesem Moment fühle: Ich bin stolz auf diese Firma (Organisation)

Wat ich gerade, d.h. genau in diesem Moment denke: Ich bin ein Teil dieser Firma (Organisation), ich gehöre dazu.

Was ich gerade, d.h. genau in diesem Moment mache: Ich engagiere mich in dieser Firma (Organisation)
} 


\section{Appendix E}

\section{A lay conception and structure of organizational commitment \\ Summary of Valk (2006)}

\section{$1 \quad$ Purpose}

This research was initiated out of a desire to understand how organizational commitment is generally conceived of by employees. That is, we wanted to understand the conceptual domain of organizational commitment (OC) and what constitutes its conceptual boundaries to lay people. There are three reasons to investigate this. First, there is a lot of confusion in lay people on the distinction between OC, job involvement, career commitment. Second, there is no measure of commitment which is able to capture the essential elements of it in a single question. That is, we wish to find out how commitment can be measured and which items are potentially suitable to use in a measure of OC. For this purpose we need to understand to what adjectives commitment is generally associated. Another reason to study the conceptual domain of OC is the problem of construct redefinition (gamma change). In chapter 4 we elaborate on this issue and have forwarded a potential solution which is called the 'gamma change detection feature'. In this feature change in the understanding of OC can be captured by assessing movement on a 'semantic map' in a dimensional space.

\section{Methods}

Adjective generation The research consists of three chronological steps: adjective generation, assessing the dimensional space and assessing the relative distance between the adjectives, and lastly reverting back to the commitment concept by asking respondents to what extent a particular adjective is associated with organizational commitment, and its neighboring constructs such as job involvement, career commitment, and work ethic. First, we find out how OC is conceived of by lay people (employees) by performing an associative task (Study 1). In this study we asked 69 respondents from a wide range of Dutch companies to complete the following sentence with 5 adjectives 'The attitude of an employee which shows commitment towards his or her company can best be described as '...'. The next step 
was creating piles of synonymous adjectives. For each pile we chose an adjective which would best represent it. Adjectives were chosen on the basis of frequency. What resulted was 37 adjectives comprising the 'associative structure' of organizational commitment.

Card sorting To assess the relative distance and the dimensionality of the "semantic space', we set out a second study with a different group of 65 subjects (33 women and 32 men; 39 of them were students, 26 were employees). Following Lunt (Lunt, 1991), each of the subjects were given 37 cards with adjectives written on them and were asked to make associative groupings (i.e., piles). We used this information to invert co-occurrence in the same pile to a distance matrix. We then calculated Euclidian distances using Multidimensional scaling (using ALSCAL in SPSS). To check for robustness of the solution we made separate matrices for employees and students and for males and females. A Mantel's test showed a correlation of .79 between the semantic maps of students and employees $(p$ $<.001)$, and a correlation $.82(p<.001)$.

Semantic boundaries The final studies was another sample of 51 subjects (UM students and 6 subject matter experts) who rated all 37 words on a 1-5 scale to what extent is was associated with organizational commitment, job involvement, career commitment, and work ethic. This was done according to the approach to content validation as advocated by Hinkin and Tracey (1999).

\section{Results}

In this section we describe the conceptual domain, as represented by various adjectives which are associated with OC. Generally, we observed that commitment is divided into two dimensions: one ranging from actions to feelings, and the other from group-orientedness to task-orientedness. Figure 10.1 displays a two-dimensional space in the semantic map, which was confirmed by a scree-plot of residual stress values. The two-dimensional solution considerably aided the interpretation of the 'semantic map'. The dimensional space of OC turned out to be indicative of a range of value orientations ranging from a group-orientation (left side) to a task-orientation (right side). The y-axis was difficult to interpret. We interpreted it as a range from actions (bottom) to feelings (top). The semantic map seems topheavy in the lower right quadrant, which would suggest that a lay conception of commitment is slanted toward taking task-oriented action. However, the third study demonstrated that these very adjectives were almost all significantly higher associated with neighboring constructs, like job involvement, work ethic, and career commitment. The adjectives in the 
lower left quadrant (group-oriented action) were significantly higher associated with OC compared to neighboring constructs. The results are presented Table 10.1. The adjectives are ordered from most highly rated associated with OC to lowest rated association with OC.

Figure 10. 1. A semantic map of organizational commitment (translated to English)

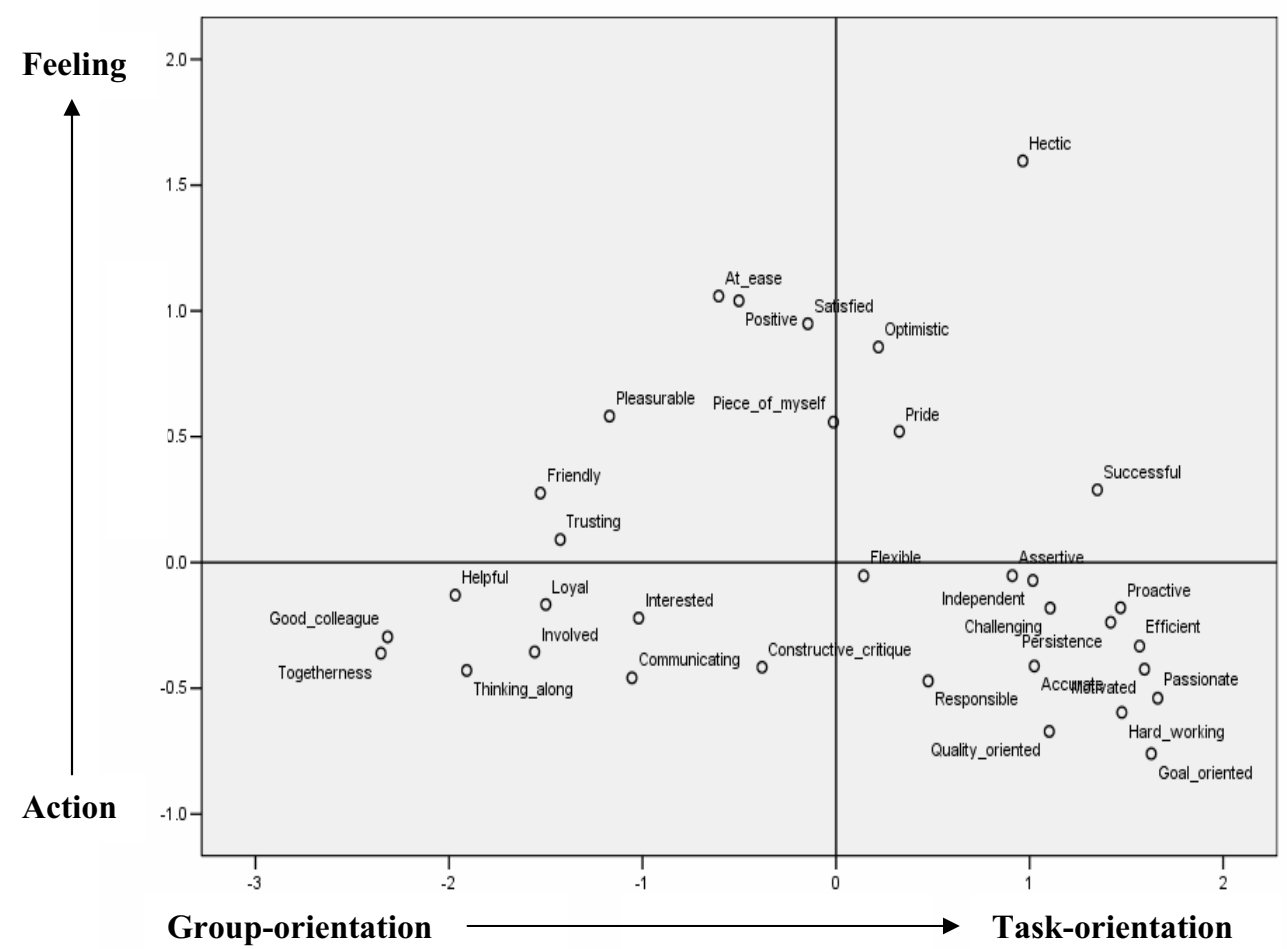

\section{Conclusion}

The aim of this study was to explore the conceptual domain of OC, as conceived by workers and students (lay men), typically approached as subjects for commitment studies. We found that the conceptual domain can be described by two dimensions. One ranging from group- to task-orientation, and the other from actions to feelings. A lay perception of OC can therefore be described as mainly an action-prone group-orientation, but also as a range of positive feelings associated with the being part of a collective. All of this is likely to be reflected in task-oriented action in the interest of the collective. The latter is, however, significantly more related to neighboring constructs like job-involvement, work ethic and career commitment. The resulting 'semantic map' of OC can potentially be used for a wide variety of purposes, 
one of which is the detection of construct redefinition (gamma change, see chapter 4). We advise researchers constructing commitment scales to pay due attention to group-oriented action, include an item tapping into the affective facet of the domain, but refrain from items tapping into specific task-related action as these items tap into the conceptual domain of neighboring constructs.

Table 10.1. Commitment adjectives and their association with neighboring constructs

\begin{tabular}{|c|c|c|c|c|c|c|c|c|}
\hline & $\begin{array}{c}\text { Organizational } \\
\text { Commitment }\end{array}$ & Sign & $\begin{array}{c}\text { Job } \\
\text { Involvement }\end{array}$ & Sign & $\begin{array}{l}\text { Work } \\
\text { Ethic }\end{array}$ & Sign & $\begin{array}{c}\text { Career } \\
\text { Commitment } \\
\end{array}$ & Sign \\
\hline Loyal & 4.71 & $* * *$ & 3.57 & & 3.65 & & 2.82 & \\
\hline Involved & 4.67 & $* * *$ & 4.02 & & 3.61 & & 3.45 & \\
\hline Fraternal & 4.45 & $* * *$ & 3.14 & & 3.43 & & 2.80 & \\
\hline Togetherness & 4.43 & $* * *$ & 2.92 & & 3.18 & & 2.39 & \\
\hline Thinking along & 4.39 & $* * *$ & 3.67 & & 3.53 & & 3.61 & \\
\hline Satisfied & 4.27 & $*$ & 3.98 & & 3.69 & & 3.33 & \\
\hline Responsible & 4.25 & $* *$ & 3.71 & & 3.86 & & 4.12 & \\
\hline Trustworthy & 4.25 & $* * *$ & 3.10 & & 3.37 & & 2.71 & \\
\hline Motivated & 4.14 & & 4.51 & $* *$ & 4.18 & & 4.69 & $* * *$ \\
\hline Communicating & 4.12 & $* * *$ & 3.06 & & 3.37 & & 3.75 & \\
\hline Positive & 4.10 & $*$ & 3.73 & & 3.65 & & 3.61 & \\
\hline Interested & 4.08 & & 4.24 & & 3.55 & & 3.73 & \\
\hline Hard working & 4.08 & & 4.65 & $* * *$ & 4.45 & $* *$ & 4.73 & $* * *$ \\
\hline Helpful & 4.02 & $* * *$ & 2.94 & & 3.47 & & 2.63 & \\
\hline Pleasant & 3.98 & & 3.69 & & 3.41 & & 3.12 & \\
\hline Friendly & 3.98 & $* * *$ & 2.75 & & 3.12 & & 2.55 & \\
\hline Pro-active & 3.92 & & 3.98 & & 4.00 & & 4.37 & $* *$ \\
\hline Quality focused & 3.82 & & 3.86 & & 3.96 & & 4.24 & $*$ \\
\hline Constructive criticism & 3.80 & $* * *$ & 3.18 & & 3.53 & & 3.80 & \\
\hline Proud & 3.75 & & 3.75 & & 3.82 & & 4.25 & $* *$ \\
\hline Passionate & 3.69 & & 4.53 & $* * *$ & 4.04 & & 4.73 & $* * *$ \\
\hline Personal & 3.69 & & 3.41 & & 3.27 & & 3.35 & \\
\hline Optimistic & 3.49 & & 3.45 & & 3.35 & & 3.75 & \\
\hline Successful & 3.47 & & 3.90 & $* *$ & 3.69 & & 4.78 & $* * *$ \\
\hline Part of me & 3.43 & & 4.12 & $* * *$ & 3.65 & & 4.12 & $* *$ \\
\hline Drive & 3.41 & & 4.02 & $* * *$ & 3.92 & $* *$ & 4.61 & $* * *$ \\
\hline Goal-oriented & 3.33 & & 3.86 & $* * *$ & 3.73 & $* *$ & 4.71 & $* * *$ \\
\hline Flexible & 3.29 & $*$ & 2.82 & & 3.27 & & 3.61 & \\
\hline Assertive & 3.18 & & 3.31 & & 3.18 & & 4.69 & $* * *$ \\
\hline Precise & 3.16 & & 3.75 & $* * *$ & 3.61 & $*$ & 3.96 & $* * *$ \\
\hline Founded & 3.14 & & 3.12 & & 3.29 & & 3.29 & \\
\hline Challenging & 3.10 & & 3.76 & $* * *$ & 3.55 & $*$ & 4.33 & $* * *$ \\
\hline Independent & 2.86 & & 4.06 & $* * *$ & 3.53 & $* * *$ & 4.45 & $* * *$ \\
\hline Hectic & 2.73 & & 3.35 & $* * *$ & 2.94 & & 3.90 & $* * *$ \\
\hline Peaceful & 2.69 & $* *$ & 2.29 & & 2.55 & & 2.10 & \\
\hline Efficient & 2.67 & & 3.02 & $*$ & 3.43 & $* * *$ & 3.59 & $* * *$ \\
\hline Reserved & 2.29 & & 2.31 & & 2.33 & & 1.61 & \\
\hline
\end{tabular}

Note: Asterisks indicate significance tests (T-tests) on whether OC scored higher than neighboring constructs or whether neighboring constructs were significantly higher rated than OC. 


\section{References}

Hinkin, T. R., \& Tracey, J. B. (1999). An analysis of variance approach to content validation. Organizational Research Methods, 2(2), 175-186.

Lunt, P. K. (1991). The perceived causal structure of loneliness. Journal of Personality and Social Psychology, 61(1), 26-34.

Valk, S. (2006). A reconceptualization of organizational commitment: Back to the drawing board. Unpublished Master's thesis. Maastricht: Maastricht University. 


\section{Appendix F}

\section{A supplementary explanation on the interpretation of BIC an $\mathrm{AIC}$}

Below we offer supplementary explanation of in the interpretation of the Bayesian Information Statistic (BIC), and the Aikake Information Statistic (AIC) in relation to the group-based modeling technique (Jones \& Nagin, 2007; Jones, Nagin, \& Roeder, 2001; Nagin, 2005). Group-based modeling can be done with a SAS add-on called Proc Traj, which was created by Nagin and Jones, which is available online ${ }^{62}$.

Finite mixture modeling is a data-driven technique based on a maximum likelihood algorithm and requires pre-specification of the number of latent groups as well as the order of the polynomial (up to cubic). A caveat mentioned by the designer (Nagin, 2005) is that there is no 'right model' in terms of the number of latent trajectories. To decide on the number of latent groups Nagin (2005) advises the use of the BIC statistic which stands for the Bayesian Information Criterion; see Nagin, 2005). It serves to seek out the most explanatory and parsimonious model. The BIC statistic is generally a large negative number. BIC is defined as follows:'

$$
\mathrm{BIC}=\log (L)-0.5 k \log (N)
$$

where $L$ is the value of the model's maximized likelihood, $\mathrm{N}$ is the sample size, and $\mathrm{k}$ is the number of parameters in the model'... As the quality of the model's fit declines, the log of the likelihood decreases (that is, becomes more negative).' (Nagin, 2005, p. 64). Thus, a higher BIC, that is, a BIC integer which approaches 0 is indicative of a better model. The first term $\log (L)$ can be seen as analogous to standard regression analyses where the R-square indicates to the proportion of explained variance. BIC rewards parsimony, that is, it penalizes the inclusion of too many parameters in the second term of the equation. The SAS Proc Traj output provides two BIC statistics: one for the total number of subjects in the sample $(\mathrm{N})$, and the other for the total number of observations in the sample $\left(\mathrm{N}^{*} \mathrm{t}\right)$. According to Nagin, the true sample size is likely somewhere in between as $\mathrm{N}$ is an underestimation and $\mathrm{N}^{*} \mathrm{t}$ is likely an overestimation - because scores in $\mathrm{N}^{*} \mathrm{t}$ are not likely to be fully independent. BIC is not

\footnotetext{
${ }^{62} \mathrm{http}: / /$ www.andrew.cmu.edu/user/bjones/
} 
informative in isolation; it is rather used as a relative metric to assess which of a series of models is most informative. Thus, the change in BIC when comparing model $i$ to $j$ is what is assessed.

Nagin advises to use a calculation on the probability correct model (PCM), which is 'the probability that a model with $j$ groups is the correct model from a set of $J$ different models. $p_{j}$ is approximated by:

$$
\frac{e^{B I C j-B I C \max }}{\sum_{j} e^{\text {BICj-BICmax }}}
$$

where $B I C_{\max }$ is the maximum BIC score of the $J$ different models under consideration' (Nagin, 2005, p. 70). As the PCM approaches 1, chances become higher that model $i$ outperforms model $j$. Aikake Information Criterion (AIC), which is calculated by

$$
\mathrm{AIC}=2 \mathrm{k}+\mathrm{n} \log (\mathrm{RSS} / \mathrm{n})
$$

where the $\mathrm{k}$ is the number of parameters in the model and RSS is the Residual Sum of Squares. The use of the AIC works differently as one checks the performance of model $i$ relative to the maximum AIC (i.e. the worst performing model). We have tried to use the evidence ratio (Burnham \& Anderson, 2004), which is based on $\mathrm{AIC}_{c}$ which corrects for a small sample size (see Burnham \& Anderson, 2004, p. 270, for how it is calculated) in testing the relative likelihood of model $i$ versus model $j$. When evidence ratio is large (e.g., $>150$ is quite large), model $i$ is a poor model relative to worst performing model $j$, based on the data.

\section{References}

Burnham, K. P., \& Anderson, D. R. (2004). Multimodel inference: Understanding AIC and BIC in model selection. Sociological Methods \& Research, 33(2), 261-304.

Nagin, D. S. (2005). Group-based modeling of development. Cambridge, MA: Harvard University Press. 


\section{Appendix G}

\section{2 person-specific patterns of week-by-week commitment development during the first six months of work}

Below individual trajectories of commitment during the first six months of work are presented. On the left side we present the average commitment score (across three components), on the right side the scores of the three attitudinal components.

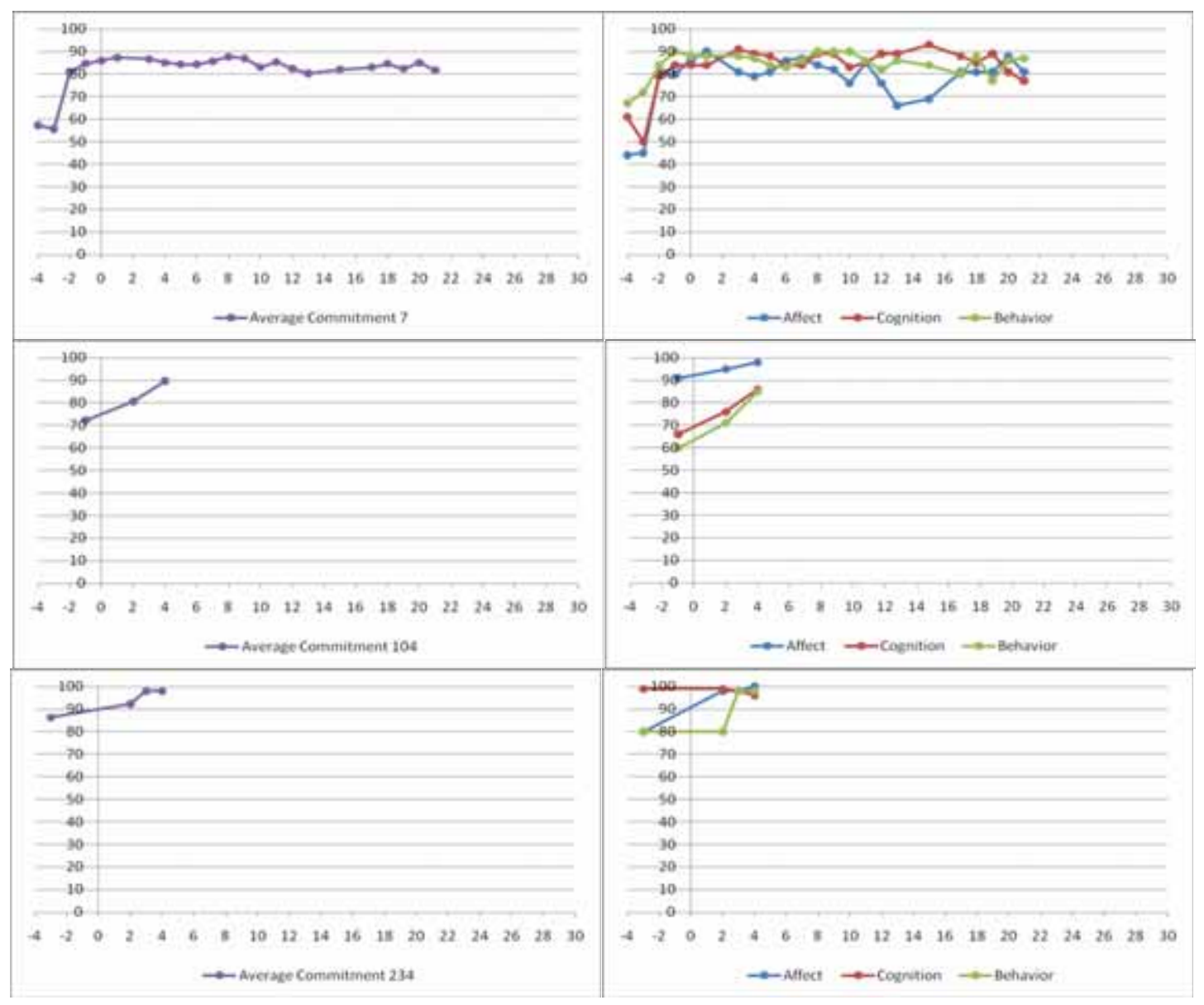




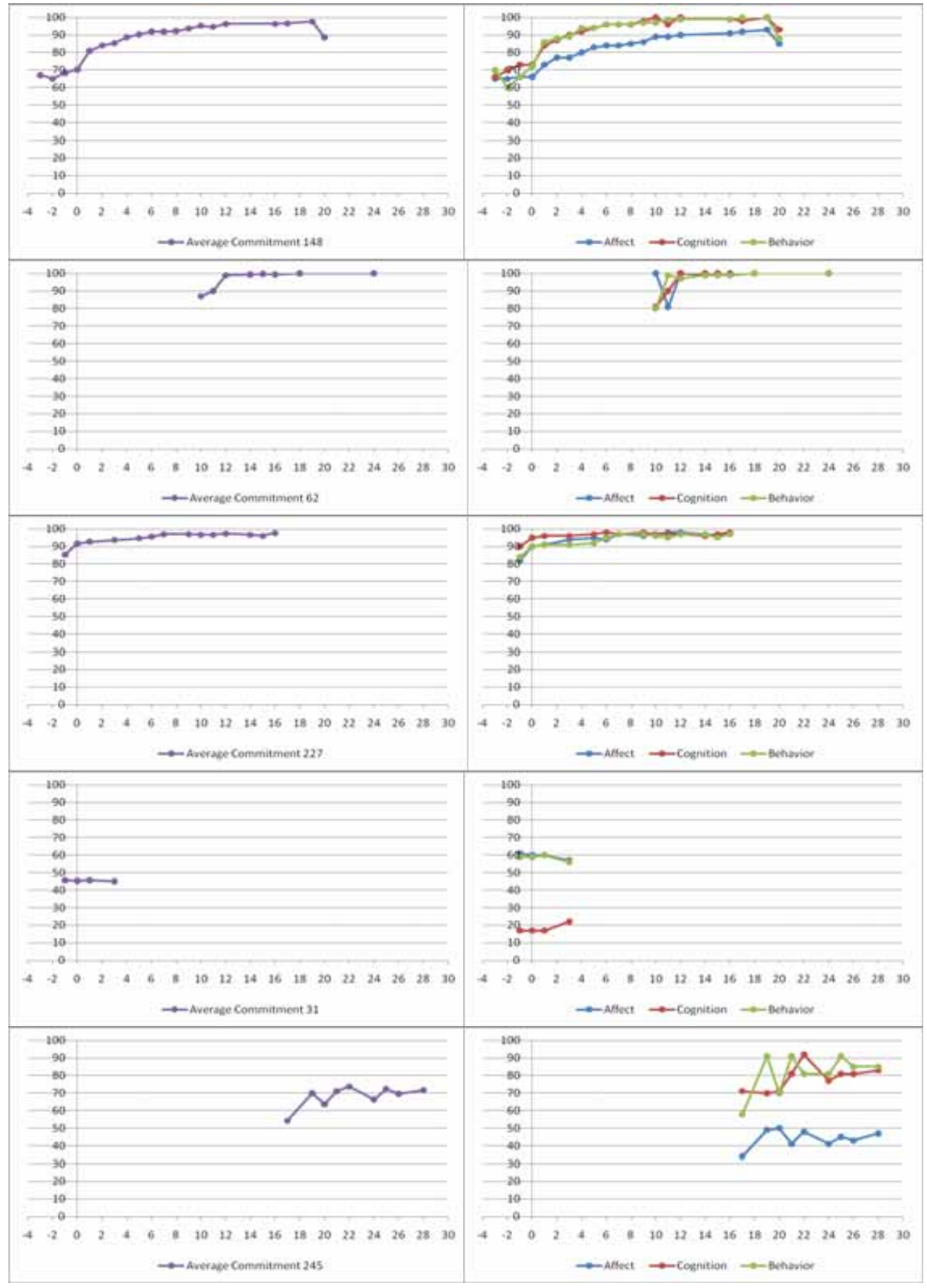




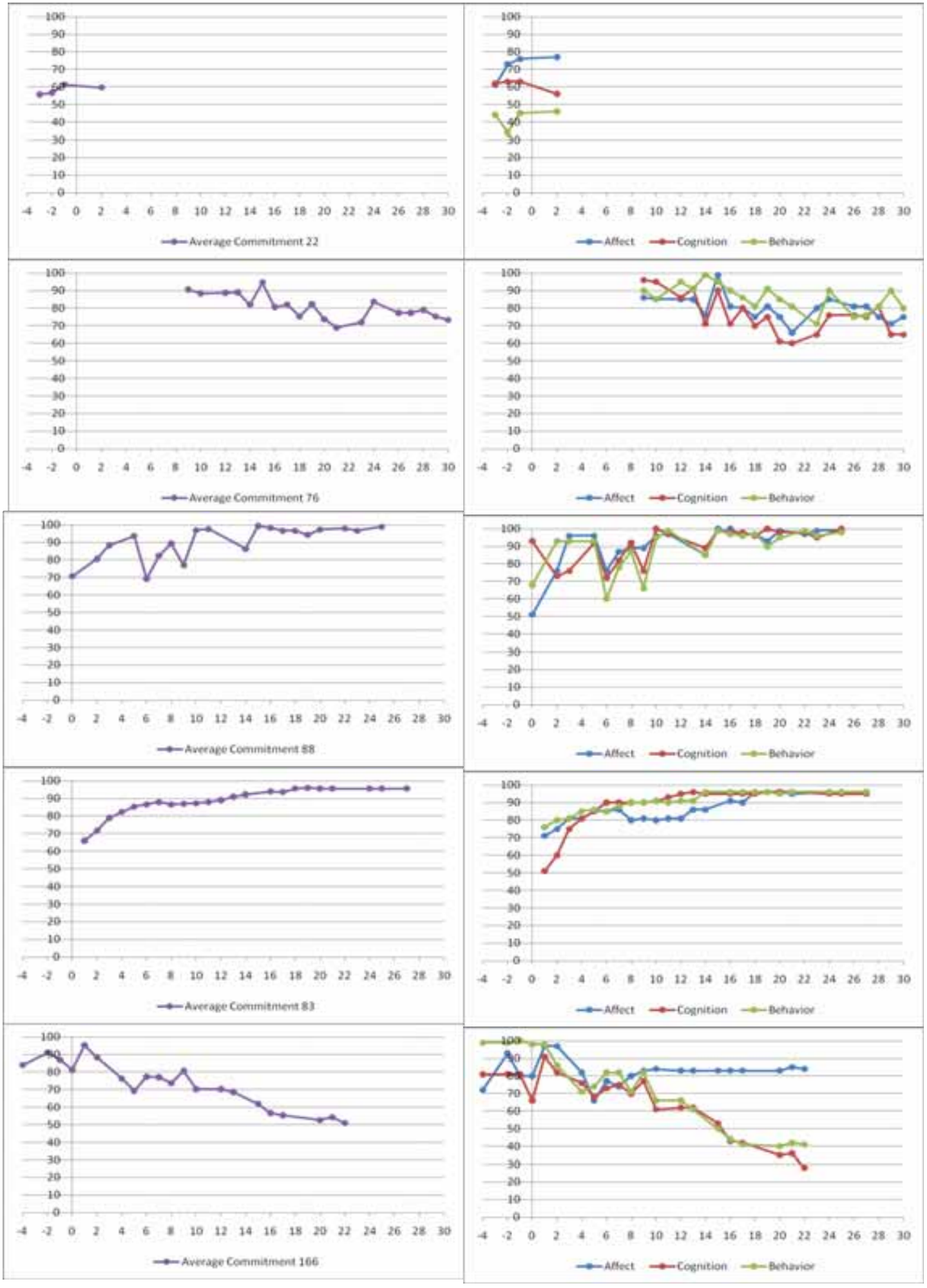




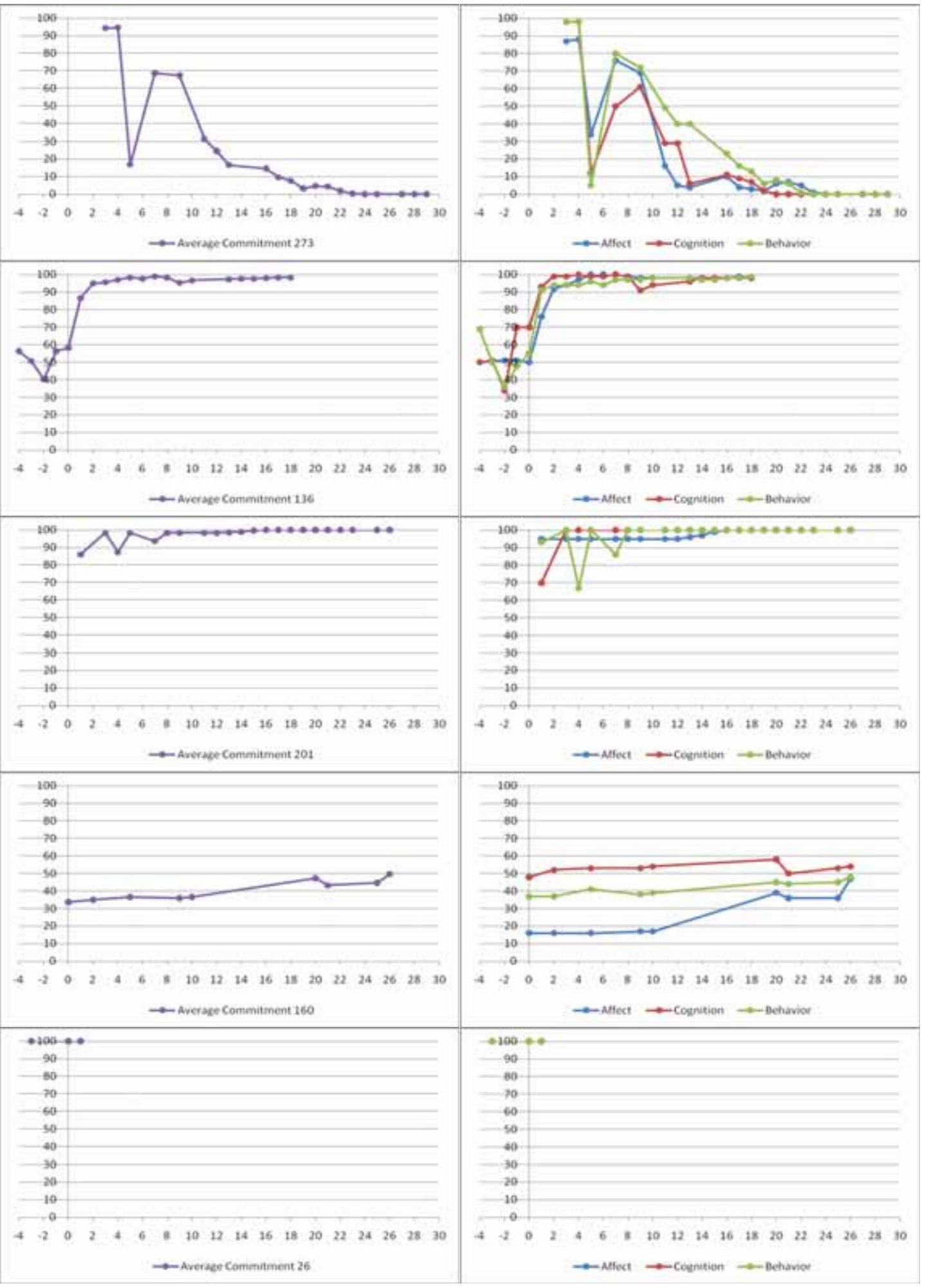



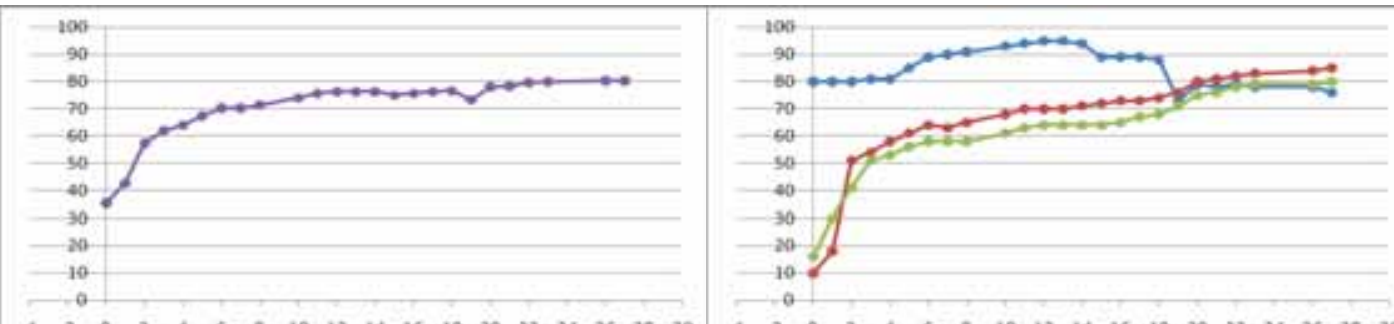

$\begin{array}{llllllllllllllllll}4 & -2 & 0 & 2 & 4 & 6 & 8 & 10 & 12 & 14 & 16 & 18 & 20 & 22 & 24 & 26 & 28 & 30\end{array}$

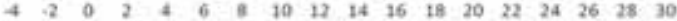

$\rightarrow$ Average Commitment 18 a

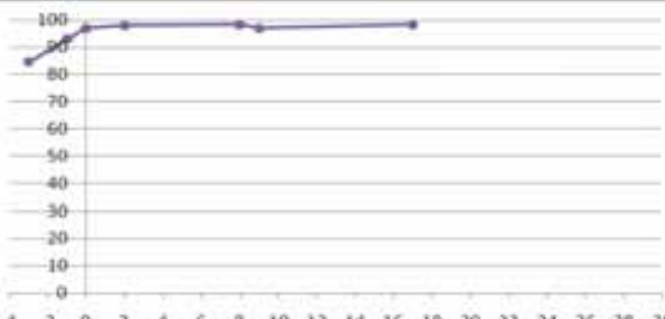

$\rightarrow$ Affect $\rightarrow$ Cogntion $\rightarrow$ Behavio

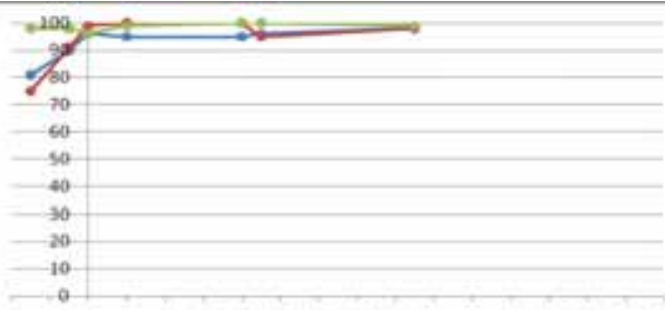

$\begin{array}{llllllllllllllllll}4 & -2 & 0 & 2 & 4 & 6 & 8 & 10 & 17 & 14 & 16 & 19 & 20 & 22 & 24 & 26 & 28 & 30\end{array}$ $\rightarrow$ Average Cominitment 12

$\rightarrow$ Affect $\rightarrow$ Cognition $\rightarrow$ Behavio

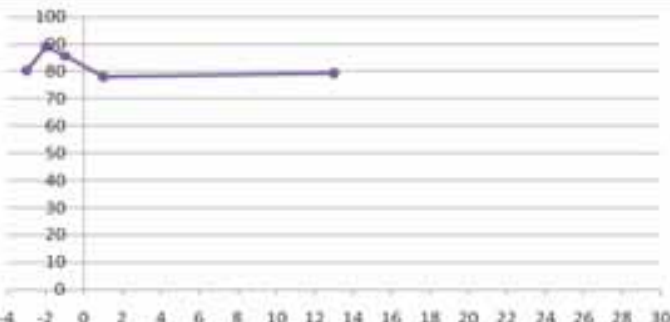

$\begin{array}{llllllllllllllllll}4 & -2 & 0 & 2 & 4 & 6 & 5 & 10 & 12 & 14 & 16 & 18 & 20 & 22 & 24 & 26 & 25 & 10\end{array}$ $\rightarrow$ Averase Commitment 64

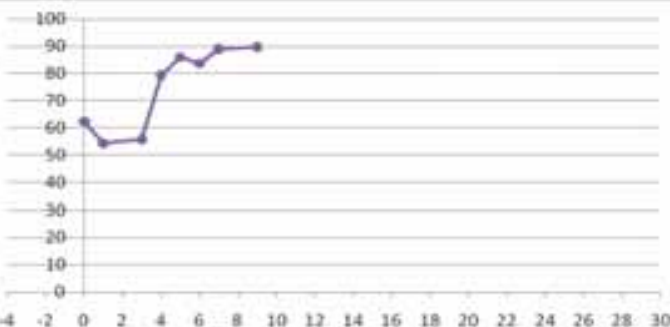

$\begin{array}{llllllllllllllllll}4 & 4 & 0 & 2 & 4 & 6 & 8 & 10 & 17 & 14 & 16 & 19 & 20 & 22 & 24 & 26 & 28 & 30\end{array}$ $\longrightarrow$ Averace Commitment 153

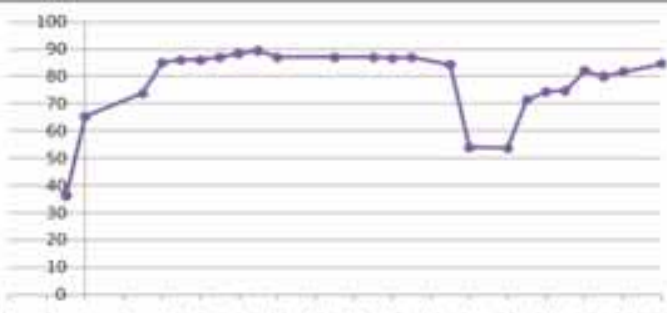

$\begin{array}{llllllllllllllllll}4 & -2 & 0 & 2 & 4 & 6 & 5 & 10 & 12 & 14 & 16 & 18 & 20 & 22 & 24 & 26 & 28 & 30\end{array}$ $\rightarrow$ Average Commitment as

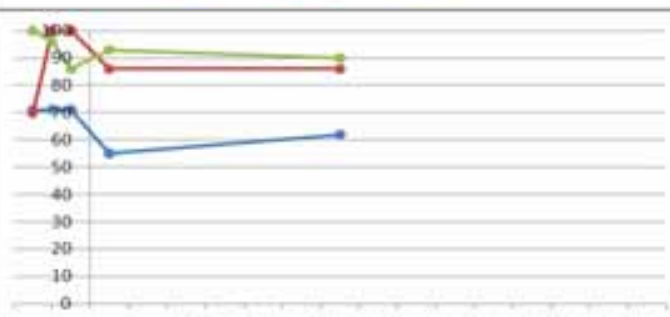

$\begin{array}{llllllllllllllllll}4 & -2 & 0 & 2 & 4 & 6 & 5 & 10 & 12 & 14 & 16 & 18 & 20 & 22 & 24 & 26 & 25 & 10\end{array}$ $\rightarrow$ Affect $\rightarrow$ Cosnition $\rightarrow$ Behavier

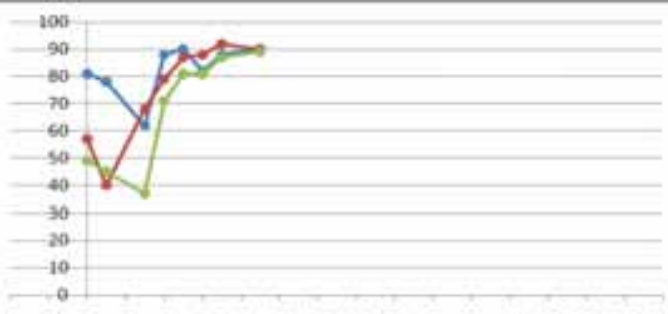

$\begin{array}{llllllllllllllllll}4 & 4 & 0 & 2 & 4 & 6 & 8 & 10 & 17 & 14 & 16 & 18 & 20 & 22 & 24 & 26 & 28 & 30\end{array}$

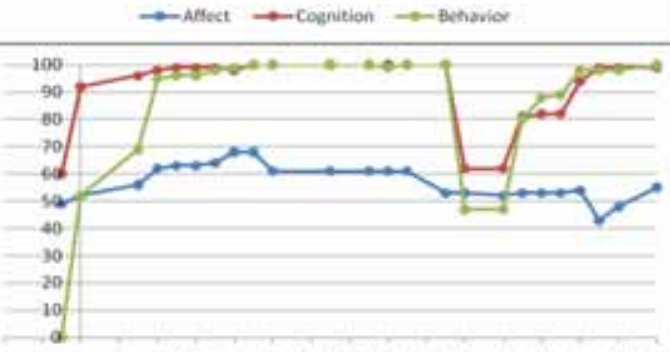

$\begin{array}{cccccccccccccccccc}4 & -2 & 0 & 2 & 4 & 6 & 5 & 10 & 12 & 14 & 16 & 15 & 20 & 22 & 24 & 26 & 25 & 10\end{array}$ $\rightarrow$ Mfect $\rightarrow$ Cosnution $\rightarrow-$ Behaviou 


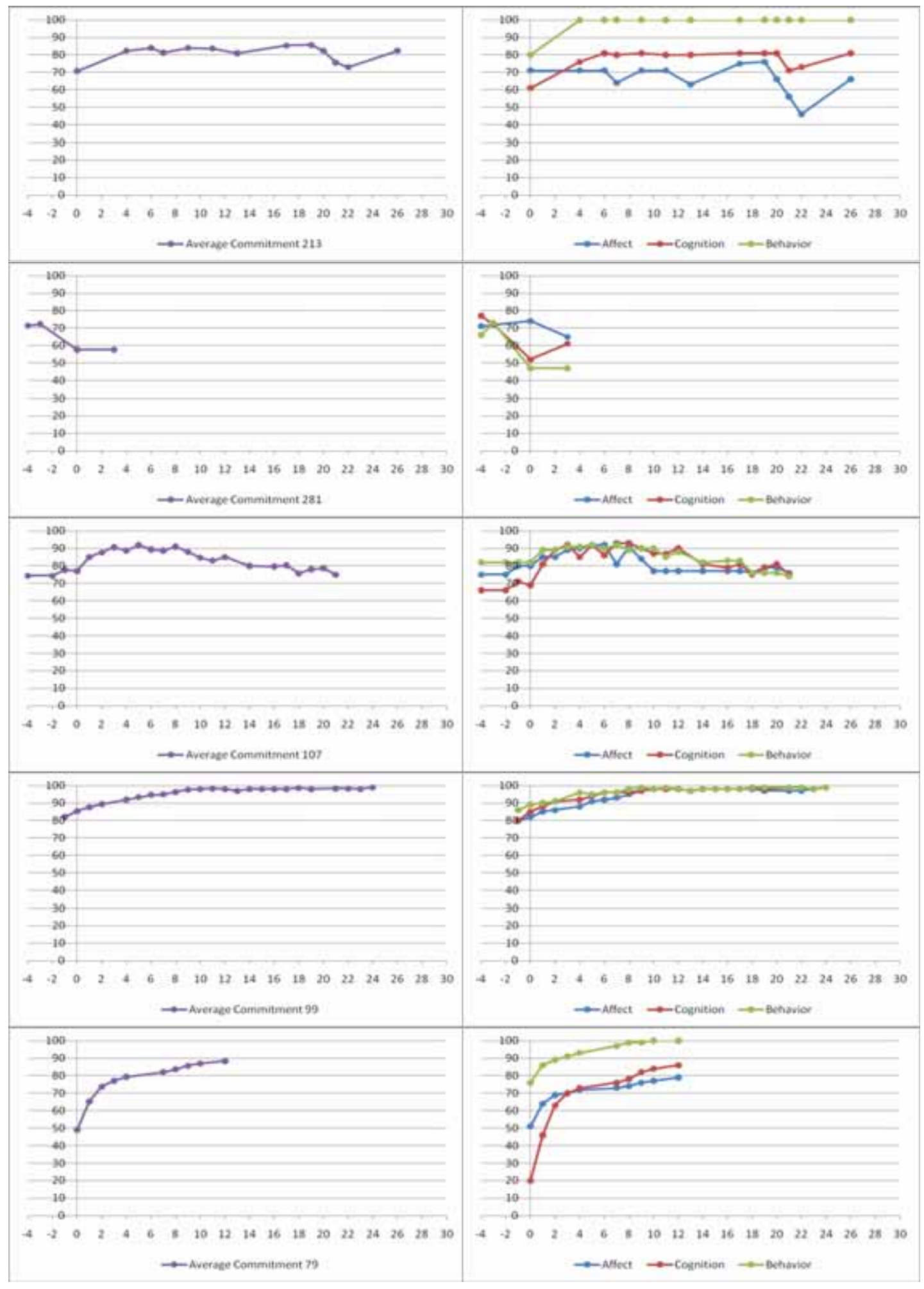




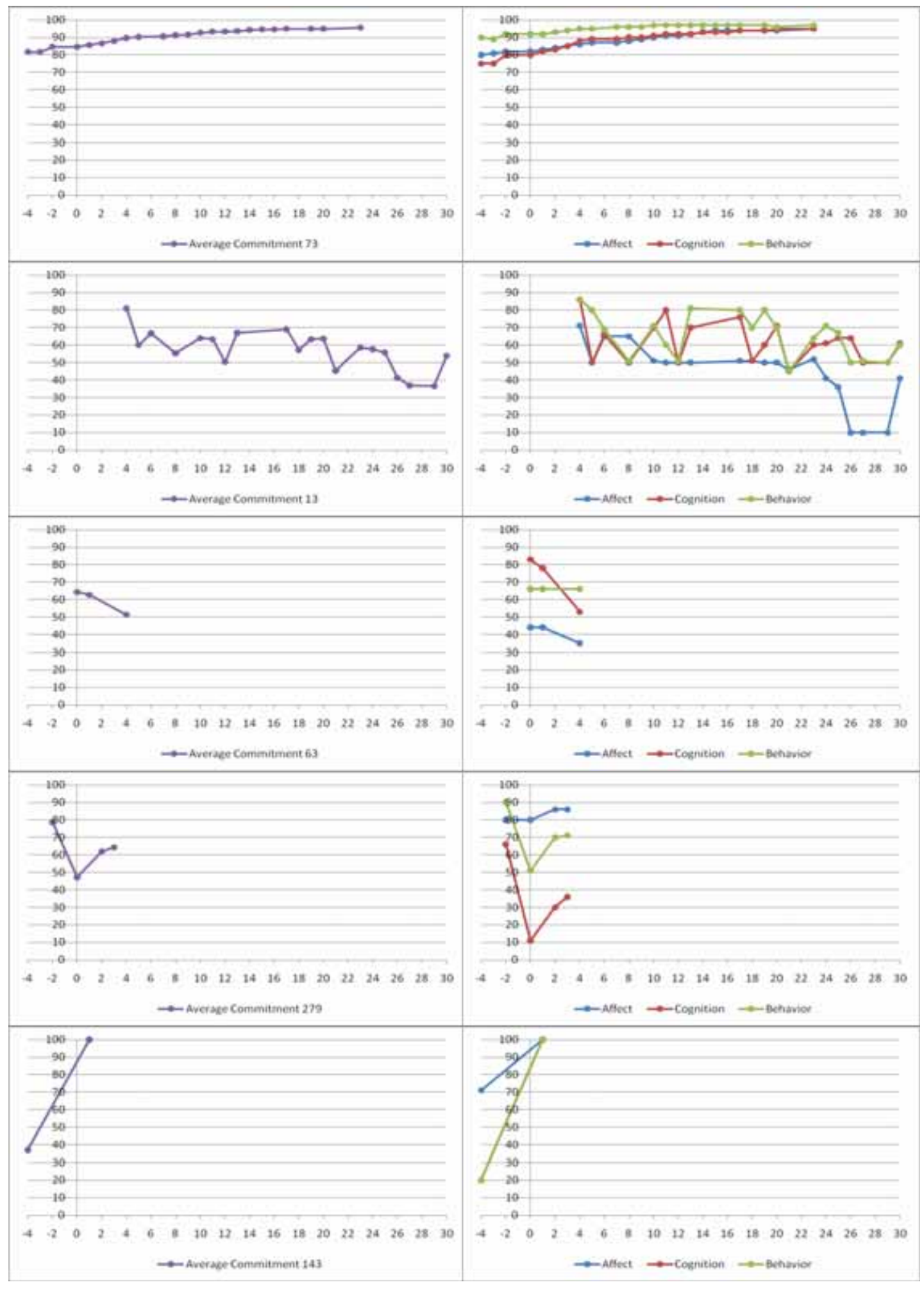




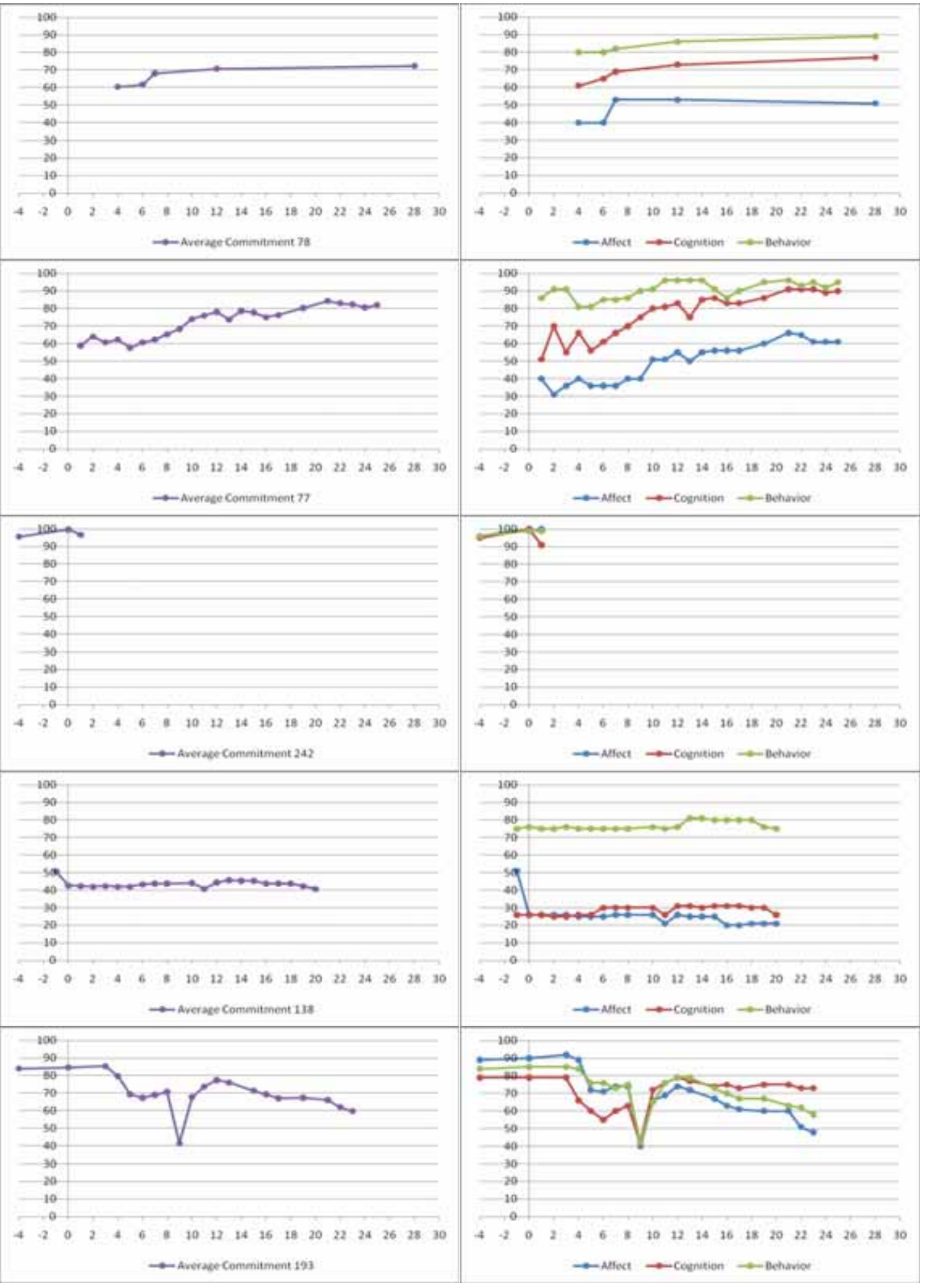




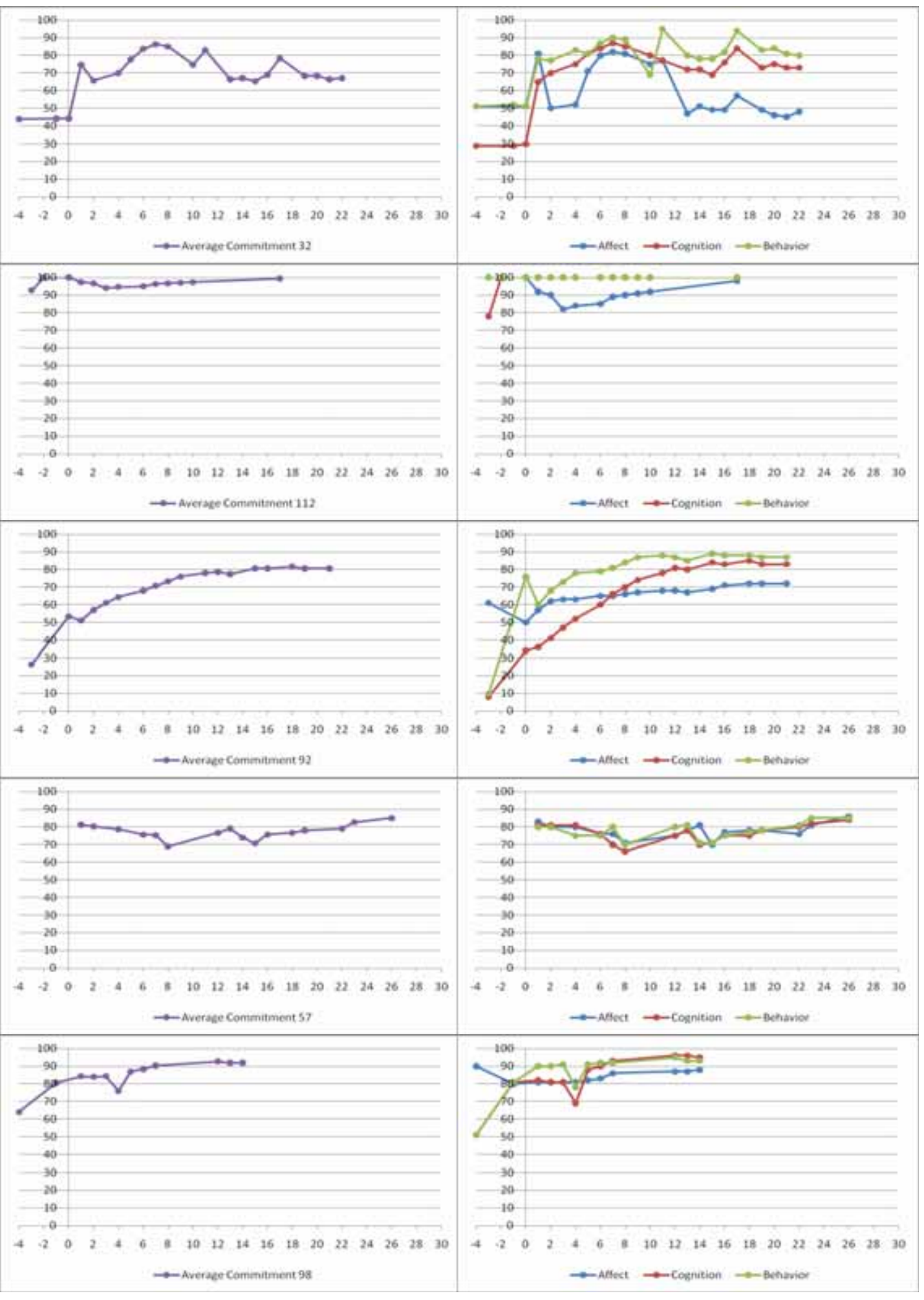




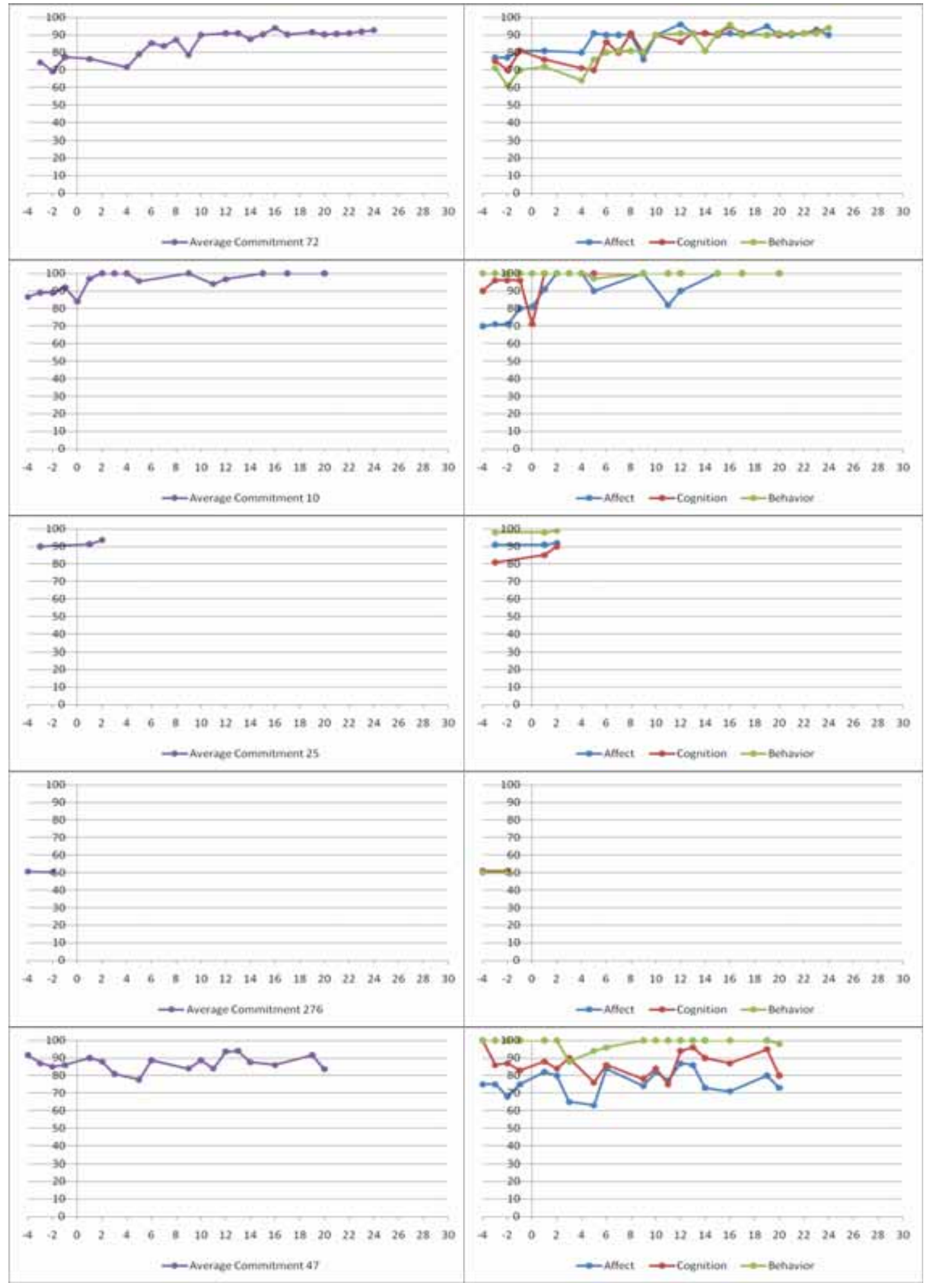




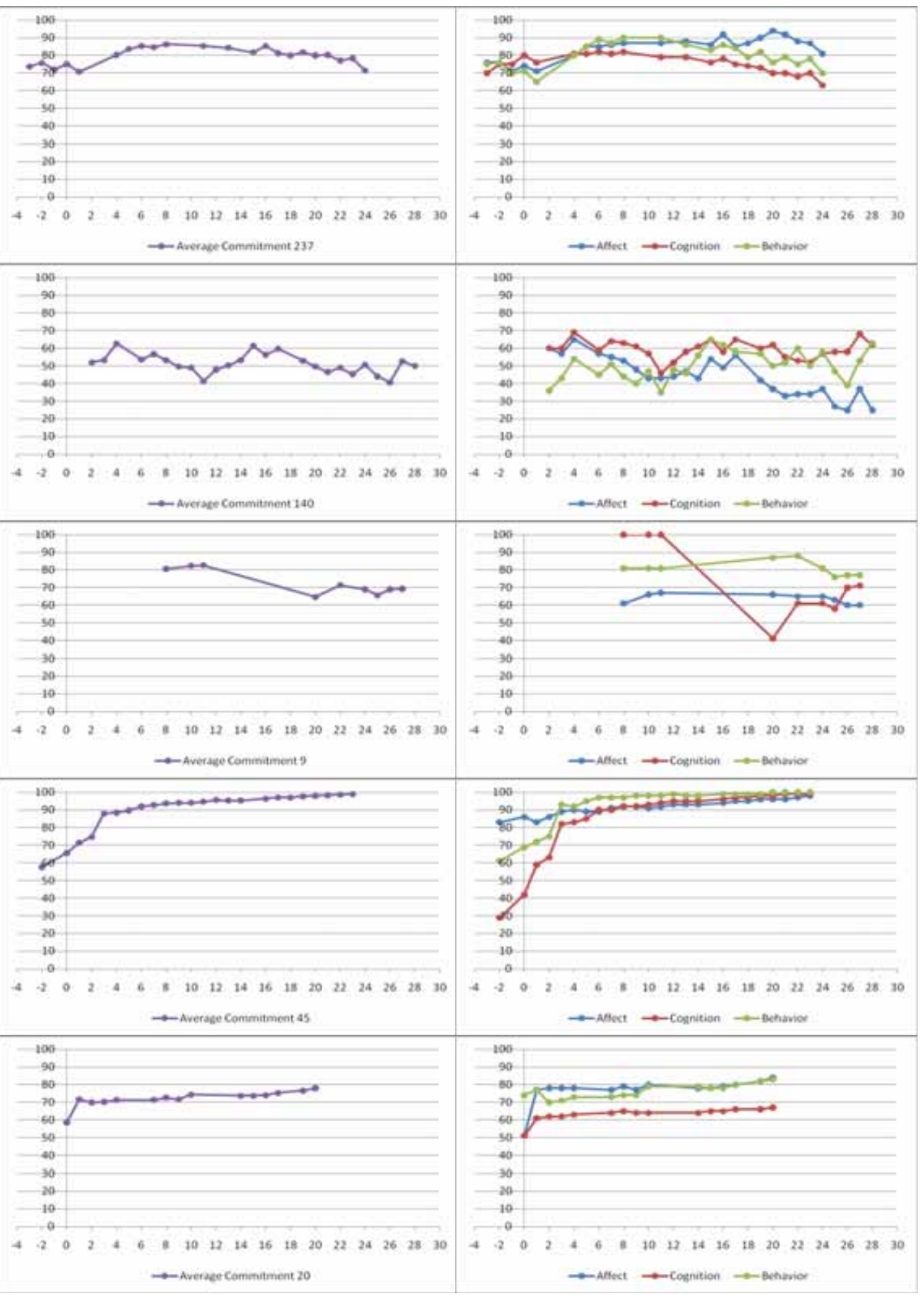




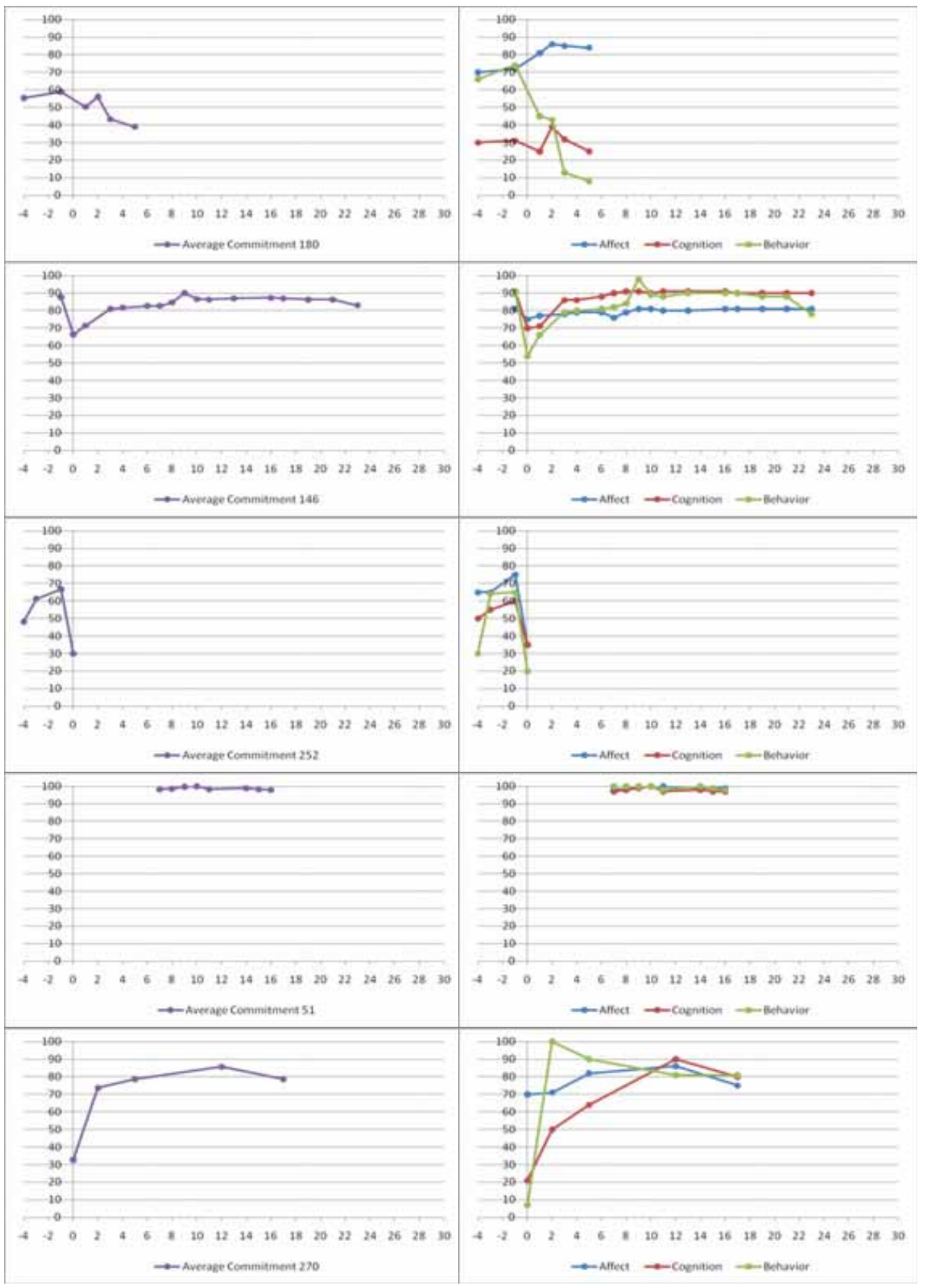




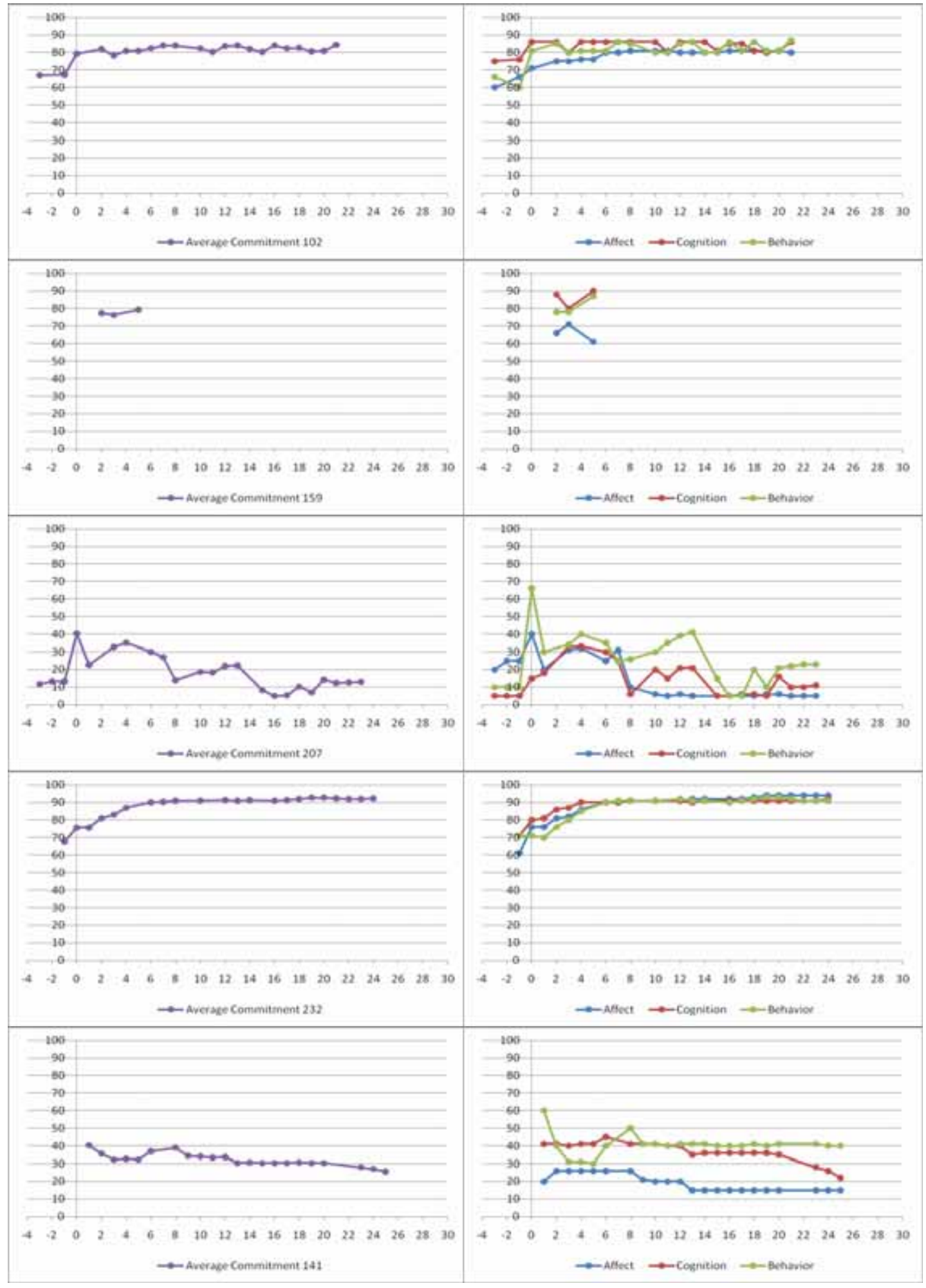




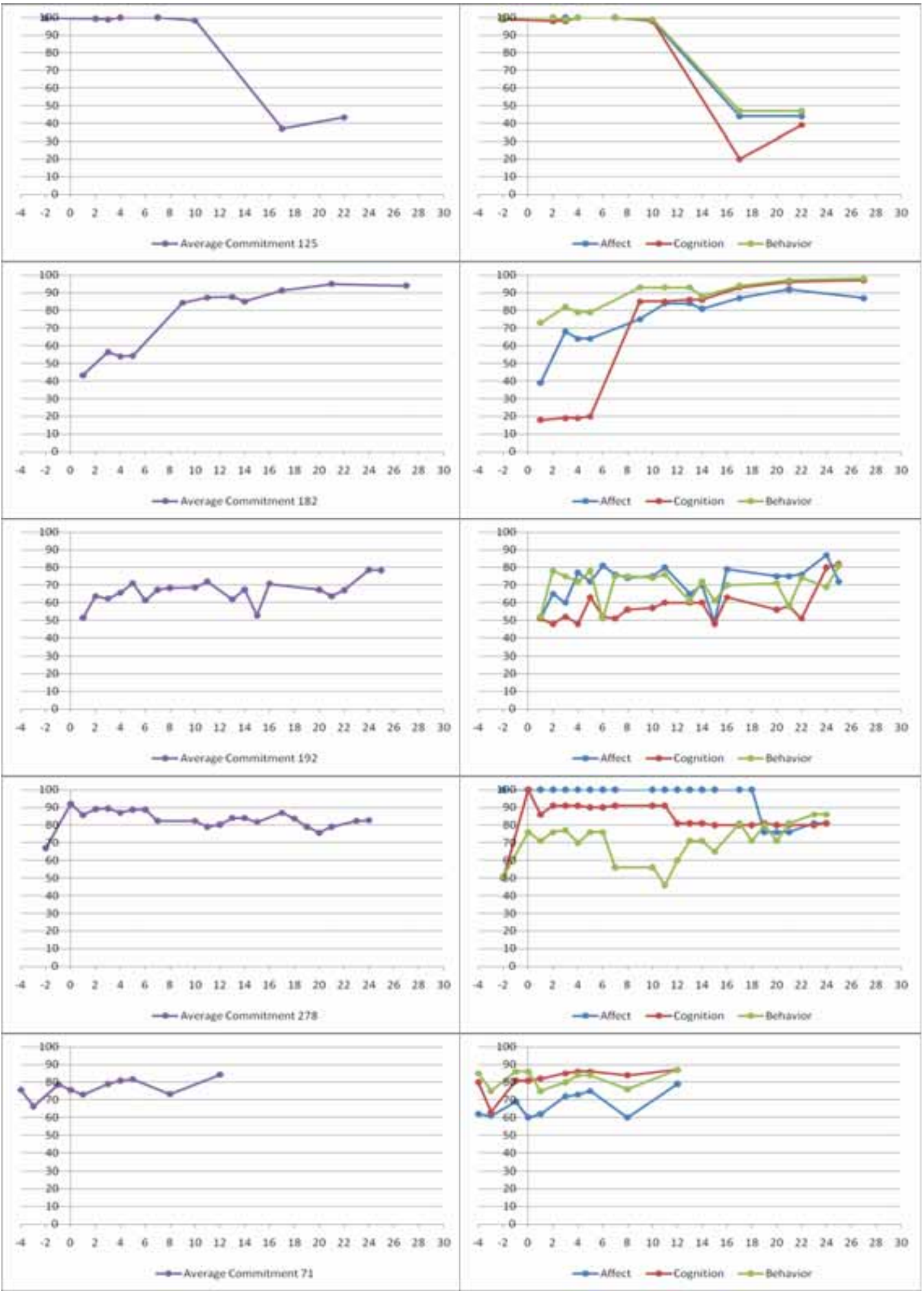




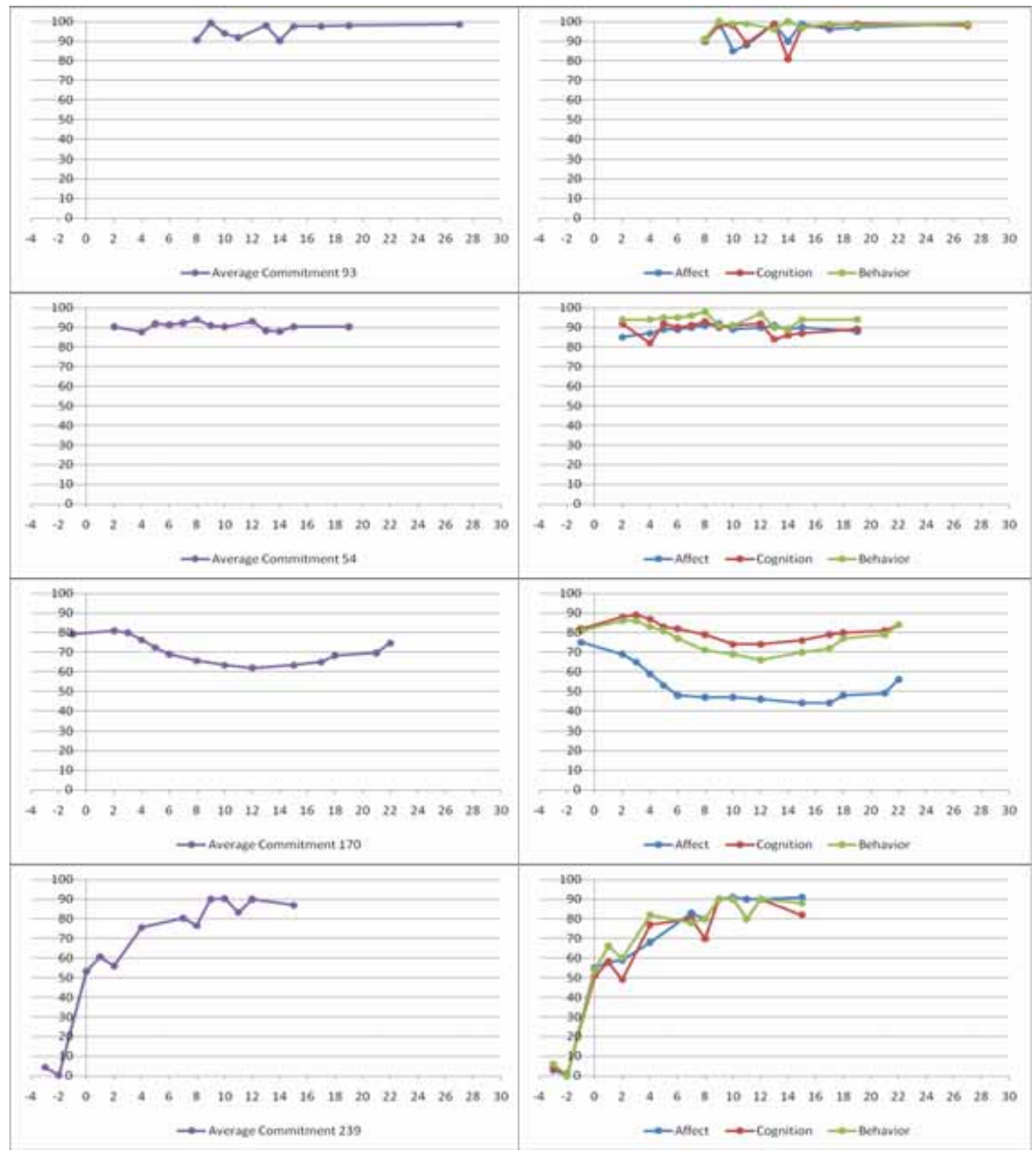




\section{Appendix $\mathbf{H}$}

\section{Figures of alternative solutions and robustness checks in group-based modeling}

Below we display the descriptive statistics of the aggregate mean development of OC in the first six months of work. These data serve to contrast the individual- and group-level analyses performed in chapter 5. The aggregate mean development of OC can be regarded as stable.

Table 13.1. Descriptive statistics on OC at the sample level

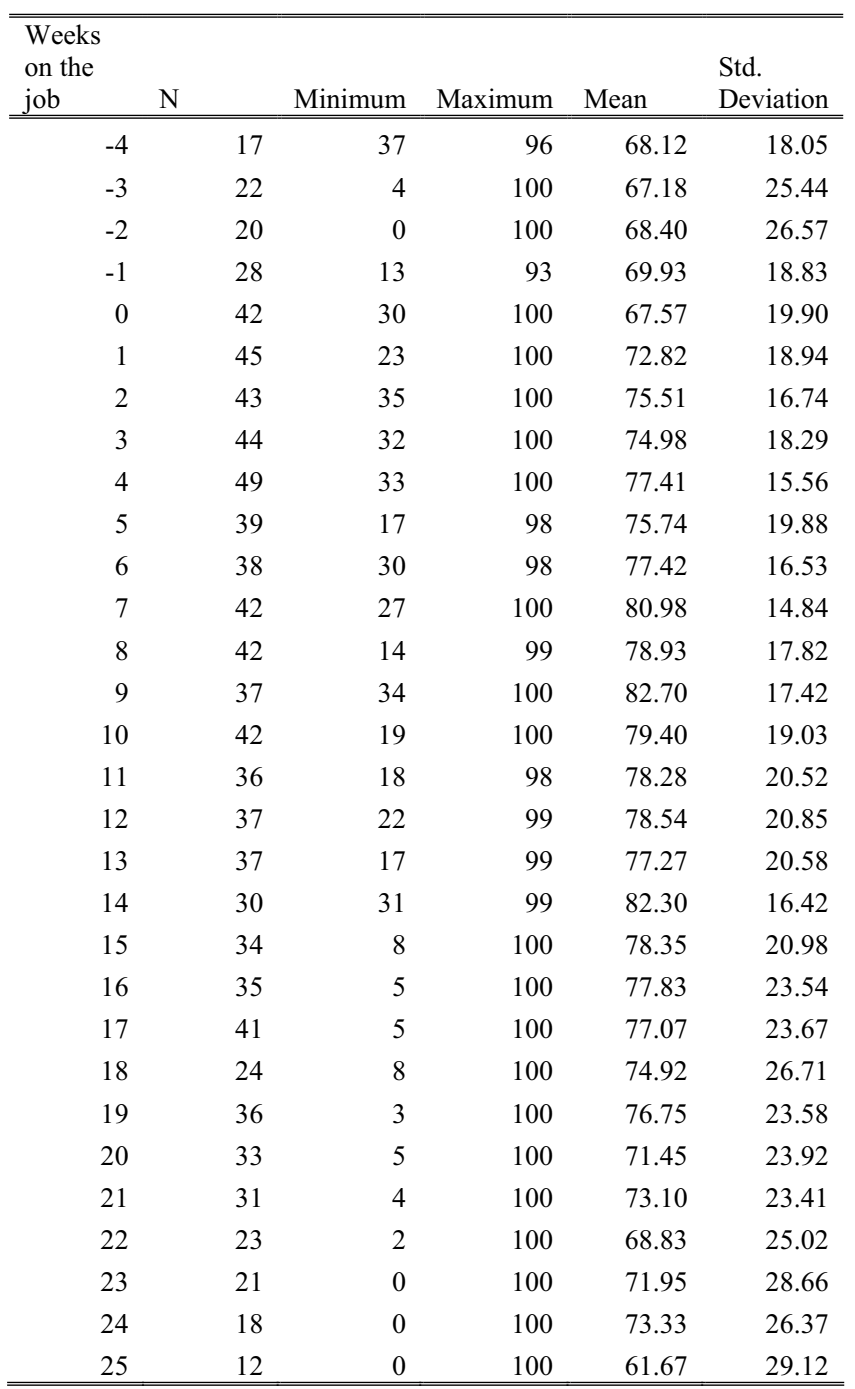


Figure 13.1. Mean progression in OC during first 6 months of work

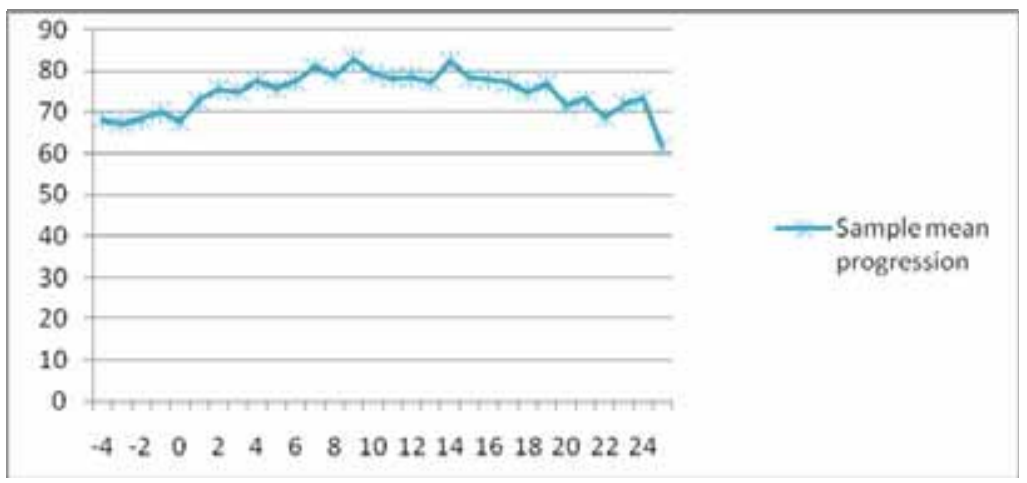

In the following figures we display the different solutions gained from the group-based modeling analysis. Figure 13.2 describes the first robustness check where we only included all even time moments, thus, deleting half of the scores. Figure 13.3 is the second robustness check, where we only included monthly measures. Both figures show no difference in shapes in the five-group solution.

Figure 13.2. First robustness check deleting all even time points

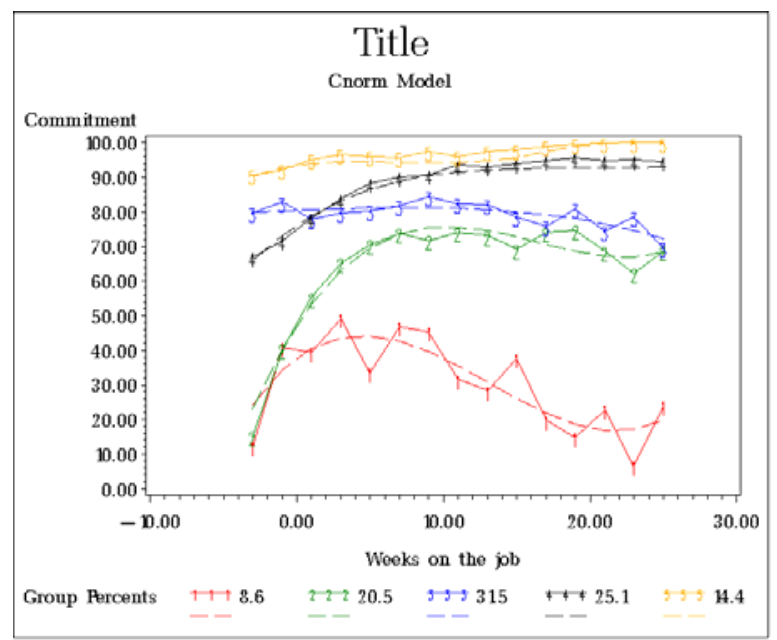


Figure 13.3. Second robustness check using only monthly measures

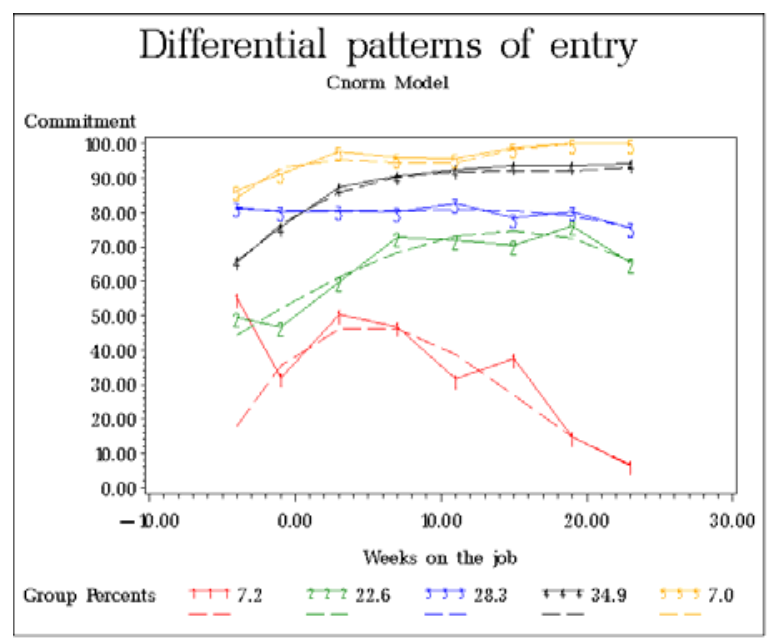

In the following we display alternative solutions when the number of latent groups was specified to four (Figure 13.4), six (Figure 13.5), and seven (Figure 13.6). In all solutions the curvature was set to cubic.

Figure 13.4. The 4-group solution

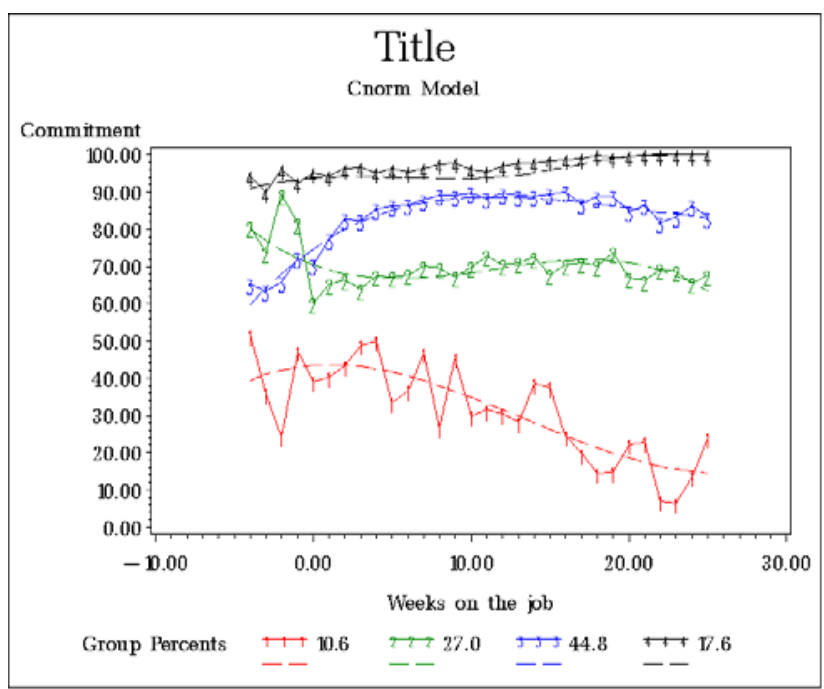


Figure 13.5. The 6-group solution

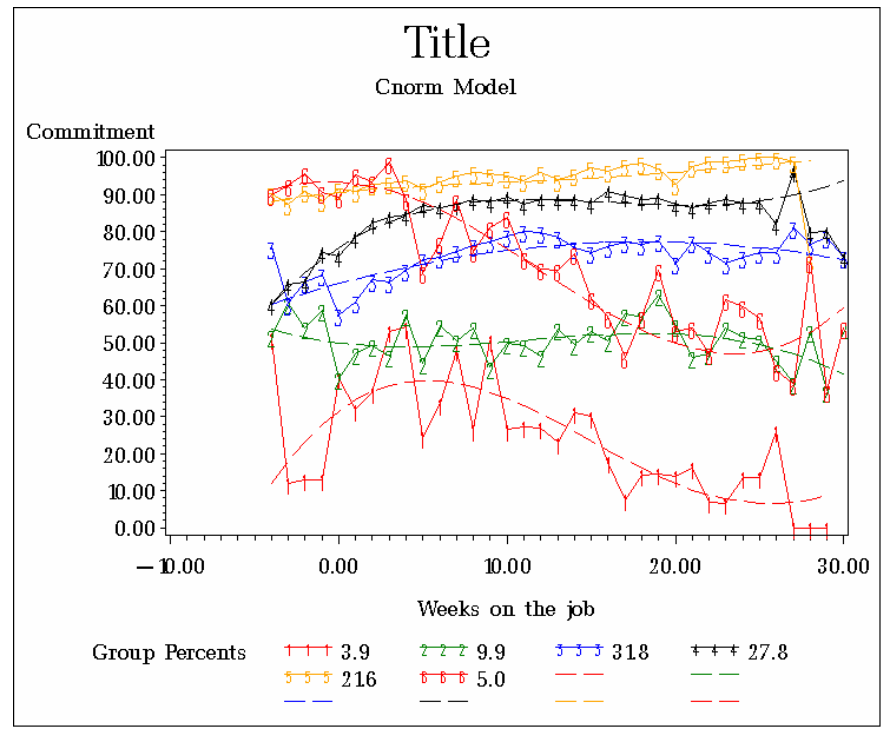

Figure 13.6. The 7-group solution

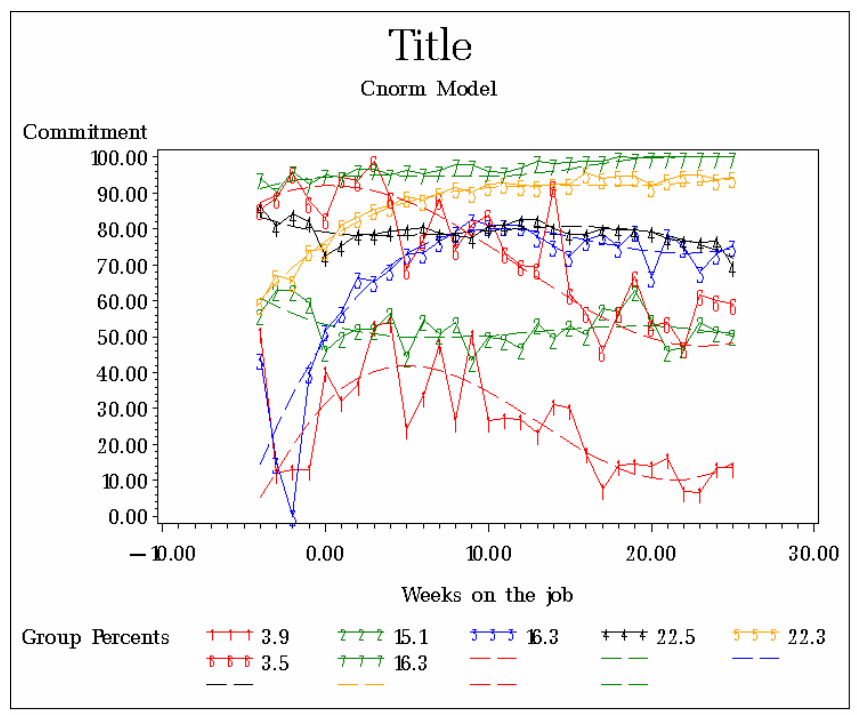




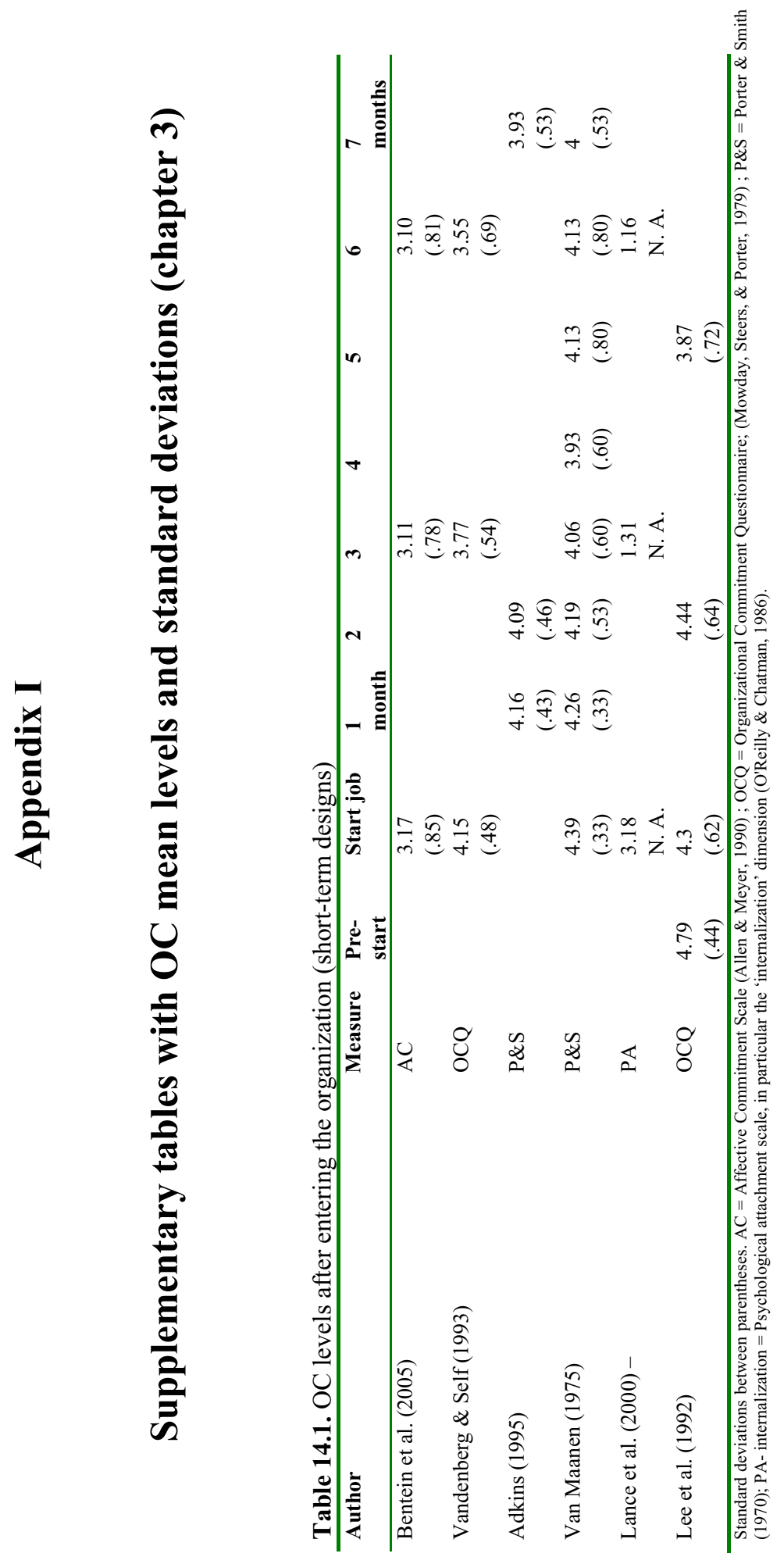




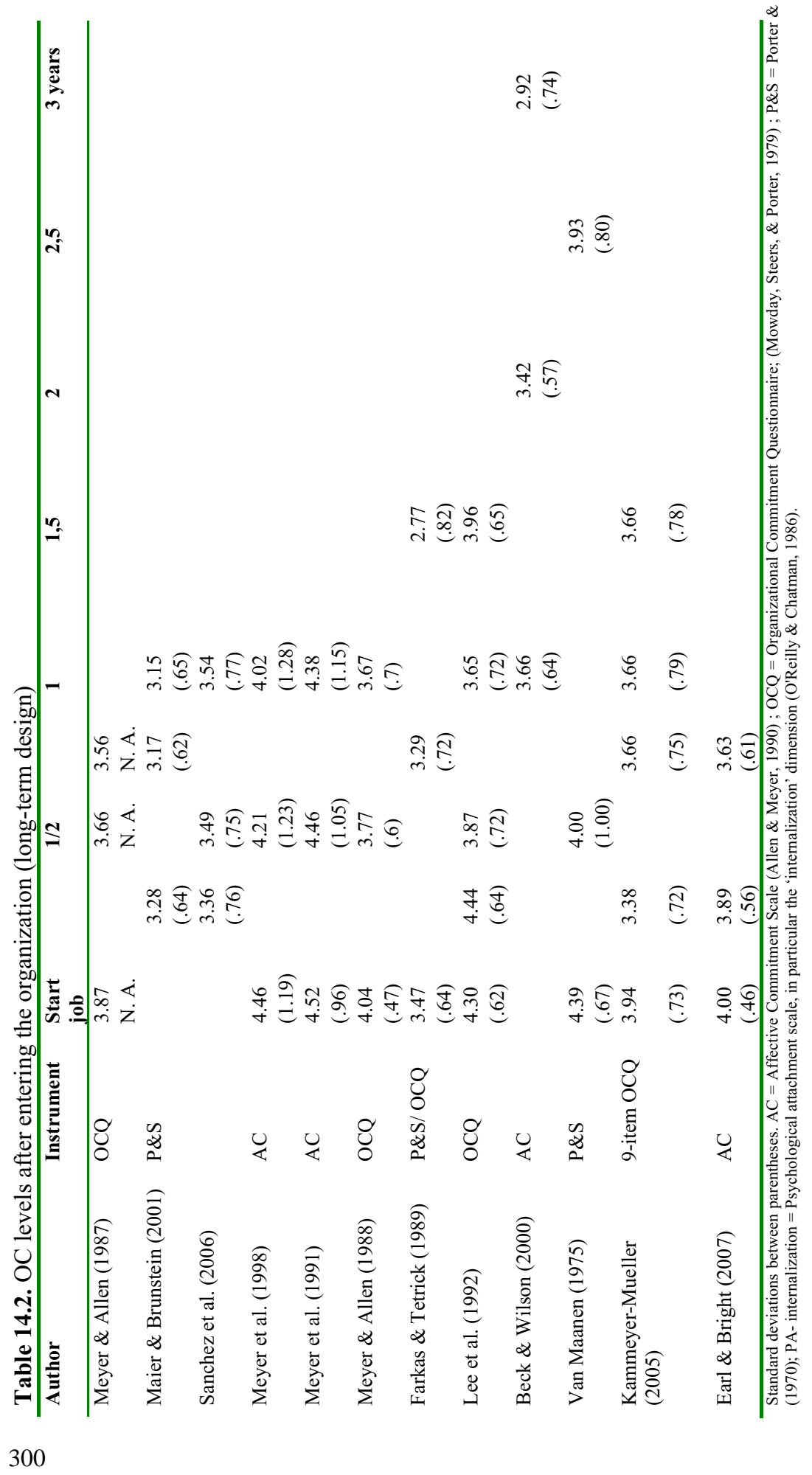




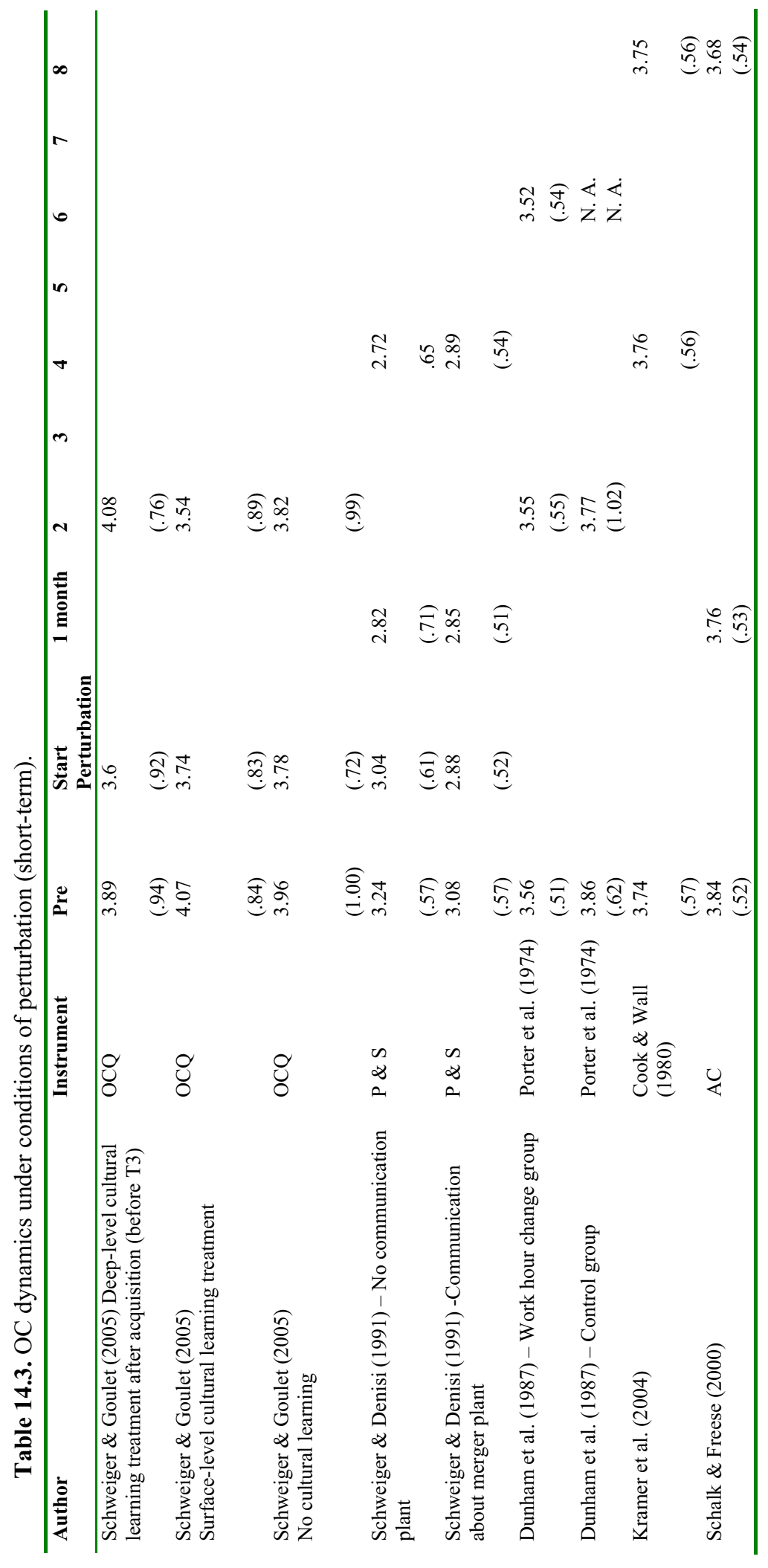




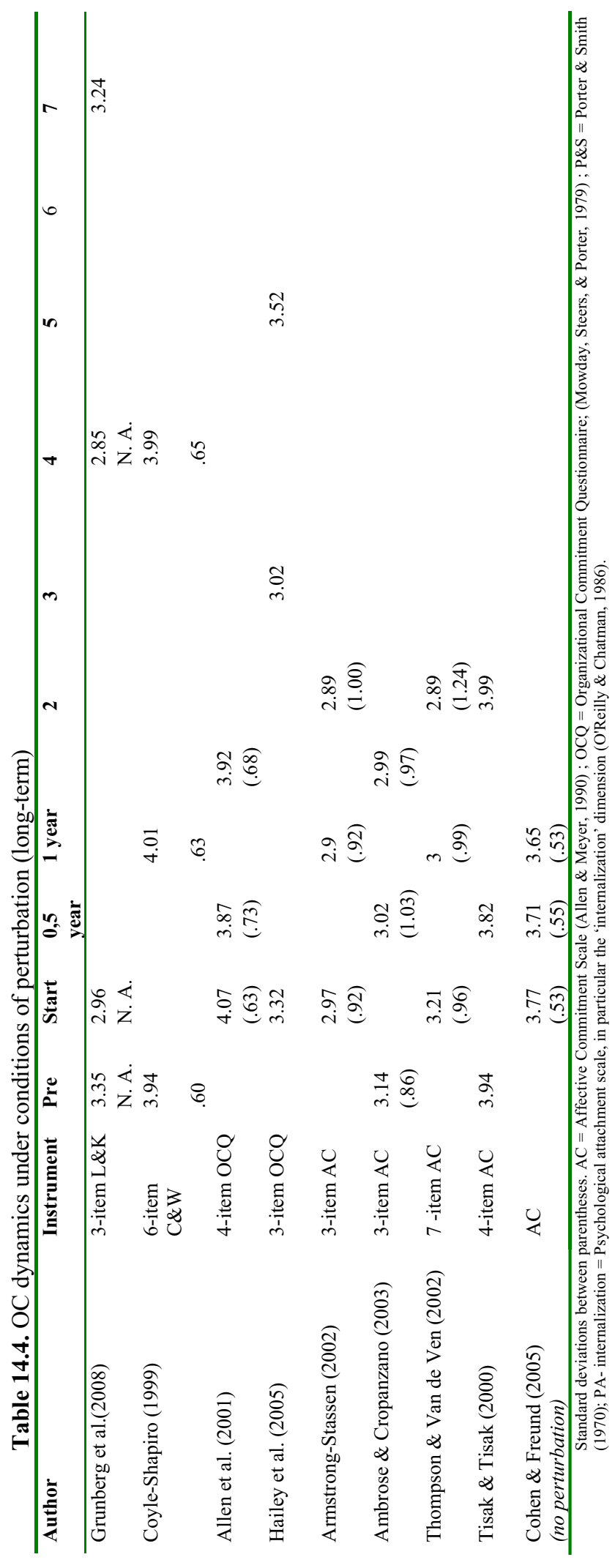




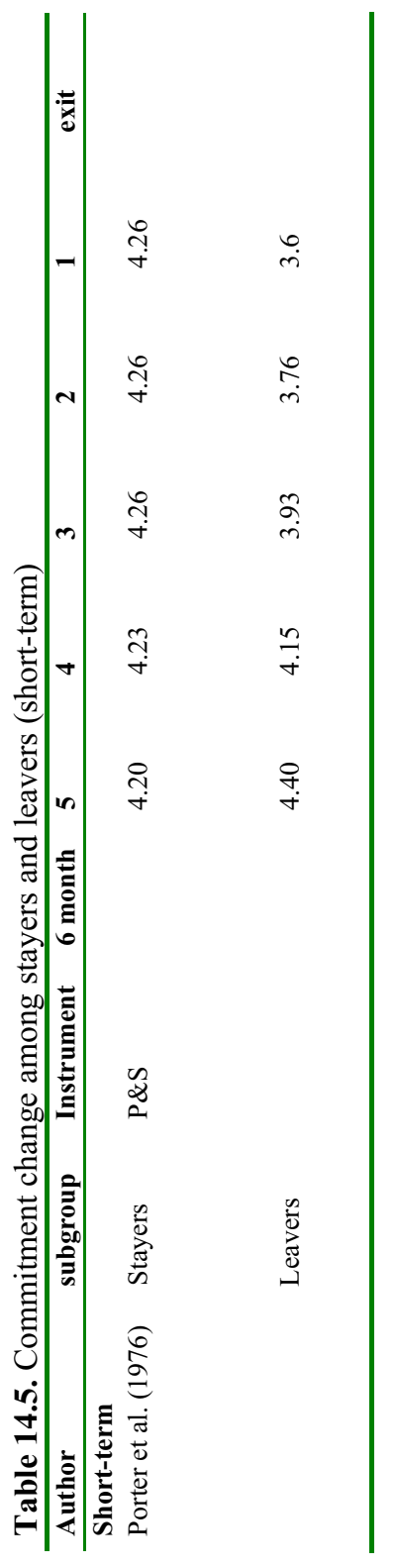




\section{Omar N. Solinger: A brief curriculum vitae}

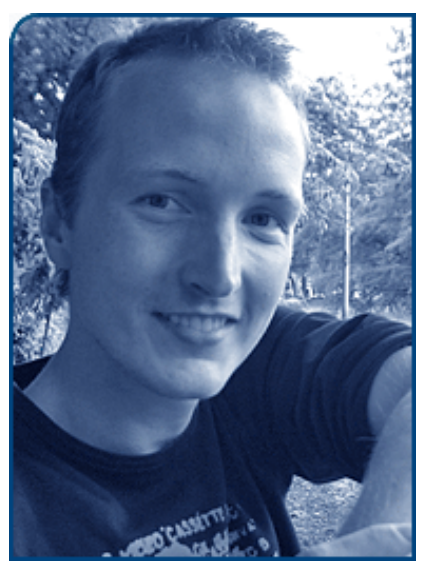

Contact:

VU University Amsterdam

Faculty of Economics and Business

Administration/Department of

Management \& Organization/

Human Resources Management

De Boelelaan 1105

1081 HV Amsterdam

The Netherlands

Room 3A-34

Telephone: +31 (0)20 - 5986123

E-mail: osolinger@feweb.vu.nl
Omar Solinger now works as an assistant professor in Industrial \& Organizational Psychology (also known as 'Organizational Behavior') at the VU University Amsterdam. He performed his $\mathrm{PhD}$ project - 'The dynamics of commitment' - under supervision of Robert Roe and Woody van Olffen. While working on his $\mathrm{PhD}$ project he appeared in the Journal of Applied Psychology (2008) and received a Junior Research Award (2008) in the department of Organization \& Strategy at Maastsricht University. Additionally, he created a longitudinal measurement tool (LOCUST) to track (real-time) historical changes in work attitudes. He studied Work \& Organizational Psychology at the Radboud University Nijmegen. As a student, he wrote his master's thesis for Royal Dutch Airlines on 'HRM \& Outsourcing: Making sense of change' (2004). A summary of his theoretical work on psychological processes during outsourcing was published by the Human Talent Trophy Foundation, and HR Strategie. In his private life he is an active pianist (in Grupo Seis Caminos), dancer (salsa) and socializer.

Position: Assistant professor in Industrial \& Organizational Psychology at the VU University Amsterdam.

Topics of interest: temporal theory, longitudinal research methodology, work attitudes (e.g. commitment, job satisfaction), psychology of change and transitions, philosophy on the art of living, and social influence processes.

\section{Publications:}

Solinger, O. N. \& Ezerman, I. C. (2009, 14 maart). Het kleine denken van de hulpverlener, Trouw.

Solinger. O. N. \& Raes, A. (2009). Robert Roe's temporal thinking: A legacy to a new generation of scholars. In A. van Iterson, F. A. Zijlstra, \& L. A. Ten Horn, Times changes work: Liber Amicorum for Robert A. Roe. Maastricht: Datawyse.

Roe, R. A., Solinger, O. N., \& Van Olffen, W. (2009). Shaping organizational commitment. In S. Clegg \& C. L. Cooper, The SAGE Handbook of Organizational Behavior, Vol II: Macro Approaches. London: SAGE.

Solinger. O. N., Van Olffen, W., \& Roe, R. A. (2008). Beyond the three-component model of organizational commitment. Journal of Applied Psychology, 93(1), 70-83.

Solinger, O.N. (2006). Een psychologische verklaring voor de "prestatiedip" bij organisatieveranderingen: De moeite van het oude loslaten terwijl het nieuwe zich aan ons opdringt. HR Strategie, 2(3), 26-31.

Solinger, O. N. (2004). Outsourcing \& HRM: Making sense of change. Unpublished master's thesis. Nijmegen: Radboud University Nijmegen.

Bercx, T. R. \& Solinger, O. N. (2003). Role transition during outsourcing from the perspective of industrial and organizational psychology. In T. Barning (Ed.), HRM as a critical success factor in outsourcing. Arnhem: Human Talent Trophy. 